Universidad Autónoma de Madrid

Programa de Doctorado en Biociencias Moleculares

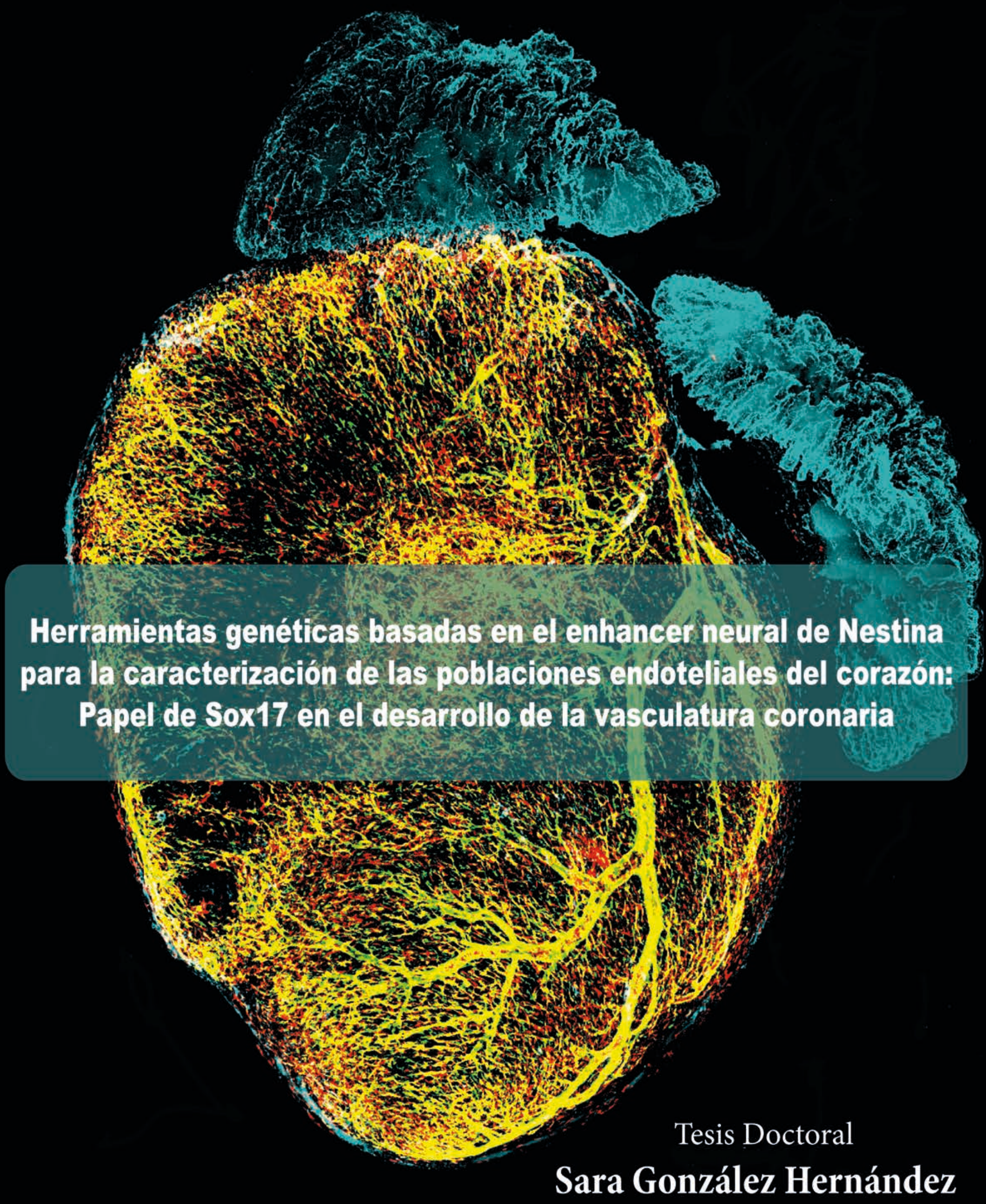

Madrid, 2018 


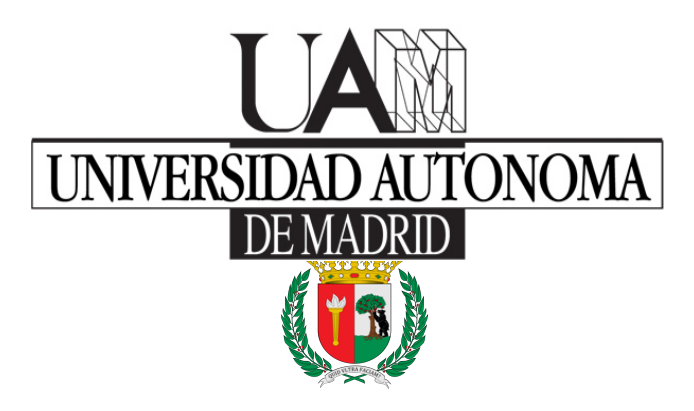

Departamento de Bioquímica

Facultad de Medicina

Universidad Autónoma de Madrid

\title{
Herramientas genéticas basadas en el enhancer neural de Nestina para la caracterización de las poblaciones endoteliales del corazón: Papel de Sox17 en el desarrollo de la vasculatura coronaria
}

\author{
Tesis Doctoral
}

\section{Sara González Hernández}

Licenciada en Biotecnología

Madrid, Julio 2018

\author{
Dirigida por el \\ Dr. Joan Isern \\ Realizada en el \\ Centro Nacional de Investigaciones Cardiovasculares \\ (CNIC)
}




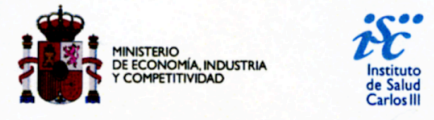

Fundaciónpörócnic 9 EXEEEENCIA

D. Joan Isern, CERTIFICA:

Que la presente memoria de tesis titulada "Herramientas genéticas basadas en el enhancer neural de Nestina para la caracterización de las poblaciones endoteliales del corazón: Papel de Soxl7 en el desarrollo de la vasculatura coronaria", que presenta Dña. Sara González Hernández para obtener el grado de Doctor, ha sido realizada bajo mi dirección, autorizándola para su presentación al Tribunal Calificador.

Madrid, 15 de Mayo de 2018

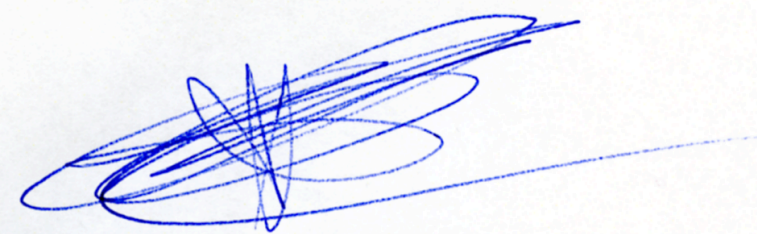

Fdo. Dr. Joan Isern Marín

Director de la Tesis Doctoral

Este trabajo se ha realizado en el laboratorio del Dr. Joan Isern, en el Área de Biología Celular y del Desarrollo del Centro Nacional de Investigaciones Cardiovasculares (CNIC), en Madrid.

El estudio ha sido financiado por el proyecto BFU2012-35892, otorgado por el Ministerio de Economía y Competitividad del Gobierno de España. Sara González Hernández ha sido beneficiaria de una beca FPI (Ayudas formación de doctorescontratos predoctorales 2013 plan estatal FPIMINECO13, ref.: BES-2013-065514), asociada al proyecto BFU2012-35892. 

A mi familia, la de parentesco y la que elegi con el tiempo. 

"Investigar es ver lo que todo el mundo ha visto, y pensar lo que nadie más ha pensado". Albert Szent-Györgyi (1893-1986)

"La ciencia será siempre búsqueda, jamás un descubrimiento real. Es un viaje, nunca una llegada". Karl Popper (1902-1994) 



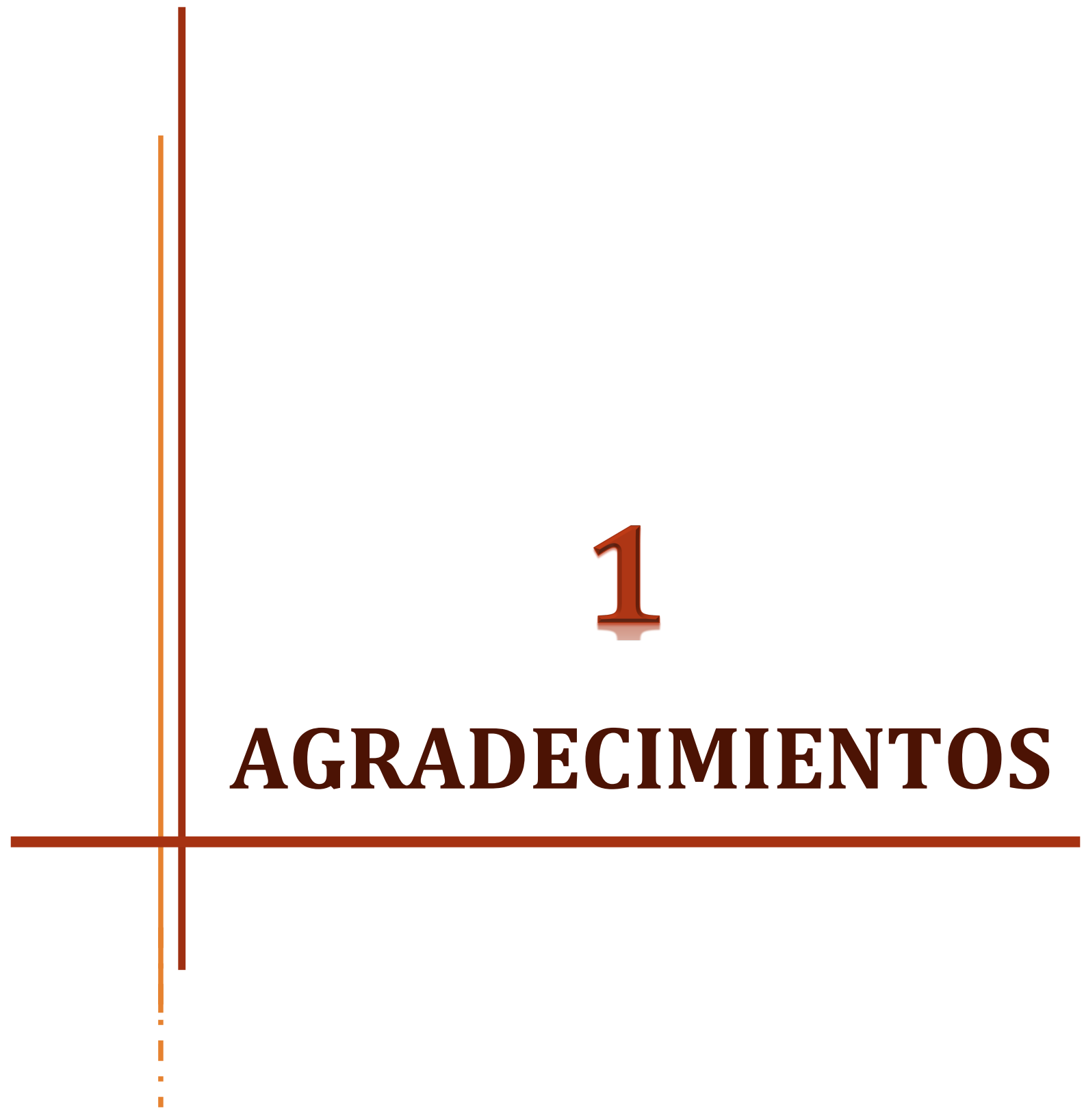



En primer lugar querría agradecer a mi jefe, Joan Isern, el haberme dado la oportunidad de realizar mi Tesis Doctoral en nuestro "pequeño grupo" de Hematopoyesis Embrionaria. Sobra decir que no ha sido fácil para ninguno de los dos. Pero a pesar de las circunstancias creo que ambos debemos estar MUY orgullosos del trabajo que hemos llevado a cabo en este proyecto y todo lo que hemos logrado. Y por supuesto, agradecer al CNIC su grandísimo apoyo, sin el cual no se habría llevado a cabo la finalización de este proyecto.

Pero como bien dicen, para entender el presente primero es necesario conocer el pasado... y mi aventura científica comenzó a casi $500 \mathrm{~km}$ de la capital, en el Centro Andaluz de Biología del Desarrollo (Sevilla). Desde el momento en el que empecé la Licenciatura de Biotecnología supe que quería dedicarme a la Investigación. En $3^{\circ}$ de carrera, cuando entré como alumna interna en el grupo de José Luis Gómez-Skarmeta, empecé mis primeros pinitos con la Biología Molecular en zebrafish gracias al Dr. José Luis Royo. Él me enseñó que paradójicamente la ciencia consistía en un acto de fe, ya que en aquellos eppendorfs vacíos en los que yo no veía absolutamente nada... tenía en realidad grandes cantidades de ADN, y eso me resultaba fascinante.

No fue hasta unos años más tarde, durante el Máster en Biotecnología Sanitaria, cuando empecé a amar la ciencia de verdad. Debo reconocer que la llegada al grupo de mi Manolillo fue un tanto accidentada... En realidad se trató de una alternativa forzada por una mala jugada del investigador con quien se suponía que iba a realizar mi Tesis Doctoral en Salamanca... y a día de hoy no podría estar más agradecida de que todo aquello sucediera (...aunque en su momento me pareciese el fin del mundo...). Ana María, Machupi, todos los miembros de Genética de la $1^{a}$ planta, Jacinto, kkCarlos, mi Mer y Manolillo... no cambiaría esos dos años con mis "Gusaneros" por nada en este mundo!! Con ese bichillo de C. elegans, y mis "mamis reventonas" comencé a disfrutar de verdad de la ciencia, aprendí a llevar mis propios proyectos y descubrí que quería dedicarme a esto el resto de mi vida.

Pero por mucho que me gustara mi proyecto en el grupo de Manolo... en un momento en el que no había financiación para la Ciencia tuve que buscar una beca con la que poder realizar mi Doctorado. Así fue como llegué a Madrid, al Centro Nacional de Investigaciones Cardiovasculares, pasando del estudio de la infertilidad en nematodo... al desarrollo de la vasculatura coronaria en ratón (...naaa que ver!!...). En general los cambios no suelen ser fáciles, pero cuando se te junta el cambio de ciudad, de trabajo, de proyecto, de modelo animal y una ruptura amorosa.... pues menos! Por suerte ahí estaban los ahora ex-Simones, para acogerme como parte de ellos desde el primer día en el que llegué. A todos ellos, GRACIAS por haber compartido unos años tan increíbles en los que, fuera cual fuese la situación dentro del lab, fuera de él encontré una nueva familia. Especialmente, a Carmen, que con su sonrisa era capaz 
de alegrar el día de cualquier persona que se cruzara en su camino. Eres una persona única, me alegro tanto de que nos reencontrásemos en Madrid. A Oli, con ese acento tan "asquerosamente" perfecto que nos gustaba tanto. Le avisaron de que no cometiera el error de volver de Cicerone al mismo grupo... pero egoístamente hablando... fueron unos meses muy divertidos y me alegro de que lo hicieras! A Xavi, que conociéndole de tan poco tiempo se convirtió en unas de las personas más importantes y que me ayudó TANTO a superar momentos muy difíciles. Llevamos años sin vernos, pero eres de esas personas que sabes que te llevas para toda la vida, las veas en días, meses o años. A Abel, que nos enseñó que en esta vida hay que perseguir nuestros sueños y ser felices con lo que hacemos por encima de todo. A Ana, quien a pesar del mal momento en el que nos conocimos, se esforzó por enseñarme todo lo que pudo hasta su último día en el CNIC. Por suerte para todos, te volvimos a recuperar! A Carlos, cuya llegada al grupo dio mucho que hablar. En esos ratillos que pasábamos Andrés, tú y yo dentro y fuera del CNIC, la risa estaba asegurada. A Andrés, a quien a pesar de darle tironcillos de oreja de vez en cuando... aprecio tantísimo. Eres un investigador brillante, estoy segura de que triunfarás cuando pases a la siguiente etapa de tu carrera, y como ya te dije el día de tu Tesis, espero seguir estando ahí para verlo! A Sandra, mi niña chiquitita, con quien he tenido algunas "peleas de barro" pero a la que quiero tanto. No sé qué echaré más de menos de ti en el futuro...si tu risa "discretita" o esos chupitasos de Ranchitos en los días malos! A Dani, mi Morenassso, porque no podría haber sobrevivido estos 4 años sin nuestras cañitas de los viernes, nuestros breikis por las tardes, ni nuestras conversaciones obscenas...

A mis niñas JAC (las “alegres")... Diana, Cristina, Carmen, Carla, Natalia, y $\mathbf{M}^{\mathrm{a}}$ Rosaria, porque LITERALMENTE alegráis el día de cualquiera que esté cerca de vosotras, con vuestras risas, cánticos, bailecitos extraños... y días de esquís. Me alegro muchísimo de haber tenido la suerte de coincidir con vosotras... derrocháis compañerismo y buen rollo por los cuatro costados... cosa que se agradece en un centro como este. A Raquelilla, que para mí siempre será más JAC que Manzanares, y te atribuyo lo mismo que a todas ellas. A Elías, por ese humor tan característico, y por lo tremendamente buena persona que eres. Eres de esos pocos que no van a lo suyo y saben identificar cuando una persona está mal y necesita hablar con alguien. A “los Hidalgo", por acogernos cuando Joan y yo nos quedamos solos. A "los de Pura", el grupo entero en general, y a Pura en particular. Porque sin tu ayuda tampoco habría sido posible la finalización de este proyecto, y a pesar de que yo no pertenezca a vuestro grupo me habéis hecho sentir desde el principio como si fuera parte de él.

GRACIAS a toda la familia que compone el CNIC: a todos los labs vecinos, especialmente los de la $3^{\text {a }}$ Sur y $3^{\text {a }}$ Norte; a todas las Unidades Técnicas, destacando Microscopía, Celómica, Vectores Virales... y por supuesto mis niños de Transgénesis; a todas las personas que 
componen el servicio de Animalario, a los lab managers que nos han dado soporte durante todos estos años, y a mi Annggeeeeee.... por esos buenos momentos cada día en la cafetería.

Y ya que hablamos de familia... GRACIAS a los míos! A mi hermano Jaime (Moniiiiiino) y Mónica, a quienes por suerte he tenido aquí en Madrid estos años para servirme de apoyo (aunque la vida del doctorando no permita tener muchos fines de semana libre....y vivís muy lejos carajo! xD). A mi mamá, quien me ha soportado tantos años de estrés en la carrera y me sorprendía con algún bombón de chocolate en las largas tardes de estudio. Siempre vamos a tener diferentes puntos de vista sobre... todo! Pero a pesar de nuestros choques de carácter sabes que te adoro. A papá y $\mathbf{M}^{\mathbf{a}}$ Luisa, quienes estando tan lejos han sabido apoyarme en todo momento. Qué decirte a ti papá...simplemente que te admiro, y que eres el verdadero hombre de mi vida. Dices siempre de la cantidad de kilómetros que hacías para llevarme cada mañana a la Universidad... pero lo cierto es que necesitaría una tesis entera para describir TODO lo que has hecho por mí durante estos 30 añazos (no los aparento, lo sé... :P). Y como no, al lado de todo gran hombre, hay siempre una gran mujer ( $\mathrm{M}^{\mathrm{a}}$ Luisa, no me lo dejes nunca!!). A mis YAYOS, porque más que unos abuelos habéis sido unos padres. No estaría aquí si no fuera por vosotros (y sin Santa Gema!!..jaja). Mi yayito, que ya no está para vivir conmigo este momento tan importante... no hay un día que llegue a casa y no recuerde que "no debo abrirle la puerta a los hombres malos" o cómo me pasabas los 5 euritos a escondidas como si fuera droga... Mi yayita, que tantos años después aún me sigue preguntando cada vez que la llamo que qué era eso tan raro que había estudiado y que cómo están la gatita y "el gatito"... espero que me lo puedas seguir preguntando muchísimos años más. A la loca de mi esposa, Irene, que entró en mi vida a los 4 añitos y se quedó para siempre.

A mis niñ@s Biotech: Inma, Sandra, Sara, Aarón, Noe, Chelo....hemos pasado 5 años increíbles en la carrera (con algunas de vosotras 2 años más de bonus en el Máster), y todos ellos han sido increíbles. Por aquellas comidas en los pasillos de la UPO, las terapias tan necesarias en los Starbucks, las quedadas de cerveceo en el Patio de San Eloy y las fiestas tan brutales en las "noches de Flora"... GRACIAS.

A la familia que se elige, mis MALVAD@S: Ana Belén, porque tú no fuiste una amiga, eres y serás siempre una HERMANA (sistersss!!). No he conocido jamás a nadie tan noble y luchadora como tú. Te vas a comer el mundo Sis... y sea en el rincón del mundo que sea... siempre estaré contigo para verlo (...pero si es California... MEJOR!!). Anika, nuestra Biotech más pivón del Cuerpo Nacional de Policía. No te quedas atrás con tu espíritu luchador y fuerza de superación... lo has conseguido mi niña!!! Ya sabes que este es nuestro año!! A Pablo, mi niño friki a la par que bello. Eres de esas contadas personas que SIEMPRE están, para lo bueno y para lo malo. Como ya os he dicho otras veces, vosotros 3 sois mi definición de HOGAR. Porque ya 
sea en Sevilla, Cádiz, Málaga, Jerez, Canarias, Islas Griegas, Barcelona, Madrid... o donde quiera que estemos en un futuro... cuando estamos juntos me siento en CASA. Y no podría sentirme más afortunada de teneros en mi vida.

A las personas tan especiales que he tenido la suerte de encontrarme en Madrid: Mi MORENO en mayúsculas, Alberto. Quién me iba a decir a mí que con ese loquito que me despertó una mañana con llamadas a las 7am porque andaba de fiesta en Sevilla (y en dudoso estado por el Jagger...) terminaría compartiendo casi 2 añitos de cenas en casa de "ensalada César" y copitas de vino. Eres todo un personaje... pero desde luego este mundo necesita a más gente como tú!! Elena, mi niña.... has sido compañera, consejera, amiga y "mami" cuando ha hecho falta. Llevas ya casi dos años en Londres pero te siento tan cerca como si estuvieras aquí... aunque los "picnic" de los sábados y domingos en el CNIC dejaron de ser lo mismo desde que te marchaste. Te quiero tantísimo..! También eres de esas pocas personas que sé que pasen los años que pasen... ya formarás parte de mi vida para siempre, y que nunca dejaremos de contar la una con la otra nos separen calles, ciudades o países. A mi BOMBÓN, Elvis! Qué decirte...eres una persona bellísima. De las casualidades más bonitas que me llevo de mi paso por Madrid. Nuestros "momentos Gourmet", nuestras noches de vinitos/cócteles, y nuestras charlas de contarnos todo...tooooooodo... me han dado la vida estos últimos dos años. A mi OJASSOS, Joan. Este último año de tesis los momentos de risas diarias contigo, con Dani y con Carles me han hecho sobrevivir a esos días en los que pensaba que ya no podía más. Se te echa muchísimo en falta... ya apenas voy a dar la lata al ala oeste desde que no trabajáis allí.

Y finalmente, a mi pollito, Carles. Entraste en mi vida en la recta final de esta aventura (vamos... que te ha tocado aguantar lo peor!!! xD). Hace apenas año y medio no nos conocíamos... y ahora se me haría imposible imaginar todo esto sin ti. Has conseguido que todos los días malos en los que el estrés me desbordaba terminasen en sonrisas al llegar a casa (... o en lágrimas... pero que también hacían falta! :P). A veces me pregunto si habría sobrevivido a estos últimos meses de locura sin ti. Con lo cabezona que soy... posiblemente sí... pero desde luego habría llegado mucho menos cuerda! Necesitaría media vida para agradecerte el tremendo apoyo que has supuesto para mí en esta etapa tan importante, y lo infinitamente feliz que soy desde aquella "Feria de Abril CNIC 2017", así que de momento... sigamos sumando meses... :-

No estaría donde estoy ni sería lo que soy sin todas las personas que componéis mi vida, 


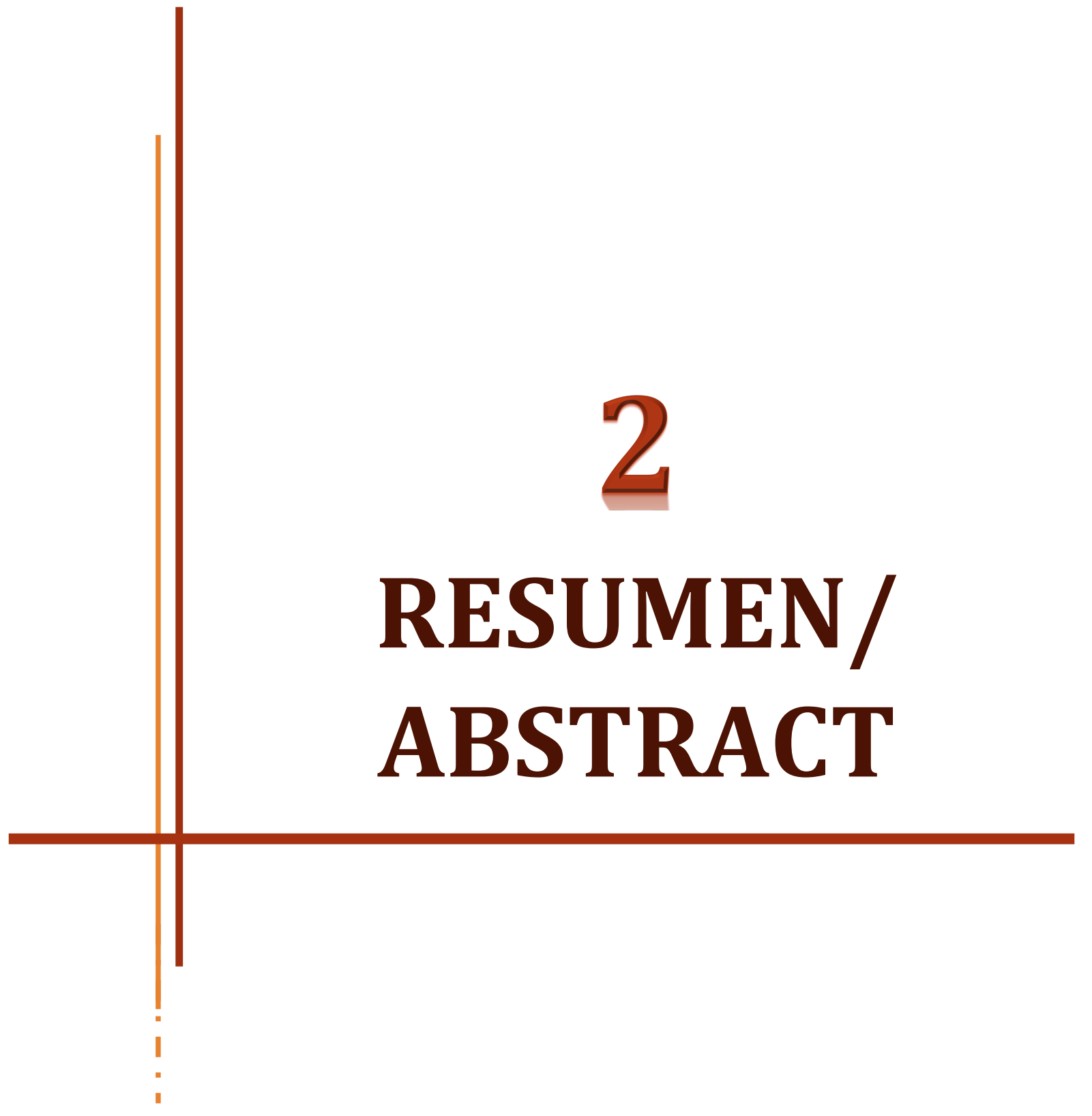



El estudio del origen y desarrollo de la vasculatura del corazón en mamíferos ha sido sujeto de intensas investigaciones en los últimos años, y a pesar de ello, las señales encargadas de regular la formación del plexo coronario siguen estando insuficientemente caracterizadas. En esta Tesis Doctoral se han empleado de forma novedosa las líneas murinas Nes-Gfp y Nes-CreER ${ }^{T 2}$ para dedicarlas al estudio de la formación del endotelio coronario durante el desarrollo cardíaco, con especial énfasis en las fases de remodelado y maduración arterio-venosa. La detallada caracterización realizada del alelo Nes-Gfp durante las etapas intermedias de cardiogénesis, indicaron que se expresa en estirpes mesenquimales del bulbo cardíaco, pericitos y células murales asociadas a los vasos (análogamente al patrón ya descrito en otros órganos), y de modo inesperado y dinámico, su expresión también se induce de manera robusta en el endotelio coronario naciente. Aprovechando dicho patrón de expresión vascular y usando técnicas de clarificación óptica de tejidos completos y microscopia confocal, hemos podido estudiar el proceso de sprouting de los vasos coronarios y el remodelado arterial a alta resolución. Además, gracias a la intensidad relativa de expresión del reportero GFP, en combinación con el marcador Endomucina, nos ha permitido discriminar entre las células de endocardio ventricular (donde la GFP apenas se expresa) y el plexo vascular coronario. Mediante citometría de flujo, logramos aislar ambas poblaciones endoteliales primarias con gran pureza, a partir de los mismos corazones y obtener así los perfiles transcripcionales correspondientes, en diferentes fases de su desarrollo: la etapa inicial de expansión angiogénica (E13.5) y durante el proceso de remodelado activo del plexo primario (E17.5). A su vez, el trazado de linaje usando el driver Nes-CreER ${ }^{T 2}$ (que comparte con la línea Nes-Gfp la presencia de secuencias reguladoras del enhancer neural del gen Nestina), nos permite marcar selectivamente el plexo coronario intramiocárdico enriquecido en endotelio capilar y arteriolar. Por ello, la combinación de ambas herramientas genéticas nos ha permitido aislar y definir transcriptómicamente las tres subpoblaciones de células vasculares sanguíneas presentes en el corazón (endocardio, arterias intramiocárdicas y venas subepicárdicas).

Esta estrategia nos permitió identificar nuevos factores enriquecidos en la rama arterial. Entre los genes diferencialmente expresados, hemos encontrado varios miembros de la familia de factores de transcripción SOX, y en especial Sox17. De manera interesante, detectamos expresión nuclear de Sox17 en las primeras células endoteliales del plexo que migraban a través del subepicardio. Más adelante, su expresión se restringe progresivamente en el domino de vasos intramurales Nes-GFP+, con fenotipo arterial. Debido a la robusta co-localización observada entre la población Sox17+ y las células GFP+, nos preguntamos si este factor de transcripción podría ser un activador transcripcional directo del enhancer neural presente en la región reguladora del alelo Nes-Gfp, verificándolo con una serie de ensayos in vitro. Por todo ello, proponemos que el enhancer neural de Nestina también podría actuar como enhancer arterial coronario en determinadas fases del desarrollo cardíaco, y cuyo estudio continuado podría ayudar a descubrir nuevas bases moleculares en este proceso tan importante y relevante para la salud humana, dada la alta incidencia de enfermedad coronaria a escala mundial. 
The study of the developmental origin of the coronary vasculature in mammals has been subject of extensive research in recent years, and yet the signals regulating the formation of the primary plexus, remain poorly understood. In this Doctoral Thesis the murine genetic tools Nes-Gfp and Nes-CreER ${ }^{T 2}$ lines have been used for studying coronary endothelium formation during cardiac development, with special emphasis on the stages of remodeling and arteriovenous maturation. The strong characterization of the Nes-Gfp allele during the intermediate stages of cardiogenesis indicated that it is expressed in mesenchymal strains of the cardiac bulb, pericytes and mural cells associated with the vessels (analogously to the pattern already described in other organs), and unexpectedly and dynamic, its expression is also induced robustly in the nascent coronary endothelium.

By taking advantage of this pattern of vascular expression and using whole-tissue clarification imaging and confocal microscopy, we aim to characterize the process of sprouting of the coronary vessels and arterial remodeling at unprecedented resolution. In addition, thanks to the relative intensity of expression of the GFP reporter, in combination with the Endomucin marker, it allowed us to discriminate between ventricular endocardial cells (where GFP is barely expressed) and the coronary vascular plexus. By cytometry, we were able to isolate both primary endothelial populations with great purity, from the same hearts and obtain the corresponding transcriptional profiles, in different phases of their development: the initial stage of angiogenic expansion (E13.5) and during the process of active remodeling of the primary plexus (E17.5). Moreover, lineage tracing using the Nes-CreER ${ }^{T 2}$ driver (which shares the presence of regulatory sequences of the neural enhancer of the Nestin gene with the NesGfp line) allows us to selectively label the intramyocardial coronary plexus enriched in capillary and arteriolar endothelium. Therefore, the combination of both genetic tools has allowed us to isolate and define transcriptomically the three subpopulations of blood vascular cells present in the heart (endocardium, intramyocardial arteries and subepicardial veins).

This strategy allowed us to identify new enriched factors in the arterial branch. Among the differentially expressed genes, we have found several members of the SOX transcription factors family, and especially Sox17. Interestingly, we detected nuclear expression of Sox17 in the first endothelial cells of the plexus that migrated through the subepicardium. Later on, its expression is progressively restricted in the domain of intramural Nes-GFP+ vessels, with an arterial phenotype. Due to the robust co-localization observed between the Sox17+ population and the GFP+ cells, we wonder if this transcription factor could be a direct transcriptional activator of the neural enhancer present in the regulatory region of the Nes-Gfp allele, verifying it with a series of assays in vitro. For all these reasons, we propose that the Nestin neural enhancer could also act as a coronary arterial enhancer in certain phases of cardiac development, and whose continued study could help to discover new molecular bases in this important and relevant process for human health, given the high incidence of coronary disease worldwide. 


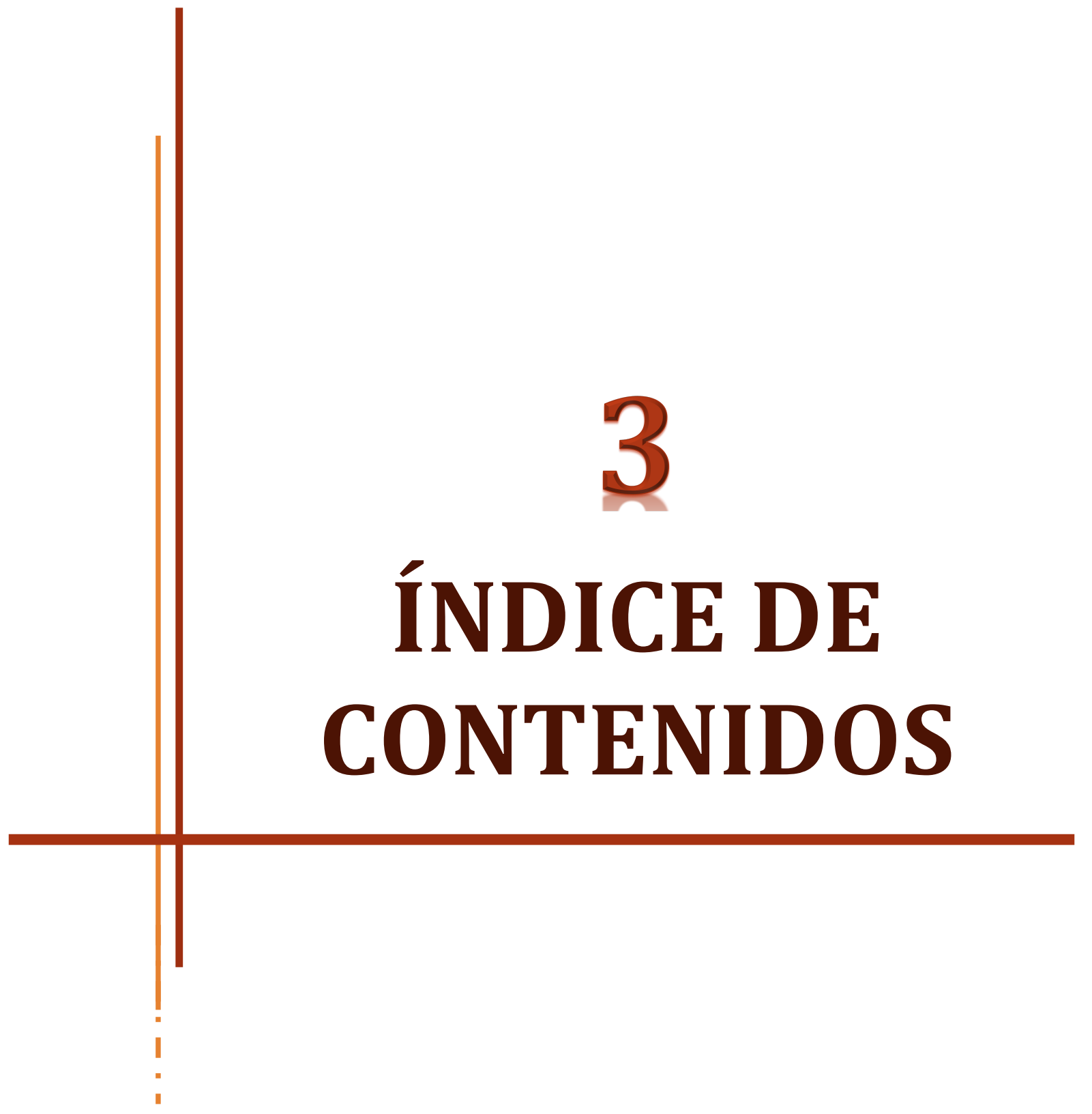





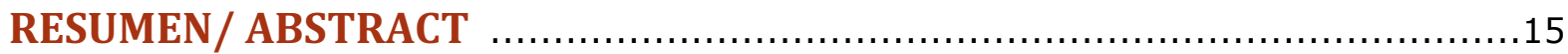

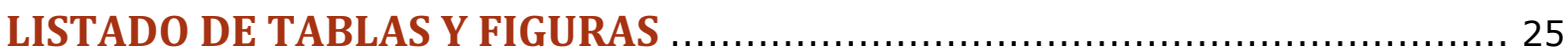

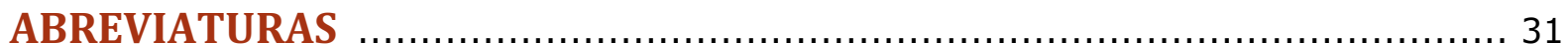

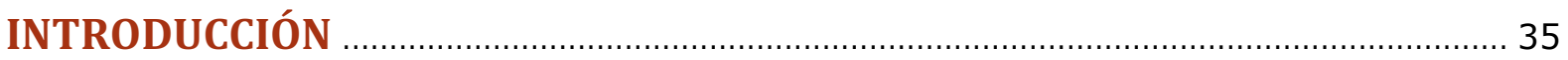

1. Formación del Corazón Durante el Desarrollo Embrionario de Ratón ..................... 37

2. Técnicas de Mapeo Genético y Trazado de Linaje Celular ........................................ 40

3. Origen y Desarrollo de la Vasculatura Coronaria en Ratón ........................................ 41

3.1. Vasculatura Coronaria Originada del Epicardio ................................................ 43

3.2. Vasculatura Coronaria Originada del Seno Venoso ............................................ 44

3.3. Vasculatura Coronaria Originada del Endocardio Ventricular .............................. 45

3.4. Consenso entro los diversos Orígenes de la Vasculatura Coronaria ....................... 46

3.5. Formación de Novo de la Vasculatura Coronaria Postnatal .................................... 48

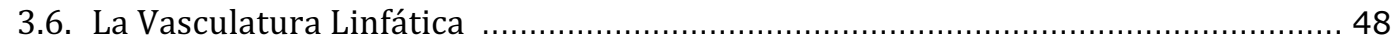

4. Modelos Genéticos de Ratón: Nestin-Gfp y Nes-CreERT2 …....................................... 49

4.1. Caracterización del Gen Nestina y Generación de Líneas Transgénicas . ................ 49

4.2. Nestin-Gfp como Principal Marcador de Progenitores Mesenquimales .................. 50

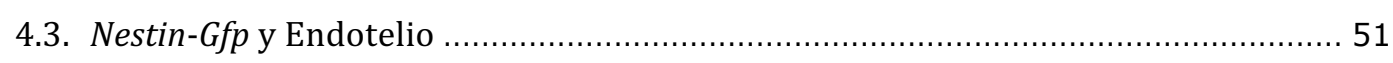

4.4. Trazado del Linaje Nestina: Diferencias entre Nes-CreERT2 y Nes-Gfp .................... 52

5. Regulación Transcripcional en la Vasculatura: Papel de los Enhancers Endoteliales y

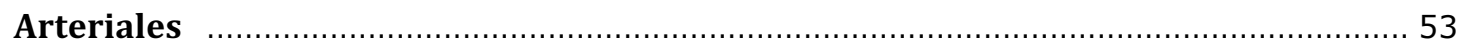

6. Factores de Transcripción SOX y su Papel en la Vasculatura Coronaria ……................ 55

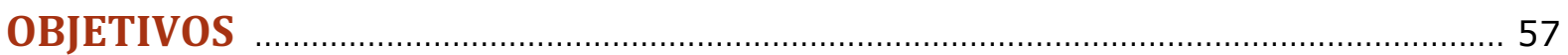

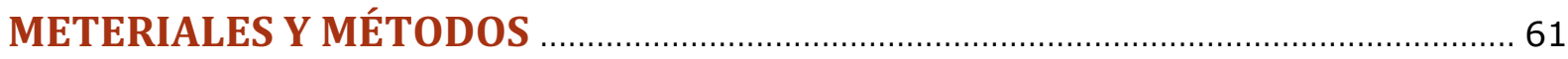

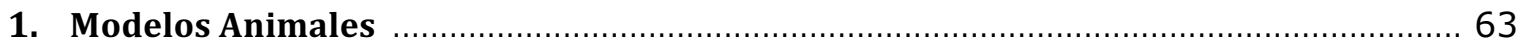

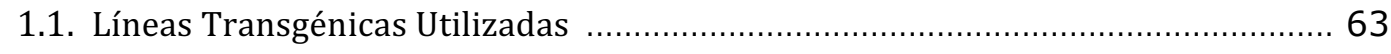

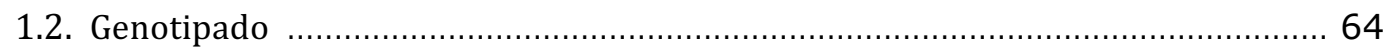

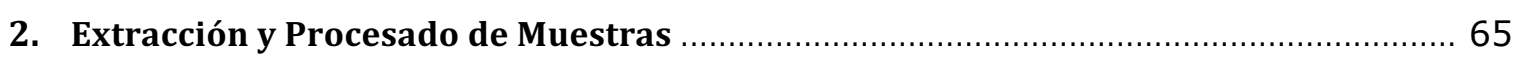

2.1. Extracción de Embriones y Corazones de Ratón ................................................. 65

2.2. Procesamiento de Muestras para Histología en OCT y Parafina ............................... 65

2.3. Clarificación de Tejidos y Embriones Enteros para Imagen ................................... 65

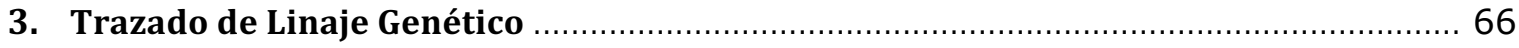

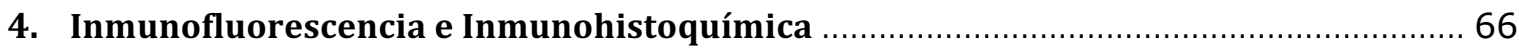

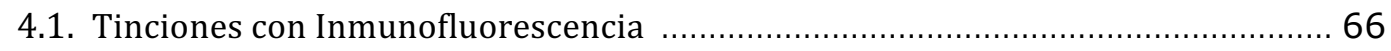


4.2. Inmunofluorescencia de Tejidos Completos ("Whole Mount") .......................... 68

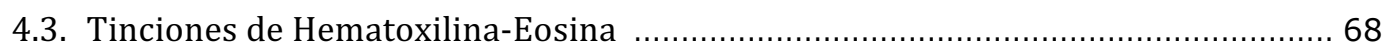

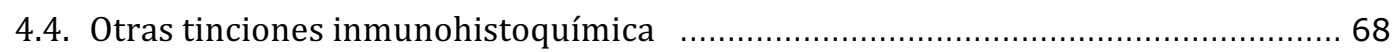

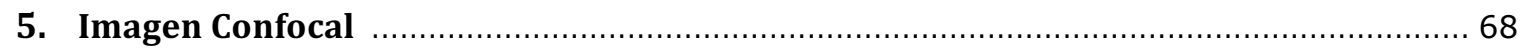

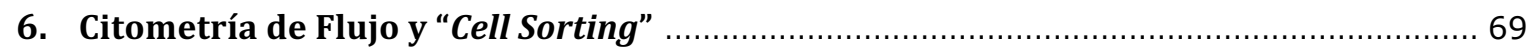

6.1. Digestión Enzimática de Corazones Embrionarios o Adultos .............................69

6.2. Tinción de Células para Citometría Analítica (FACS) ...................................69

6.3. “Clasificación” de Células ("Cell Sorting") ............................................. 70

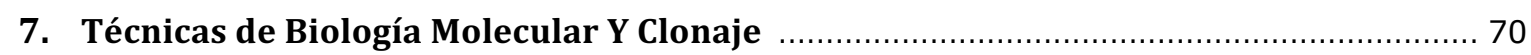

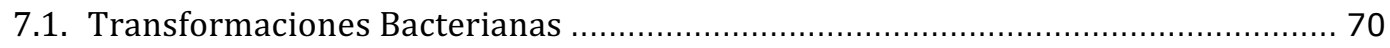

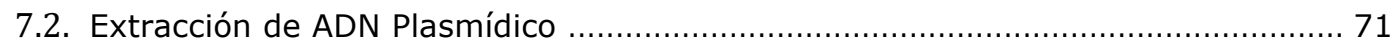

7.3. Digestiones Enzimáticas y Extracción de ADN a partir de Bandas de Agarosa ..... 71

7.4. Ligaciones y Ensamblado de Múltiples Fragmentos de ADN ............................. 71

7.5. Plásmidos Comerciales y Construcciones Generadas ............................... 72

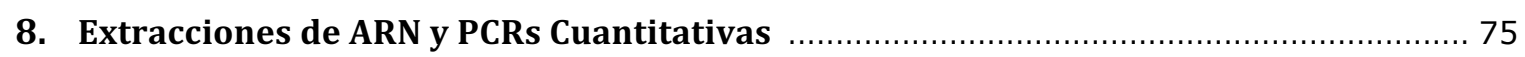

8.1. Extracciones de ARN de Corazones Embrionarios ........................................ 75

8.2. Obtención del ADN Codificante mediante Reacción de Retrotranscripción ............. 75

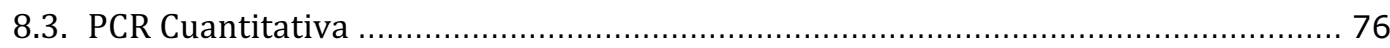

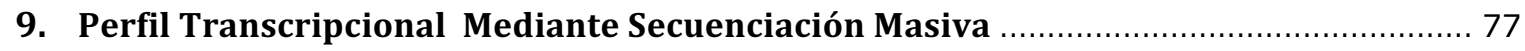

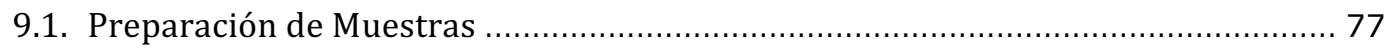

9.2. Secuenciación del Transcriptoma Completo (RNAseq) ................................ 78

9.3. Análisis de los Genes Diferencialmente Expresados ................................... 78

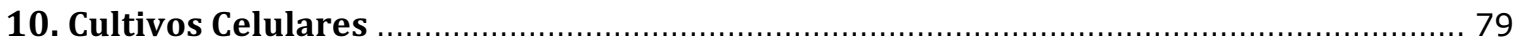

10.1. Mantenimiento de Líneas Celulares In Vitro ......................................... 79

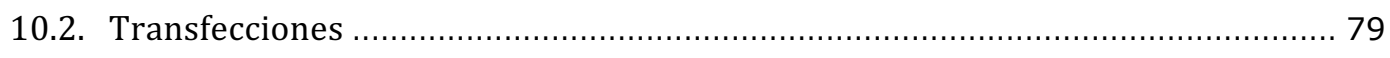

10.3. Líneas y Clones Celulares Generados ....................................................... 79

10.4. Ensayos de Reportero Luciferasa .......................................................... 80

10.5. Ensayos de Angiogénesis con Explantes de Corazón In Vitro ............................ 81

11. Ensayo de Cambio en la Movilidad Electroforética (EMSA) …........................... 81

11.1. Preparación de Extractos Nucleares de Proteína ..................................... 81

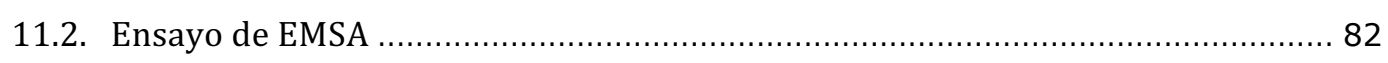

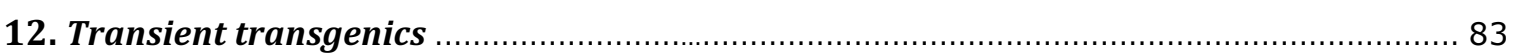

12.1. Preparación de los Transposones y la Transposasa .............................. 83

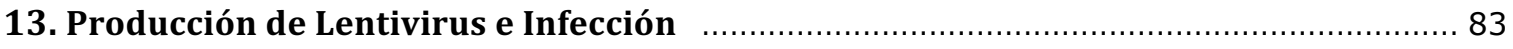

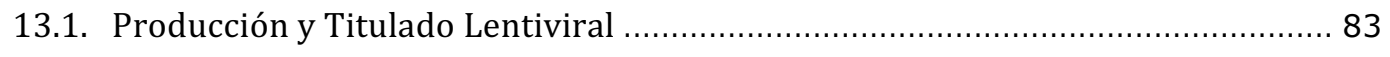

13.2. Infección de Explantes de Corazón In Vitro ........................................... 84

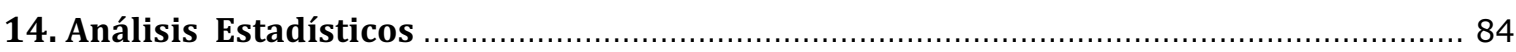


1. Caracterización del Alelo Nestin-Gfp en el Desarrollo Cardíaco de Ratón 87

1.1. El alelo Nes-GFP marca de forma dinámica distintas poblaciones cardíacas, entre las que se encuentran las células mesenquimales y la vasculatura coronaria en formación

1.2. Las células Nestin-GFP+ son una fuente importante de producción de la quimoquina Cxcl12 92

1.3. Las células Nes-GFP+ marcan el endotelio primitivo en desarrollo y nos permiten diferenciar entre las subpoblaciones de la vasculatura coronaria 101

2. El Trazado de Linaje Nes-CreER ${ }^{T 2}$ Revela una Especial Contribución a la Vasculatura Coronaria pero no Endocardio Ventricular 107

3. Trazado de linaje Nestina en corazones adultos de ratón 111

4. Combinación del Alelo Nes-Gfp y el Trazado de Linaje con Nes-CreER ${ }^{T 2}$ para el Estudio del Desarrollo del Plexo Coronario y la Arteriogénesis 112

4.1. Perfil transcripcional de las células del endocardio ventricular frente a la vasculatura coronaria

4.2. Perfil transcripcional de subpoblaciones enriquecidas en arterias/capilares intramiocárdicas frente a venas subepicárdicas 120

5. Los Miembros de la Subfamilia Soxf Podrían Activar el Enhancer Neural de Nestina en la Vasculatura Angiogénica 123

5.1. Sox17 es detectado en los primeros brotes de la vasculatura coronaria que emerge del seno venoso a E11.5

5.2. Generación de líneas celulares para la sobreexpresión de los factores Sox17 y Sox18 127

5.3. El análisis funcional de los sitios putativos”de unión de los factores Sox en el i2E demuestra que Sox17 es capaz de activar el enhancer neural de Nestina ...... 130

6. La Pérdida de Función de los Miembros de SoxF en el Endotelio Angiogénico podría Impedir el Correcto Desarrollo de la Vasculatura Coronaria 135

6.1. Ensayos de angiogénesis en explantes de corazón embrionario como modelo de pérdida de función in vitro 135

6.2. Expresión del dominante negativo RaOp en la vasculatura coronaria mediante transgénicos transitorios ("transient transgenics")

1. El Alelo Nes-Gfp Se Expresa De Forma Muy Dinámica En Multitud De Linajes A Lo Largo Del Desarrollo Embrionario Y Vida Adulta Del Ratón 143 
2. El Trazado De Linaje Nestina Con El Alelo Nes-CreER ${ }^{T 2}$ Como Herramienta Para El Estudio De La Vasculatura Coronaria En Desarrollo Y Ratón Adulto 145

2.1. Herramienta genética para el marcaje/eliminación d genes exclusivos de la vasculatura coronaria en estadios embrionarios 145

2.2. Herramienta genética para modificación génica restringida a la microvasculatura coronaria en adultos 147

3. Genes Diferencialmente Expresados En Las Subpoblaciones Endoteliales Del Corazón E Identificación De Nuevos Marcadores Coronarios 148

3.1. Comparación de perfiles transcripcionales entre endocardio ventricular y vasculatura coronaria en las fases de angiogénesis y remodelado 148

3.2. Comparación de perfiles transcripcionales entre endocardio ventricular, arteria/capilares intramiocárdicos y venas subepicárdicas tras remodelar ... 151

4. Caracterización Del Enhancer Neural De Nestina Para El Estudio De La Vasculatura Coronaria: Papel De Los Factores SoxF En La Regulación De La Expansión Vascular Coronaria Y Posterior Especificación Arterio-Venosa 153

4.1. La activación del i2E de Nestina en SNC depende principalmente de los factores POU, en combinación con miembros de la familia Sox 153

4.2. En la vasculatura coronaria la activación del i2E depende del factor Sox17 en combinación con otros factores no pertenecientes a la familia POU 154

4.3. Posible regulación por mecanismos activadores/represores del enhancer neural de Nestina en las células endoteliales del corazón 156 


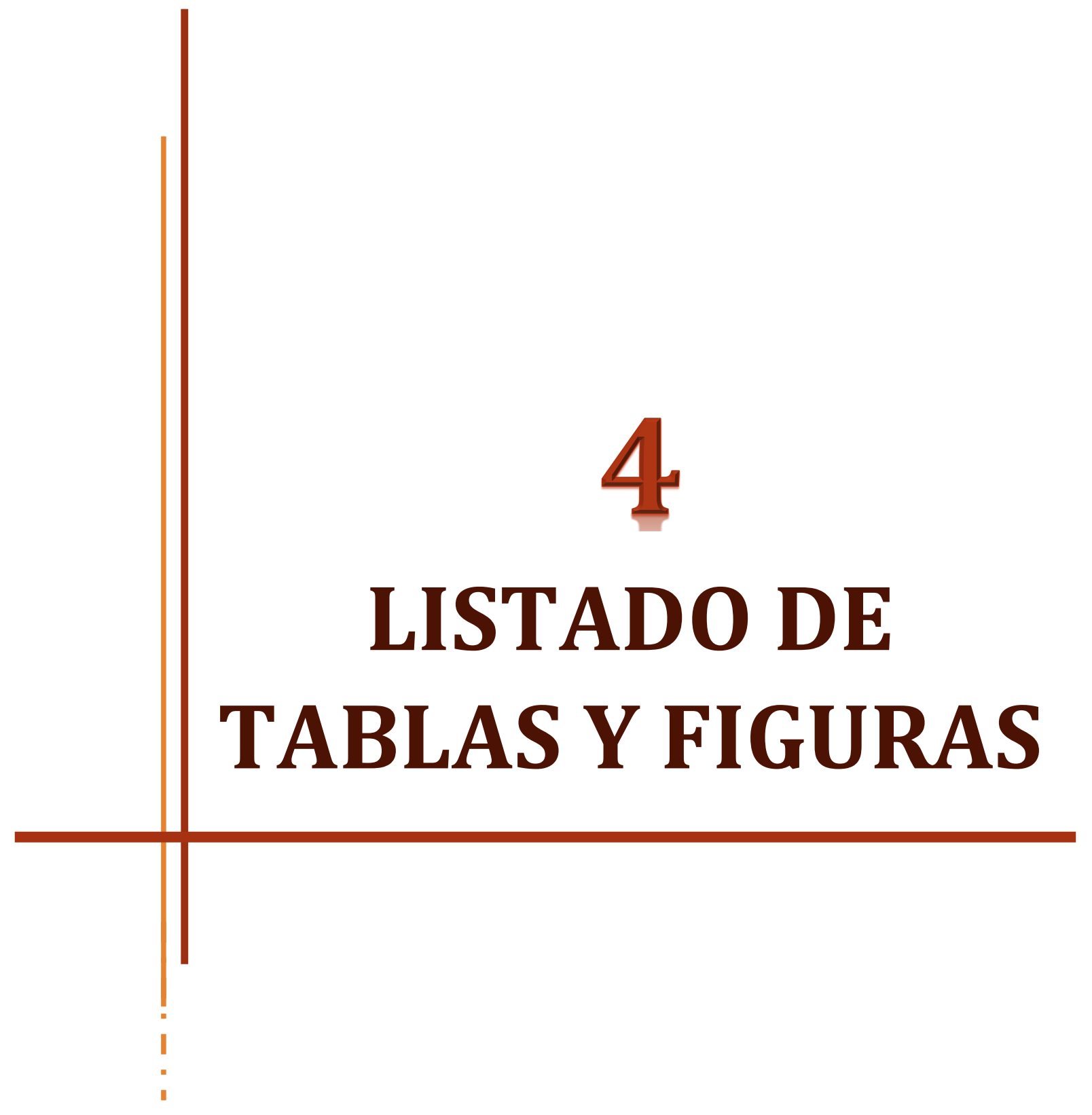





\section{ÍNDICE DE TABLAS}

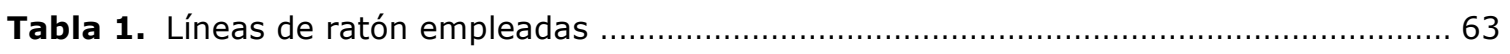

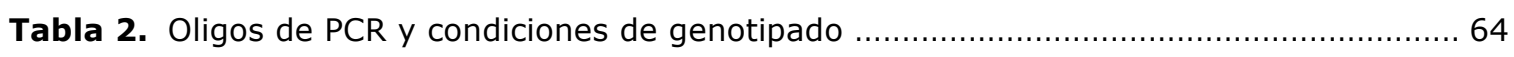

Tabla 3. Listado de anticuerpos primarios para inmunofluorescencia ..................................67

Tabla 4. Listado de anticuerpos secundarios para inmunofluorescencia ................................67 67

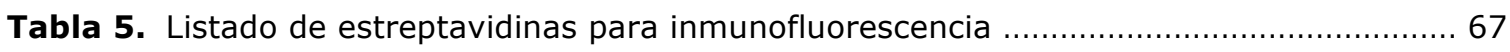

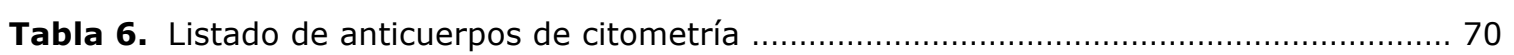

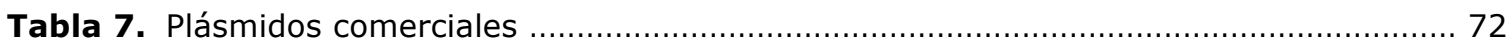

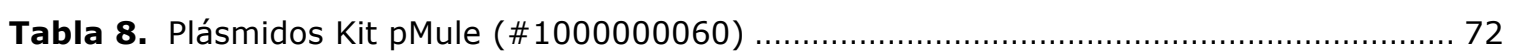

Tabla 9. Plásmidos para el sistema de transposón Sleeping Beauty …………………...........72

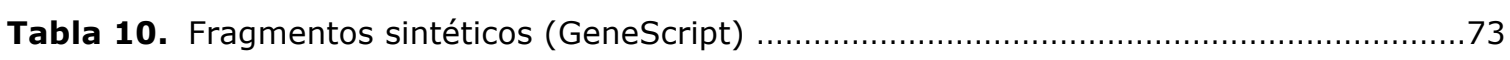

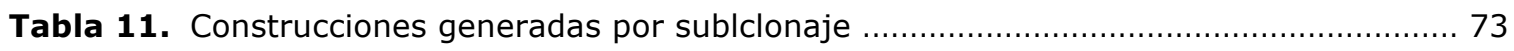

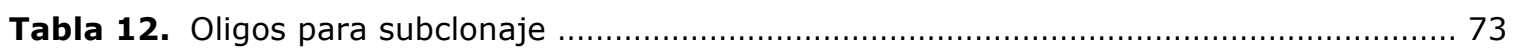

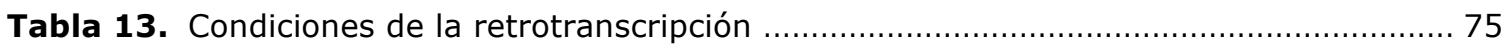

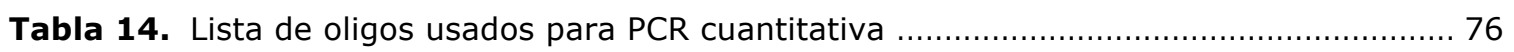

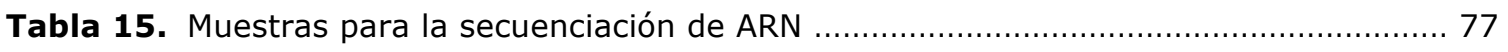

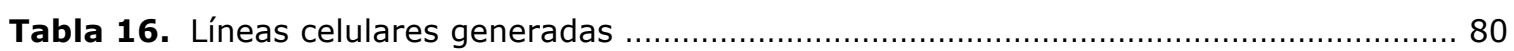

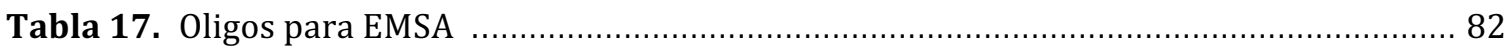

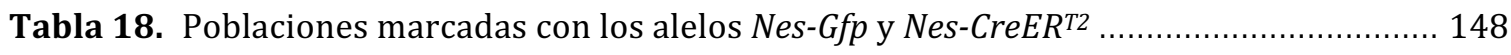

Tabla 19. Comparación de genes diferenciales entre endocardio y vasculatura coronaria .....151 


\section{ÍNDICE DE FIGURAS}

Figura 1. Formación del corazón embrionario en ratón ……............................................. 39

Figura 2. Esquema del sistema de recombinasas Cre/LoxP para fate mapping .................... 41

Figura 3. Formación de los vasos por vasculogénesis y angiogénesis ................................. 42

Figura 4. Desarrollo de la vasculatura coronaria en ratón .................................................... 47

Figura 5. Esquema de la estructura de los transgenes Nes-Gfp y Nes-CreER ${ }^{T 2}$.................... 52

Figura 6. Esquema de la familia SoxF y mutaciones Ragged ................................................. 56

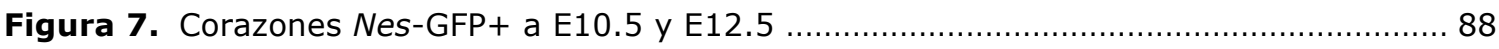

Figura 8. Citometría analítica (FACS) en corazones Nes-Gfp en desarrollo ............................. 89

Figura 9. Análisis por FACS del linaje Wt1 en corazones Nes-Gfp a E17 ……..................... 90

Figura 10. Corazón triple transgénico Wt1-Cre; R26-Tomato;Nes-Gfp a E17.5 .................... 91

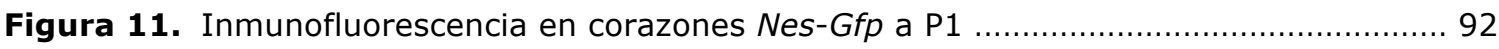

Figura 12. Comparación de patrones de expresión de la GFP en las líneas genéticas $C x C l 12^{\text {GFP }}$

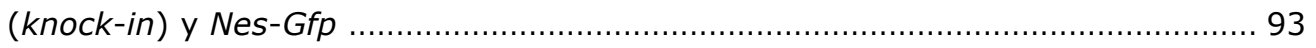

Figura 13. Embriones CxCl12; Nes-Gfp WT y KO a E17.5 ................................................. 94

Figura 14. Defectos en la morfología cardíaca de los mutantes de $C x \mathrm{C} / 12$ …...................... 95

Figura 15. Los mutantes de Cxcl12 presentan deslocalización de los grandes vasos y ausencia del sistema parasimpático ................................................................ 96

Figura 16. Comparación de la población de macrófagos en corazones WT y corazones deficientes en $\mathrm{CxCl} 12$

Figura 17. Vasculatura coronaria en los mutantes de $\mathrm{Cxcl} 12$ antes (E14.5) y después del remodelado (E17.5) ............................................................................ 98

Figura 18. Inmunofluorescencia con Caveolina en corazones WT y KO a E13.5 y E16.5 ...100

Figura 19. Mutantes condicionales de $\mathrm{CxCl} 12$ en el linaje Nestina ....................................... 101

Figura 20. Desarrollo de la vasculatura coronaria en corazones Nes-GFP+ ......................... 103

Figura 21. Corazón Nes-GFP+ tras el remodelado a E17.5 ….......................................... 104

Figura 22. Los niveles de expresión relativos de GFP en combinación con CD31 y Endomucina nos permiten diferenciar por FACS endorcardio, plexo coronario enriquecido en arterias, y plexo subepicárdico enriquecido en venas 105

Figura 23. Separación por citometría de flujo de las diferentes poblaciones endoteliales y análisis por PCR cuantitativa de genes conocidos 106

Figura 24. El trazado de linaje Nestina con el triple transgénico Nes-CreER ${ }^{T 2}$; R26-Tomato; Nes-Gfp induciendo la recombinación a E12.5 revela una principal contribución a la vasculatura coronaria excluyendo el endocardio ventricular 107

Figura 25. Comparación de los patrones del linaje Nestina en tomato cuando la recombinación se produce a E10.5 o E12.5 108

Figura 26. Análisis por FACS del trazado de linaje Nestina cuando se induce la recombinación a E10.5 y E12.5 109

Figura 27. Trazado de linaje en corazones Nes-CreER ${ }^{T 2}$ a $E 15.5$ cuando se induce la recombinación a E10.5 y E12.5, respectivamente 
Figura 28. Trazado de linaje Nestina en corazones adultos ................................... 111

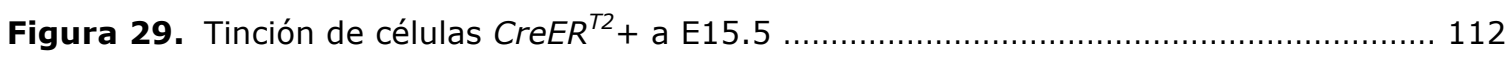

Figura 30. Comparación de la recombinación en tomato cuando se induce con diferentes dosis de tamoxifeno

Figura 31. Trazado de linaje en corazones Nes-CreER ${ }^{T 2}$; R26-Tomato; Nes-Gfp para marcar exclusivamente el plexo intramiocárdico

Figura 32. Separación del endocardio ventricular y el plexo coronario en los estadíos E13.5 y E17.5 para el perfil transcripcional (RNAseq) 116

Figura 33. Heatmap resultado del perfil transcripcional del plexo coronario y endocardio a E13.5 y E17.5 117

Figura 34. GO plot circular del cluster III 118

Figura 35. Marcadores de membrana para separar endocardio ventricular y vasculatura coronaria

Figura 36. Separación de endocardio, capilares/arterias intramiocárdicas y venas subepicárdicas a E17.5 para el perfil transcripcional (RNAseq) ..................... 120

Figura 37. Genes diferencialmente expresados entre venas y arterias/capilares ............ 122

Figura 38. Perfil transcricional de la familia SoxF ................................................ 123

Figura 39. Expresión de Sox17 en la vasculatura coronaria durante la fase de expansión angiogénica

Figura 40. Expresión de Sox17 en la vasculatura remodelada ....................................... 125

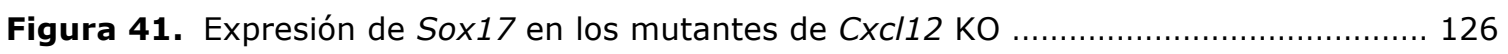

Figura 42. Análisis de expresión por RT-PCR de las MCEC ..................................... 127

Figura 43. Generación de construcciones Sleeping Beauty para integrarlas por transposición en el genoma de las MCEC.

Figura 44. Análisis por RT-PCR del comportamiento de los clones tras la administración de doxiciclina

Figura 45. El alineamiento de las secuencias del i2E entre varias especies muestra regiones muy conservadas

Figura 46. Análisis por EMSA de la interacción de Sox17 con los sitios putativos de unión al ADN

Figura 47. Estudio de la actividad del enhancer i2E mediante ensayos de actividad luciferasa en MCEC

Figura 48. Ensayos de actividad lucferasa en el clon inducible con dox 133

Figura 49. La sobreexpresión de Sox17 en células activa la expresión del i2E ...................... 134

Figura 50. Explantes de ápex de corazones in vitro ..................................................................... 136

Figura 51. Estrategia para la infección con lentivirus en el modelo de explantes ................. 137

Figura 52. Comparación de embriones controles y experimentales (RaOp) ............................ 138

Figura 53. Alteraciones en el desarrollo de la vasculatura coronaria en los embriones experimentales (RaOp)

Figura 54. Perfil de genes marcadores para las diferentes subpoblaciones endoteliales a E17.5 152

Figura 55. Posibles factores co-reguladores de la actividad del i2E 157 
Figura 56. Resumen de las poblaciones marcadas con el alelo Nes-Gfp en sistema nervioso central y corazón 158 


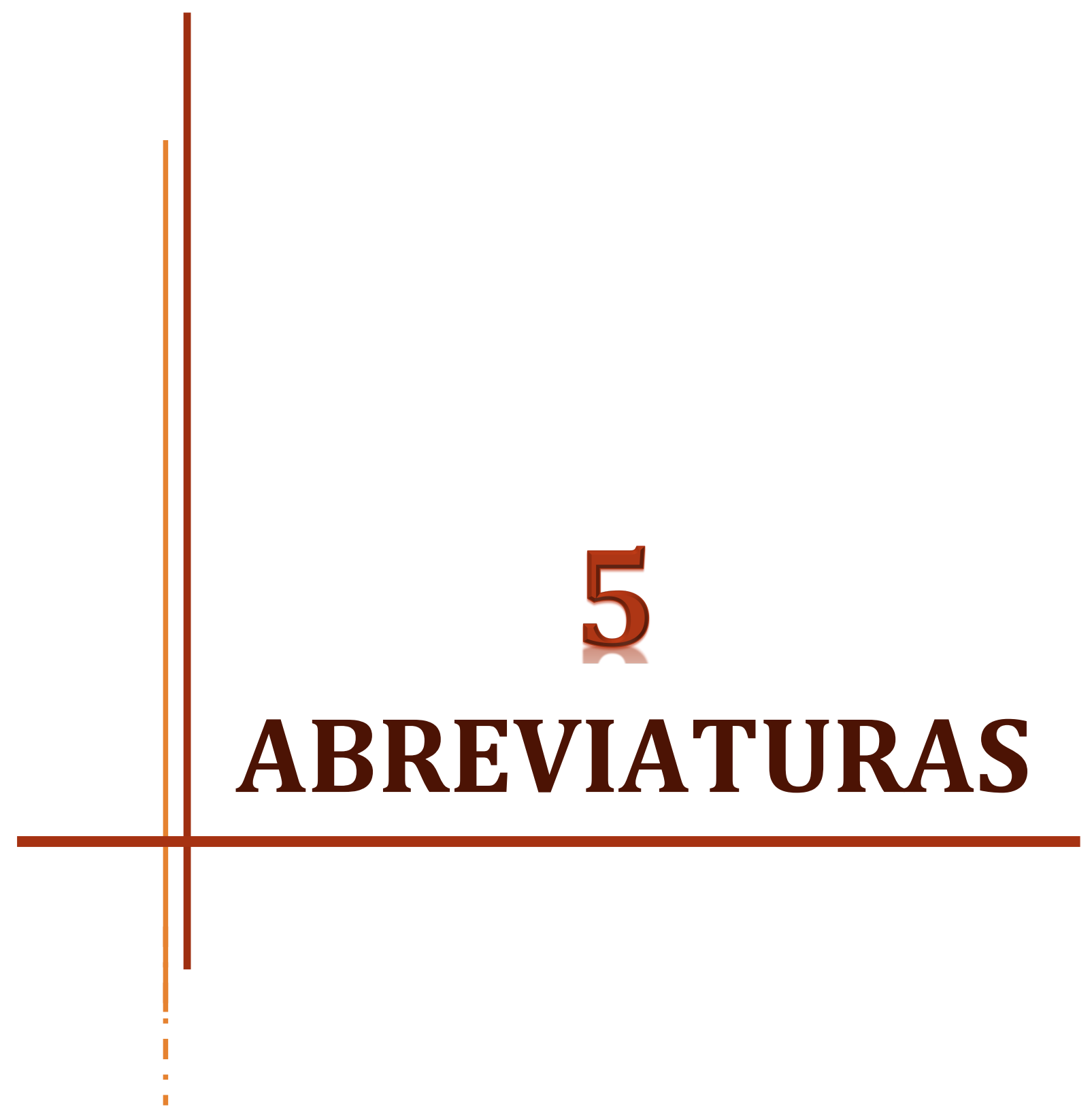



En esta Tesis Doctoral se han referido los nombres de los genes en cursiva con la primera letra en mayúsculas, los nombres de las proteínas de ratón sin cursiva con la primera letra en mayúsculas, y los nombres de proteínas humanas y genes sintéticos con todas las letras en mayúsculas.

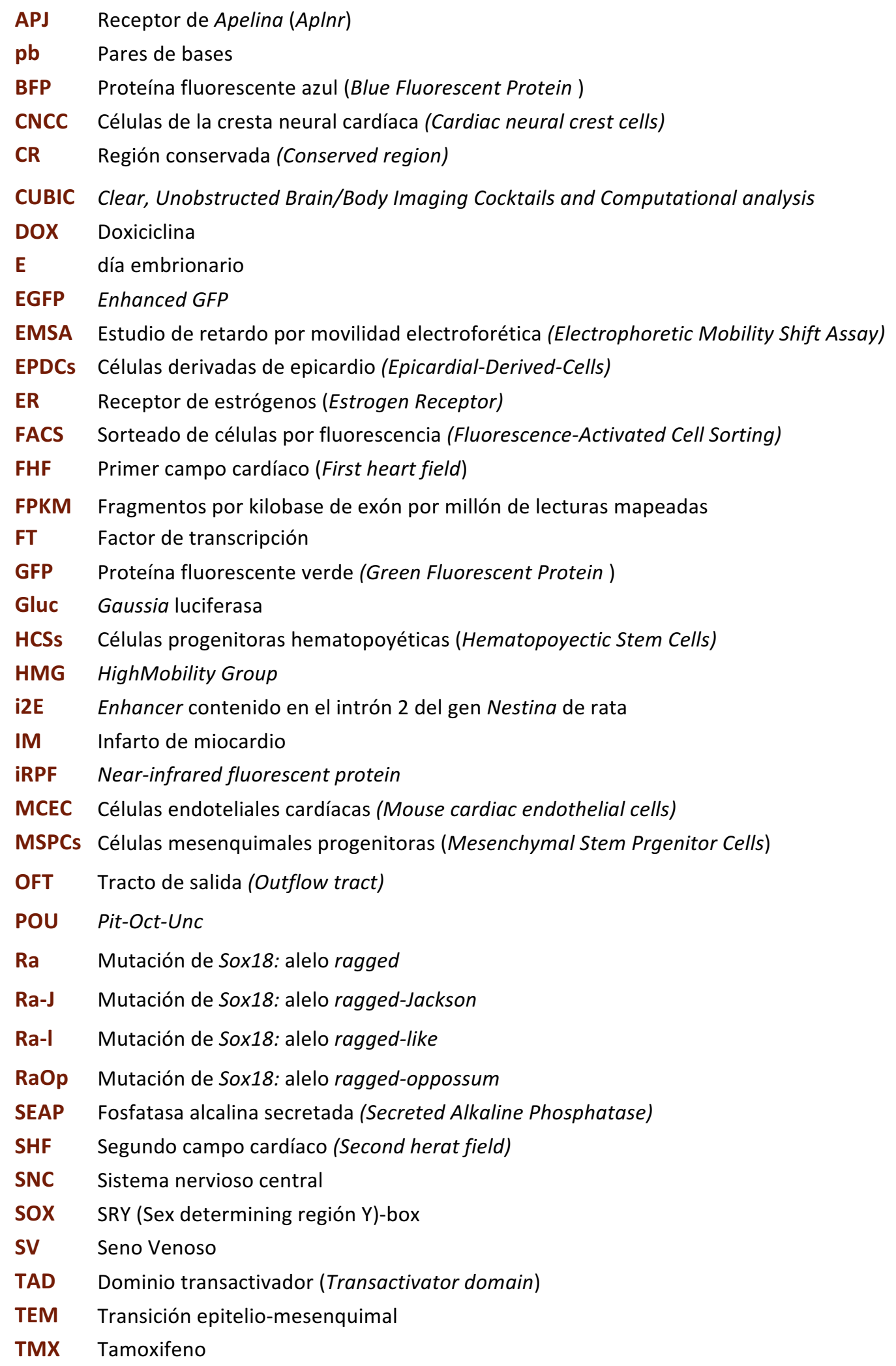





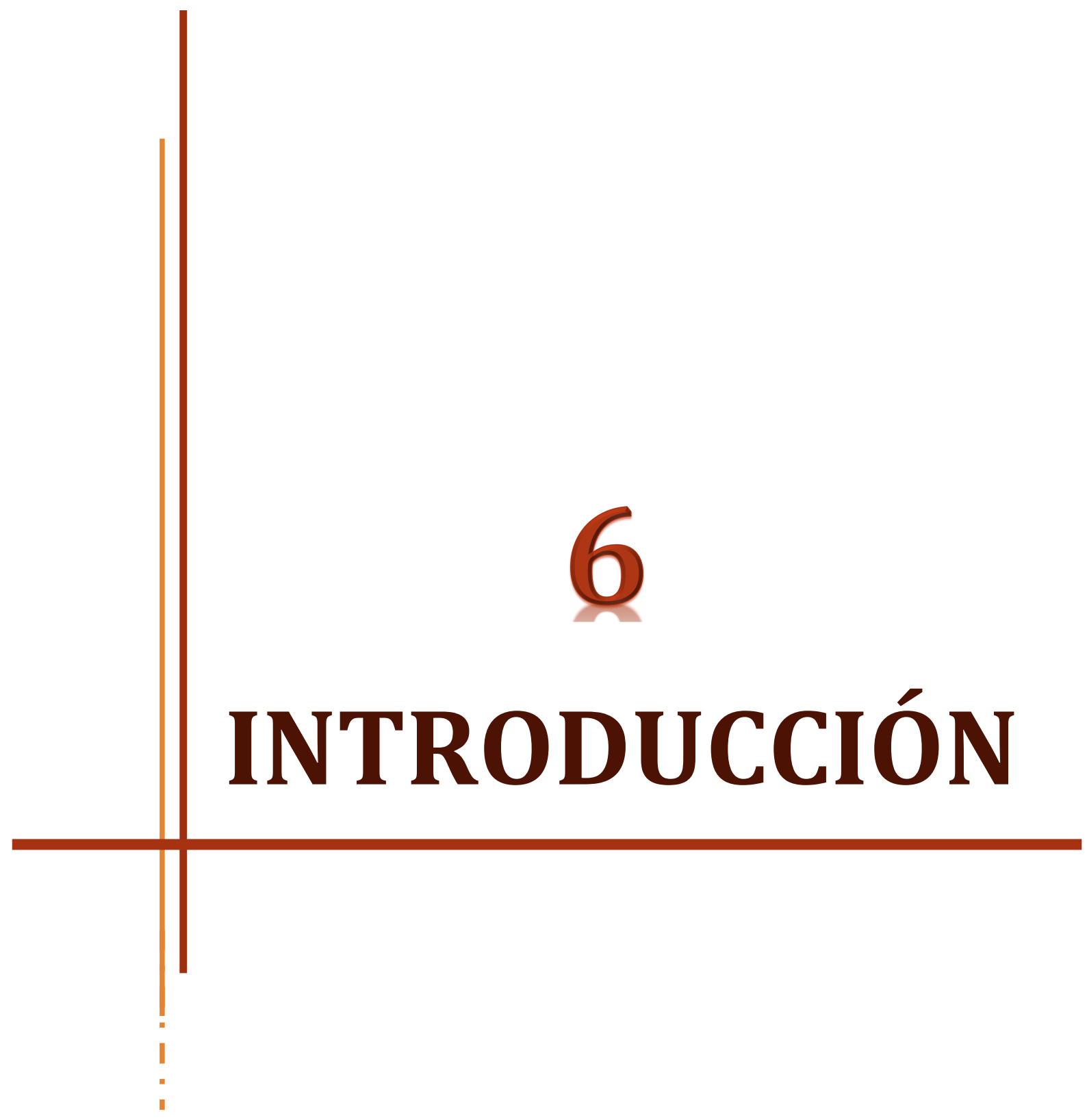





\section{Formación del Corazón durante el Desarrollo Embrionario De Ratón}

El corazón es una estructura compleja compuesta por diversos tipos celulares con funciones altamente especializadas. Las células cardíacas progenitoras derivan principalmente del mesodermo esplénico del primer y segundo campo cardíaco, también conocidos como First Heart Field (FHF) y Second Heart Field (SHF). Además, una contribución adicional de las células de la cresta neural derivadas del neuroectodermo tendrán un papel que va a ser crítico para la maduración del polo arterial (Vincent and Buckingham, 2010, Miquerol and Kelly, 2013).

En vertebrados es el primer órgano que se forma durante el desarrollo embrionario, estableciendo con su bombeo el sistema circulatorio primordial responsable de proporcionar oxígeno y nutrientes al embrión así como toda la eliminación de los residuos, una vez que el número de células aumenta y ya no es posible la difusión directa de los mismos (Buckingham et al., 2005, Olivey and Svensson, 2010, Vincent and Buckingham, 2010, Dyer et al., 2014).

En el corazón se pueden diferenciar tres capas principales de tejido: el endocardio, que forma el revestimiento endotelial interno del corazón; el miocardio, que constituye la capa muscular central donde se va a formar la vasculatura coronaria durante el desarrollo; y el epicardio, que forma la capa más externa de este órgano, y cuyas células mesoteliales derivan originariamente del proepicardio.

Brevemente, la morfogénesis cardíaca en ratón comienza a día embrionario 7.0 (E7.0) con la especificación de las primeras células del mesodermo cardíaco que constituyen un epitelio en forma de media luna, compuesta por dos poblaciones diferentes de células progenitoras del FHF y SHF. Un día más tarde (E8.0), esta media luna se fusiona en la zona central para formar un tubo cardíaco lineal primitivo que rápidamente comienza a bombear la sangre. Inicialmente el tubo cardíaco derivado de progenitores del FHF está compuesto tan sólo por dos capas de epitelio, el miocardio externo y el endocardio interno, separadas por una matriz extracelular conocida como gelatina cardíaca (Manasek, 1969, Vincent and Buckingham, 2010). En el extremo más craneal nos encontramos con el polo arterial, que dará lugar al futuro tracto de salida, mientras que el extremo caudal del tubo, denominado polo venoso, desarrollará las futuras aurículas y tracto de entrada cardíaca (Kelly and Buckingham, 2002).

Acto seguido, el tubo cardíaco primitivo comienza a crecer por la incorporación a los polos venoso y arterial de un segundo grupo de células progenitoras procedentes del SHF. El hecho de que su crecimiento dentro de la cavidad pericárdica se produzca a mayor velocidad que el de la cavidad que lo contiene, provoca un replegamiento del tubo cardíaco hacia la derecha (E8.5), mediante el cual la aurícula primitiva se coloca anteriormente, dorsal a las cámaras ventriculares y el tracto de salida se desplaza a la derecha, quedando así alineadas las futuras cuatro cámaras del corazón (E10.5) (Christoffels et al., 2000, Watanabe and Buckingham, 2010, Kelly and Buckingham, 2002). Este desplazamiento del tubo cardíaco primitivo constituye una de las primeras señales de asimetría izquierda-derecha en el embrión (Ocaña et al., 2017). La rotación y septación del tracto de salida resulta en la conexión del ventrículo derecho al tronco pulmonar, así como la del ventrículo izquierdo a la aorta, mientras que el septo auricular y ventricular 
separarán aurículas y ventrículos respectivamente en el corazón maduro (E14.5). Al mismo tiempo que se produce el giro, el corazón se incrementa de tamaño de forma drástica, incrementado entre 4-5 veces en tan sólo 24 horas (Kelly and Buckingham, 2002, Watanabe and Buckingham, 2010, Miquerol and Kelly, 2013). También se va a producir una maduración simultánea de las cámaras ventriculares en el que tendrá lugar el proceso de trabeculación que comienza a E9.5 regulado por señales del endocardio y epicardio vía Notch y Neuroregulina (Grego-Bessa et al., 2007, Peshkovsky et al., 2011) o las cascadas de señalización del ácido retinoico y factor de crecimiento de fibroblastos (Merki et al., 2005), respectivamente; el establecimiento simultáneo del sistema de conducción generará una red de cardiomiocitos especializados encargados de propagar los impulsos eléctricos de manera coordinada, regulando las contracciones cardíacas y el engrosamiento del miocardio compacto (Miquerol and Kelly, 2013).

El rápido aumento de tamaño durante este dinámico período del desarrollo viene acompañado del recubrimiento del órgano muscular primigenio con células mesoteliales, que envolverán al corazón formando el epicardio. El órgano proepicárdico del que deriva es una estructura extracardíaca mesenquimal transitoria compuesta por un grupo heterogéneo de células cercanas al polo venoso del corazón entre los días embrionarios E9.5-E10.5, y se caracterizan por la expresión de los marcadores Wt1 y Tbx18 (del inglés, Wilms'tumor 1 y $T$-Box gene 18 , respectivamente). Una vez en contacto con el miocardio, algunas de ellas sufrirán una transición epitelio-mesenquimal (TEM) y tras delaminarse de la capa epitelial, se adentrarán en el corazón para contribuir a la población de músculo liso que rodea los vasos coronarios, células fibroblásticas e intersticiales, principalmente (Vincent and Buckingham, 2010, Katz et al., 2012, Mikawa and Brand, 2010). Otro papel importante del epicardio en el proceso de cardiogénesis será su implicación como centro de señalización, estimulando el crecimiento del miocardio ventricular mediante la liberación de mitógenos solubles (Sucov et al., 2009, Lavine and Ornitz, 2010), así como el desarrollo de los vasos coronarios.

Por su parte, existe una aportación de células originarias de la cresta neural cardíaca que migran dorso-ventralmente a través de los arcos faríngeos para incorporarse al SHF, jugando un papel crítico en la maduración del polo arterial del corazón, el correcto desarrollo de la vasculatura coronaria y el remodelado del tracto de salida debido a su contribución a la formación del septo y las válvulas cardíacas (Creazzo et al., 1998, Meilhac et al., 2014, Vincent and Buckingham, 2010, Mikawa and Brand, 2010).

Con respecto a la vasculatura coronaria, se forma más adelante, ya que en los primeros estadios de la morfogénesis cardíaca el corazón consiste en una fina capa de músculo miocárdico y dada la facilidad de oxigenación por la sangre que fluye por el lumen se permite la difusión directa de nutrientes y oxígeno. A medida que el órgano va creciendo y madurando, comienza a requerirse la aparición de un sistema vascular funcional que nutra al miocardio, en la que se pueden diferenciar dos etapas principales: la formación de un plexo vascular primitivo mediante angiogénesis que va a sufrir una expansión masiva para cubrir e infiltrar por completo el miocardio, seguido de un proceso de remodelado en el que dicho plexo se conecta 
a la aorta mediante anastomosis, y el flujo sanguíneo promueve una serie de señales que dan como resultado la transformación del plexo en una disposición jerárquica de arterias, venas y capilares consecuencia de la maduración del mismo, permitiendo así la distribución de oxígeno de forma eficiente por todo el tejido miocárdico (Zeini et al., 2009, Red-Horse et al., 2010, Sharma et al., 2016).

Una vez que el corazón ha madurado completamente, en organismos adultos se sabe que la composición celular del mismo cuenta con una población de cardiomiocitos que corresponden entre el 25\%-35\% del total de células cardíacas. Con respecto a la población no miocítica, estudios recientes han demostrado que las células endoteliales constituyen más del $60 \%$ de dicha fracción, habiendo un ratio aproximado de 3 células endoteliales por cada cardiomiocito en la masa total del corazón. El resto de la fracción no miocítica estaría compuesta aproximadamente por un 5\%-10\% de células derivadas de las células hematopoyéticas y menos de un $20 \%$ correspondería a los fibroblastos, que en un principio se pensaba que tenían una mayor abundancia en este órgano (Pinto et al., 2016).

Dada la importancia de la vasculatura coronaria en la morfogénesis cardíaca, así como en el objeto de estudio de esta Tesis Doctoral, dedicaremos un posterior apartado para explicar el controvertido origen y desarrollo de la misma.

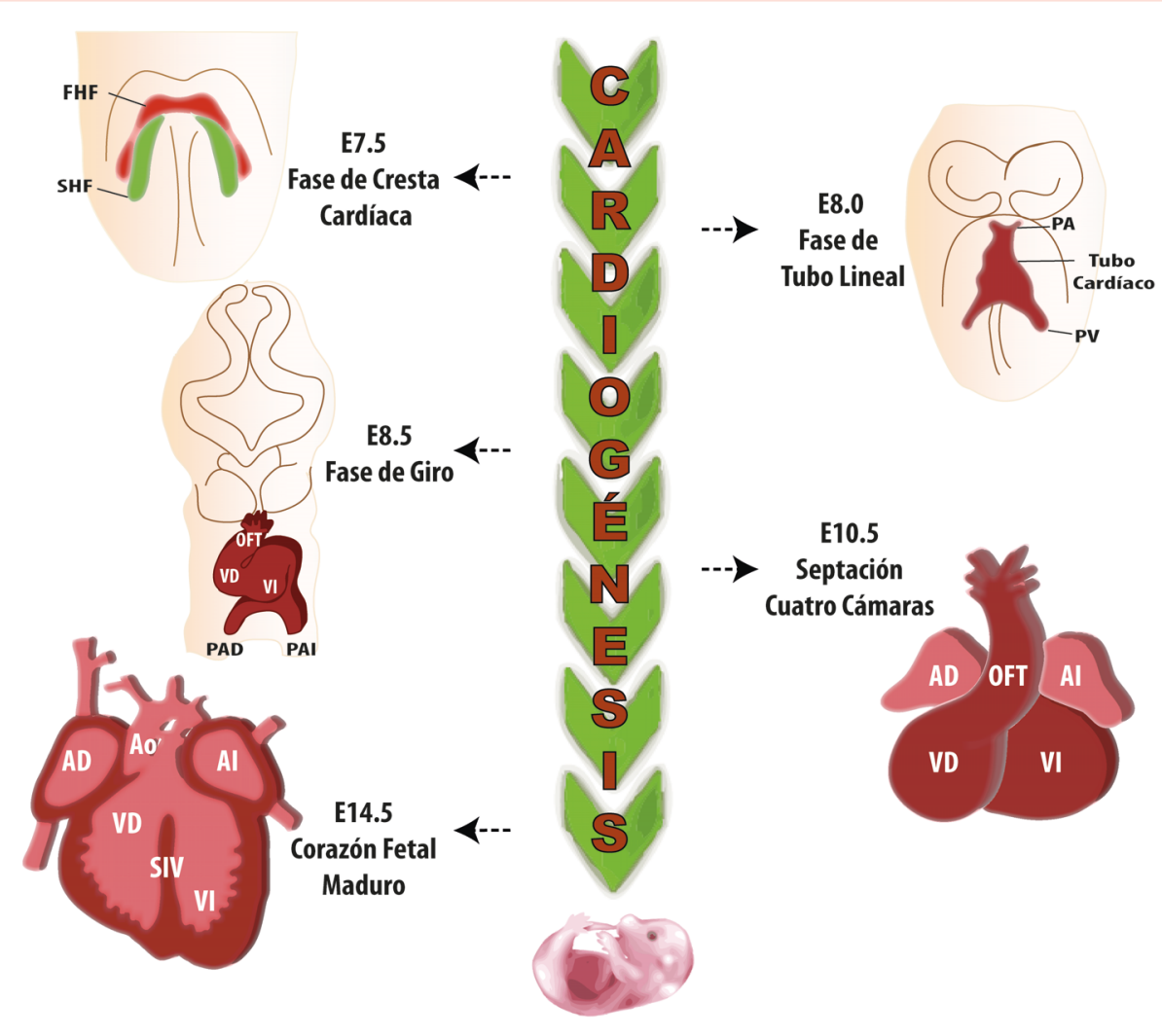

Figura 1. Formación del corazón embrionario en ratón. Se muestran las diferentes fases del desarrollo cardíaco: formación de la cresta cardíaca (E7.5), fusión de la cresta para dar lugar al tubo lineal cardíaco (E8.0), fase de giro o "looping" hacia la derecha (E8.5), septación para dar lugar a las cuatro cámaras (E10.5), y el corazón fetal maduro completamente compartimentalizado (E14.5). FHF, First Heart Field; SHF, Second Heart Field; PA, Polo Arterial; PV, Polo Venoso; PAD, Polo Arterial Derecho; PAI, Polo Arterial Izquierdo; AD, Aurícula Derecha; Ao, Aorta; AI, Aurícula Izquierda; VD, Ventrículo Derecho; SIV, Septo Interventricular; VI, Ventrículo Izquierdo. 


\section{2o Técnicas de Mapeo Genético y Trazado de linaje Celular}

Para poder entender los resultados obtenidos en esta Tesis Doctoral es necesario introducir primero una de nuestras principales herramientas de estudio, el uso de las técnicas de mapeo genético para el trazado de linajes celulares, comúnmente conocidas como "lineage tracing" o "genetic fate mapping"

El método más común actualmente para el mapeo celular en vertebrados es el trazado de linaje, combinando el sistema Cre/loxP de recombinación dirigida (Kretzschmar and Watt, 2012) con la presencia de locus genético reportero, que produzca un marcador detectable en las células que expresan Cre. Dicho sistema de marcaje es altamente eficaz y se compone de la recombinasa cre, una enzima capaz de catalizar la recombinación entre dos secuencias específicas de ADN, y los sitios loxp, que pueden ser reconocidos por la recombinasa de manera altamente específica en el genoma (Hamilton and Abremski, 1984). Dependiendo de la localización y de la orientación de estas repeticiones, la Cre podrá invertir, insertar, suprimir o intercambiar fragmentos de ADN en sistemas procariontes o eucariotas (Kilby et al., 1993, Sauer, 1998). En la mayoría de los casos, la aplicación del sistema Cre/loxP va a resultar en la escisión de la secuencia de ADN flanqueada ("floxed") por dos sitios loxP.

La expresión restringida de la actividad Cre en un órgano determinado o en el linaje celular de interés se consigue controlando su expresión con promotores tejido-específicos o, cada vez más, en combinación con secuencias de regulación "potenciadoras" conocidas como enhancers. Para el mapeo celular, a su vez se requiere que el gen reportero cuya expresión se pretende, esté localizado en un locus permisivo como Rosa26 (Friedrich and Soriano, 1991), pero bloqueado transcripcionalmente por un casete en $5^{\prime}$ (conocido como "stop cassette") que a su vez se encuentra flanqueado por dos dianas loxP. Estos genes "indicadores" suelen codificar para proteínas detectables fácilmente por actividad como $\beta$-galactosidasa o proteínas fluorescentes como la GFP (Green Fluorescent Protein), YFP (Y Yellow Fluorescent Protein), Tomato, etc. Una vez escindido el stop cassette (únicamente en células donde se exprese la Cre), pasarán a expresarse de manera permanente y heredable. La célula que sufre el evento de recombinación originariamente quedará marcada, y con el tiempo, toda su posible descendencia, siga expresando o no la Cre. Por este motivo, el poder de la tecnología Cre/loxP es que nos permite marcar un determinado linaje celular y trazar hacia dónde migra su progenie o a qué otros tipos celulares se diferencia (Tian et al., 2015, Sharma et al., 2016, Das and Red-Horse, 2017).

No obstante, este sistema genético también presenta limitaciones, ya que debemos ser muy cuidadosos a la hora de interpretar los resultados obtenidos. La expresión de un gen suele ser dinámica con el tiempo, especialmente durante el desarrollo, de manera que células que no expresan un determinado gen en un momento concreto pueden expresarlo en un futuro, $y$ viceversa, pudiendo conducir a interpretaciones erróneas al realizar trazado de linaje con el empleo de recombinasas Cre que se expresan constitutivamente.

Una forma de tratar de reducir esta limitación es el desarrollo de líneas genéticas Cre expresadas de forma inducible, permitiendo así la regulación, no sólo espacial, sino también 
temporal, al poder restringir la ventana de inducción de la recombinasa en el tejido deseado. Para ello se fusiona la Cre a un receptor de estrógenos, generando una CreER (Estrogen Receptor) que aun siendo tejido-específica, se encontrará inactiva en ausencia de su ligando, el tamoxifeno. Por tanto, sólo en presencia de tamoxifeno se producirá la transcripción del gen reportero mediado por la recombinación de la CreER.

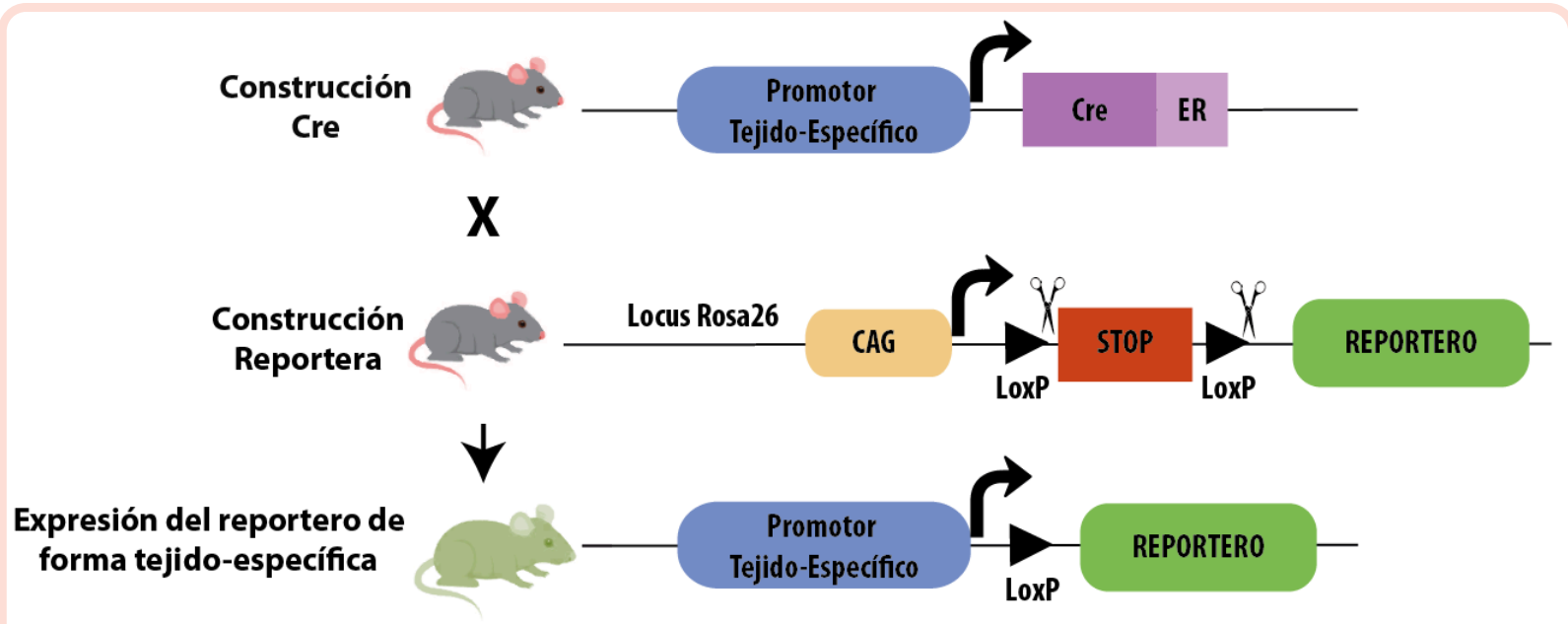

Figura 2. Esquema del sistema de recombinasas Cre/LoxP para fate mapping. Una vez se escinde el casete LoxP-stop-LoxP (LSL), mediado por la acción de la Cre, se desbloquea la transcripción del gen reportero controlada por el potente promotor CAG. CAG (CMV, Actin, Globin): promotor sintético conformado por un elemento early enhancer del virus CMV, una porción del promotor del gen de la betaactina de pollo y un aceptor de splicing del gen de la beta-globina del conejo.

\section{3o Origen y Desarrollo de la Vasculatura Coronaria en Ratón}

La enfermedad coronaria es el tipo más común de enfermedad cardíaca, siendo la principal causa de muerte cada año en los países desarrollados (Wong, 2014). Consiste en el depósito de grasa, colesterol, calcio, y otras sustancias presentes en la sangre, en la pared arterial formando una placa o ateroma (motivo por el cual también se conoce como arterosclerosis). Dicho ateroma puede afectar al flujo de sangre responsable de proporcionar oxígeno y nutrientes al músculo cardíaco. Dependiendo del grado de bloqueo arteriosclerótico, las personas con esta patología podrían sufrir angina o ataque cardíaco, así como insuficiencia cardíaca o arritmia derivada de la debilitación del miocardio con el paso del tiempo (Red-Horse et al., 2010, Riley and Smart, 2011, Sharma et al., 2016).

Actualmente los principales tratamientos para esta enfermedad consisten en intervenciones quirúrgicas entre las que se encuentran la intervención coronaria percutánea (comúnmente conocida como "angioplastia") y la cirugía de derivación cardíaca ("bypass"), no obstante el principal objetivo de la investigación cardiovascular persigue el desarrollo de nuevos y mejores métodos para reparar, y especialmente, regenerar las arterias y zonas afectadas tras el infarto de miocardio (Rubanyi, 2013, Tian et al., 2015, Sharma et al., 2016). Pero para poder desarrollar estrategias que estimulen la formación de nuevos vasos en el tejido dañado primero es necesario conocer y entender las bases celulares y moleculares que desencadenan el 
desarrollo de la vasculatura coronaria durante la embriogénesis para poder así diseñar herramientas terapéuticas que permitan su reactivación en tejidos adultos (Riley and Smart, 2011).

El establecimiento del sistema vascular se forma de novo mediante un proceso conocido como vasculogénesis. Las células mesodérmicas se diferencian en precursores endoteliales que formarán los vasos primitivos, siendo rápidamente remodelados mediante la expansión endotelial, la ramificación e intususcepción de vasos sanguíneos preexistentes. En mamíferos, los progenitores vasculares aparecen primero en el saco vitelino, donde los precursores mesodérmicos hematopoyéticos y endoteliales forman unas estructuras conocidas como "islas de sangre" (Flamme et al., 1997, Patan, 2004). Por su parte, el desarrollo de la vasculatura coronaria comprende un programa angiogénico gradual que consta de dos etapas: primero se forma un plexo vascular primitivo mediante angiogénesis que migra a través de la superficie del corazón, a la vez que penetra el miocardio. Este plexo aún sin perfundir se extiende también hacia la aorta, conectándose con el endotelio aórtico por anastomosis a través de dos aberturas que permiten el inicio del flujo sanguíneo arterial. De este modo, el plexo indiferenciado que se encuentra inmediatamente por debajo del punto de conexión a la aorta experimenta los niveles más altos de presión por flujo sanguíneo, lo que desencadena señales que promueven su arterialización dando lugar a las arterias coronarias izquierda y derecha. Por tanto, la respuesta producida por las señales de flujo arterial desencadenan la segunda etapa de remodelado, en la que el plexo inmaduro se reconfigura para dar lugar a vasos de mayor calibre recubiertos por células de músculo liso y fibroblastos adventicios que forman la capa más externa de las arterias coronarias (Dyer et al., 2014, Sharma et al., 2016).

En cuanto al origen celular del endotelio coronario, los primeros estudios anatómicos realizados en humanos y otros mamíferos hace un siglo a partir de cortes histológicos llevaron a la conclusión de que las arterias coronarias debían brotar de la aorta, mientras que las venas surgían del seno venoso (Bennett, 1936, Goldsmith and Butler, 1937). Sin embargo, la combinación de la histología con otras técnicas como el análisis clonal y los estudios de recombinación tisular ex vivo rebatieron dichos resultados.

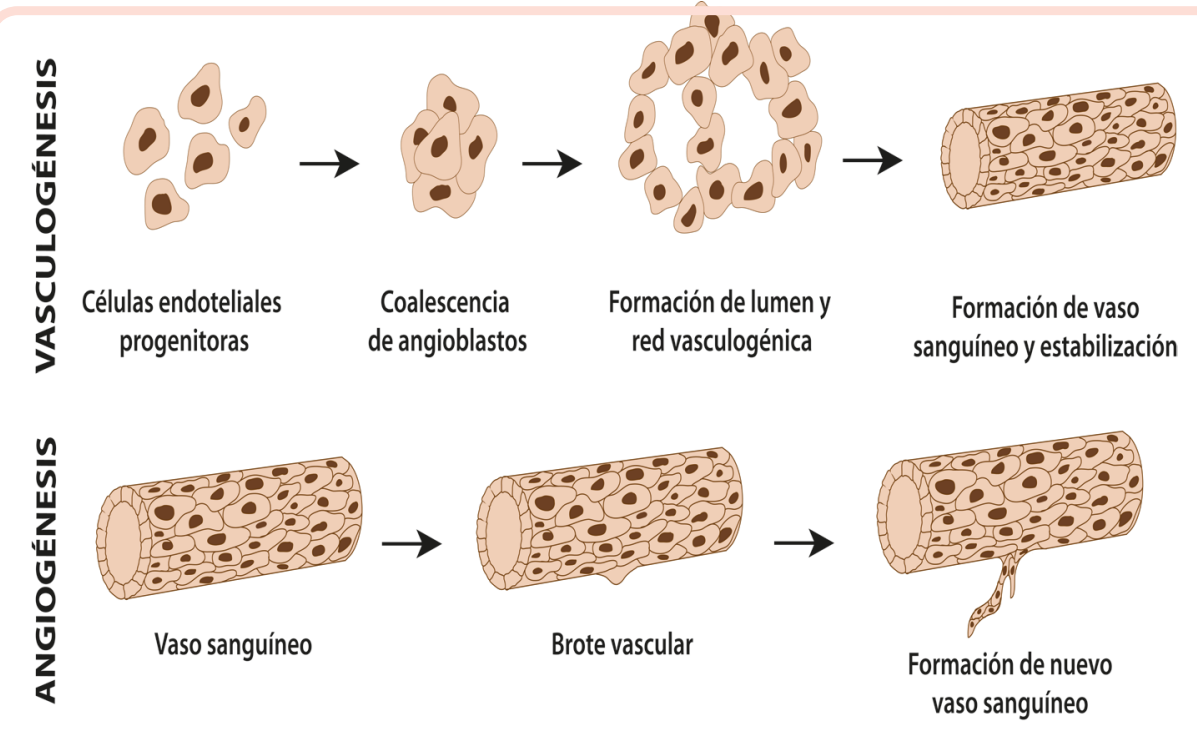

Figura 3. Formación de los vasos por vasculogénesis $y$ angiogénesis. Se representan las principales diferencias entre ambos procesos. En la vasculogénesis, se trata de una formación de novo de vasos sanguíneos, mientras que en el proceso de angiogénesis los vasos se expanden a partir de vasculatura preexistente 
Actualmente se han identificado tres fuentes diferentes para la vasculatura coronaria: el (pro)epicardio, el seno venoso (SV) y el endocardio ventricular. Aun así, la contribución de cada una de estas fuentes a la vasculatura coronaria en ratón ha sido objeto de intenso debate y controversia en los últimos 30 años (Dyer et al., 2014, Sharma et al., 2016).

\section{1. Vasculatura Coronaria Originada del Epicardio}

Como ya se ha descrito, el órgano proepicárdico es una estructura extra cardíaca transitoria cuyas células migran y se extienden por la superficie del corazón formando la capa de epitelio conocida como epicardio. Esta capa cumplirá dos funciones principales durante el desarrollo: una subpoblación del epicardio sufre una transición epitelio-mesenquimal para dar lugar a una importante población de células mesenquimales, músculo liso y fibroblastos cardíacos. Por otro lado, la interfaz miocardio-epicardio constituirá un centro de señalización crítico para el crecimiento del miocardio y desarrollo de vasos coronarios.

Durante más de dos décadas se pensó que el órgano proepicárdico era la principal fuente de la vasculatura coronaria en base a experimentos de trazado de linaje realizados en embriones de pollo, que incluían el marcaje retroviral con adenovirus, marcaje con colorante DiI, y el trasplante cruzado entre las especies de codorniz y pollo (Männer, 1999, Männer et al., 2001, Muñoz-Chápuli et al., 2002, Ratajska et al., 2008). En el trabajo pionero llevado a cabo por Mikawa y Fischman inyectaron retrovirus deficientes en la replicación para que expresara el marcador LacZ en el proepicardio. Cuando el corazón continuaba su desarrollo, identificaron células de músculo liso, fibroblastos y células endoteliales positivas para el marcaje con lacz. Estaba bien establecido que el proepicardio era fuente de células de músculo liso y fibroblastos derivados de las EPDCs (EPicardial-Derived Cells), pero este experimento estableció el paradigma de que los vasos endoteliales coronarios surgían del proepicardio (Mikawa and Fischman, 1992, Mikawa and Gourdie, 1996). Dicha teoría se vio reforzada por las quimeras de codorniz-pollo en las cuales se trasplantaba el proepicardio de embriones de codorniz en embriones receptores de pollo, donde detectaban posteriormente la contribución de las células donadoras (marcadas con el anticuerpo endotelial especifico de codorniz $\mathrm{QH}-1$ ) a la vasculatura coronaria y células de músculo liso (Pérez-Pomares et al., 1998).

No obstante, estos experimentos fueron rebatidos al presentar limitaciones clave. En primer lugar, en el estudio de las quimeras pudo haber contaminación en la cual se cotrasplantaba con el proepicardio parte del primordio hepático o del SV, pudiendo ser éstas las verdaderas fuentes de las células endoteliales (Poelmann et al., 1993). Por otro lado, gracias a la tecnología del sistema Cre-LoxP se ha logrado un marcaje específico del linaje epicárdico en ratón empleando marcadores bien establecidos como Tbx-18 y Wt-1. Estos estudios demuestran que, si bien se podía observar una pequeña contribución de las células marcadas al endotelio coronario, debía descartarse que el órgano proepicárdico fuera la principal fuente de la vasculatura coronaria (Zhou et al., 2008, Cai et al., 2008). 


\section{2. Vasculatura Coronaria Originada del Seno Venoso}

El seno venoso es otra estructura transitoria durante el desarrollo cardiovascular que recibe la sangre venosa de las venas vitelina, umbilical y cardinal común para devolverla a la aurícula. Una vez que el corazón madura, esta estructura se integra en la aurícula derecha formando el seno coronario.

A finales de los 90, trabajos de diferentes grupos sugirieron que la vasculatura coronaria podía surgir como una extensión de los vasos lumenizados presentes en el SV (Poelmann et al., 1993, Vrancken Peeters et al., 1997), sin embargo estas teorías permanecieron periféricas en un momento en el que casi toda la investigación se centraba en el papel del proepicardio. Fue en el año 2010 cuando el trabajo realizado por el grupo de Mark Krasnow consigue centrar de nuevo la atención a la posibilidad de que el SV experimentase una expansión angiogénica enviando vasos a la superficie del corazón, dejando atrás el convencimiento de que el proepicardio era la principal fuente del plexo coronario (Red-Horse et al., 2010).

En este estudio se realiza un exhaustivo análisis anatómico e histológico del desarrollo de la vasculatura coronaria en embriones de ratón usando marcadores endoteliales y trazado de linaje endotelial con la línea apelin-nlacZ, que permitía un marcaje con $\beta$-galactosidasa específicamente en el plexo coronario pero no en las células endoteliales del endocardio. A su vez, la combinación de estas técnicas con sistemas de cultivo de órgano in vitro así como el análisis clonal usando la línea inducible por tamoxifeno VE-cadherin-CreER, permitieron establecer que los progenitores de las arterias coronarias surgían principalmente a partir de células VE-Caderin+ que brotaban del SV y migraban a través de la superficie del corazón y a través del miocardio a medida que se convertían en arterias coronarias. El análisis de marcadores específicos mostró que las células que brotaban inicialmente del SV tenían una identidad venosa, pero que a medida que migraban, dicha identidad se iba perdiendo para que en 24 horas (E12.5), los vasos que invadían el miocardio adquiriesen identidad arterial, mientras que los que permanecían en la superficie reactivaban los marcadores venosos. Estos resultados concluían por tanto que la principal fuente del plexo coronario procedía del SV, con una pequeña contribución de vasos procedentes del endocardio ventricular, a partir de unas estructuras conocidas como "islas de sangre" situadas cerca del septo interventricular, de las que parecían brotar algunas células endoteliales que se unían al resto de la vasculatura coronaria en desarrollo (Red-Horse et al., 2010). Estas estructuras, descritas inicialmente por Hutchins y colaboradores (Hutchins et al., 1988), también han recibido el nombre de "flores endocárdicas" (Miquerol et al., 2015, Yzaguirre et al., 2015, Ratajska et al., 2009). Parecen surgir como resultado de invaginaciones de las trabéculas del endocardio, y se ha demostrado en modelos de daño vascular (IM) o bloqueo de la angiogénesis de vasos procedentes del SV, se activan progenitores endocárdicos de dichas estructuras para tratar de compensar el daño (Miquerol et al., 2015, Sharma et al., 2017).

El modelo descrito por Red-Horse recibió diferentes aceptaciones. El hecho de que una subpoblación de las células endoteliales procedentes del SV ya expresara el marcador arterial Notch1, sugería una plasticidad de esta microvasculatura embrionaria en lugar de un programa 
de desdiferenciación/rediferenciación (Pérez-Pomares and De La Pompa, 2011). Trabajos posteriores mostraron la heterogeneidad de células endoteliales presentes en el SV, compuesto por células endoteliales maduras positivas para APJ (receptor de Apelina) y células inmaduras negativas para APJ. De esta forma, las células endoteliales APJ- migrarían desde el SV hacia el miocardio en respuesta a la señalización de Angiopoyetina-1 secretada por el propio miocardio, señalización que a su vez regularía la diferenciación de estas células subepicárdicas inmaduras hacia un fenotipo venoso APJ+ (Arita et al., 2014). Trabajos más recientes han descrito el papel de la angiopoyetina-1 junto con VEGF-C (expresada por el epicardio) como señales paracrinas clave en promover la expansión angiogénica de la vasculatura procedente del SV hacia el miocardio (Chen et al., 2014).

Independientemente del modelo, lo que sí pareció ser ampliamente aceptado fue el establecimiento del SV como principal fuente de la vasculatura coronaria en desarrollo, con contribuciones en menor medida del endocardio y del proepicardio. Trabajos posteriores apoyaron los resultados obtenidos por Red-Horse tras la generación de una línea $A p / n-C r e E R^{T 2}$ inducible que permitía marcar los vasos subepicárdicos y toda su descendencia. De esta forma, se corroboraba que la vasculatura coronaria del subepicardio (procedente del SV) se expandía y migraba para invadir el miocardio compacto, donde formarían la mayor parte de la vasculatura intramiocárdica, incluyendo arterias y capilares, además de las venas coronarias que se mantienen en el subepicardio (Tian et al., 2013, Liu et al., 2015a).

\section{3. Vasculatura Coronaria Originada del Endocardio Ventricular}

El endocardio es un endotelio especializado que recubre las superficies internas del corazón, representando un reservorio de endotelio distribuido a lo largo de la superficie luminal del miocardio ventricular. Similar al proceso sufrido en epicardio, algunas de sus células se pueden delaminar y migrar para, mediante un proceso de transición endotelio-mesenquimal (endoMT), dar lugar a células mesenquimales y murales en el miocardio (Tian et al., 2015).

En el trabajo realizado en el año 2012 por el grupo de Bin Zhou en Nueva York evaluaron la contribución del endocardio como fuente de la vasculatura coronaria. Para ello realizaron un trazado de linaje endocárdico usando una nueva línea constitutiva Nfatc1-Cre desarrollada por ellos, y observaron que la mayoría de las arterias coronarias intramiocárdicas quedaban marcadas ( $81 \%)$. Por su parte, los vasos subepicárdicos, principalmente las venas coronarias, apenas fueron marcadas con esta Cre, sugiriendo un nuevo modelo en el cual un subconjunto de células endocárdicas ventriculares invadiría la pared del miocardio desde la parte luminal, migraría hacia la superficie externa (epicárdica) del corazón y se diferenciaría en vasculatura arterial, mientras que las venas subepicárdicas debían de desarrollarse por otro mecanismo (Wu et al., 2012).

Este modelo fue respaldado por datos funcionales en los que afectando la señalización de VEGF-A, ya fuese inactivando VEGF-A en el miocardio o desactivando su receptor VEGFR2 en endocardio, reducía significativamente la vasculatura coronaria en el miocardio sin afectar a los vasos del subepicardio (Wu et al., 2012). Aun así, el modelo entraba en conflicto con los 
resultados obtenidos con el trazado de linaje de las líneas VE-Cadherin-CreER ${ }^{\mathrm{T2}}$ y Apln-CreER (Red-Horse et al., 2010, Tian et al., 2013). Además, se demostró que la línea Nfatc1-Cre no era completamente específica de endocardio ventricular, ya que también parecía marcar parcialmente células del SV, dando como resultado una sobreestimación de la contribución del endocardio a las arterias coronarias (Tian et al., 2015).

\section{4. Consenso entre los Diversos Orígenes de la Vasculatura Coronaria}

No es extraño postular que tanto el epicardio, como el seno venoso y el endocardio estén implicados en el desarrollo de la vasculatura coronaria, permitiendo múltiples posibilidades de readaptación si alguno de los procesos se viese afectado durante el desarrollo. Sin embargo los porcentajes de contribución al conjunto de plexo total atribuidos a cada uno de ellos ha dependido de los enfoques experimentales e interpretaciones de los resultados de marcaje. Ya se comentaba anteriormente que, a pesar de ser una herramienta tremendamente útil, la especificidad de tejido de las distintas líneas Cre generadas a lo largo de los años no es total y la interpretación crítica de los investigadores será crucial a la hora de sacar conclusiones. Trabajos actuales han conseguido elucidar la contribución de las distintas fuentes a la vasculatura coronaria en ratón de una manera más cuantitativa.

El grupo de Bin Zhou en Shangai identificó un nuevo gen más específico para el endocardio ventricular que, a diferencia de Nfatc1, no marcaba células del SV. Este gen era el Npr3 (receptor 3 del péptido natriurético), a partir del cual generaron una nueva línea para el trazado de linaje del endocardio (Npr3-CreER). La combinación de esta línea con la de Fabp4-Cre, para trazar específicamente los vasos coronarios, les permitió concluir que el seno venoso era la principal fuente del endotelio coronario en las paredes ventriculares del embrión (He et al., 2014, Zhang et al., 2016).

Con respecto a la discutida contribución del epicardio, los grupos de J. Epstein y C. Tabin demuestran que el proepicardio es en realidad una población heterogénea. Mientras que los trazados de linaje empleando las líneas Wt1-Cre y Tbx5-Cre descartaron su aportación a la vasculatura coronaria en ratón, en este trabajo identifican una subpoblación de células proepicárdicas Sema3D+Scx+ que sí contribuyen al endotelio coronario del órgano cardíaco (Katz et al., 2012).

Finalmente, Chen et al. combinan el marcaje genético selectivo con una línea específica de vasos derivados del SV (Apj-CreER), la línea utilizada hasta el momento de endocardio (Nfatc1Cre), y una línea de proepicardio (Sema3D-Cre) para conciliar las contribuciones de cada fuente al plexo coronario. Concluyen así que el SV y el endocardio contribuyen a la vasculatura de regiones complementarias y excluyentes en el corazón en desarrollo, mientras que el proepicardio realiza aportaciones dispersas por todo el órgano cardíaco. Los brotes angiogénicos procedentes del SV recubren la superficie dorsal y lateral del corazón respondiendo a VEGF-C y al axis de señalización ELABELA-APJ (Sharma et al., 2017) y penetran el miocardio. El endocardio por su parte emerge desde el lumen cardíaco en respuesta a VEGF-A y contribuye a 


\section{Fase de Expansión Angiogénica}
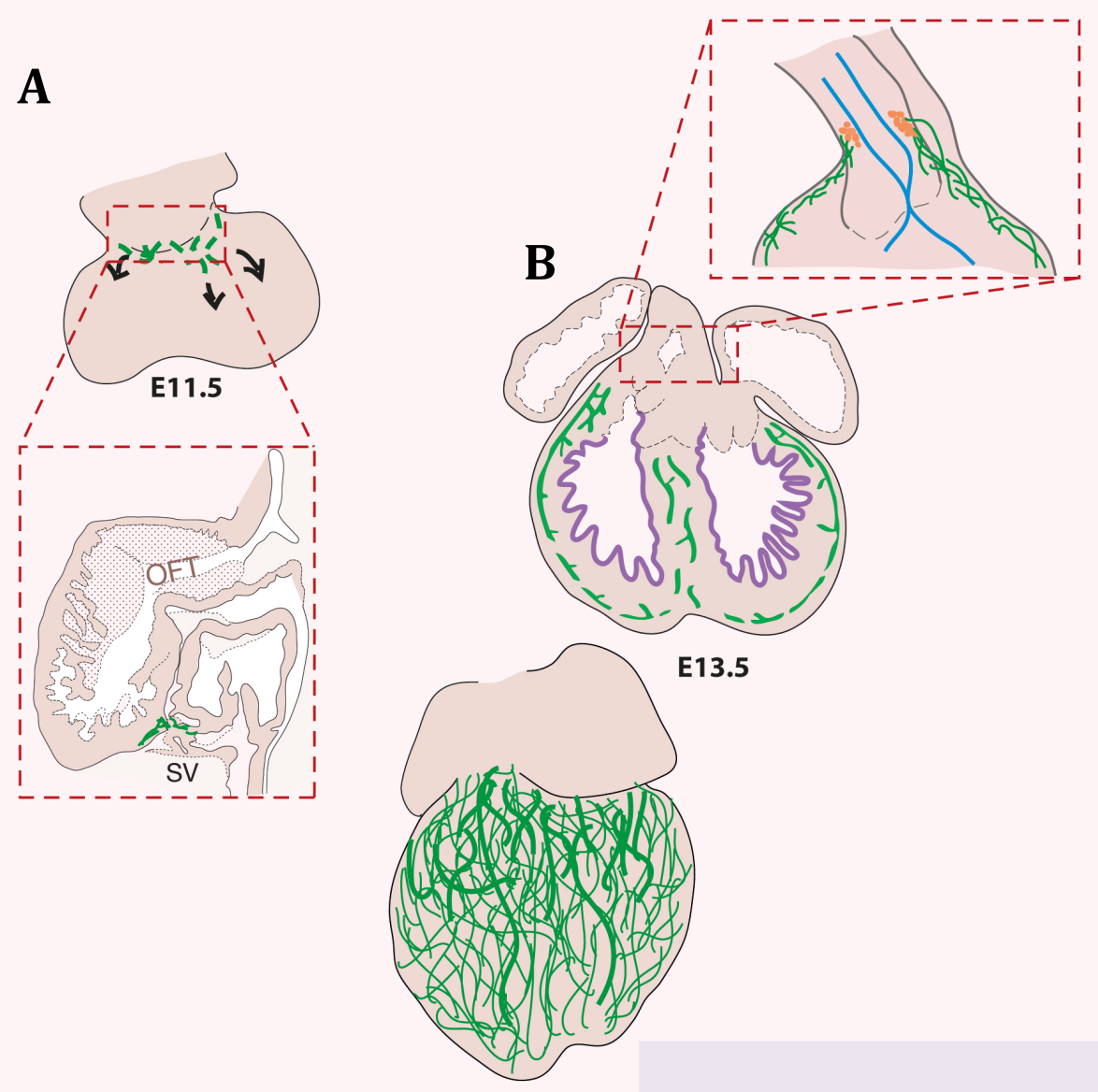

Fase de Remodelado

Figura 4. Desarrollo de la vasculatura coronaria en ratón. (A) Durante la fase de expansión angiogénica, se muestra el plexo que comienza a invadir el corazón por la parte del seno venoso (SV). (B) A E13.5 la parte dorsal del corazón se encuentra completamente cubierta por el plexo primitivo que ya invade el miocardio distinguiéndose las zonas de plexo subepicárdico e intramiocárdico. A este estadio también se produce la unión del plexo a la aorta por anastomosis, permitiendo la entrada del flujo sanguíneo que desencadena las señales para el remodelado. (C-D) En la fase de remodelado, el plexo sigue expandiéndose y madurando para dar lugar a las arterias y venas coronarias.
C

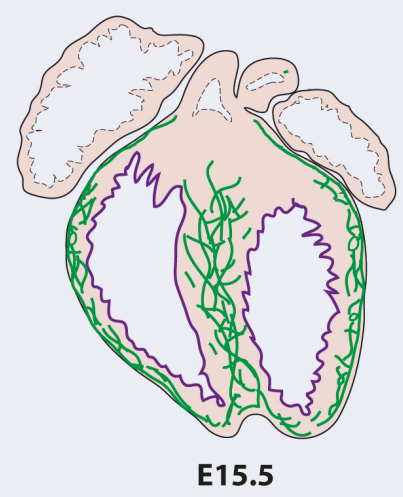

D

E17.5

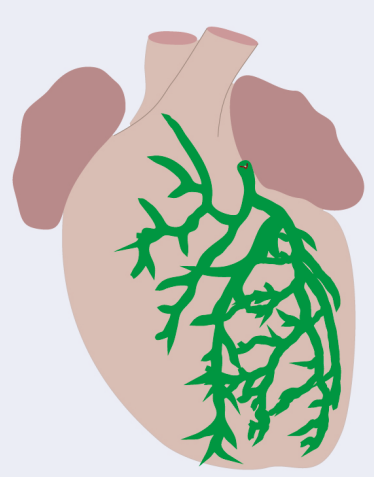


los vasos presentes en el septo interventricular y de la superficie ventral del corazón. Así, parece ser que la combinación de todas las fuentes ha sido resultado de un mecanismo de evolución que permite una rápida y eficiente vascularización del órgano cardíaco con la posibilidad de compensación si alguna de las vías de señalización se viese afectada durante el desarrollo (Chen et al., 2014).

\section{5. Formación de Novo de la Vasculatura Coronaria Postnatal}

Si bien se llegó al consenso de que durante la cardiogénesis embrionaria la mayor contribución a la vasculatura procedía de la expansión angiogénica de las células procedentes del $\mathrm{SV}$, un estudio llevado a cabo en estadios posnatales (durante la primera semana de vida de los ratones) ha determinado que existe una oleada de vasos procedentes del endocardio que se origina de novo. Debido al cambio del sistema de circulación del estado fetal al postnatal, el miocardio trabecular debe fusionarse rápidamente con el miocardio compacto. Durante el proceso de compactación trabecular las células del endocardio en la superficie de las trabéculas quedan atrapadas dentro del miocardio compacto. Posiblemente los progenitores que queden atrapados, en respuesta a hipoxia y a su nuevo ambiente intramiocárdico, empiezan a formar los vasos que suministran la sangre al recién establecido miocardio compacto (Tian et al., 2014, He et al., 2014, Tian et al., 2017).

\section{6. La Vasculatura Linfática}

Además de la vasculatura coronaria y el endocardio, encontramos un tercer tipo de endotelio en la circulación linfática. Consiste en un sistema circulatorio complementario que devuelve el fluido extracelular (o linfa) a la sangre y organiza la respuesta inmune.

El desarrollo de la vasculatura linfática cardíaca comienza en el día embrionario E12.5 emergiendo de regiones extra-cardíacas cercanas al tracto de salida, en el lado ventral del corazón (Flaht et al., 2012). A E18.5 los vasos linfáticos continúan expandiéndose y proyectándose hacia el ápex del corazón maduro tanto en la superficie dorsal como ventral del órgano. Una vez que los ratones nacen, esta vasculatura continua expandiéndose y ramificándose, finalizando su crecimiento en el día postnatal P15. Esta segunda vasculatura cardíaca se identifica por los marcadores VEGFR3, Lyve-1 y Prox1 (Klotz et al., 2015).

Estudios en ratón han establecido que a día E9.5 una pequeña porción de células dentro de la capa endotelial de la vena cardinal comienza a expresar el factor de transcripción Prox1 y migra fuera en respuesta a VEGF-C. Estos progenitores por tanto se ensamblan formando los primeros vasos linfáticos que se diseminan por todo el organismo. Este modelo implica así la transdiferenciación de las células endoteliales venosas a linfáticas (Srinivasan et al., 2007, Yang and Oliver, 2014). No obstante, experimentos recientes de trazado de linaje han demostrado que, si bien la vía venosa es la más abundante, podría existir también la contribución de otros tipos celulares a la formación de la vasculatura linfática (Martinez-Corral et al., 2015, Klotz et al., 2015). 


\section{Modelos Genéticos de Ratón: NeStin-GFP y NeSTIN-CREERT2}

Las principales líneas transgénicas que se han empleado para el desarrollo de esta Tesis son el alelo Nestin-Gfp (Mignone et al., 2004) y el modelo inducible para realizar trazado de linaje con el alelo Nestin-CreER ${ }^{\text {T2 }}$ (Balordi and Fishell, 2007).

\section{1. Caracterización dell Gen Nestina y Generación de Líneas Transgénicas}

El gen de Nestina codifica para una proteína estructural de la familia de filamentos intermedios cuya expresión se ha relacionado con células madre neuroepiteliales y células progenitoras de músculo esquelético (Wiese et al., 2004). Un epítopo de la proteína de rata fue identificado inicialmente cuando trataban de encontrar genes expresados específicamente en las células madre del sistema nervioso central (SNC) durante el desarrollo (Hockfield and McKay, 1985). El anticuerpo monoclonal Rat.401 lo reconocía en zonas proliferativas del tubo neural que expresaban la proteína, posteriormente relacionadas con la presencia de células madre neurales (Frederiksen and McKay, 1988). El hecho de que este antígeno se perdiese una vez que dichas células se diferenciaban, lo convirtió en un importante marcador para la identificación en ratas de progenitores neurales del SNC con capacidad de auto-renovación. Finalmente el ADNc de Nestina se clonó en 1990 y su estructura genómica fue caracterizada (Lendahl et al., 1990). El gen Nestina de rata, con un tamaño de 5.945 pb, está compuesto por 4 exones y 3 intrones (Lendahl et al., 1990, Calderone, 2012). Codifica para una proteína de 240 kDa que, a diferencia de otros filamentos intermedios, no es capaz de auto-ensamblarse para formar homodímeros debido a su corto extremo $\mathrm{N}$-terminal, sin embargo sí que es capaz de formar heterodímeros con otras proteínas estructurales como Vimentina y Desmina. Debido a sus similitudes estructurales con filamentos intermedios de tipo III (Vimentina, Desmina) y tipo IV (Neurofilamentos, ainternexina), se incluyó en una nueva categoría de filamentos intermedios: los de clase VI (Wiese et al., 2004). Con respecto a su regulación transcripcional, este gen presenta características únicas. Análisis realizados en ratones transgénicos demostraron que en las $5.8 \mathrm{~kb}$ de promotor no parecía haber elementos reguladores, sin embargo, identificaron enhancers importantes contenidos tanto en el primer como en el segundo intrón del gen responsables de la expresión de Nestina en percursores miogénicos y progenitores neuroepiteliales, respectivamente (Zimmerman et al., 1994).

El segundo intrón del gen de Nestina, donde se encuentra el enhancer neural (en adelante, i2E), ha sido objeto de un amplio estudio desde el momento en el que fue caracterizado. Para identificar los elementos reguladores responsables de dirigir la expresión de Nestina en las células madre y progenitoras del sistema nervioso central, generaron deleciones superpuestas a lo largo de las 1670 pb del intrón en ratones transgénicos que contenían las diferentes formas mutantes del enhancer ligados al reportero lacZ y bajo la expresión de un promotor mínimo (Yaworsky and Kappen, 1999). De esta forma, caracterizó en primer lugar una región mínima de 714 pb en el extremo $3^{\prime}$ del intrón, con dominios de unión al ADN ampliamente conservados entre ratón, rata y humanos, que contenía los elementos reguladores necesarios para 
recapitular el patrón del enhancer completo (Lothian and Lendahl, 1997). En estudios posteriores identificaron dentro de dicha región dos dominios diferentes, uno responsable de la expresión de células progenitoras del sistema nervioso central, y otro que controlaba la expresión en el cerebro medio (Lothian et al., 1999, Yaworsky and Kappen, 1999, Calderone, 2012).

Fue en el año 2004 cuando Mignone et al. generaron la línea transgénica de Nestin-Gfp que usamos actualmente en este proyecto. El transgén contiene las $5.8 \mathrm{~kb}$ del promotor de Nestina, la versión de la proteína fluorescente EGFP (Enhanced Green Fluorescent Protein) y el segundo intrón de $1.8 \mathrm{~kb}$ que contiene el enhancer neural, que se había comprobado ser el responsable de la expresión del gen en células progenitores neurales tanto en sistema nervioso en desarrollo como adulto. Para demostrar que las células Nestina-GFP+ eran realmente progenitores neurales aislaron células individuales in vitro y confirmaron que eran capaz de formar neuroesferas que, una vez que se diferenciaban a neuronas, astrocitos o oligodendrocitos, dejaban de expresar el marcador fluorescente, indicando así que el enhancer dejaba de estar activo (Mignone et al., 2004).

Actualmente, los numerosos estudios realizados con esta línea transgénica han demostrado que el reportero está activo en multitud de tipos celulares con características progenitoras, entre los que se encuentran las células ovales del hígado, las células madre multipotentes adultas en la pituitaria anterior, las células madre mesenquimales en la médula ósea, las células satélite en músculo, las células Leydig productoras de precursores de la testosterona, la piel, y las células madre pluripotentes asociadas a los folículos capilares (Mignone et al., 2016).

\section{2. Nestin-Gfp como Principal Marcador de Progenitores Mesenquimales}

Las células madre progenitoras mesenquimales (MSPCs, Mesenquimal Stem Progenitor Cells) se caracterizan por su capacidad para diferenciarse en los tres principales linajes mesenquimales (hueso, cartílago y tejido adiposo) bajo condiciones específicas de cultivo in vitro. A su vez, pueden dar lugar a células estromales de la médula ósea que promueven la hematopoyesis (Frenette et al., 2013).

El concepto de "nicho" hematopoyético hace alusión a la unidad regulatoria que dirige la

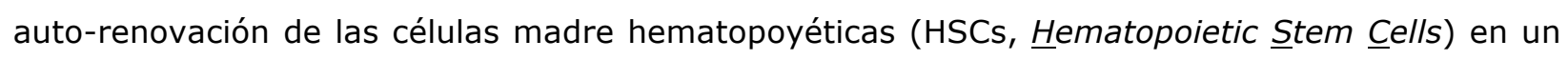
microambiente especializado dentro de la médula ósea. A pesar de ser un concepto controvertido, se considera que el nicho hematopoyético está compuesto principalmente por osteoblastos, células endoteliales, células madre progenitoras mesenquimales y células estromales perivasculares capaces de producir factores necesarios para el mantenimiento de las HSPCs, entre los que se encuentran la Angiopoyetina y la quimoquina perivascular $C x C l 12$ ( $\underline{C}-\underline{X}-\underline{C}$ Ligand 12) (Frenette et al., 2013, Anthony and Link, 2014). Sin embargo, el trabajo realizado por Méndez-Ferrer et al. demostró que las células Nestina-GFP+ marcaban una población específica de MSPCs esencial para el mantenimiento del nicho hematopoyético en la médula. Estas células Nestina-GFP+ podían formar colonias clonales (CFU-F, Fibroblastic Colony Forming Units) y mesenferas con capacidad de auto-renovarse al crecerlas en condiciones no adherentes que podían diferenciarse en los diferentes linajes mesenquimales, convirtiendo así al gen de 
Nestina en el principal marcador de células estromales perivasculares (Méndez-Ferrer et al., 2010).

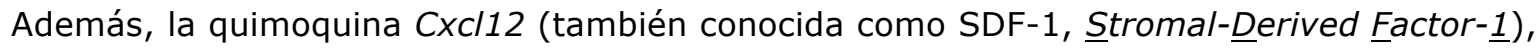
conocida por su crucial papel en el mantenimiento y función de las células madre hematopoyéticas, es expresada en altos niveles por las células CAR (ㅡXXCL12-abbundant reticular cells), células estromales positivas para el receptor de leptina, y especialmente, las células Nestina-GFP+, demostrando por tanto la importancia de dichas células en la formación del nicho hematopoyético durante el desarrollo de la médula ósea (Isern and Méndez-Ferrer, 2011, Anthony and Link, 2014, Isern et al., 2014).

\section{3. Nestin-Gfp y Endotelio}

A pesar de que el gen Nestina fue identificado como marcador de células progenitoras neurales y músculo esquelético, diversos estudios realizados en los últimos años también han relacionado este marcador con células progenitoras cardíacas y endoteliales durante fases de activa angiogénesis. En el caso de gliomas humanos, se demostró la expresión de Nestina en siete líneas diferentes, incluyendo cáncer cervical, de pulmón, estómago y colon. Sin embargo, la región reguladora presente en el enhancer responsable de su expresión en el endotelio angiogénico aún no ha sido identificada (Aihara et al., 2004, Amoh et al., 2005).

Por su parte, esta proteína de filamentos intermedios también fue relacionada con el tejido cardíaco en estudios de daño por IM. En concreto, determinaron que en el corazón de rata y ratón contenía en situación basal una población residente de células Nestina+ derivadas de la cresta neural que se encontraba intercalada entre los cardiomiocitos Nestina-, de manera que tras un daño en el miocardio, las células Nestina+ eran capaces de migrar hacia la zona afectada para promover su reparación, donde se observaba una diferenciación a músculo liso vascular o a células endoteliales capaces de formar vasos sanguíneos de novo durante la cicatrización del tejido miocárdico (Mokrý et al., 2004, Tomita et al., 2005, El-Helou et al., 2005, El-Helou et al., 2008, Béguin et al., 2011, Calderone, 2012). No sólo parecían ser capaces de regenerar el tejido tras un daño isquémico, sino que además durante la respuesta fibrótica de reparación se identificaron células Nestina+ en los nuevos vasos que se habían formado en la cicatriz (Calderone, 2012).

Estudios previos durante la caracterización del gen de Nestina habían determinado que era en el primer intrón del gen donde se encontraban los elementos reguladores responsables de su expresión en células endoteliales (Aihara et al., 2004), no obstante, los trabajos de IM realizados en ratones transgénicos Nes-Gfp, donde la expresión del reportero dependía únicamente de los elementos reguladores contenidos en el segundo intrón del gen, demostraron que el enhancer neural también dirigía la expresión de la proteína Nestina en la subpoblación de células cardíacas residentes capaces de diferenciarse a un fenotipo vascular promoviendo la formación de vasos sanguíneos de novo. Esto convertiría a Nestina en un marcador de revascularización durante los procesos reparativos (Calderone, 2012, El-Helou et al., 2013). 


\section{4.Trazado del Linaje Nestina: Diferencias entre Nes-CreER ${ }^{T 2}$ y Nes-Gfp}

Del mismo modo que se generaron transgenes Nes-Gfp usando diferentes elementos reguladores del gen de Nestina, existen varias líneas Cre inducibles por tamoxifeno resultado de la fusión de la recombinasa con el dominio de unión al ligando receptor de estrógenos humano (Cre-ER) para permitir el control espacio-temporal de la recombinación (Feil et al., 1997).

La línea empleada en este proyecto para el trazado de linaje de las células Nestina fue generada por Balordi y Fishell en 2007. El transgén Nes-CreER ${ }^{T 2}$ expresa la forma mutante T2 de la recombinasa, con una mayor eficiencia a la hora de responder al tamoxifeno. Con respecto a los elementos reguladores presentes en esta construcción, contiene un promotor mínimo de la TK bajo el control del enhancer neural contenido en el segundo intrón del gen Nestina, el mismo empleado para la línea Nes-Gfp, pero insertado en el lado $5^{\prime}$ del promotor, lo que podría llevar a diferencias transcripcionales (Balordi and Fishell, 2007).

A pesar de que ambas líneas contengan el enhancer neural, existen discrepancias experimentales observadas entre ambos transgenes que han generado confusión y malinterpretación de los resultados. Fue en 2014 cuando Isern et al. demostraron que los transgenes Nes-Gfp y Nes-CreER ${ }^{T 2}$ presentaban diferentes patrones de expresión en las células estromales y endoteliales de la médula ósea fetal, mientras que existía una alta colocalización entre ambas líneas durante la primera semana postnatal (Isern et al., 2014).

Estas diferencias entre ambas líneas se deben a que las actividades transcripcionales se encuentran controladas por sistemas genéticos diferentes. En el caso de la construcción Nes-Gfp, su expresión está dirigida fundamentalmente por las $5.8 \mathrm{~kb}$ del promotor de Nestina en el extremo $5^{\prime}$ y las $1.8 \mathrm{~kb}$ del enhancer neural contenido en el segundo intrón del gen, pudiendo existir interacciones entre los complejos reguladores del promotor y del enhancer. Por su parte, la línea Nes-CreER ${ }^{T 2}$ está dirigida por un promotor de la TK bajo el control del mismo enhancer neural de Nestina, de forma que en esta construcción el promotor de Nestina se encuentra ausente. Además de las diferencias de los elementos reguladores y sus orientaciones en el vector de expresión, el número de integraciones en cada transgén al azar en los cromosomas del ratón podría ser un motivo adicional de diferencias entre ellos (Chen et al., 2017).

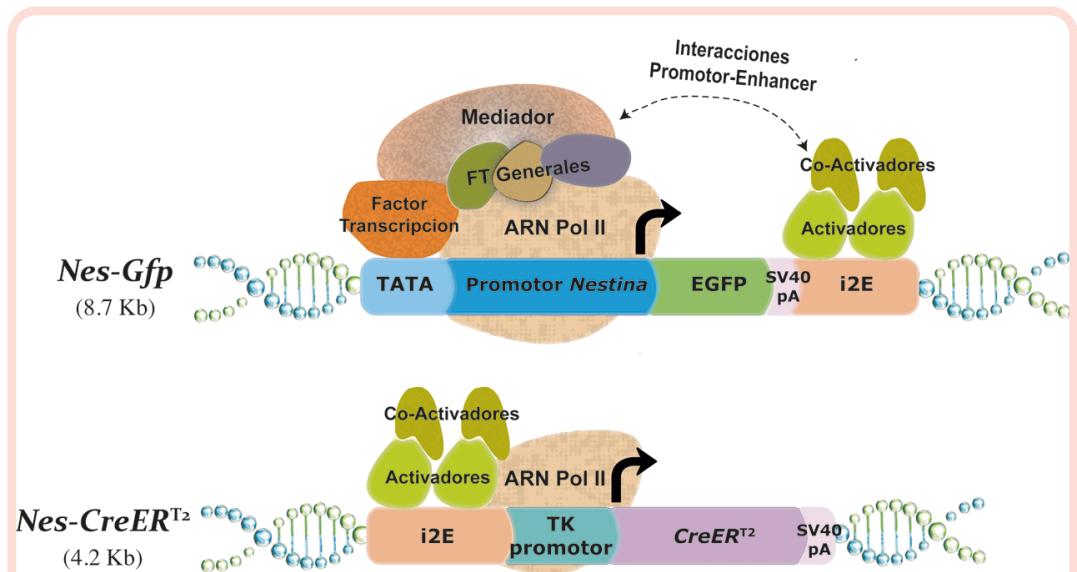

Figura 5. Esquema de la estructura de los transgenes Nes-Gfp y Nes-CreER ${ }^{T 2}$. El alelo Nes-Gfp contiene $5.8 \mathrm{~kb}$ del promotor del gen de nestina de rata, seguido del gen reportero EGFP y en $3^{\prime}$ el $2^{\circ}$ intrón (i2E) de $1.8 \mathrm{~kb}$ del gen Nes de rata. Dicho intrón contiene el enhancer activo en progenitores neurales. El complejo transcripcional específico del promotor podría interactuar con los factores de transcripción (FT) activadores cercanos unidos al enhancer. El alelo Nes-CreERT2 se compone únicamente del enhancer i2E seguido del promotor mínimo de la timidina quinasa (TK) del virus HSV. 


\section{5o Regulación Transcripcional en la Vasculatura: Papel de los Enhancers}

\section{ENDOTELIALES Y ARTERIALES.}

La expresión génica está regulada a nivel transcripcional por un conjunto interconectado de elementos reguladores (promotores, enhancers, etc) y factores de transcipción (FT), cuya acción integrada determinan los patrones temporales y anatómicos característicos para cada gen y cada linaje (Spitz and Furlong, 2012). Los enhancers en concreto, son secuencias no codificantes de ADN reguladoras en cis que aumentan la actividad transcripcional de sus promotores diana, controlando su expresión tanto temporal como espacialmente. No necesitan estar cercanos a los genes que controlan, pudiéndose encontrar en $5^{\prime}$ de los genes diana, en $3^{\prime}$ o incluso dentro de los mismos en regiones intrónicas. Además, su orientación en el genoma es independiente a su función en la mayoría de los casos. La conservación evolutiva extrema de regiones del ADN no codificantes entre especies distantes suele ser indicativo de funciones reguladoras importantes, aunque no siempre se relaciona con la presencia de un enhancer (Pennacchio et al., 2006, Prabhakar et al., 2006). En cuanto a su función en la transcripción, se ha descrito que los FT generales y la ARN polimerasa II son reclutados por estas secuencias reguladoras para formar el complejo de pre-iniciación de la transcripción (Visel et al., 2009, Narlikar and Ovcharenko, 2009, Pennacchio et al., 2013).

Con el advenimiento de la Genómica y sus técnicas moleculares, se ha logrado identificar un sinfín de nuevos elementos reguladores. Dentro de la vasculatura, además de los FT endoteliales, cobran especial importancia los enhancers con actividad en el endotelio arterial, ya que existe un interés creciente en definir mejor los programas transcripcionales responsables de la especificación arterio-venosa. Entre ellos se destacan las familias Sox, Ets, Forkhead (FOX), GATA y Krüppel-like (De Val and Black, 2009). De manera destacada, la gran familia de FTs Ets juega un papel crucial en el control transcripcional de muchos genes implicados en el desarrollo vascular. Estas proteínas reconocen unas secuencias consenso presentes en múltiples enhancers y promotores endoteliales (Dejana et al., 2007, Sato, 2001). Sin embargo, los sitios de unión de los factores Ets no son únicamente específicos de genes endoteliales (Maroulakou and Bowe, 2000, Hollenhorst et al., 2007, Hollenhorst et al., 2004), por lo que se cree que se unirían al ADN con poca afinidad y para llevar a cabo la activación específica de sus genes diana requerirían de la acción cooperativa con otras proteínas (Hollenhorst et al., 2007).

Trabajos llevados a cabo por el grupo de Brian L. Black identificaron dos regiones enhancers altamente conservadas en el locus Mef2c, una de las cuales conferiría especificidad endotelial durante el desarrollo. Dentro de dicha región funcional, lograron delimitar una secuencia discreta de $A D N(44 \mathrm{pb})$ que contenía toda la información regulatoria mínima en cis necesaria para dirigir la expresión de un gen reportero específicamente al endotelio vascular, permitiendo así poder rastrear en ella los lugares potenciales de unión a FT conocidos, necesarios para su activación. Entre ellos, un miembro de la familia Ets, el factor Etv2, demostró ser capaz de unirse a lugares ETS de dicha región mínima y activar el enhancer en la vasculatura, especialmente cuando la unión se producía en combinación con la de otro factor de 
transcripción, Foxc2, que se uniría a lugares FOX cercanos. Por lo tanto si se producía una activación sinérgica de los dos factores conjuntamente, se incrementaba la actividad hasta 40 veces. De esta forma establecieron que motivos compuestos del tipo FOX:ETS podrían estar presentes y tener un papel relevante en la activación específica de muchos genes endoteliales (De Val et al., 2008). En trabajos posteriores identificaron otro enhancer especialmente activo en endotelio arterial, en el locus del gen humano ECE1 (Endothelin-Converting Enzyme 1). Observaron que dicha secuencia conservada confería expresión en los progenitores endoteliales tempranos, pero más tarde su actividad quedaba restringida exclusivamente al endotelio arterial y endocardio cardíaco. Además de los motivos FOX:ETS, al comparar las secuencias de este enhancer entre humanos, roedores y marsupiales descubrieron otro motivo perfectamente conservado, un sitio de unión SOX (Robinson et al., 2014). Dado que Sox17 ya había sido descrito como un regulador clave del desarrollo arterial (Corada et al., 2013), demostraron in vivo e in vitro el requerimiento de dicho de dicho factor para la correcta activación del enhancer, proporcionando así otro ejemplo de la acción cooperativa de diversos FTs (Fox2, Etv2 y Sox17) para la activación sinérgica de enhancers arteriales (Robinson et al., 2014).

Por otra parte, el grupo de Benoit G. Bruneau identificó una región enhancer localizada en el tercer intrón del gen D/l4 (Delta-like 4) capaz de dirigir la expresión específicamente a endotelio arterial y endocardio. Dentro de la región, delimitaron una secuencia mínima de 36 pb que conseguía recapitular el patrón completo de expresión del gen endógeno. Demostraron que la activación conferida por esta secuencia dependía inicialmente -de forma exclusiva- de la unión de factores Ets, a pesar de contener también sitios potenciales de unión para Mef2, E2F, Ets y RBPJk. Propusieron un modelo en el que, durante la especificación arterial, factores de la familia Ets (como Erg) se unirían a los sitios ETS en respuesta a la señalización generada por la cascada Vegf/MAPK en las primeras células precursoras arteriales. Aunque el factor de crecimiento endotelial Vegf también activa la vía de señalización de Notch (a través de NICD/RBPJk), se cree que la señalización por Notch no es requerida para la expresión temprana de D/l4 en el endotelio arterial. Una vez que D/l4 es activado, activa a Notch4 y la señalización de Notch comienza a ser necesaria para mantener la expresión de los genes arteriales (Wythe et al., 2013). Además de las vías de Vegf y Notch, la especificación arterio-venosa requiere también de la señalización por la vía de Hedgehog, que induce la expresión de Vegf en el embrión temprano (Lawson et al., 2002). Las futuras células endoteliales arteriales reciben altas concentraciones de Vegf, lo que activa la cascada p42/p44 MAPK. Esto induce la activación de la señalización de Notch en el endotelio arterial. Una vez activado, el dominio intracelular del receptor de Notch (NICD) interacciona con su cofactor (RBPJk) en el núcleo para inducir la expresión de genes como Hey1/2, Hes1, EphrinB2 y otros genes arteriales (Yamamizu et al., 2010). Sin embargo, el hecho de que la activación del enhancer arterial contenido en el gen ECE1 no contuviese ningún sitio de unión para RBPJk, el efector aguas abajo de la señalización de Notch, sugería que la restricción arterial era independiente a la activación directa de la señalización via Notch. Esto indicaría que en la especificación arterial podrían estar actuando vías de señalización aguas arriba o paralelas a la señalización de Notch, como por ejemplo la señalización llevada a cabo a través del factor de transcripción Sox17 (Robinson et al., 2014). 


\section{6o Factores de Transcripción SoX y Su Papel en la Vasculatura Coronaria}

Las proteínas Sox ( $\underline{S} R Y$-related HMG box ) pertenecen a una superfamilia de factores de transcripción que se unen al surco menor del $A D N$, implicadas en la regulación de diversos procesos durante el desarrollo, entre los que se encuentran la formación de la línea germinal, el desarrollo de órganos y la especificación de múltiples linajes celulares. Contienen un dominio de unión al ADN de tipo HMG ( dentro de la familia. En función del grado de homología de las secuencias que componen la caja HMG, las proteínas SOX se dividen en 10 subgrupos, denominados A-I (Wegner, 1999, Hou et al., 2016).

Para el desarrollo de esta Tesis Doctoral nos centraremos en la subfamilia SoxF dada su importancia en el desarrollo cardiovascular, así como la especificación de la vasculatura sanguínea y linfática. En la mayoría de mamíferos, incluidos ratón y humano, el subgrupo SoxF está compuesto únicamente por 3 miembros: Sox7, Sox17 y Sox18. Estructuralmente, los factores SoxF poseen un dominio muy conservado de unión a $\beta$-catenina en su extremo Cterminal, un dominio transactivador (TAD) y el dominio HMG que reconoce una secuencia consenso de ADN. También cabe destacar que estas proteínas reclutan a otras proteínas para formar complejos que regulan programas transcripcionales específicos (François et al., 2008, Lilly et al., 2016). Por ejemplo, Sox18 interacciona físicamente con el factor de transcripción Mef2c ( $\underline{\text { myocyte }}$ enhancer factor-2) ) en las células endoteliales (Hosking et al., 2001a). Por su parte, Sox17 interacciona con Oct4 a través de sus respectivos dominios de unión, HMG y POU, para regular el desarrollo del endodermo (Lilly et al., 2016).

Los factores de tanscripción SoxF se expresan en las células endoteliales durante el desarrollo temprano (Francois et al., 2010, Young et al., 2006). Se han empleado modelos de ratón y pez cebra para tratar de esclarecer el papel de cada uno de los miembros de SoxF analizando los efectos resultantes de eliminar cada una de las proteínas por separado o bien combinaciones entre ellas, sin embargo la redundancia funcional existente entre ellos complica la interpretación de los resultados (Matsui et al., 2006, Sakamoto et al., 2007, Zhou et al., 2015). Además, existen contradicciones debido al fondo genético empleado, existiendo fenotipos más severos al realizarse en ratones de fondo puro (B57BL/6) frente al fondo mixto (C57/129/CD1). Mientras que los mutantes globales de $\operatorname{Sox} 7$ y Sox17 son letales a estadios embrionarios, la deficiencia de Sox18 en fondo mixto es viable, fértil y no parece presentar defectos cardiovasculares, observándose una sobreexpresión de Sox7 y Sox17 para compensar su ausencia (François et al., 2008, Cermenati et al., 2008, Hosking et al., 2009).

Sox? es indispensable para el remodelado angiogénico, siendo su deficiencia letal a estadios muy tempranos del desarrollo. Ha sido descrito que la expresión de Sox7 y Sox17 es promovida por VEGF en las células endoteliales angiogénicas (Kim et al., 2016).

Sox17 ha sido considerado un importante regulador de múltiples procesos biológicos, incluyendo la formación del endodermo durante la gastrulación (Kanai-Azuma et al., 2002), la segregación de linajes ventrales anteriores (Spence et al., 2009), y el mantenimiento fetal de la 
identidad de las HSCs (Kim et al., 2007, Niakan et al., 2010). La falta de este factor de transcripción produce la muerte del embrión a E10.5 por la eliminación del endodermo definitivo (Kanai-Azuma et al., 2002). Para estudiar si la deficiencia en Sox17 también conlleva a un fenotipo vascular, se han realizado diversos mutantes condicionales que eliminan la proteína constitutivamente o de forma inducible en las células endoteliales en fondo genético puro, observándose defectos en el remodelado vascular así como en la especificación a arterias, provocando letalidad in utero (Corada et al., 2013).

Por su parte, la falta de Sox18 conlleva al Síndrome Hipotricosis-Linfedema-Telangiectasia (HLT) en humanos, motivo por el cual esta proteína se ha asociado principalmente con la linfagiogénesis (Irrthum et al., 2003, Cermenati et al., 2008, Downes et al., 2009). Estudios genéticos in vivo realizados en ratón demostraron que Sox18 es requerido para la activación del factor de transcripción Prox1 que conduce al desarrollo de la vasculatura linfática (François et al., 2008).

Existe una mutación espontánea en el gen de Sox18 que causa problemas en el pelaje de los ratones y especialmente en el sistema cardiovascular. La mutación consiste en la deleción de una única base en el dominio TAD que genera un codón stop prematuro dando lugar a una proteína truncada. A pesar de que el dominio HMG de unión al ADN permanece intacto, la afectación en el TAD impide la unión de Sox18 con sus cofactores, afectando a la activación transcripcional del complejo (Carter and Phillips, 1954, Slee, 1957). En función de la variante de proteína Sox18 truncada obtenida por cuatro tipos distintos de mutación, se distingue la siguiente serie alélica (de menor a mayor severidad en el fenotipo): ragged (Ra), raggedJackson (RaJ), ragged-like $(R a l)$ y ragged-opossum $\left(R a^{o p}\right)$. Mientras que $R a, R a J$ y $R a l$ son fenotípicamente parecidas, $R a^{o p}$ muestra el fenotipo realmente severo, causando la muerte temprana (E11.5) del embrión por la rotura de la microvasculatura que da lugar a edemas y hemorragias (Hosking et al., 2001a, Hosking et al., 2001b, Pennisi et al., 2000, Downes and Koopman, 2001, James et al., 2003, Downes et al., 2009, Green and Mann, 1961). El hecho de que las mutaciones ragged presenten un fenotipo cardiovascular que no se encuentra en la deleción global de Sox18 ha generado la teoría de que estas proteínas truncadas actúan como dominante-negativo de toda la familia SoxF, ya que el fenotipo no puede ser compensado por la presencia de Sox7 y Sox17 en las células endoteliales (James et al., 2003).

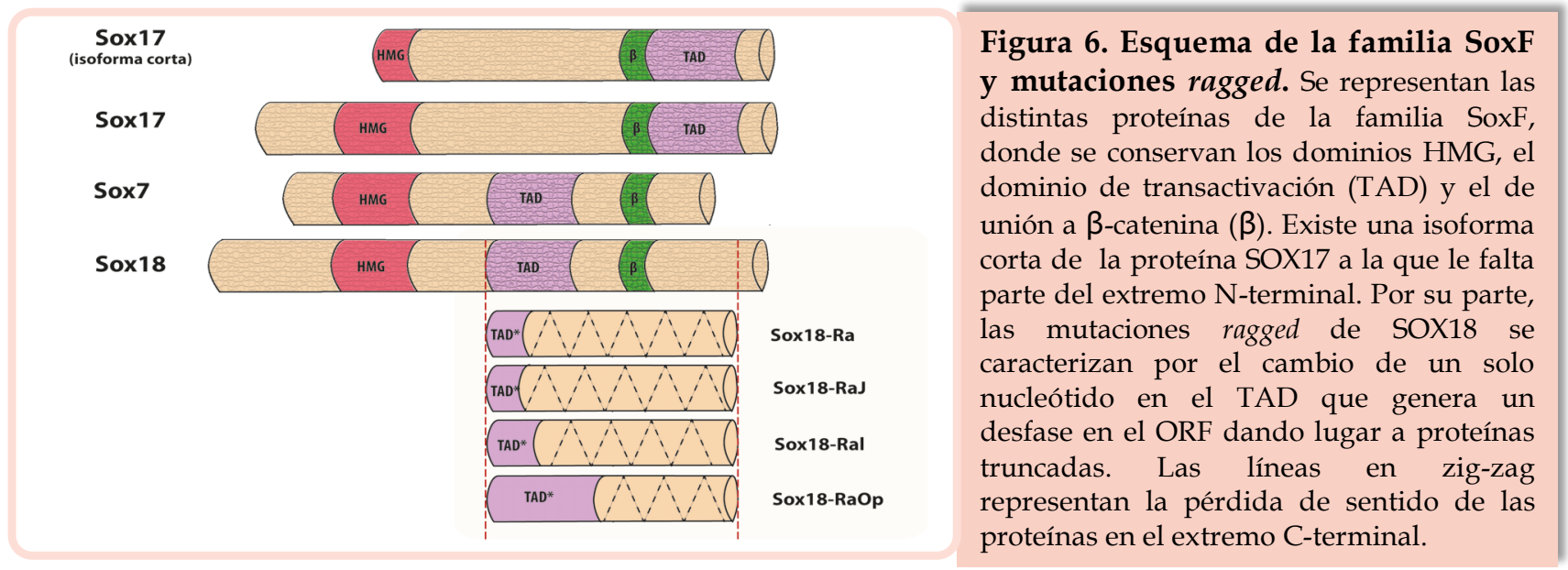




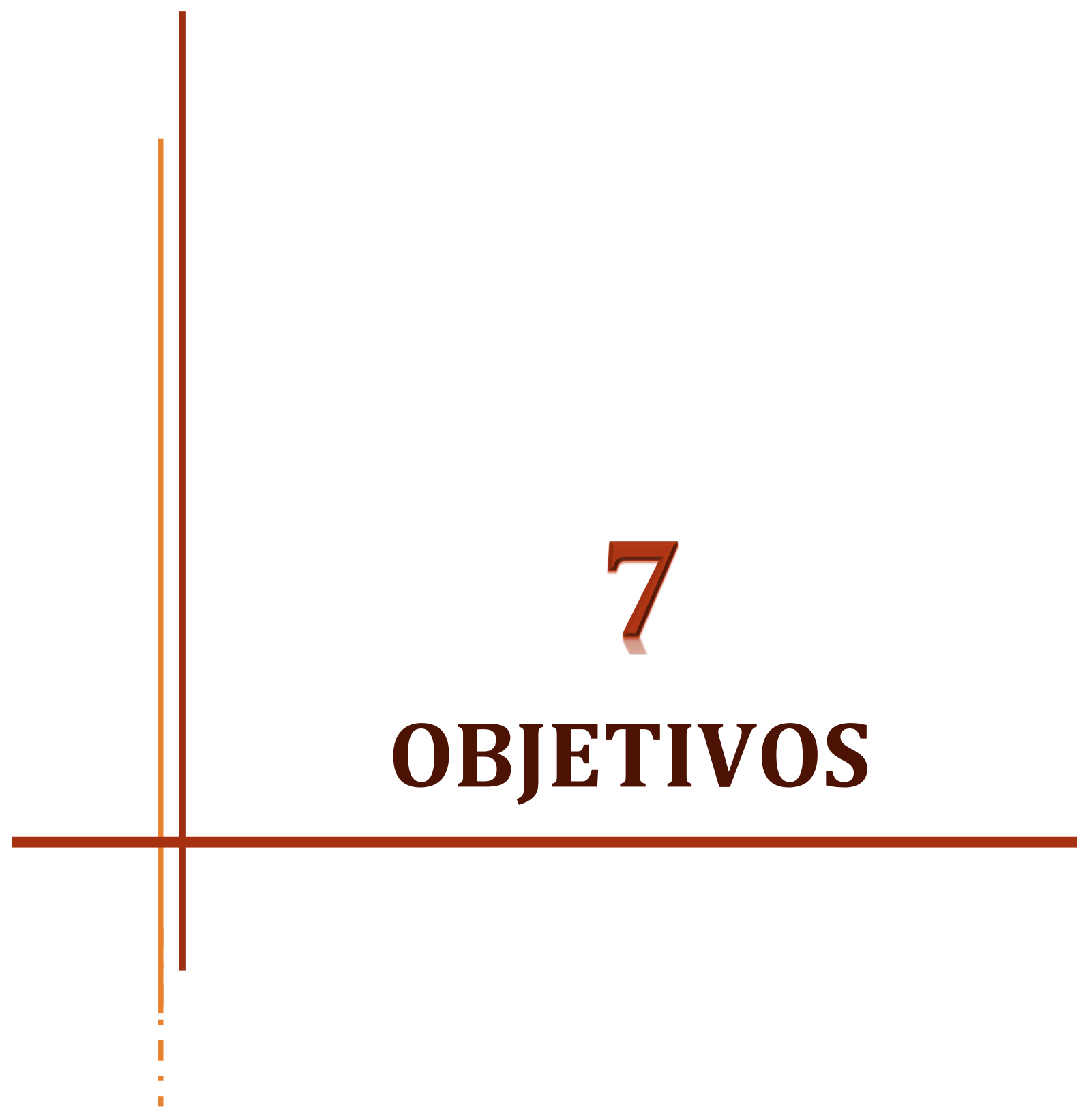



En los últimos años el desarrollo de la vasculatura coronaria durante la morfogénesis cardíaca ha sido objeto de amplio estudio y controversia. Actualmente es aceptado que existen varias fuentes a partir de las cuales se genera el plexo vascular primitivo, siendo la principal contribución al desarrollo del mismo las células endoteliales angiogénicas que brotan y se expanden a partir del seno venoso y el endocardio ventricular. No obstante, a pesar de la caracterización llevada a cabo, los mecanismos implicados en la regulación de este importante proceso del desarrollo continúan siendo poco conocidos.

Durante el transcurso de esta Tesis Doctoral se han adaptado los modelos genéticos Nes-Gfp y Nes-CreER ${ }^{T 2}$ para el estudio detallado de la formación de la vasculatura durante los diferentes estadios embrionarios de la cardiogénesis, para poder así elucidar factores de señalización implicados en el proceso. Para ello, los principales objetivos tanto generales como específicos perseguidos en este proyecto han sido los siguientes:

1. Caracterizar detalladamente el patrón de expresión de las células Nestin-GFP+ durante la formación del corazón embrionario en ratón, así como el trazado de linaje con el modelo genético inducible Nes-CreER ${ }^{T 2}$.

2. Realizar estudios funcionales in vitro de la actividad del enhancer neural de Nestina contenido en el segundo intrón del gen responsable de controlar la expresión de la proteína reportera EGFP.

3. Llevar cabo un perfil transcripcional de las diferentes subpoblaciones que componen la vasculatura coronaria (endocardio, arterias-capilares, venas) para identificar posibles factores de transcripción candidatos a tener un papel importante en la regulación de este proceso.

- Descifrar el patrón de expresión de Sox17 durante la formación de la vasculatura coronaria y su relación con la activación de Nes-Gfp.

- Realizar modelos de pérdida de función in vitro e in vivo de la familia de factores de transcripción Soxf para ver su repercusión en la formación de la vasculatura coronaria. 



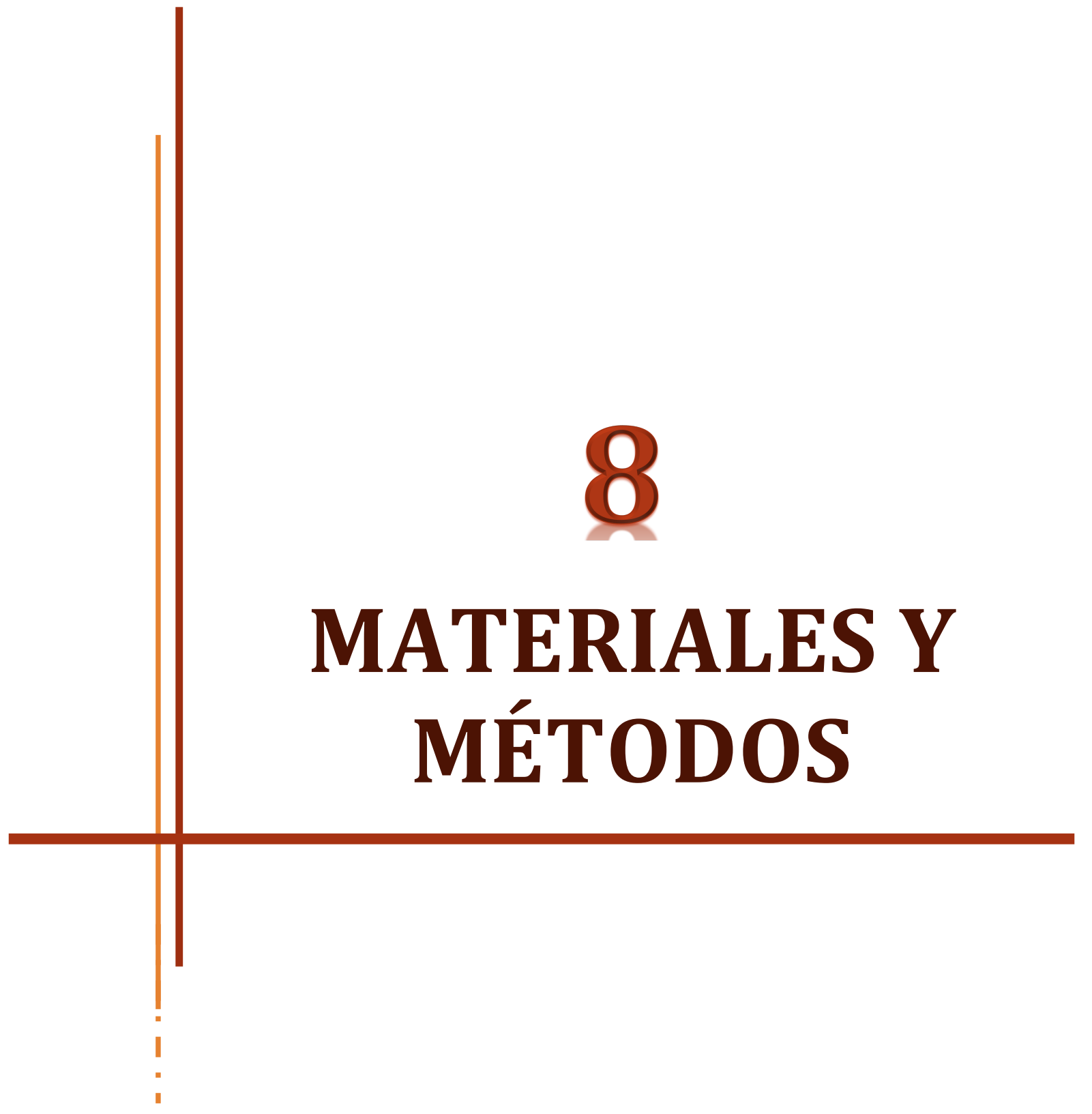





\section{Modelos Animales}

\subsection{LÍNEAS TRANSGÉNICAS UTILIZADAS}

Las líneas de ratones transgénicos empleados en este proyecto se muestran en la Tabla1. Las cepas silvestres C57BL/6 y CD1 fueron obtenidas de Charles River y Harlan, respectivamente. Todos los animales fueron mantenidos en condiciones libres de patógenos específicos (SPF, Specific Patogen Free) en el animalario del CNIC. Los procedimientos experimentales fueron aprobados por el Comité Ético de Cuidado Animal del Centro Nacional de Investigaciones Cardiovasculares (PA CNIC-07/14) así como las autoridades regionales y nacionales correspondientes.

\begin{tabular}{|c|c|c|c|c|c|}
\hline $\begin{array}{l}\text { Nombre } \\
\text { Corto }\end{array}$ & Símbolo & ID. MGI & $\begin{array}{l}\text { Nombre } \\
\text { Original }\end{array}$ & Referencia & Descripción \\
\hline Nes-Gfp & Tg(NesEGFP)33Enik & 5523870 & Nestin-GFP & $\begin{array}{l}\text { (Mignone et } \\
\text { al., 2004) }\end{array}$ & $\begin{array}{l}\text { Expresión de la EGFP dirigida por } \\
\text { elementos reguladores y enhancers } \\
\text { neurales del gen de rata nestina; } \\
\text { integración al azar }\end{array}$ \\
\hline CXCl12-GFP & Cxcl12tm2Tng & 3579534 & CXCL12GFP & $\begin{array}{l}\text { (Ara et al., } \\
\text { 2003) }\end{array}$ & $\begin{array}{l}\text { Expresión de la EGFP conducida } \\
\text { por el locus del gen Cxcl12; alelo } \\
\text { knock-in (nulo) }\end{array}$ \\
\hline $\begin{array}{l}\text { Nes- } \\
\text { CreERT2 }^{T 2}\end{array}$ & $\mathrm{Tg}(\mathrm{Nes}-\mathrm{cre} / \mathrm{ERT} 2) 1_{\mathrm{Fsh}}$ & 3774417 & NestinCreERT2 & $\begin{array}{l}\text { (Balordi and } \\
\text { Fishell, 2007) }\end{array}$ & $\begin{array}{l}\text { Cre recombinasa inducida por } \\
\text { tamoxifeno bajo el control de los } \\
\text { elementos reguladores del gen } \\
\text { nestina de rata; integración al azar }\end{array}$ \\
\hline Wnt1-Cre2 & $\operatorname{Tg}($ Wnt1-cre $) 2^{\text {Sor }}$ & 5485027 & Wnt1-Cre2 & $\begin{array}{l}\text { (Lewis et al., } \\
\text { 2013) }\end{array}$ & $\begin{array}{l}\text { Cre recombinasa conducido por el } \\
\text { promotor de Wnt1. Expresión en } \\
\text { linajes derivados de cresta neural; } \\
\text { integración al azar }\end{array}$ \\
\hline Tie2-Cre & $\operatorname{Tg}($ Tek-cre $) 1^{Y w a}$ & 2450311 & Tie2-Cre & $\begin{array}{l}\text { (Kisanuki et } \\
\text { al., 2001) }\end{array}$ & $\begin{array}{l}\text { Recombinasa cre bajo el control } \\
\text { del promotor/ enhancer del gen } \\
\text { Tek de ratón (Tie2). Integración al } \\
\text { azar }\end{array}$ \\
\hline WT1-Cre & $\operatorname{Tg}(W t 1-c r e)$ & 5308608 & Wt1-Cre & $\begin{array}{l}\text { (delMonte et } \\
\text { al., 2011) }\end{array}$ & $\begin{array}{l}\text { Recombinasa Cre bajo el control } \\
\text { de la región reguladora del gen de } \\
\text { ratón Wilms Tumor-1 (WT1) }\end{array}$ \\
\hline$R C E$ & $\begin{array}{l}\text { Gt(ROSA)26Sortm1.1(C } \\
\text { AG-EGFP)Fsh }\end{array}$ & 4412373 & RCE:loxP & $\begin{array}{l}\text { (Sousa et al., } \\
2009 \text { ) }\end{array}$ & $\begin{array}{l}\text { Proteína fluorescente EGFP } \\
\text { expresada bajo la recombinación } \\
\text { mediada por la Cre en el locus } \\
\text { Rosa26. Alelo Knock-in }\end{array}$ \\
\hline $\begin{array}{l}\text { R26- } \\
\text { Tomato }\end{array}$ & $\begin{array}{l}\text { Gt(ROSA)26Sortm14(CA } \\
\text { G-tdTomato)Hze }\end{array}$ & 3809524 & Ai14 & $\begin{array}{l}\text { (Madisen et } \\
\text { al., 2010) }\end{array}$ & $\begin{array}{l}\text { Proteína fluorescente tdTomato } \\
\text { expresada bajo la recombinación } \\
\text { mediada por Cre en el locus } \\
\text { Rosa26. Alelo knock-in }\end{array}$ \\
\hline $\begin{array}{l}\text { Cxcl12- } \\
\text { floxed }\end{array}$ & Cxcl12tm1.1Ystz & 4888352 & Cxcl12F & $\begin{array}{l}\text { (Tzeng et al., } \\
\text { 2011) }\end{array}$ & $\begin{array}{l}\text { Alelo condicional flanqueado por } \\
\text { LoxP para el gen de ratón Cxcl12; } \\
\text { mutación dirigida }\end{array}$ \\
\hline Cxcl12 KO & - & - & - & Esta tesis & $\begin{array}{l}\text { Obtenido tras la excisión en línea } \\
\text { germinal del alelo floxeado } C x c l 12\end{array}$ \\
\hline
\end{tabular}




\subsection{GENOTIPADO}

El genotipado de los ratones adultos se realizó con el extremo final de la cola que se corta usando un cauterizador hemostático en el momento del destete ( 21 días). En el caso de los embriones, se cortaba el extremo caudal de los mismos o sólo la cola, dependiendo del estadio embrionario. En todos los casos, los tejidos se inoculaban en $300 \mu \mathrm{l}$ de solución de lisis ( $50 \mathrm{mM}$ $\mathrm{NaCl}, 50 \mathrm{mM}$ Tris- $\mathrm{KCl}$ pH 8.0, 5mM EDTA, 0.2\% SDS) a los que se le añadían $8 \mu$ de proteinasa K (03115801001, Roche, Suiza) a una concentración de $20 \mathrm{mg} / \mathrm{mL}$. La incubación se realizaba a $55^{\circ} \mathrm{C}$ con agitación durante un par de horas en el caso de tejidos embrionarios o durante toda la noche, en tejidos adultos. Una vez digeridos, el ADN se precipitaba con isopropanol (Sigma, EEUU) y etanol 70\% (Merck, Alemania). El pellet final se resuspendía en $300 \mu$ de buffer TE $1 x$ (10 mM Tris- $\mathrm{HCl} \mathrm{pH}$ 8.0, 1 mM EDTA).

Las reacciones de PCR se realizaban en un volumen final de $20 \mu \mathrm{l}$. De ellos, $10 \mu \mathrm{l}$ correspondían a la mezcla comercial AccuStart ${ }^{\mathrm{TM}}$ II PCR SuperMix 2x (95137, Quanta Biosciences, EEUU), la mezcla de oligos directo y reverso a una concentración de $10 \mu \mathrm{M}$, el ADN molde entre 1-3 $\mu$ l según el caso, y el volumen final se ajustaba con agua destilada. Las reacciones de PCR se llevaron a cabo principalmente en el termociclador ProFlex PCR System (4484073, ThermoFisher Scientific, EEUU).

\begin{tabular}{|c|c|c|c|c|c|c|}
\hline Gen & Oligonucle & tidos & $\mathrm{T}_{\mathrm{a}}^{\mathrm{anillado}}$ & $\mathbf{t}_{\text {extensión }}$ & Ciclos & Producto \\
\hline \multirow{2}{*}{ Cre } & Directo & 5'-AATGCTTCTGTCCGTTTGCCGGT-3' & \multirow{2}{*}{$55^{\circ} \mathrm{C}$} & \multirow{2}{*}{$1 \mathrm{~min}$} & \multirow{2}{*}{ x35 } & \multirow{2}{*}{$518 \mathrm{pb}$} \\
\hline & Reverso & 5'-CCAGGCTAAGTGCCTTCTCTACA-3' & & & & \\
\hline \multirow{2}{*}{ Nes-Cre } & Directo & 5'-CTTGGCTTTGTACTTTCTGTGACTG-3' & \multirow{2}{*}{$58^{\circ} \mathrm{C}$} & \multirow{2}{*}{$1 \mathrm{~min}$} & \multirow{2}{*}{$x 30$} & \multirow{2}{*}{$300 \mathrm{pb}$} \\
\hline & Reverso & 5'-ССТССАTCCCAGACAAATACATTAC-3' & & & & \\
\hline \multirow{2}{*}{ Cxcl12 KO } & Directo & 5'-GGGAGCAGCTACAAATCCAGCAG-3' & \multirow{2}{*}{$65^{\circ} \mathrm{C}$} & \multirow{2}{*}{$1 \mathrm{~min}$} & \multirow{2}{*}{$x 30$} & KO: $277 \mathrm{pb}$ \\
\hline & Reverso & 5'-GCATTGCTCCAGCTGCTGCATC-3' & & & & WT: $1.3 \mathrm{~Kb}$ \\
\hline \multirow{2}{*}{ Cxcl12 floxed } & Directo & 5'-GCTGGAGTGTGATGGTAGCTGCC-3' & \multirow{2}{*}{$65^{\circ} \mathrm{C}$} & \multirow{2}{*}{$40 \mathrm{seg}$} & \multirow{2}{*}{$x 30$} & Floxed: $273 \mathrm{pb}$ \\
\hline & Reverso & 5'-GCATTGCTCCAGCTGCTGCATC-3' & & & & WT: $227 \mathrm{pb}$ \\
\hline \multirow{2}{*}{ GFP } & Directo & 5'-ATCATGGCCGACAAGCAGAAGAAC-3' & \multirow{2}{*}{$60^{\circ} \mathrm{C}$} & \multirow{2}{*}{$1 \mathrm{~min}$} & \multirow{2}{*}{$x 30$} & \multirow{2}{*}{$280 \mathrm{pb}$} \\
\hline & Reverso & 5'-GTACAGCTCGTCCATGCCGAGAGT-3' & & & & \\
\hline \multirow{4}{*}{ Tomato } & Directo 1 & 5'-AAGGGAGCTGCAGTGGAGTA-3' & \multirow{4}{*}{$57^{\circ} \mathrm{C}$} & \multirow{4}{*}{$30 \mathrm{seg}$} & \multirow{4}{*}{ x35 } & \multirow{2}{*}{ WT: 297 pb } \\
\hline & Reverso 1 & 5'-CCGAAAATCTGTGGGAAGTC-3' & & & & \\
\hline & Directo 2 & 5'-GGCATTAAAGCAGCGTATCC-3' & & & & \multirow{2}{*}{ Mut: $196 \mathrm{pb}$} \\
\hline & Reverso 2 & 5'-CTGTTCCTGTACGGCATGG-3' & & & & \\
\hline
\end{tabular}

Una vez finalizadas las reacciones, las muestras se analizaban mediante electroforesis en geles de agarosa (8032, CONDA, España) del 2\%, usando el marcador de peso molecular $1 \mathrm{~Kb}$ Plus DNA Ladder (10787018, ThermoFisher, EEUU). 


\section{2o ExTRACCión Y Procesado de Muestras}

\subsection{EXTRACCión DE EMbriones y CORAZONES DE RATón}

Los animales fueron sacrificados por inhalación de $\mathrm{CO}_{2}$ en el caso de adultos o por decapitación en el de neonatos menores a una semana de nacimiento. Las hembras preñadas se sacrificaban en el estadio gestacional necesario, contando como E0.5 la mañana en la que se detectaba el tapón vaginal. Tras comprobar la muerte del animal por ausencia de reflejos, se abrió la cavidad abdominal y extrajeron los embriones, a partir de los cuales se diseccionaba el corazón fetal o el resto de órganos correspondientes. Cuando era necesario, los corazones adultos se perfundieron con tampón fosfato PBS (137 mM NaCl, $2.7 \mathrm{mM} \mathrm{KCl}, 10 \mathrm{mM} \mathrm{Na} \mathrm{HPO}_{4}, 2$ $\mathrm{mM} \mathrm{KH} \mathrm{PO}_{4}, \mathrm{pH} 7.4$ ) y posteriormente se fijaron con paraformaldehído (818715, Merck, EEUU) al $4 \%$. La perfusión se realizaba seccionando la aurícula derecha y perfundiendo a través del ventrículo izquierdo mediante punción con una aguja de calibre 21G (1026304432, BD Microlance 3).

\subsection{Procesamiento de Muestras Para Histología en OCT y Parafina}

Una vez extraídos los tejidos o embriones necesarios, se dejaban fijando toda la noche en paraformaldehído al $2 \%$ con agitación suave a $4^{\circ} \mathrm{C}$. Al día siguiente, los tejidos eran lavados varias veces en PBS con agitación a $4^{\circ} \mathrm{C}$.

El procesamiento para realizar la histología en parafina requería la deshidratación de los tejidos por inmersión en etanol $70 \%$ y su posterior inclusión en parafina realizado por la Unidad de Histopatología del CNIC. Una vez obtenidos los bloques, se cortaron en el micrótomo (Microtomo automático RM2255, Leica Biosystems) a 8 micras de grosor y los cortes se almacenaron a temperatura ambiente.

Para la histología realizada en OCT, las muestras se pasaban por un gradiente de sacarosa ( $15 \%$ y $30 \%$, respectivamente) antes de ser incluidos en Tisue-Tek O.C.T Compound (4583, Sakura Finetek Europe, Holanda) para congelar los bloques de tejido rápidamente en nieve carbónica antes de almacenarlos a $-80^{\circ} \mathrm{C}$. Las criosecciones finas se realizaban con el criostato motorizado (Leica CM1950) con grosores variables entre 10-25 micras.

\subsection{Clarificaciones de tejidos Y Embriones Enteros Para Imagen}

Las clarificaciones de tejidos y embriones completos se realizaron siguiendo el método CUBIC descrito por Susaki et al. (Kolesová et al., 2016, Susaki et al., 2014, Susaki et al., 2015) con pequeñas variaciones. Tras fijar y lavar los tejidos, se incubaban en la reacción CUBIC I (35\% peso/volumen $\mathrm{H}_{2} \mathrm{O}, 25 \% \mathrm{p} / \mathrm{v}$ urea, $25 \% \mathrm{p} / \mathrm{v} \mathrm{N}, \mathrm{N}, \mathrm{N}^{\prime}, \mathrm{N}^{\prime}$-tetrakis (2-hidroxi-propil) etilendiamina, $15 \% \mathrm{p} / \mathrm{v}$ tritón $\mathrm{X}-100$ ) a temperatura ambiente durante varias horas (en el caso de corazones embrionarios aislados) o días (en embriones completos o corazones adultos). Una vez clarificados los tejidos se escaneaban directamente en el microscopio confocal preservando la fluorescencia endógena. En el caso de realizar además una inmunofluorescencia whole-mount 
(ver apartado 4.2), se realizaba el protocolo normal de tinción y posteriormente los tejidos se equilibraban en sacarosa $30 \%$ y posteriormente se incubaban en la solución CUBIC II ( $15 \% \mathrm{p} / \mathrm{v}$ $\mathrm{H}_{2} \mathrm{O}, 10 \% \mathrm{p} / \mathrm{v}$ trietanolamina, $50 \% \mathrm{p} / \mathrm{v}$ sacarosa, $25 \% \mathrm{p} / \mathrm{v}$ urea) durante toda la noche.

\section{3o Trazado De Linaje Genético}

La preparación de tamoxifeno fresco (T5648, Sigma,EEUU) se realizaba disolviéndolo en aceite de maíz (C-8267, Sigma, EEUU) a una concentración final de $20 \mathrm{mg} / \mathrm{mL}$. En el caso de realizar el trazado de linaje en embriones, la inoculación se realizaba vía oral a la hembras en el estadio de gestación correspondiente ajustando la dosis por peso, de forma que se inoculaban $8.5 \mu \mathrm{l}$ de tamoxifeno/gramo de ratón. De forma excepcional, para realizar el marcaje específico de la población arterial/capilar con Nes-CreER ${ }^{\mathrm{T} 2}$ usamos una dosis 30 veces más diluida de 0.1 $\mathrm{mg} / \mathrm{mL}$. Para el trazado de linaje en adultos, la inoculación se realizaba vía intraperitoneal (3 mg tamoxifeno).

\section{INMUNOFLUORESCENCIA E INMUNOHISTOQUímiCA}

Todos los tejidos y embriones fueron previamente fijados como se describe anteriormente (apartado 2.2).

\subsection{Tinciones CON InMunofluorescencia}

Las tinciones de inmunofluorescencia se realizaron en criosecciones. En primer lugar se lavaban los portaobjetos con PBS para retirar restos de OCT y, sólo en caso de ser necesario, se permeabilizaba levemente con PBS-T (Buffer PBS con $0.1 \%$ Tritón X-100). Una vez permeabilizados los tejidos y lavados de nuevo con PBS, se bloqueaban con TNB durante 1-2 horas a temperatura ambiente $(100 \mathrm{mM}$ Tris- $\mathrm{HCl}, \mathrm{pH} 7.5 ; 150 \mathrm{mM} \mathrm{NaCl} ; 0.5 \% \mathrm{p} / \mathrm{v}$ agente de bloqueo (PekinElmer FP1020)). Tras el bloqueo se incubaban con el anticuerpo primario (diluido en buffer TNB) durante toda la noche en una cámara húmeda a $4^{\circ} \mathrm{C}$. Al día siguiente, se realizaban varios lavados de 10 minutos con PBS y se incubaba durante $1-2 \mathrm{~h}$ a temperatura ambiente con el anticuerpo secundario (diluido en TNB). Tras la incubación, volvían a realizarse varios lavados de PBS, se teñían los núcleos durante 5 minutos con DAPI (124653, Merk, EEUU) diluido 1/1000 en PBS, y se ponían los cubres con el medio de montaje (S3023, Dako, EEUU).

A continuación se muestran las tablas 3 y 4 con la lista de anticuerpos primarios y secundarios empleados, respectivamente.

Sólo en el caso de los anticuerpos primarios Sox17 y Sox7 realizamos la tinción en tres pasos, amplificando la señal con el uso de biotina y estreptavidina conjugada al fluorocromo. En estos casos particulares, tras la fijación con PBS-T, se debía realizar un bloqueo de la biotina y estreptavidina endógena con un kit comercial (E21390, ThermoFisher, EEUU) antes de iniciar el bloqueo con TNB. En la tabla 5 se muestran la lista de estreptavidinas empleadas. 


\section{Tabla 3. Listado de Anticuerpos Primarios para Inmunofluorescencia}

\begin{tabular}{|c|c|c|c|c|c|c|}
\hline Nombre & Especie & Referencia & Compañía & Dilución & $\mathbf{P}$ & Comentarios \\
\hline Troponina & conejo & ab58544 & abcam & $1 / 100$ & & \\
\hline NG2 & Conejo & ab5320 & Merck & $1 / 100$ & & \\
\hline ESR & Conejo & ab27595 & abcam & Gota & & \\
\hline Endomucina & Rata & Sc-65495 & Santa Cruz & $1 / 100$ & & \\
\hline CD140b & Rata & $14-1402-81$ & eBioscience & $1 / 100$ & $x$ & PBS-T (Triton X-100 0.1\%) \\
\hline CD90.2 & Rata & 105301 & Biolegend & $1 / 50$ & & \\
\hline CD31 & Rata & 550274 & BD Biosciences & $1 / 100$ & & \\
\hline sox17 & Cabra & 563259 & R\&D & $1 / 1000$ & $\mathrm{x}$ & PBS-T (Triton X-100 0.5\%) \\
\hline SOX7 & Cabra & AF2766 & R\&D & $1 / 1000$ & $x$ & PBS-T (Triton X-100 0.5\%) \\
\hline Caveolina1 & Conejo & $3267 S$ & Cell Signaling & $1 / 100$ & & \\
\hline ISO $_{\text {B4 }}$ AF647 & & I32450 & $\begin{array}{l}\text { Life } \\
\text { Technologies }\end{array}$ & $1 / 200$ & & Directamente conjugado \\
\hline SM22 & Conejo & ab14106 & abcam & $1 / 100$ & & \\
\hline
\end{tabular}

P. Permeabilización

\section{Tabla 4. Listado de Anticuerpos Secundarios para Inmunofluorescencia}

\begin{tabular}{llllll} 
Nombre & Especie & Reactividad & Referencia & Compañía & Dilución \\
\hline \hline AlexaFluor 594 & Cabra & anti-rata IgG & $112-585-143$ & Jackson Immunoresearch & $1 / 300$ \\
AlexaFluor 647 & Cabra & anti-rata IgG & $112-605-143$ & Jackson Immunoresearch & $1 / 300$ \\
AlexaFluor 488 & Cabra & anti-rata IgG & $112-545-143$ & Jackson Immunoresearch & $1 / 300$ \\
AlexaFluor 594 & Cabra & anti-conejo IgG & $111-585-144$ & Jackson Immunoresearch & $1 / 300$ \\
AlexaFluor 647 & Cabra & anti-conejo IgG & $111-605-144$ & Jackson Immunoresearch & $1 / 300$ \\
OregonGreen 488 & Cabra & anti-conejo IgG & O-6381 & Jackson Immunoresearch & $1 / 300$ \\
AlexaFluor 488 & Cabra & anti-pollo IgY & $103-545-155$ & Jackson Immunoresearch & $1 / 300$ \\
Biotin-SP & Burro & anti-rata IgG & $712-066-150$ & Jackson Immunoresearch & $1 / 200$ \\
Biotin-SP & Burro & anti-cabra IgG & $705-066-147$ & Jackson Immunoresearch & $1 / 200$ \\
Biotin-SP & Burro & anti-conejo IgG & $711-066-152$ & Jackson Immunoresearch & $1 / 200$ \\
\hline \hline
\end{tabular}

\section{Tabla 5. Listado de Estreptavidinas para Inmunofluorescencia}

\begin{tabular}{ccccc} 
Nombre & Reactividad & Referencia & Compañía & Dilución \\
\hline \hline AlexaFluor 488 & anti-biotina & S11223 & Thermofisher & $1 / 300$ \\
AlexaFluor 568 & anti-biotina & S11226 & Thermofisher & $1 / 300$ \\
AlexaFluor 647 & anti-biotina & S21374 & Thermofisher & $1 / 300$ \\
\hline \hline
\end{tabular}




\subsection{InMunOFluorescencia de TEjidos Enteros ("WhOLE-Mount")}

Para la tinción de tejidos completos se procedía primero a la clarificación con CUBIC I. Posteriormente los tejidos se lavaban varias veces con PBS antes de empezar la tinción. El bloqueo se realizaba con TNB-T (TNB con $0.1 \%$ Tritón X-100) durante $24 \mathrm{~h}$. El anticuerpo primario diluido $1 / 300$ en TNB-T $(0.05 \%$ Tritón $X-100)$ se incubaba durante toda la noche con agitación suave a $4^{\circ} \mathrm{C}$. Al día siguiente se realizaban lavados con PBS-T (0.05\% Tritón X-100) durante todo el día, y se incubaba con el anticuerpo secundario diluido 1/400 - 1/500 en PBS-T durante la noche a $4^{\circ} \mathrm{C}$ con agitación. Se realizaban lavados durante todo el día siguiente con PBS-T y finalmente se equilibraban los tejidos con sacarosa $30 \%$ antes de incubarlos con el reactivo CUBIC II. Una vez en este medio de clarificación, podían almacenarse a temperatura ambiente (protegidos de la luz) durante varios días hasta ser escaneados en el microscopio confocal.

En el caso de corazones embrionarios la tinción solía realizarse del órgano entero. En el caso de embriones o corazones adultos, a veces se devastaba parte del tejido en el criostato y se procedía a la tinción whole-mount con el resto que quedaba.

\subsection{Tinciones de Hematoxilina-Eosina}

Las secciones se desparafinaron durante 30 minutos a $65^{\circ} \mathrm{C}$ en una estufa. Acto seguido, se hidrataban y deshidrataban siguiendo los siguientes pasos: $10 \mathrm{~min}$ xilol; $10 \mathrm{~min}$ xilol; $5 \mathrm{~min}$ etanol Absoluto; $5 \mathrm{~min}$ etanol 96\%; $5 \mathrm{~min}$ etanol 70\%; $5 \mathrm{~min}$ agua destilada; $5 \mathrm{~min}$ hematoxilina (tiñe las estructuras ácidas de azul/púrpura); $5 \mathrm{~min}$ de lavados con agua corriente; 1 min eosina (tiñe componentes básicos de color rosa); $1 \mathrm{~min}$ de lavado con agua corriente; 30 segundos etanol 70\%; 30 segundos etanol 96\%; $1 \mathrm{~min}$ etanol absoluto; $3 \mathrm{~min}$ xilol; $3 \mathrm{~min}$ xilol. Una vez finalizado este proceso, el montaje de los portas se realizaba con DPX (06522, Sigma, EEUU).

Los portaobjetos teñidos se digitalizaron con un escáner NanoZoomer-XR Digital slide scanner (Hamamatsu, Japón).

\subsection{OTRAS Tinciones InMUNOHISTOQUímicas}

Las tinciones de endotelio y de proliferación celular en cortes de parafina de corazones adultos con los marcadores CD31 y Ki67, respectivamente, fueron realizados por el servicio de Histopatología del CNIC.

\section{5o IMAGEN CONFOCAL}

Los microscopios confocales empleados fueron el Zeiss LSM780 multifotón y el microscopio confocal invertido Zeiss LSM700. Para el montaje de los tejidos gruesos empleamos unos aisladores adhesivos de silicona (Grace Bio-Labs, EEUU) de diferentes diámetros y grosores (desde $0.1 \mathrm{~mm}$ hasta $2.5 \mathrm{~mm}$ ) en función del tamaño de las muestras. El medio de 
montaje para tejidos completos era el propio reactivo de clarificación CUBIC, tapado con un cubre. En el caso de cortes de tejidos, se usaba el medio de montaje Dako (S3023, Dako). Para el análisis de las imágenes se utilizaron los paquetes software Fiji (NIH) y Adobe Photoshop (Adobe, CA).

\section{6o Citometría de Flujo Y Cell Sorting}

\subsection{Digestión Enzimática de Corazones Embrionarios o Adultos}

Antes de comenzar se preparaban la Solución de Digestión con $26 \mathrm{U} / \mathrm{mL}$ Liberase $^{\mathrm{TM}} \mathrm{TM}$ Reserach Grade (05 401119 001, Merck, EEUU) y 10 U/mL DNaseI (D5025, Merck, EEUU) en medio HBSS 1x (14025092, Gibco, ThermoFisher, EEUU) y la Solución de FACS (medio HBSS $+2 \%$ suero fetal bovino).

Los corazones aislados se colocaban en placas de $35 \mathrm{~mm}$ de diámetro con medio HBSS, donde se diseccionaban las aurículas para dejar sólo los ventrículos. Posteriormente se pasaban a una placa nueva sin medio y se troceaban con tijeras. Se añadía $1 \mathrm{~mL}$ de solución de digestión para poder transferir los corazones troceados a tubos de poliestireno de $15 \mathrm{~mL}$ con el fondo redondo. La incubación se realizaba en una baño a $37^{\circ} \mathrm{C}$ con agitación suave durante 30 minutos. Cada 5-10 minutos se pipeteaba suavemente para deshacer los agregados y conseguir una suspensión de células independientes. Tras la digestión, la solución se filtraba $(70 \mu \mathrm{m})$ para eliminar los agregados que pudiesen quedar y se lavaba con $5 \mathrm{~mL}$ de medio HBS frío en tubos Falcon de $50 \mathrm{~mL}$. Las células en suspensión se centrifugaban a $300 \times \mathrm{g}$ durante 5 minutos a $4{ }^{\circ} \mathrm{C}$, y el pellet final se resuspendía en $1 \mathrm{~mL}$ de buffer FACS, manteniendo las células siempre en hielo.

\subsection{Tinción de Células Para Citometría Analítica (FACS)}

Para las tinciones, el pellet de células obtenido tras la digestión enzimática de los corazones se separaba en diferentes tubos eppendorf de $1.5 \mathrm{~mL}$ para poder teñirlos con diferentes cócteles de anticuerpos, además de los controles. Los anticuerpos se diluían en solución de FACS y la incubación de las células en ellos se realizaba siempre en hielo (1-2 horas) y protegidos de la luz. En la tabla 6 se muestran los anticuerpos empleados.

Tras la incubación, se lavaban dos veces con $1 \mathrm{~mL}$ de solución de FACS y se centrifugaban 5 minutos a $300 \times \mathrm{g}$ a $4^{\circ} \mathrm{C}$. El pellet final se resuspendía en $300 \mu \mathrm{l}$ de solución de FACS con DAPI diluido 1/1000. Las suspensiones de células teñidas se transferían a tubos de citometría de $5 \mathrm{~mL}$ filtrándolas previamente (Cell strainer, 40um, BD). Durante todo el proceso las células debían mantenerse a $4^{\circ} \mathrm{C}$. El análisis de las células por citometría analítica se realizó empleando el equipo LSR Fortessa (BD). Se utilizó DAPI para excluir las células muertas, y una vez descartados los eventos de debris y dobletes celulares, se seleccionaba la población 
Ter119/CD45 negativa, para excluir células hematopoyéticas y eritrocitos contaminantes del análisis.

\begin{tabular}{lllll}
\multicolumn{5}{c}{ Tabla 6. Listado de Anticuerpos para Citometría } \\
Color & Marcador & Referencia & Compañía & Dilución \\
\hline \hline PE & CD90.2 & 553014 & BD Biosciences & $1 / 100$ \\
APC & CD90.2 & $17-0902-82$ & eBioscience & $1 / 100$ \\
APC & CD31 & 551262 & BD Biosciences & $1 / 100$ \\
PE-Cy7 & CD31 & $25-0311-82$ & eBioscience & $1 / 100$ \\
PE & CD36 & 6154806 & BD Biosciences & $1 / 100$ \\
PE & Ly6c & 5309904 & BD Biosciences & $1 / 100$ \\
APC-Cy7 & CD45.2 & $25-0454$ & BD Pharmingen & $1 / 100$ \\
APC-Cy7 & Ter119 & 560509 & BD Pharmingen & $1 / 100$ \\
eFluor 660 & endomucina & $50-5851-80$ & eBioscience & $1 / 100$ \\
APC & mEF-SK4 & $130-102-302$ & Miltenyi & $1 / 100$ \\
\hline \hline
\end{tabular}

\section{3. “Clasificación” de Células (Cell Sorting)}

Los equipos utilizados para sortear las células en base a su fluorescencia endógena o las tinciones con marcadores de membrana fueron el BD FACS Aria Cell Sorter y el FACS Synergy 4L Cell Sorter (Sony), principalmente. En algunos casos puntuales se realizó una separación por bolitas magnéticas con el AutoMACS Pro Separator (Miltenyi Biotec).

Las distintas poblaciones sorteadas para realizar la posterior extracción de ARN se recogían en eppendorf con el buffer de lisis correspondiente, según el kit de extracción que se fuese a emplear en cada caso. Cuando el objetivo era sembrar células individuales en placas de 96 pocillos para cultivos celulares, todo el proceso se llevaba a cabo bajo condiciones de esterilidad y las células se recogían en las placas con su correspondiente medio de cultivo en cada pocillo.

\section{7ํ TÉCniCas de Biología Molecular y ClonajE}

\subsection{TRANSFORMACIONES BACTERIANAS}

Las transformaciones de plásmidos puros comerciales se realizaron en $100 \mu \mathrm{l}$ de bacterias competentes E. coli DH5 $\alpha$ caseras. Brevemente, se descongelaban los viales de bacterias durante $10 \mathrm{~min}$ en hielo y se añadían $100 \mathrm{ng}$ de plásmido en condiciones de esterilidad. Tras volver a incubarlas 15 minutos en hielo, se daba el choque térmico (30 min a $37^{\circ} \mathrm{C}$ y 2 min en hielo). A continuación, se añadían 4 volúmenes de medio rico SOC (New England BioLabs, B9020S, EEUU) y se dejaban creciendo durante 1 hora a $37^{\circ} \mathrm{C}$ con agitación 
suave $(250 \mathrm{rpm})$. Transcurrido el tiempo de incubación, se centrifugaban $3 \mathrm{~min}$ a 2000 x g y se plaqueaban en placas de LB agar con los antibióticos correspondientes. Se dejaban creciendo las colonias durante una noche a $37^{\circ} \mathrm{C}$.

Para las transformaciones de plásmidos resultado de productos de ligación o ensamblado de varios fragmentos se emplearon las bacterias competentes comerciales $N E B$ E. Coli $5 \alpha$ (C2987H, New England BioLabs, EEUU). En este caso, el protocolo de transformación era el indicado por la casa comercial, donde la principales diferencias se correspondían con la incubación inicial en hielo ( $30 \mathrm{~min}$ ) y el choque térmico ( 30 segundos a $42^{\circ} \mathrm{C}$ y $5 \mathrm{~min}$ en hielo).

\subsection{Extracción de ADN Plasmídico}

Para extraer pequeñas cantidades de ADN plasmídico se empleaba el QIAprep Spin Miniprep Kit (27104, Qiagen, EEUU) a partir de cultivos de $5 \mathrm{~mL}$ de LB más el antibiótico necesario que se crecían durante una noche a $37^{\circ} \mathrm{C}$ en agitación. Para cantidades mayores de ADN, los kits Plasmid Midi (12143, Qiagen, EEUU) y EndoFree Plasmid Maxi Kit (12362, Qiagen, EEUU) siguiendo las instrucciones del fabricante.

\subsection{Digestiones Enzimáticas Y Extracción de ADN a Partir de Bandas de Agarosa}

Las digestiones enzimáticas se realizaron siguiendo las instrucciones de cada una de las enzimas de restricción empleadas. Cuando era necesario, una vez digeridos los plásmidos se desfosforilaban con el uso de Rapid Alkaline Phosphatase (4898133001, Sigma, EEUU). Las muestras se corrían por electroforesis en geles de agarosa al 2-3 \% y 100-120V para chequear las bandas digeridas. En el caso de ser fragmentos que debían subclonarse, se preparaban geles preparativos al $1.5 \%$ de agarosa sin bromuro de etidio y se corrían a 90V durante 1 hora. Posteriormente se teñían con bromuro y se cortaban las bandas de interés bajo luz UV en el transiluminador. EI ADN de las bandas cortadas se extraía siguiendo las instrucciones del kit QIAquick Gel Extraction (28704, Qiagen, EEUU).

\subsection{Ligaciones y ENSAMblado de MÚltiples Fragmentos de ADN}

Las ligaciones de fragmentos de ADN y vector plasmídico (defosforilado) se realizaron con fragmentos obtenidos a través de digestión enzimática y purificados en geles de agarosa, o bien amplificados por PCR. En este último caso, se usaba la taq Platinum SuperFi DNA Polymerase (12351010, ThermoFisher, EEUU) y los fragmentos amplificados se purificaban con el kit QIAquick PCR Purification (28104, Qiagen, EEUU). Para la ligación se usó la ligasa Quick-Stick Ligase (BIO-27027, Bioline).

Para el ensamblado de múltiples fragmentos de ADN en un vector plasmídico se usó el reactivo NEBuilder HiFi DNA Assembly Cloning Kit (E5520S, New England BioLabs, EEUU) siguiendo las instrucciones del fabricante. 


\subsection{Plásmidos Comerciales y Construcciones Generadas}

En las siguientes tablas se muestran los plásmidos comerciales que se utilizaron; los plásmidos empleados del sistema pMuLe (Multiple Lentiviral Expression, \#1000000060, Addgene) para generar construcciones por el sistema de recombinación homóloga Gateway; los plásmidos para generar las distintas construcciones para la transposición por Sleeping Beauty (Addgene); las construcciones que contienen los fragmentos de genes que se mandaron soitetizar (GeneScript); y la lista de construcciones que se generaron para este proyecto.

\section{Tabla 7. Plásmidos Comerciales}

\begin{tabular}{lcl} 
Nombre & Tamaño $(\mathrm{pb})$ & Referencia \\
\hline \hline pGluc Mini-TK2 & 5028 & NEB \#N8086S \\
pSF-pA-PromMCS-SEAP & 5395 & Oxford Genetics \#OG238 \\
pBS aP2 promoter pA & 8734 & Addgene \#11424 \\
mCerulean3-H2B-C-10 & 5079 & Addgene \#55422 \\
\hline \hline
\end{tabular}

\begin{tabular}{rlcl}
\multicolumn{4}{c}{ Tabla 8. Plásmidos Kit pMuLe (\#1000000060) } \\
Código & Nombre & Tamaño (pb) & Referencia \\
\hline \hline A1 & pENTR L1-MCS-R5 & 2717 & Addgene \#62084 \\
A2 & pENTR L5-MCS-L2 & 2665 & Addgene \#62085 \\
A7 & pENTR L1-CMV-R5 & 3390 & Addgene \#62090 \\
A10 & pENTR R4-CMV-R3 & 3448 & Addgene \#62093 \\
F3 & pENTR L5-SV40/mCherry-L2 & 4043 & Addgene \#62146 \\
F6 & pENTR L5-CMV/mCherry-L2 & 3703 & Addgene \#62149 \\
F7 & pENTR L3-SV40/mCherry-L2 & 3699 & Addgene \#62150 \\
F10 & pENTR L3-SV40 tdTomato-L2 & 4403 & Addgene \#62153 \\
G2 & pENTR L5-CMV-iRFP-L2 & 4255 & Addgene \#62157 \\
H9 & pLenti DEST X1 Neo & 9377 & Addgene \#62176 \\
\hline \hline
\end{tabular}

\section{Tabla 9. Plásmidos para el sistema de Transposición Sleeping Beauty}

\begin{tabular}{lcl} 
Nombre & Tamaño $(\mathrm{pb})$ & Referencia \\
\hline \hline pT2/BH & 3558 & Addgene \#26556 \\
pCMV (CAT)T7-SB100 & 4752 & Addgene \#34879 \\
pSBtet-BH & 8429 & Addgene \#60499 \\
pSBbi-RP & 6625 & Addgene \#60513 \\
\hline \hline
\end{tabular}




\begin{tabular}{llc}
\multicolumn{2}{c}{ Tabla 10. Fragmentos Sintéticos (GeneScript) } & Tamaño (pb) \\
\hline Nombre & Descripción & 5404 \\
\hline \hline pUC57/i2_full_TH_GFP-pA & Contiene el i2E del gen Nestina de rata & 3412 \\
i2_SpeI_deltaCR1 (pUC57-simple) & Contiene el i2E con la deleción del fragmento CR1 & 3411 \\
i2_SpeI_deltaCR2 (pUC57-simple) & Contiene el i2E con la deleción del fragmento CR2 & 6612 \\
RaOp-smURFP (pcDNA3.1 (-) zeo) & Contiene el gen mutado de Sox18 (RaOp) & 4311 \\
RaOp-smURFP (pUC57) & Contiene el gen mutado de Sox18 (RaOp) & 6650 \\
Sox17-pcDNA3.1_C_(K)-DYK & Contiene el gen Sox17 & 6524 \\
Sox18-pcDNA3.1_C_(K)-DYK & Contiene el gen Sox18 & 6 \\
\hline \hline
\end{tabular}

Para los ensayos de actividad luciferasa, los distintos fragmentos del i2E (i2_full, i2_D452; i2_D322; i2_deltaCR1; i2_deltaCR2) se subclonaron en el vector hGluc. Dado que el plásmido de la fosfatasa alcalina SEAP carecía de promotor, se le clonó un promotor constitutivo SV40 obtenido de uno de los plásmidos del sistema pMuLe. Para el sistema de transposición Sleeping Beauty se generaron construcciones donde la expresión de los genes introducidos en el transposón (Sox17 y Sox18) dependía de la inducción con doxiciclina (DOX).

También se hicieron dos transposones para microinyectarlos en los pronúcleos de los oocitos fecundados y generar transgénicos transitorios (transient transgenics). Uno de ellos llevaba la secuencia completa del i2E 5' del reportero tomato, y la otra construcción expresaba la proteína mutante Sox $18^{\mathrm{RaOp}}$ bajo el promotor Fabp4.

Con el sistema de recombinación Gateway se generaron dos construcciones para empaquetarlas en lentivirus deficientes en la replicación. Una de ellas expresaría la proteína mutante Sox $18^{\text {RaOp }}$ en las células infectadas y el reportero iRFP, y la otra tan sólo llevaría la proteína fluorescente (control). Las reacciones de Gateway consistían en la recombinación homóloga entre el plásmido destino (H9) y el plásmido con el gen deseado. La reacción se llevó a cabo con la LR Clonase II Plus Enzyme (12538120, ThermoFisher, EEUU) durante 16$20 \mathrm{~h}$ a $25^{\circ} \mathrm{C}$ y una inactivación con proteinasa $\mathrm{K}$ durante $10 \mathrm{~min}$ a $37^{\circ} \mathrm{C}$. Tras la recombinación se transformaron en bacterias competentes comerciales NEB E. Coli $5 \alpha$ y sólo en el caso en el que se produjera la recombinación correctamente, se perdía el gen suicida del plásmido destino ccdB y las colonias podrían crecer.

\begin{tabular}{|c|c|c|c|}
\hline & Nombre & Descripción & Tamaño $(\mathrm{pb})$ \\
\hline \multirow{5}{*}{$\begin{array}{l}\text { Ensayos de } \\
\text { Luciferasa }\end{array}$} & SV40_SEAP & $\begin{array}{l}\text { Promotor SV40 introducidoen el vector pSF-pA- } \\
\text { PromMCS-SEAP }\end{array}$ & \\
\hline & pi2_full_hGluc & Fragmento i2_full clonado en hGluc & 6727 \\
\hline & pi2_D452_hGluc & Fragmento D452 clonado en hGluc & 5471 \\
\hline & pi2_D322_hGluc & Fragmento D322 clonado en hGluc & 5341 \\
\hline & pi2_delta CR1_hGluc & Fragmento i2_deltaCR1 clonado en hGluc & 6700 \\
\hline
\end{tabular}




\begin{tabular}{|c|c|c|c|}
\hline & pi2_delta CR2_hGluc & Fragmento i2_deltaCR2 clonado en hGluc & 6694 \\
\hline \multirow{2}{*}{$\begin{array}{c}\text { Expresión } \\
\text { inducible por } \\
\text { DOX }\end{array}$} & pSBtet_BH_Sox17 & Gen Sox17 en pSBtet-BH & 8076 \\
\hline & pSBtet_BH_Sox18 & Gen Sox18 en pSBtet-BH & 7968 \\
\hline \multirow{8}{*}{$\begin{array}{c}\text { Vectores para } \\
\text { microinyección } \\
\text { pronuclear }\end{array}$} & $\begin{array}{l}\text { pSB(T2)_i2full_TK_ } \\
\text { Tomato_pA }\end{array}$ & $\begin{array}{l}\text { Fragmentos (i2_full+tdTomato }+\mathrm{pA}) \text { en vector } \mathrm{pT} 2- \\
\mathrm{BH}\end{array}$ & 6941 \\
\hline & i2_full & amplificado del pUC57/i2_full_TH_GFP-pA & \\
\hline & tdTomato & amplificado del pENTR L3-SV40 tdTomato-L2 & \\
\hline & $\mathbf{p A}$ & amplificadodel pUC57/i2_full_TH_GFP-pA & \\
\hline & pFabp4_RaOp_ & & \\
\hline & SmURFP & fragmento Fabp4 en vector pSB(T2)-RaOp-smURFP & 10733 \\
\hline & Promotor Fabp4 & amplificado de $\mathrm{pBS} \mathrm{aP} 2$ promoter $\mathrm{pA}$ & \\
\hline & pSB(T2)-RaOp-smURFP & Fragmento RaOp-smURFP clonado en pT2-BH & \\
\hline \multirow{3}{*}{$\begin{array}{l}\text { Producción de } \\
\text { lentivirus }\end{array}$} & Lenti_Control_iRFP & $\begin{array}{l}\text { Combinación por Gateway de los plásmidos DEST, } \\
\text { A1 y A10 }\end{array}$ & 9415 \\
\hline & & Combinación por Gateway de los plásmidos H9, G2 & \\
\hline & Lenti_RaOp_iRFP & en vector A7) & 11104 \\
\hline
\end{tabular}

\begin{tabular}{|c|c|c|}
\hline & Nombre & Secuencia 5' -> 3' \\
\hline $\begin{array}{l}\text { Construcciones } \\
\text { Luciferasa }\end{array}$ & $\begin{array}{l}\text { D322-Fw-Xhol } \\
\text { D452-Fw-XhoI } \\
\text { D452/322-TK-Rev } \\
\text { SV40-Fw-SpeI } \\
\text { SV40-Rev }\end{array}$ & $\begin{array}{l}\text { tactgtgctcgaggtgtggacaaaaggcaataattagcatgagaatc } \\
\text { tactgtgctcgaggggagctgaattcatttgcttttgtc } \\
\text { ttaagcgggtcgctgcagg } \\
\text { tactgtgactagtagttgctgtggaatgtgtgtcag } \\
\text { ggatccgagctcggtaccaag }\end{array}$ \\
\hline pSB_tet_BH_Sox17 & $\begin{array}{l}\text { Sox17-Fw } \\
\text { Sox17-Rev }\end{array}$ & $\begin{array}{l}\text { ctcgaaaggcctctggagctcggatccgccac } \\
\text { gaagcttggcctgaccagcgggtttatcacttatcgtcg }\end{array}$ \\
\hline pSB_tet_BH_Sox18 & $\begin{array}{l}\text { Sox18-Fw } \\
\text { Sox18-Rev }\end{array}$ & $\begin{array}{l}\text { ctcgaaaggcctctggagctcggatccgccac } \\
\text { gaagcttggcctgaccagcgggtttatcacttatcgtcg }\end{array}$ \\
\hline $\begin{array}{l}\mathrm{pDEST}-\mathrm{SB}(\mathrm{T} 2)- \\
\mathrm{R} 1 \mathrm{R} 2\end{array}$ & $\begin{array}{l}\text { R1R2-Fw } \\
\text { R1R2-Rev }\end{array}$ & $\begin{array}{l}\text { tttagaagctagatctggccatctagagcggccgcgcgcaattccagtgtggtggaattgagtattc } \\
\text { ttcgagtagccttccacaagcttgatatccatggaattcaaaggcattaaagcagcgtatccac }\end{array}$ \\
\hline $\begin{array}{l}\text { pT2(SB)--i2_Full- } \\
\text { TK-Tom-pA }\end{array}$ & $\begin{array}{l}\text { Full_Fw } \\
\text { Full_Rev } \\
\text { Tom-Fw } \\
\text { Tom-Rev } \\
\text { SV40-Fw-SpeI } \\
\text { SV40-Rev }\end{array}$ & $\begin{array}{l}\text { gcttgatatccatggaattcagtacacagtgctgactgtcctcg } \\
\text { ttgctcaccatggtggctttacc } \\
\text { aaagccaccatggtgagcaagggcga } \\
\text { ccgactctagttacttgtacagctcgtccatgccgt } \\
\text { gtacaagtaactagagtcggggcggccg } \\
\text { gagcggccgcgcgcagatggatccaacttgtttattgcagcttataatggttacaaa }\end{array}$ \\
\hline Lentivirus & $\begin{array}{l}\text { RaOp-BamHI-Fw } \\
\text { RaOp-XhoI-Rev }\end{array}$ & $\begin{array}{l}\text { cttggatccctggccaccatgcagagatc } \\
\text { gtactcgagttaagtagccttatcgtcgtcatccttg }\end{array}$ \\
\hline $\begin{array}{l}\mathrm{pSB}(\mathrm{T} 2)-\mathrm{aP} 2- \\
\mathrm{RaOp}-\mathrm{smURFP}\end{array}$ & $\begin{array}{l}\text { aP2-2step-fwd.FOR } \\
\text { aP2-2step-rev.REV }\end{array}$ & $\begin{array}{l}\text { aagctagatctggccatattcccagcaggaatcaggtag } \\
\text { cagaggccacgcgttctgcagcacaggagggtg }\end{array}$ \\
\hline
\end{tabular}




\section{EXTRACCIONES DE ARN y PCRs CuAntitativas}

\subsection{EXTRACCIÓn DE ARN dE CoRAZONES EMbrionarios}

Se han empleado tres kits comerciales diferentes para extraer el ARN de las subpoblaciones cardíacas. De forma general se separaban la población mesenquimal y endotelial en corazones embrionarios o neonatales por citometría de flujo y se recogían directamente en el buffer de lisis del Dynabeads ${ }^{T M}$ mRNA Purification Kit (61006, ThermoFisher, EEUU) para la extracción de ARN mensajero. La extracción de ARN total se realizaba con el RNeasy Mini Kit (74104, QIAGEN, EEUU). Para la extracción de ARN de las muestras que se iban a secuenciar por RNAseq, empleamos el PicoPure ${ }^{\text {TM }}$ RNA Isolation Kit (KIT0204, ThermoFisher, EEUU). En el caso de células en cultivo, el pellet de células se resuspendía en $300 \mu$ de buffer de lisis con $10 \%$ de $\beta$-mercaptoetanol.

\subsection{OBTEnCión DEL ADN CodifiCANTE MEdiante ReACCión DE RETRotranSCRiPCión}

Las retrotranscripciones para la obtención del ADN complementario se llevaron a cabo con el uso de la SuperScript IV Reverse Transcriptase (ThermoFisher, EEUU) siguiendo las instrucciones del fabricante. Dependiendo de si partíamos de ARN mensajero extraído con el kit de Dynabeads o de ARN total extraído con las columnas de Qiagen, se empleaban programas diferentes detallados en la siguiente tabla:

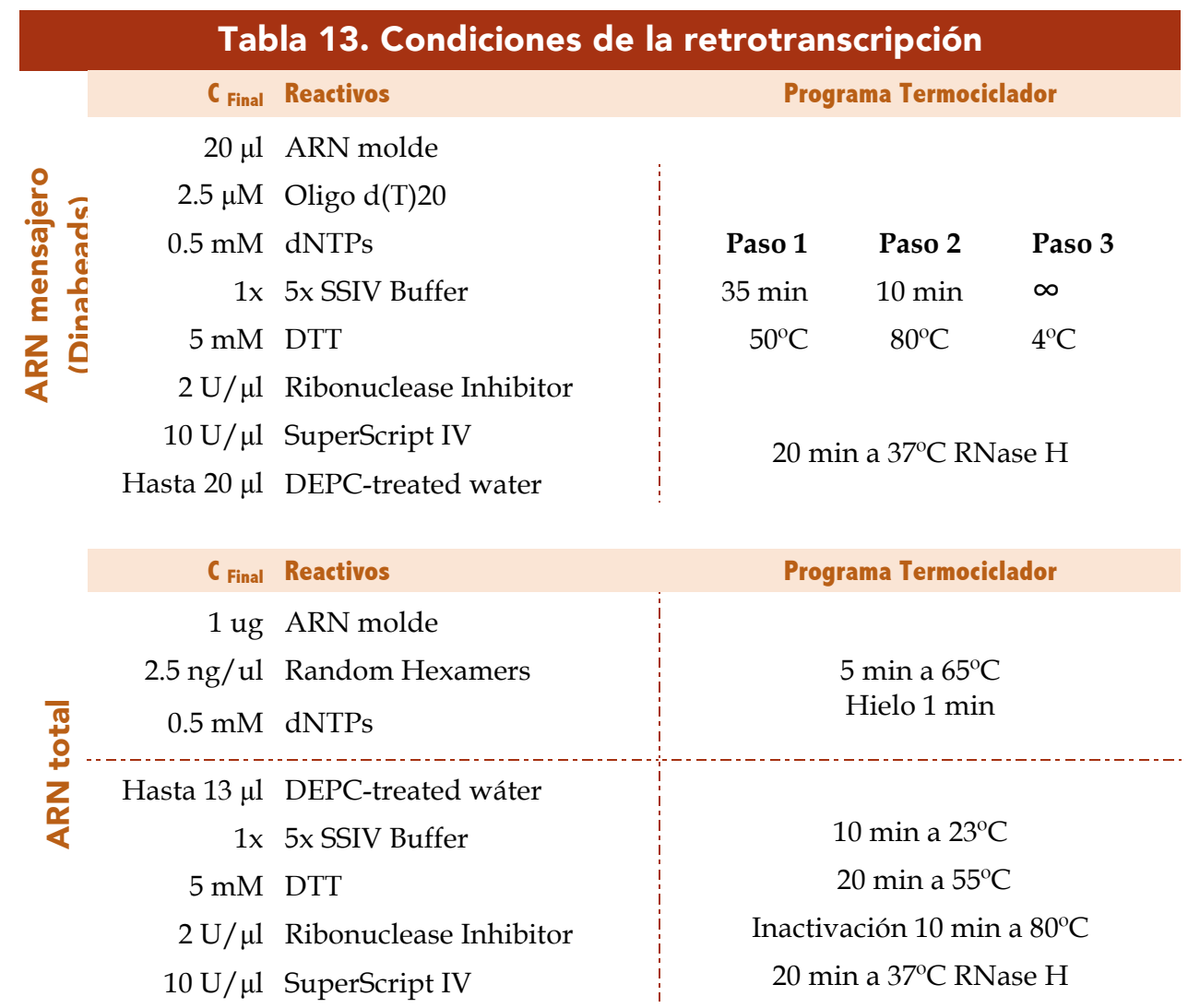




\subsection{PCR CUANTITATIVA}

El ADN complementario obtenido mediante retrotranscripción se diluía en $\mathrm{H}_{2} \mathrm{O}$ entre 5-20 veces en función de la cantidad de ARN de partida y el número de genes que se quisieran analizar. Las reacciones de PCR cuantitativa se llevaban a cabo con Power SYBR ${ }^{\mathrm{TM}}$ Green Master Mix 2x (4367659, ThermoFisher, EEUU). Las secuencias de oligonucleótidos empleados se detallan en la Tabla 14.

\begin{tabular}{|c|c|c|}
\hline Gen & Oligo Directo 5'-3' & Oligo Reverso 5'-3' \\
\hline APJ & CCACTGTGGGCCACTTAT ACC & CAGCCTTAGCCGAGCATT G \\
\hline Apln & GTGCCCTCCCGGTG CGG TCT CT & GAGACCACGCCATTAGAGGAA \\
\hline Cdh11 & CTGGGTCTGGAACCAATTCTTT & GCCTGAGCCATCAGTGTGTA \\
\hline Col4a1 & CTGGCACAAAAGGGACGAG & ACGTGGCCGAGAATTTCACC \\
\hline COUP II TF & GCAAGTGGAGAAGCTCAAGG & TTCCAAAGCACACTGGGACT \\
\hline Cxcl12 & TGCATCAGTGACGGTAAACCA & TTCTTCAGCCGTGCAACAATC \\
\hline Dach1 & GTGGAAAACACCCCTCAGAA & CTTGTTCCATCTTCCATTTC \\
\hline Den & TCTTGGGCTGGACCATTTGAA & CATCGGTAGGGGCACATAGA \\
\hline DII4 & TGCCTGGGAAGTATCCTCAC & GTGGCAATCACACACTCGTT \\
\hline Dpt & TGGATGGGTGAATCTTAACCGC & TCAGAGCCTTCCTTCTTGCTA \\
\hline EGFP & AGCTGACCCTGAAGTTCATCTG & AAGTCGTGCTGCTTCATGTG \\
\hline Efnb2 & TGTTGGGGACTTTTGATGGT & GTCCACTTTGGG GCAAATAA \\
\hline Emcn & CCAAAAGTGACGTATCCCAAA & TGTTCTGGGAACCTGGTAGC \\
\hline EphB4 & CTGGATGGAGAACCCCTACA & CCAGGTAGAAGCCAGCTTTG \\
\hline Fabp4 & TGGAAGCTTGTCTCCAGTGA & TCGACTTTCCA TCCCACTTC \\
\hline FoxC1 & CCCCGGACAAGAAGATCACTC & AGGTTGTGCCGTATGCTGTTC \\
\hline FoxP1 & GGTCTGAGACAAAAAGTAACGGA & CGCACTCTAGTAAGTGGTTGC \\
\hline Gja5 & CCACAGTCATCGGCAAGGTC & CTGAATGGTATCGCACCGGAA \\
\hline Hif2a & CTAAGTGGCCTGTGGGTGAT & GTGTCTTGGAAGGCTTGCTC \\
\hline isox17 & GACTGCGGAGTGAACCTCTC & TGTCTATCGATGGAAGCTTGG \\
\hline isox18 & TAGCAGCGCGGTCTATTACA & TATCGATGGAAGCTTGGCCT \\
\hline Jag1 & GACCAGAACGGCAACAAAACTTGCATGGAA & TTGGTCTCACAGAGGCACTGCCAGGGTTCA \\
\hline Lpar4 & AGTGCCTCCCTGTTTGTCTTC & GCCAGTGGCGATTAAAGTTGTAA \\
\hline Meox1 & GAAACCCCCACTCAGAAGATAGC & TCGTTGAAGATTCGCTCAGTC \\
\hline Meox2 & GGCAGAATTTGCCCATCATA & TGCTCAGAGCTGTGGTCACT \\
\hline mHPRT & GAGGAGTCCTGTTGATGTTGCCAG & GGCTGGCCTATAGGCTCATAGTGC \\
\hline Nestin & GCTGGAACAGAGATTGGAAGG & CCAGGATCTGAGCGATCTGAC \\
\hline Nfatc1 & GACCCGGAGTTCGACTTCG & TGACACTAGGGGACACATAACTG \\
\hline Notch1 & TGTCGTGTGTCAAGCTGATGAGGA & GGTTGTGCTCTTAGGAGCTACTGGTT \\
\hline Notch4 & AGTAAGTAACCAGTGGCCCATCCA & AGTGACTGGAGAACATGGCCTCAT \\
\hline Npr3 & ACTAGGTGCTGGCTTGCTAA & TCTGCTCCGTTGATGTCTGT \\
\hline Ogn & ACCATAACGACCTGGAATCTGT & AACGAGTGTCATTAGCCTTGC \\
\hline Pdgfb & ATCCGCTCCTTTGATGATCT & GAGCTTTCCAACTCGACTCC \\
\hline Pecam 1 & ATGGAAAGCCTGCCATCATG & TCCTTGTTGTTCAGCATCAC \\
\hline Plvap & GCTGGTACTACCTGCGCTATT & CCTGTGAGGCAGATAGTCCA \\
\hline
\end{tabular}




$\begin{array}{lll}\text { Sema3g } & \text { GGTTCCCTAGACCTCCAAGTC } & \text { GTCTTTTCCCTTGCGGACACA } \\ \text { Smoc1 } & \text { AATCCACAGGCTACTGTTGGT } & \text { CATCGGCCTCTATGCTCTTGG } \\ \text { Sox13 } & \text { CAGGATGCCACCAACGCTAA } & \text { TGCTGGTCTCTTGGGTTCTG } \\ \text { Sox17 } & \text { ACGCTAGCTCAGCGGTCTACTATT } & \text { AGGGATTTCCTTAGCGCTTCCAGG } \\ \text { Sox18 } & \text { TTTCCCAATCCTCTGTCACCACCA } & \text { ACTGGTCAAATTCGGTGAGGTCCA } \\ \text { Sox7 } & \text { CAAACAAACACCCTGTGACACCCA } & \text { ATACACGTGTCCAAGGGCAGACAA } \\ \text { Tomato } & \text { GCCGACATCCCCGATTACAAGA } & \text { CGATGGTGTAGTCCTCGTTGTGG } \\ \text { Unc5b } & \text { CGGGACGCTACTTGACTCC } & \text { GGTGGCTTTTAGGGTCGTTTAG } \\ \text { Ywhaz } & \text { CGTTGTAGGAGCCCGTAGGTC } & \text { TCTGGTTGCGAAGCATTGGG }\end{array}$

\section{9o Perfiltranscripcional Mediante Secuenciación Masiva}

\subsection{Preparación de Muestras}

Los corazones de los estadios correspondientes se digirieron con liberasa y las diferentes poblaciones se separaron por citometría de flujo, recogiendo las células en tubos eppendorf suavemente e incubaron $30 \mathrm{~min}$ a $42^{\circ} \mathrm{C}$. Tras ser centrifugadas $2 \mathrm{~min}$ a $3000 \mathrm{xg}$, se pasaron a tubos eppendorf limpios y se congelaron a -80C hasta el momento de la extracción.

Tras la extracción del ARN con el kit comercial PicoPure ${ }^{T M}$ RNA Isolation Kit (KIT0204, ThermoFisher, EEUU), las muestras que se iban a secuenciar sin amplificación (\#1-\#12) se eluyeron en un volumen final de $22 \mu \mathrm{l}$, y las que requerían ser amplificadas (\#13-\#21) en 11 $\mu \mathrm{l}$. De todas ellas se cogió $1 \mu \mathrm{l}$ para medir las concentraciones obtenidas en el BioAnalyzer. A excepción de una, todas las muestras obtuvieron un RIN entre 9-10, indicando la alta pureza de la extracción.

Para la secuenciación, las muestras \#1-\#12 se dejaron a una concentración final de 90 ng en un volumen de 50ul, mientras las que iban a ser amplificadas (\#13-\#21), se dejaron a $3 n g$ en $10 \mu$ l.

\begin{tabular}{|c|c|c|c|c|c|}
\hline Muestra & Nombre & $\mathrm{N}^{\circ}$ corazones & $N^{\circ}$ Células & $\operatorname{ARN}_{\text {total }}(\mathrm{ng})$ & Amplificación \\
\hline 1 & \multirow{4}{*}{ Endocardio E13.5 } & 16 & 100.000 & 215 & No \\
\hline 2 & & 10 & 53.000 & 145 & No \\
\hline 3 & & 24 & 162.000 & 170 & No \\
\hline 4 & & 24 & 122.000 & 150 & No \\
\hline 5 & \multirow{4}{*}{ Plexo Coronario E13.5 } & 16 & 30.000 & 135 & No \\
\hline 6 & & 10 & 20.000 & 78 & No \\
\hline 7 & & 24 & 77.000 & 108 & No \\
\hline 8 & & 24 & 57.000 & 136 & No \\
\hline
\end{tabular}




\begin{tabular}{|c|c|c|c|c|c|}
\hline 9 & \multirow[t]{2}{*}{ Endocardio E17.5 } & 8 & 59.000 & 143 & No \\
\hline 10 & & 7 & 71.000 & 194 & No \\
\hline 11 & \multirow{2}{*}{ Plexo Coronario E17.5 } & 8 & 180.000 & 172 & No \\
\hline 12 & & 7 & 204.000 & 205 & No \\
\hline 13 & \multirow{3}{*}{ Endocardio E17.5 } & 3 & 15.000 & 5 & Sí \\
\hline 14 & & 5 & 54.000 & 4.7 & Sí \\
\hline 15 & & 4 & 38.000 & 6 & Sí \\
\hline 16 & \multirow{3}{*}{ Plexo Intramiocárdico E17.5 } & 3 & 9.000 & 4.4 & Sí \\
\hline 17 & & 5 & 10.000 & 3 & Sí \\
\hline 18 & & 4 & 8.000 & 1.7 & Sí \\
\hline 19 & \multirow{3}{*}{ Plexo Subepicárdico E17.5 } & 3 & 10.000 & 6 & Sí \\
\hline 20 & & 5 & 37.000 & 5.4 & Sí \\
\hline 21 & & 4 & 28.000 & 9.9 & Sí \\
\hline
\end{tabular}

\subsection{Secuenciación del Transcriptoma Completo (RNA-SEQ)}

Se construyeron librerías marcadas e indexadas de ADNc a partir de 500ng de ARN total mediante el kit TruSeq RNA Sample Preparation vs2 (Illumina, EEUU) siguiendo las instrucciones del fabricante. Se cuantificaron mediante un ensayo Quant-iT sdDNA HS en un fluorímetro Q-bit (Life Technologies, EEUU). El tamaño medio de la librería y su distribución de tamaños se determinó mediante un ensayo DNA 1000 en un analizador Agilent 2100 Bioanalyzer. Senormalizaron a una concentración de $10 \mathrm{nM}$ mediante $10 \mathrm{mM}$ Tris- $\mathrm{HCl}$ pH8.5 con $0.1 \%$ Tween20, sometidas a una celda de flujo Illumina para la generación de clusters mediante el kit TrueSeq SR Cluster Kit V2 cBot (Illumina, EEUU) y secuenciadas por síntesis. Se generaron lecturas únicas de $75 \mathrm{pb}$ mediante el kit TruSeq SBS v5 (Illumina, EEUU) en una plataforma de análisis genómico IIx siguiendo un protocolo estándar de secuenciación de RNA. Las lecturas se procesaron posteriormente mediante el paquete CASAVA (Illumina, EEUU) para separarlas según los índices de los adaptadores y generar los archivos fastq.

Las lecturas fueron preprocesadas con Cutadapt v1.3 (Martin, 2011) para eliminar restos de adaptadores de Illumina y descartar las secuencias menores de 30 nucleótidos. En el caso de las librerías amplificadas con Ovation, se eliminaron, además, los primeros 8 nucleótidos con fastx_trimmer (http://hannonlab.cshl.edu/fastx toolkit). La calidad de las lecturas fue monitorizada con FastQC (Andrews, 2010) antes y después del preprocesamiento. El conjunto de lecturas resultante se mapeó contra el transcriptoma de ratón correspondiente a la versión 76 de Ensembl (GRCm38), y se cuantificó la expresión a nivel de gen mediante RSEM v1.2. (Li and Dewey, 2011). Los valores de expresión crudos así obtenidos se procesaron mediante el paquete de Bioconductor Limma (Ritchie et al, 2015) para su normalización, mediante el método TMM, y el análisis de expresión diferencial, utilizando una variable aleatoria para definir bloques de muestras con el mismo origen. Para el análisis de expresión diferencial sólo se tuvieron en cuenta aquellos genes expresados a un nivel mínimo de 1 cuenta 
por millón en al menos dos muestras. Se consideraron significativos aquellos cambios de expresión asociados a un p-valor ajustado por el método Benjamini-Hochberg menor a 0.05

\subsection{AnÁlisis de los Genes Diferencialmente Expresados}

Para el análisis empleamos la conversión de datos a FPKM (fragmentos por kilobase de exón por millón de lecturas mapeadas) como una forma de normalizar los valores por el número total de lecturas en la muestra y por la longitud del gen. Para las comparaciones de genes diferencialmente expresados entre dos condiciones diferentes, tenemos en cuenta los valores del logFC (Fold $\underline{C}$ hange) y el p value ajustado (adj p. value).

Las principales comparaciones que se llevaron a cabo fueron la expresión de genes entre endocardio ventricular y plexo coronario en cada estadio (E13.5 y E17.5); el cambio de expresión entre los genes del plexo coronario de E13.5 a E17.5; y los genes diferencialmente expresados a E17.5 entre endocardio, plexo subepicardico (enriquecido en venas) y plexo intramiocárdico (enriquecido en arterias y capilares).

El HeatMap muestra diferentes clusters en los que se agrupan los genes diferencialmente expresados en función del patrón de expresión. Adicionalmente se muestran GO plots circulares de categorías de genes concretos, así como volcano plot. Las ontologías de cada cluster se analizaron por DAVID 6.8. Los términos enriquecidos se filtraron aplicando un umbral al p-valor de 0.01 .

\section{Cultivos Celulares}

\subsection{Mantenimiento de Líneas Celulares In Vitro}

Se han utilizado células comerciales inmortalizadas de la microvasculatura coronaria de ratones neonatales denominadas MCEC (Mouse Cardiac Endothelial Cells, CLU510, Cedarlane/CELLutions Biosystems) (Barbieri and Weksler, 2007). Se cultivaban en placas cubiertas de gelatina al $0.2 \%$ con medio DMEM (ㅁulbecco's Modified Eagle Medium, ThermoFisher, EEUU) suplementado con $10 \mathrm{mM}$ Penicilina/Estreptomicina (15140122, ThermoFisher, EEUU), $10 \mathrm{mmol} / \mathrm{L}$ HEPES (7365-45-9, Merck, EEUU)y 5\% suero fetal bovino (631106, Takara, EEUU). Los pases de las células se realizaban cada 3-4 días, haciendo diluciones $1 / 10$. Para ello se retiraba el medio de cultivo, se lavaban las células dos veces con buffer PBS, se tripsinizaban durante 5 minutos con Tripsina-EDTA (25200072, ThermoFisher, EEUU) y se neutralizaban con medio fresco de cultivo. Las centrifugaciones se llevaban a cabo a temperatura ambiente durante 5 minutos a $500 \times \mathrm{g}$. Para las congelaciones, el pellet de células se resuspendía en $90 \%$ de suero fetal bovino y $10 \%$ de DMSO (67-68-5, Merck, EEUU). 


\subsection{TRANSFECCIONES}

Las transfecciones se realizaron con el reactivo FuGENE HD Transfection Reagent (E2311, Promega, España) siguiendo las instrucciones del fabricante. Para ello, las células se sembraban un día antes a una confluencia aproximada del $70 \%$ en medio de cultivo sin antibióticos. Las cantidades de reactivo de transfección y de ADN a transfectar dependían del diámetro de las placas usadas en cada experimento. Al día siguiente se retiraba el medio y se cambiaba por medio de cultivo fresco con antibióticos.

\subsection{Líneas y Clones Celulares Generados}

Las células MCEC se transfectaron de forma independiente con los plásmidos pSBtet_BH_Sox17 y pSBtet_BH_Sox18, ambos en combinación con el plásmido de la transposasa pCMV(CAT)T7-SB100 para que la célula los integrase. Tras una semana con selección de $500 \mathrm{ng} / \mathrm{mL}$ higromicina B (10687010, ThermoFisher, EEUU), sobrevivieron únicamente aquellas células que habían integrado el transposón en su genoma, lo que les confería resistencia al antibiótico. Adicionalmente, se transfectaron MCEC con la combinación de plásmidos pSBtet_BH_Sox17, pi2_full_Tomato_pA y pCMV(CAT)T7-SB100. Una vez generadas las líneas MCEC_Sox17, MCEC_Sox18 y MCEC_Sox17_i2E_Tomato, se sortearon por citometría de flujo células individuales en placas de 96 pocillos y se expandieron cada uno de los clones para luego comprobar por RT-PCR que expresaban el gen de interés cuando se inducían con doxiciclina, de forma que nos quedamos con un único clon de cada una de las construcciones (Tabla 16).

\begin{tabular}{lcc}
\multicolumn{2}{c}{ Tabla 16. Líneas Celulares Generadas } & Reporteros \\
Nombre & Descripción & No \\
\hline \hline MCEC & Mouse Cardiac Endothelial Cells (comercial) & BFP \\
MCEC_Sox17 clon\#2 & MCEC con SB integrado para expresión de Sox17 & BFP \\
MCEC_Sox17 clon\#3 & inducible por Dox & BCEC con SB integrado para expresión de Sox18 \\
MCEC_Sox18 clon\#2 & inducible por Dox & BFP \\
MCEC_Sox18 clon\#8 & BFP \\
MCEC_Sox17_i2E_Tom* clon\#2 & SB integrado para expresión de Sox17 inducible & BFP/Tomato* \\
MCEC_Sox17_i2E_Tom* clon\#5 & por Dox y secuencia i2E 5' de Tomato & BFP/Tomato* \\
MCEC_Sox17_i2E_Tom clon\#56 & & BFP/Tomato \\
\hline \hline
\end{tabular}

* Expresión constitutiva de Tomato

\subsection{EnSAYOS DE REPORTERO LUCIFERASA}

Para los ensayos de luciferasa, las células MCEC se sembraron en placas de 24 pocillos a una densidad del $60-70 \%$ en medio completo sin antibióticos. A las $24 \mathrm{~h}$ se transfectaron con los plásmidos correspondientes empleando el reactivo de transfección FuGENE. De forma 
general se transfectaron 300-400 ng de la construcción con la Gaussia Luciferasa, 5 veces menos con del plásmido SEAP que contiene la luciferasa control y $300 \mathrm{ng}$ de los plásmidos Sox17 o Sox18.

Una vez realizada la transfección, se dejaban las placas en el incubador durante 48 horas. Transcurrido ese tiempo, se tomaban $100 \mu$ l de cada pocillo en un tubo eppendorf para realizar las medidas de las diferentes luciferasas. En el caso de no poder realizar las cuantificaciones el mismo día, los sobrenadantes podían mantenerse congelados a $-20^{\circ} \mathrm{C}$.

La cuantificación de la Gaussia luciferasa clonada 3' de los diferentes fragmentos del i2E (Tabla 12) se realizó empleando el BioLux Gaussia Luciferase Assay Kit (E3300S, New England Biolabs, EEUU), siguiendo las instrucciones del fabricante. Por su parte, la cuantificación de la fosfatasa alcalina secretada (SEAP) se realizó con Phospha-Light ${ }^{T M}$ System (T1015, ThermoFischer, EEUU). Para ello se empleaban placas de 96 pocillos en las que se llenaban dos pocillos de sobrenadante por cada una de las muestras transfectadas, para poder medir en paralelo ambas luciferasas.

Todas las medidas fueron tomadas con el luminómetro de placas (Orion microplate luminometer). Para el análisis de los datos, cada muestra se normalizó dividiendo el valor de la Gaussia Luciferasa entre el valor de SEAP. A su vez, los valores de las muestras hGluc (MCEC transfectadas con el plásmido de la Gaussia Luciferesa sin haber clonado ningún enhancer) se normalizaron a 1 , y los valores del resto de medidas se dividieron entre la media de los valores de hGluc.

\subsection{Ensayos de Angiogénesis con Explantes de Corazón In Vitro}

Los embriones empleados eran triples transgénicos Nes-Gfp; Nes-CreER ${ }^{T 2}$; R26-Tomato en los que se le administraba el tamoxifeno vía oral a las madres cuando estaban en el día de gestación E12.5 y se extraían entre 24-48 horas más tarde. Tanto la extracción del útero como las posteriores disecciones debían realizarse en condiciones de esterilidad, por lo que la extracción de los embriones en el animalario se realizaba tras rociar todo el material de cirugía así como las ratonas gestantes con etanol $70 \%$, y las posteriores disecciones se realizaron en las campanas de flujo laminar de cultivos celulares.

Se diseccionaban los ápex de los corazones para incluirlo en un sándwich de colágeno. Para ello se preparaba la cantidad necesaria de colágeno (A1048301, ThermoFisher, EEUU) a una concentración final de $1.5-2 \mathrm{mg} / \mathrm{mL}$ (colágeno $3 \mathrm{mg} / \mathrm{mL}$, PBS10X, VEGF-A $\mathrm{A}_{165} 10 \mathrm{ng} / \mathrm{mL}$, $\mathrm{NaOH} 1 \mathrm{M}$, agua destilada) y se mantenía en hielo todo el tiempo para evitar la solidificación a temperatura ambiente. El medio de cultivo empleado era el 199 (21157029, ThermoFischer, EEUU) suplementado con $2 \%$ FBS y $10 \mathrm{ng} / \mathrm{mL}$ VEGF- $\mathrm{A}_{165}$.

Se ponía una base de colágeno en el pocillo y se dejaba solidificar en el incubador a $37^{\circ} \mathrm{C}$ durante $30 \mathrm{~min}$. Posteriormente se colocaban los ápex de corazones y se cubrían con más colágeno que se volvía a dejar solidificando en el incubador. Una vez transcurridos otros 
$30 \mathrm{~min}$, se añadía el medio de cultivo y las placas se cultivaban en una cámara de hipoxia a $3 \%$ de $\mathrm{O}_{2}$ y $5 \%$ de $\mathrm{CO}_{2}$ durante una semana. Una vez crecidos los explantes, se fijaban y teñían con DAPI para adquirir la fluorescencia endógena y el marcador de núcleos en el microscopio confocal.

\section{1ํㅡㄹ EAyo de CAMbio en Movilidad Electroforética (EMSA)}

\subsection{Preparación de Extractos Nucleares de Proteínas}

Las células MCEC_Sox17 \#2 se crecieron durante varios días en placas de 100x21mm. En una de ellas se añadió doxiciclina $(10 \mu \mathrm{g} / \mathrm{mL})$ para sobreexpresar la proteína Sox17 y en la otra (control) sin doxiciclina. Una vez confluentes, las células se recogieron y se extrajeron los extractos nucleares de proteínas siguiendo el protocolo descrito por Smith y Delbary-Gossart (Smith and Delbary-Gossart, 2001). Los extractos de alicuotaron y congelaron a $-80^{\circ} \mathrm{C}$ hasta su uso en los ensayos.

\subsection{ENSAYo DE EMSA}

Para nuestros ensayos de EMSA usábamos oligonucleótidos marcados con iRDye 700/800, por lo que empleamos el protocolo de la casa comercial Odyssey Infrared Imaging System. Brevemente, cada reacción se realizó con la cantidad de extracto nuclear de proteínas y oligos deseados en un volumen final de $20 \mu \mathrm{l}$ con Buffer 10x $(100 \mathrm{mM}$ Tris, $450 \mathrm{mM} \mathrm{KCl}, 50 \mathrm{mM} \mathrm{NaCl}$, $10 \mathrm{mM}$ DTT; $\mathrm{pH} 7.5) ; 1 \mathrm{\mu g} / \mu \mathrm{l}$ Poly(dI·dC) en $10 \mathrm{mM}$ Tris, $1 \mathrm{mM}$ EDTA; $\mathrm{pH} 7.5 ; 25 \mathrm{mM}$ DTT/2.5\% Tween20 y agua.

Las muestras se corrieron en geles nativos al 6\% de acrilamida/bisacrilamida (ratio 29:1) con $50 \mathrm{mM}$ Tris- $\mathrm{HCl}$ pH 7.5, $0.38 \mathrm{M}$ glicina y $2 \mathrm{mM}$ EDTA pH 8.0. Las electroforesis fueron llevadas a cabo a $100 \mathrm{~V}$ en la cámara fría con oscuridad, precorriendo inicialmente los geles durante media hora.

En la tabla 17 se detalla la información de los oligos empleados. Los oligos diseñados con las regiones CR1 y CR2 del i2E fueron marcados con IRDye700/IRDye800, respectivamente. En cada reacción se usaban a una concentración de $100 \mathrm{fmol} / \mu \mathrm{l}$. Por su parte, los oligos sin marcar WT y mutantes se añadían 100 veces más concentrados. Las reacciones de hibridación de las cadenas directa/reversa se realizó mezclando cantidades equimolares e incubándolas 3 min a $100^{\circ} \mathrm{C}$ y luego dejándolas enfriar hasta llegar a temperatura ambiente. 


\begin{tabular}{ll} 
& Tabla 17. Oligos para EMSA \\
\hline Nombre & Secuencia 5" => 3" \\
\hline \hline iRDye700 CR1 Fw & AATTCATTTGCTTTTGTCTGTTACCAGCTC \\
iRDye700 CR1 Rev & GAGCTGGTAACAGACAAAAGCAAATGAATT \\
CR1_WT Fw & AATTCATTTGCTTTTGTCTGTTACCAGCTC \\
CR1_WT Rev & GAGCTGGTAACAGACAAAAGCAAATGAATT \\
CR1_MUT Fw & AATTCATTTGCTagcacgTGTTACCAGCTC \\
CR1_MUT Rev & GAGCTGGTAACAcgtgctAGCAAATGAATT \\
iRDye800 CR2 Fw & GGTAGTGTGGACAAAAGGCAATAATTAGCA \\
iRDye800 CR2 Rev & TGCTAATTATTGCCTTTTGTCCACACTACC \\
CR2_WT Fw & GGTAGTGTGGACAAAAGGCAATAATTAGCA \\
CR2_WT Rev & TGCTAATTATTGCCTTTTGTCCACACTACC \\
CR2_MUT Fw & GGTAGTGTGCgtgctAGGCAATAATTAGCA \\
CR2_MUT Rev & TGCTAATTATTGCCTagcacgCACACTACC \\
\hline \hline
\end{tabular}

\section{$12^{\circ}$ Transient Transgenics}

La microinyección pronuclear de las construcciones en zigotos de la línea Nes-Gfp fue realizada por la Unidad de Transgénesis del CNIC. Brevemente, las hembras C57BL/6JCrl prepúberes (4 semanas) fueron hormonadas con 5UI de PMSG (pregnant mare's serum gonadotropin) y con 5UI de hGC (gonadotropina coriónica) 48 horas post-PMSG y puestas en cruce con los machos Nes-GFP+. La mañana del tapón $(0.5 \mathrm{dpc})$, se recogieron los zigotos y se microinyectaron con la mezcla de transposón linearizado $(0.8-4 \mathrm{ng} / \mu \mathrm{l})$ y $A R N m$ de la transposasa $(5 \mathrm{ng} / \mu \mathrm{l})$ correspondientes. Al día siguiente, los embriones que se encuentran en estadio de dos células (1.5 dpc) son transferidos a hembras pseudogestantes Crl:CD1(ICR). Una vez que los zigotos pasaban a dos células, se transferían a hembras pseudogestantes CD1. Los embriones se extrajeron a E14.5.

\subsection{PREPARACIÓN DE LOS TRANSPOSONES Y LA TRANSPOSASA}

Se precipitaron $5 \mu \mathrm{g}$ del transposón (pSB(T2)-i2full_TK_Tomato_pA) y de la transposasa (pCMV (CAT)T7-SB100) con fenol/cloroformo siguiendo el protocolo descrito por Ivics y colaboradores (Ivics et al., 2014). Para la obtención del ARNm de la transposasa, se linearizaron $2 \mu \mathrm{g}$ de plásmido y se empleó el mMessage mMachine T7 kit (AM1344, ThermoFisher, EEUU) para la retrotranscripción in vitro.

\section{Producción de Lentivirus e Infección}

\subsection{Producción Y Titulado Lentiviral}

Se produjeron lentivirus con las construcciones Lenti_Control_iRFP y Lenti_RaOp_iRFP descritas en la Tabla 12. La producción fue llevada a cabo por la Unidad de Vectores Virales del 
CNIC. Brevemente, el plásmido con la construccion de interés, el plásmido psPAX2 (expresa Gag y Pol, que codifican para las proteínas de la cápside y la retrotranscripción, respectivamente) y el plásmido pMD2.G (proteínas de empaquetamiento) se transformaron en células HEK293T. Tras 48h de cultivo, se recogieron y centrifugaron los medios celulares y el sobrenadante se filtró para posteriormente concentrar las partículas virales, que se resuspendieron en PBS frío y almacenaron a $-80^{\circ} \mathrm{C}$.

La titulación de los lentivirus producidos se realizó por citometría analítica (FACS) ya que nuestras construcciones expresaban la proteína fluorescente iRFP. Para ello se sembraron células HEK293T y transdujeron con diluciones seriadas de las partículas lentivirales. Tras 48h, las células se analizaron por FACS y se calculó el título viral (PV/mL) con la siguiente fórmula:

$$
\text { Título }=\frac{\% \text { células positivas } * n^{\text {o }} \text { células sembradas }}{\text { dilución }}
$$

\subsection{Infección De Explantes De Corazón In Vitro}

Los explantes infectados con lentivirus se realizaron de la misma forma que se explica en el apartado 10.4., con la diferencia de que la mezcla de colágeno contenía los virus (control y RaOp, respectivamente). De esta forma, se generaba la primera capa de colágeno normal, se dejaba solidificar, y cuando se ponían los ápex de corazón sobre ella, el colágeno que se añadía encima ya contenía los lentivirus.

\section{4o AnÁlisis Estadísticos}

Los análisis estadísticos se realizaron con el test-t de Student usando el programa inGraph Pad (Prism versión 5.0a). Los valores se representaron como media \pm SEM. Las diferencias se consideraron significativas cuando $p$ valor $<0.05$. 


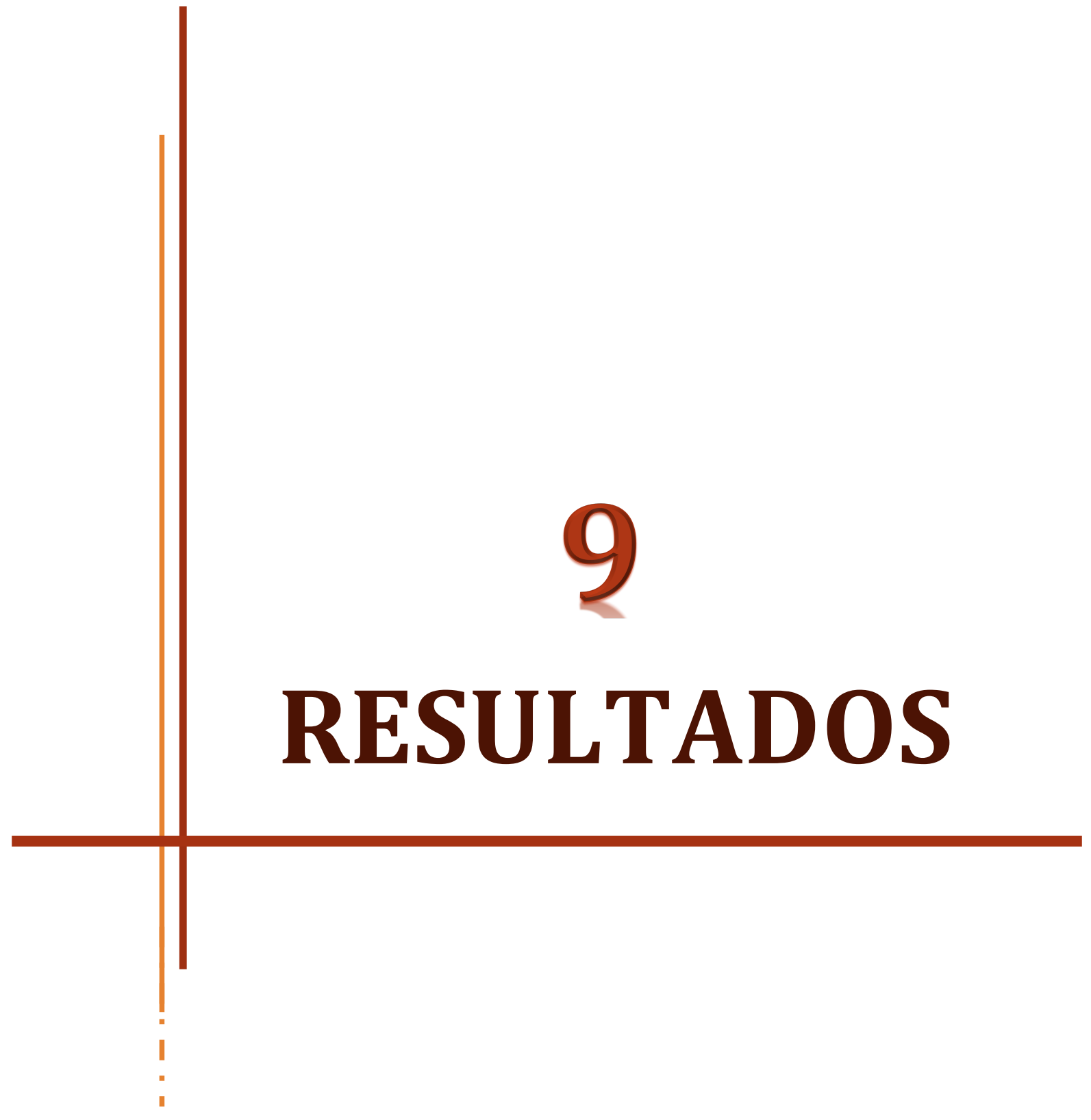





\section{Caracterización Del Alelo Nestin-GFP En El Desarrollo Cardíaco De Ratón}

Durante el desarrollo del corazón embrionario, las células que se delaminan del epicardio y sufren la transición epitelio-mesenquimal dan lugar a EPDCs. Estas células invaden la matriz subepicárdica y migran hacia el miocardio, constituyendo una de las principales fuentes de la población mesenquimal cardíaca. Los tipos celulares en los que se diferencian principalmente son fibroblastos intersticiales, células de músculo liso vascular y fibroblastos adventicios que sustentan la vasculatura coronaria (Gittenberger-de Groot et al., 2010, von Gise and Pu, 2012). También se conoce que una pequeña población de éstas células se diferencia a endotelio coronario (Katz et al., 2012). Pero las EPDCs procedentes del epicardio no son la única fuente de células mesenquimales durante el desarrollo del corazón.

En los estadios más tempranos de la cardiogénesis, las células progenitoras de la cresta neural cardíaca (también conocidas como CNCCs, Cardiac Neural Crest Cells) se delaminan del tubo neural, sufren TEM y migran hacia el corazón siguiendo señales quimotácticas. Tras atravesar los arcos faríngeos 3,4 y 6, llegan al tracto de salida del corazón (OFT), donde constituirán una población de células mesenquimales necesarias para la correcta formación de las válvulas cardíacas y la septación del OFT, que debe separarse en las arterias aórtica y pulmonar (Maschhoff and Baldwin, 2001, Snider et al., 2009). También existe una contribución de la cresta neural preótica a las poblaciones de músculo liso vascular de las arterias coronarias (Arima et al., 2012).

El hecho de que las células mesenquimales procedentes de epicardio y del tubo neural tengan orígenes embrionarios diferentes (mesodermo y ectodermo, respectivamente) ha sugerido que estas dos poblaciones presentes en el corazón en desarrollo tengan funciones distintas (Kirby, 1999, Kirby, 2002, Huston and Kirby, 2003). Para tratar de diferenciar ambas poblaciones residentes en el órgano, decidimos emplear la línea transgénica Nes-Gfp (Mignone et al., 2004), ya que al haber sido generada principalmente como una herramienta para el marcaje de células progenitoras neurales, pensamos que nos serviría para seguir específicamente a la población mesenquimal procedente de la cresta neural cardíaca.

\subsection{El alelo Nestin-Gfp marca de forma dinámica distintas poblaciones cardíacas, entre las que se encuentran las células mesenquimales y la vasculatura coronaria en formación}

En primer lugar comenzamos por caracterizar las poblaciones de células Nes-GFP+ presentes en el corazón durante los diferentes estadios del desarrollo embrionario y posnatal temprano. Para ello empleamos principalmente las técnicas de inmunofluorescencia para la adquisición con microscopía confocal y la citometría de flujo para realizar un análisis más cuantitativo. 
Las CNCCs comienzan a migrar hacia el corazón a E8.5, alcanzando el tracto de salida a E10.5. En la Figura 7 podemos observar embriones Nes-GFP+ en los estadios E10.5 y E12.5, donde se aprecia que la zona del OFT es completamente positiva para la GFP (Figura 7A). El panel de la derecha muestra una ampliación del OFT donde se observa la septación en la aorta y el tronco pulmonar a E12.5. En el panel de abajo (Figura 7B), secciones de corazón a E10.5 muestran que la población de células Nes-GFP+ a ese estadio se concentran principalmente en la zona del OFT, existiendo alguna colocalización con el marcador endotelial $\mathrm{ISO}_{\mathrm{B} 4}$.
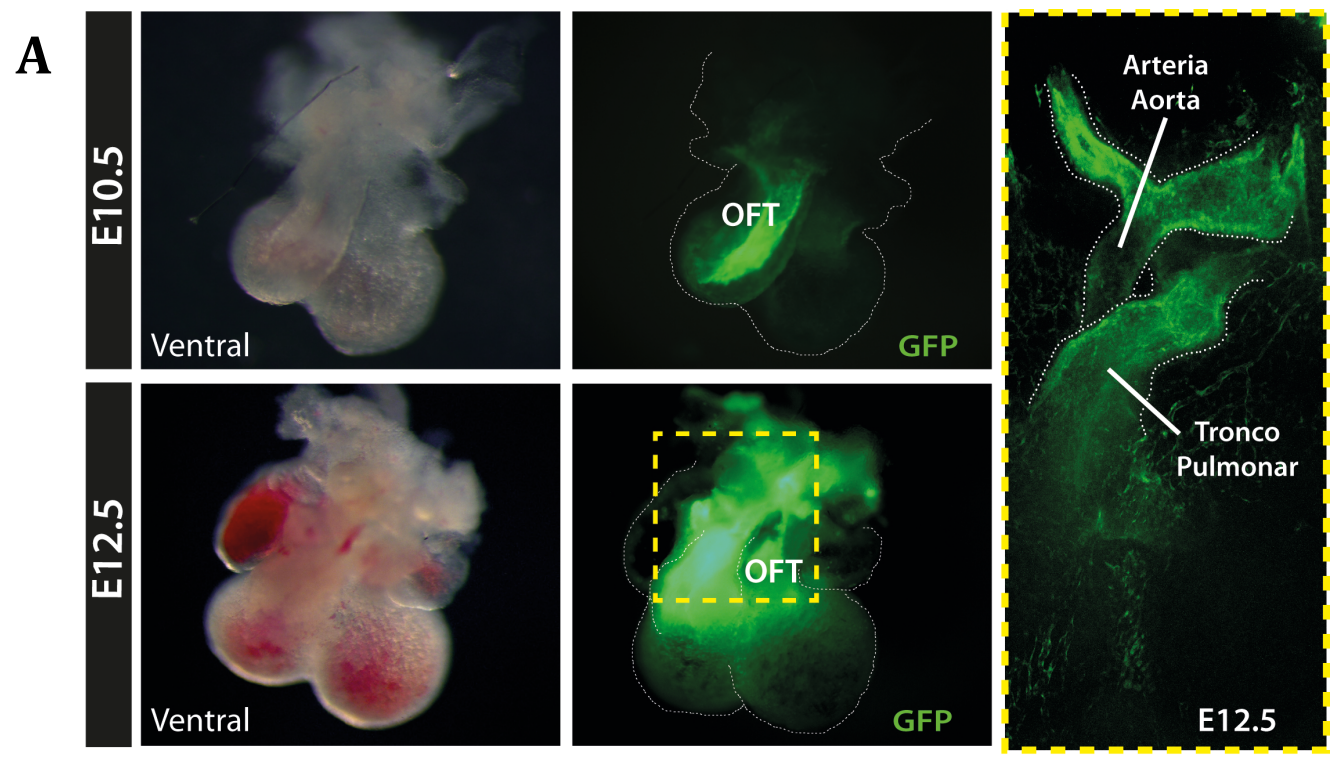

B
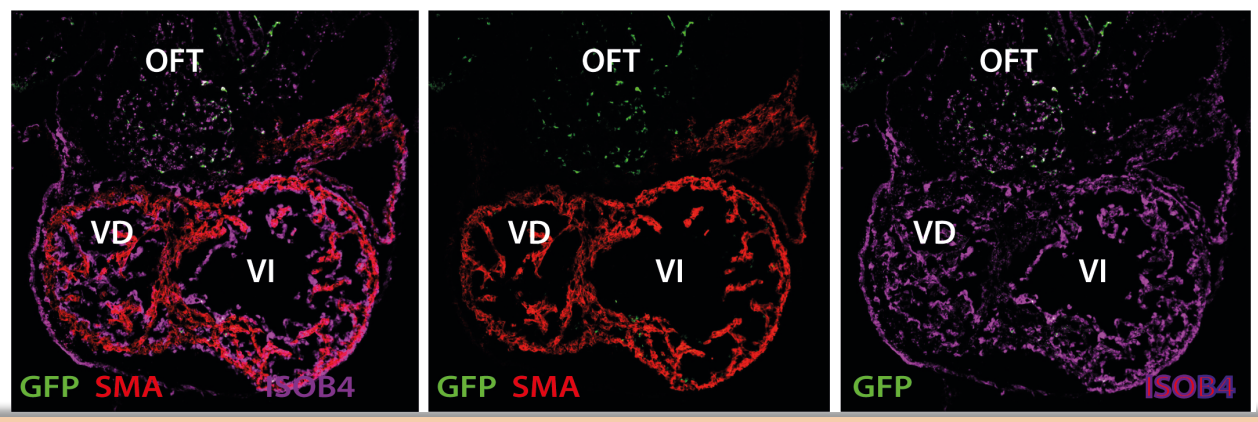

Figura 7. Corazones Nes-Gfp a E10.5 y E12.5. (A) Corazones a la lupa en campo claro y en el canal GFP. A la derecha, ampliación del tracto de salida (OFT) completamente septado en las arterias aórtica y tronco pulmonar a E12.5. (B) Inmunofluorescencia realizada en secciones de OCT a E10.5. Se usan los marcadores SMA (Ś

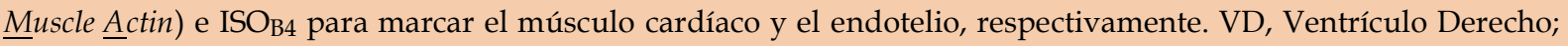
VI, Ventrículo Izquierdo.

Para el análisis por citometría de flujo, los corazones Nes-GFP+ fueron digeridos con liberasa a diferentes estadios embrionarios y teñidos con los correspondientes cócteles de anticuerpos. Debido al procedimiento llevado a cabo de disgregación de células, así como las condiciones empleadas para la adquisición por el FACS (Fluorescence-Activated Cell Sorting), perdemos la población de cardiomiocitos presentes en la muestra, por lo que nuestros análisis están enriquecidos principalmente en las poblaciones de células cardíacas no miocíticas. 
Empleamos los marcadores DAPI, Ter119 y CD45 para descartar las células no viables y el linaje hematopoyético (incluyendo eritrocitos). Una vez excluidas estas células, con el anticuerpo CD31 identificamos las células endoteliales. Para la población mesenquimal inicialmente usábamos el anticuerpo CD90, sin embargo recientemente se demostró que era un marcador subóptimo para identificar la población residente de fibroblastos cardíacos, por lo que comenzamos a usar el antígeno MESK4 al ser descrito que presentaba mayor especificidad para esta población tan heterogénea (Pinto et al., 2016).

En la Figura 8A podemos observar un ejemplo de análisis por FACS en corazones NesGFP+ a E17.5. Dentro de las células GFP+, el $65 \%$ de la población es mesenquimal (MESK4+), mientras que alrededor del 30\% es endotelial (CD31+).

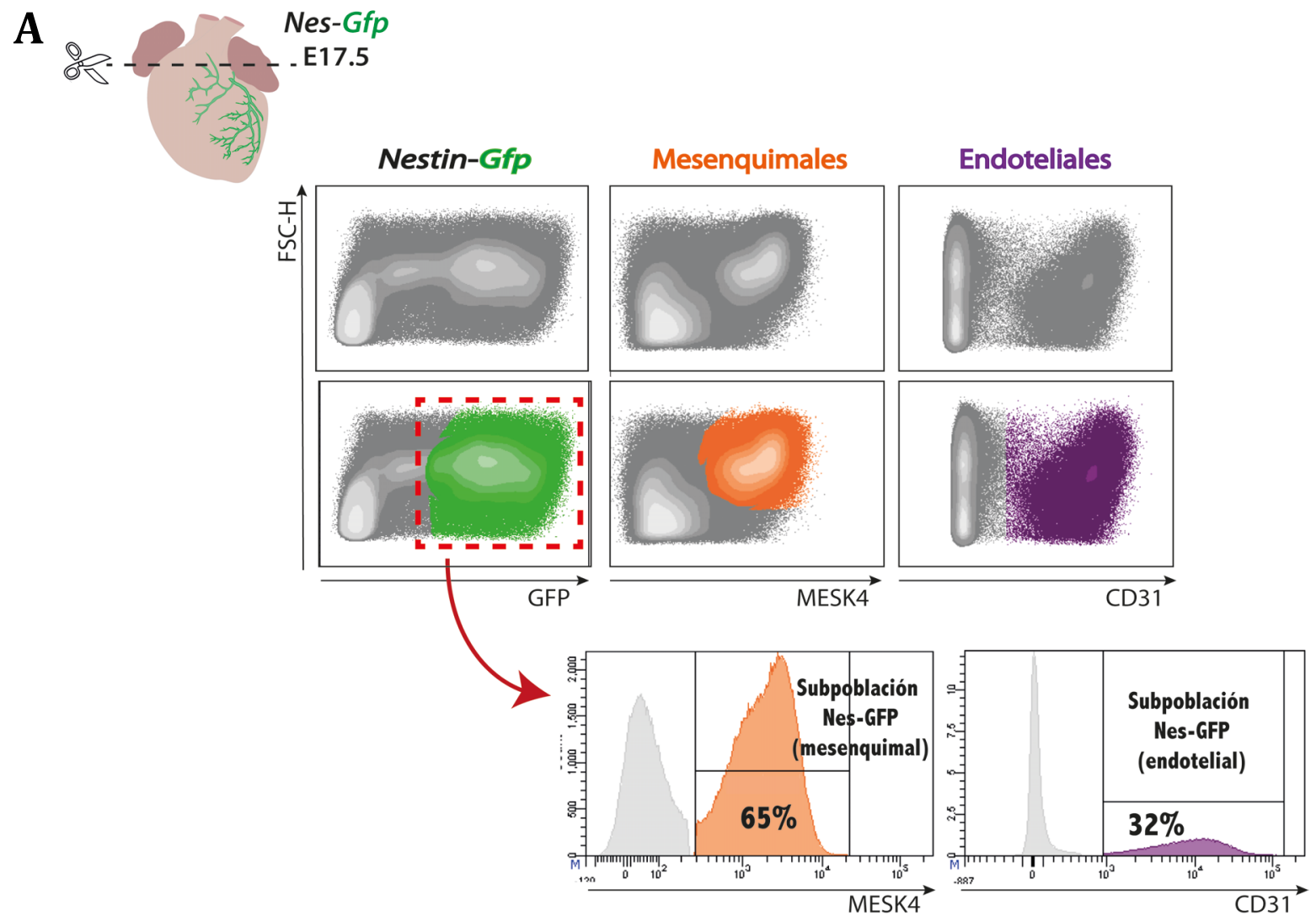

B

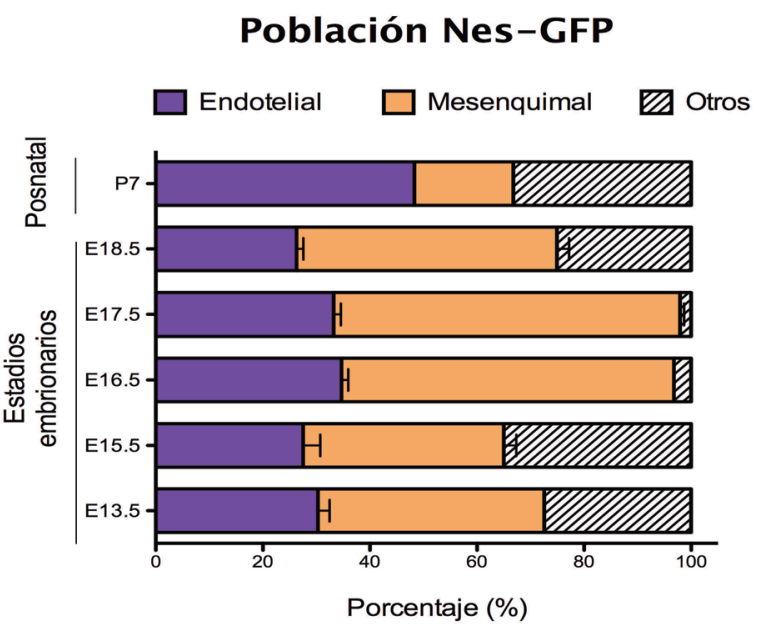

Figura 8. Citometría analítica (FACS) en corazones Nes-Gfp en desarrollo. (A) Se muestra como ejemplo el análisis en el estadio E17.5. La población analizada es DAPI- Ter119CD45-. Se emplean los marcadores MESK4 y CD31 para separar las poblaciones mesenquimal y endotelial, respectivamente. Dentro de la población GFP+, se analizan las subpoblaciones mesenquimal (65\%) y endotelial (32\%) positivas para el alelo Nes-Gfp. (B) Gráfica representando las contribuciones de mesenquimales y endotelio en la población GFP+ a lo largo del desarrollo embrionario y posnatal. 
Como se puede apreciar, la población mesenquimal constituye la mayor parte de las células Nes-GFP+, variando entre 30-60\% en los corazones embrionarios, y reduciéndose a un 20\% durante la primera semana posnatal (Figura 8B). Para tratar de elucidar si esta abundante subpoblación GFP+ se correspondía con derivados procedentes de la cresta neural cardíaca o del epicardio, y aprovechando las líneas transgénicas presentes en el laboratorio, realizamos un marcaje genético con ratones que contenían los alelos Wt1-Cre; R26-Tomato; Nes-Gfp.

Mediante el driver Wt1-Cre (que contiene elementos reguladores del gen Wilm's Tumour 1), se marcan principalmente los linajes mesoteliales y en el corazón las células epicárdicas (Pérez-Pomares et al., 2002, Simões and Riley, 2018). Los cruces llevados a cabo se realizaban con machos que portaban la Cre, mientras que las hembras empleadas eran doble homocigotas para R26-Tomato y Nes-Gfp. Por ese motivo, todos los embriones resultantes serían Nes-GFP+ y sólo en aquellas células donde Wt1 estuviera expresado o el linaje de células que lo hubiesen expresado en algún momento del desarrollo, serían Tomato+. Así, lo que pretendíamos ver era si las células mesenquimales GFP+ eran a su vez positivas para Tomato. De serlo, sugeriría que serían EPDCs procedentes de epicardio, mientras que las mesenquimales GFP+ Tomatodeberían tener otro origen.
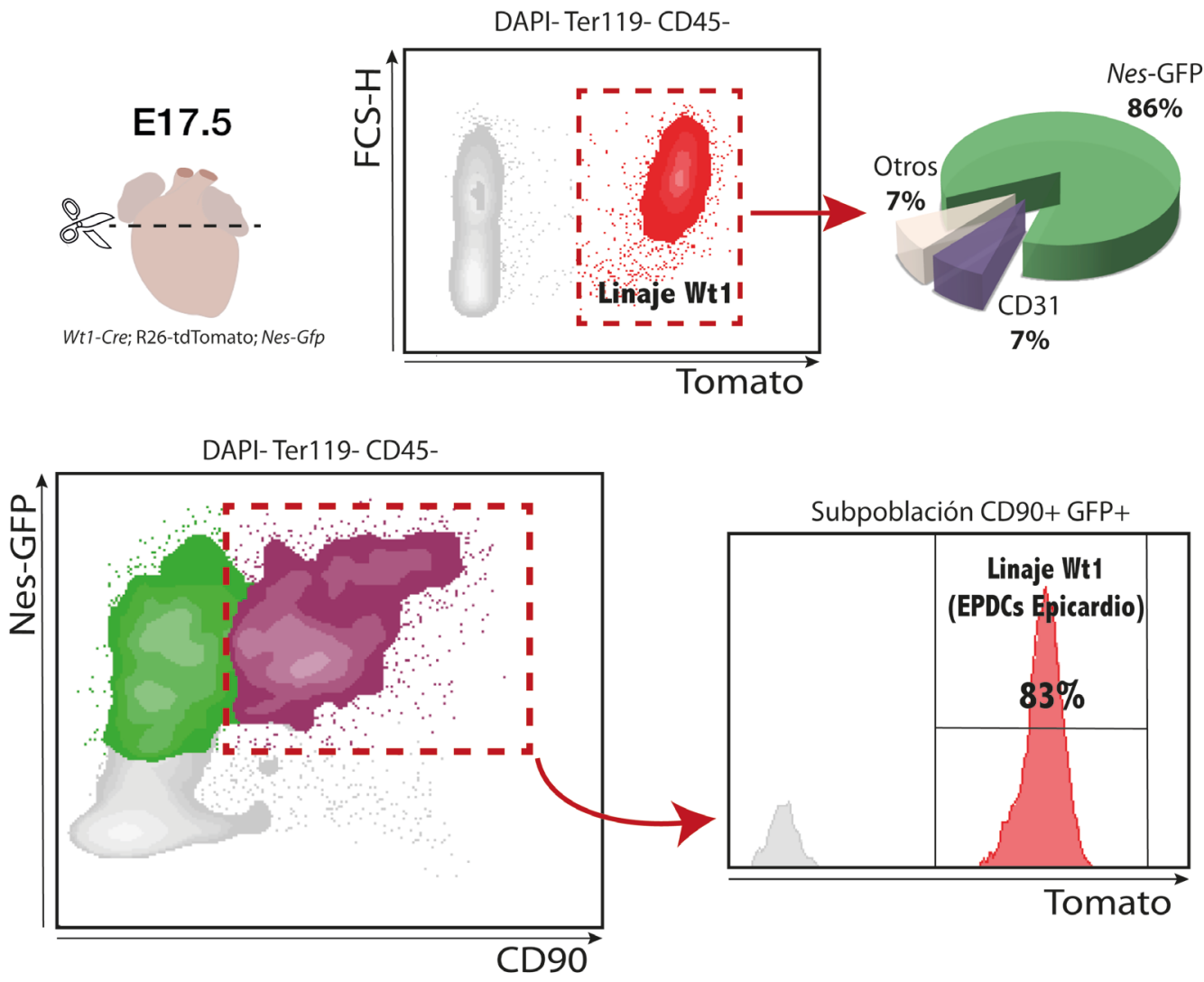

Figura 9. Análisis por FACS del linaje $W t 1$ en corazones Nes-Gfp a E17.5. El panel superior muestra que la mayor parte de células Tomato+ (linaje $W t 1)$ son a su vez positivas para GFP. En el panel inferior, la población de Nes-Gfp mesenquimal (CD90+GFP+) procede de EPDCs derivadas de epicardio. 
Los embriones triple transgénicos se sacaron en el estadio E17.5 y analizamos sus corazones por FACS y microscopía confocal. En la Figura 9 podemos observar que dentro del linaje Wt1 (Tomato+) la inmensa mayoría de las células eran a su vez Nes-GFP+ (86\%). Tan sólo un 7\% era endotelial (CD31+) y otro 7\% no se detectaba con los anticuerpos empleados. Si nos centramos en la población Nes-Gfp mesenquimal (doble positivas para GFP y CD90), observamos que el $83 \%$ de estas células son Tomato+, indicando que la mayor parte de EPDCs marcadas con el alelo Nestin-Gfp proceden del linaje Wt1.

En la Figura 10 se muestra uno de estos corazones triple transgénicos a E17.5. En el panel de la izquierda, el corazón ha sido escaneado bajo la lupa en el canal Tomato. En el centro, tenemos un corte longitudinal mostrando las células Tomato+. En el panel de la derecha el corazón clarificado mediante CUBIC fue escaneado por completo con el microscopio confocal y lo que vemos es una sección óptica de varios Z-stack internos donde apreciamos los canales Tomato y GFP juntos. Debajo de estos paneles se puede apreciar una ampliación de una zona de plexo vascular donde aparece una arteria coronaria. Todo el endotelio de la arteria es Nes-

\section{Wt1-Cre; Rosa26-Tomato; Nes-gfp}
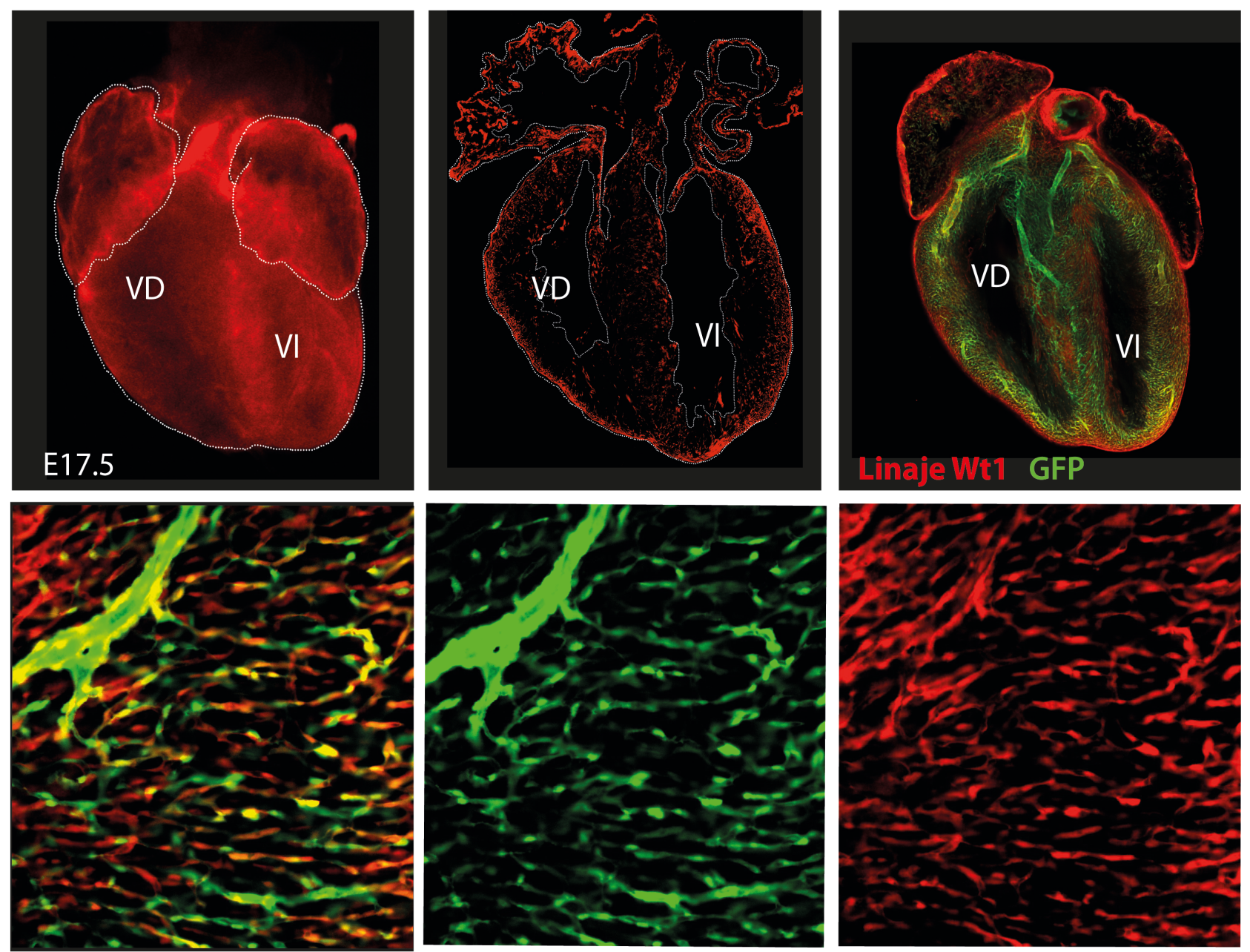

Figura 10. Corazón triple transgénico Wt1-Cre; R26-Tomato; Nes-Gfp a E17.5. El panel superior muestra el órgano completo escaneado a la lupa, en secciones, y una sección óptica del microscopio confocal. En el panel de abajo se amplifica la microvasculatura para ver el recubrimiento del vaso de mayor calibre con músculo liso y pericitos procedentes del linaje Wt1. 
GFP+, al igual que la capa de músculo liso vascular que la cubre y los pericitos asociados al vaso, que a su vez colocalizan con el canal Tomato por ser linaje Wt1.

La información aportada por la citometría de flujo se acompaña con tinciones de inmunofluorescencia realizadas en criosecciones de corazones Nes-GFP+. En la Figura 11 se muestra un vaso sanguíneo en corazón neonatal (P1) marcado con ISO $_{\mathrm{B} 4}$. Todas las células endoteliales son GFP+, pero a su vez los pericitos asociados al endotelio, detectados con antiNG2 (Neural/GGlial antigen 2) también son GFP+. Así, a diferencia de lo que se pensaba en un inicio, el alelo Nes-Gfp no sólo se encuentra activo en células progenitoras procedentes del tubo neural. También observamos entre la población GFP+ una importante subpoblación de células endoteliales, constituyendo aproximadamente un 30-35\% en los estadios embrionarios, y hasta un $50 \%$ en los estadios posnatales tempranos (Figura 8B).
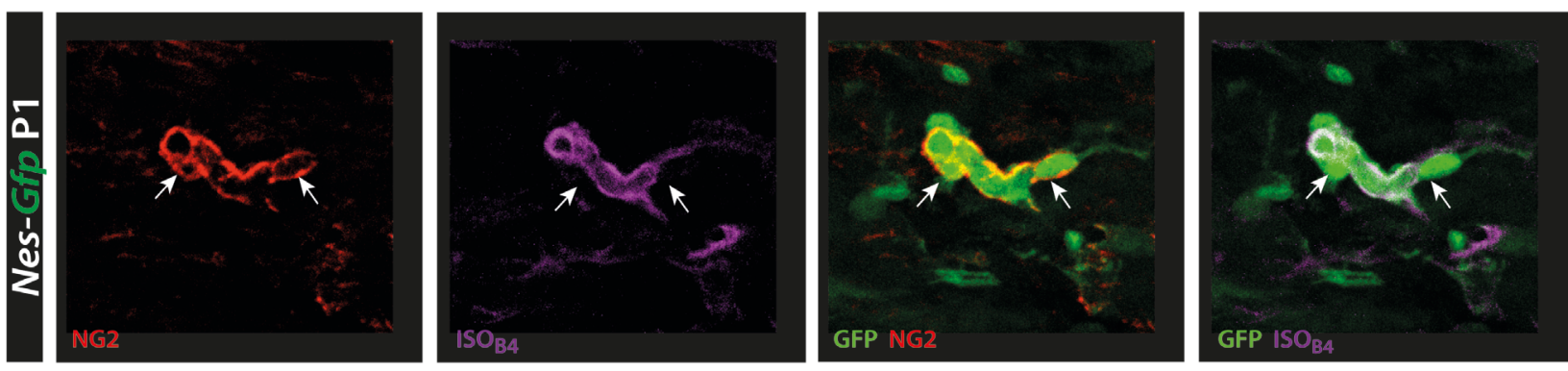

Figura 11. Inmunofluorescencia en corazón Nes-Gfp a P1. Se muestran una ampliación de un vaso sanguíneo donde la capa de endotelio está marcada con $\mathrm{ISO}_{\mathrm{B} 4}$ y los pericitos asociados al vaso se detectan con NG2. Ambas poblaciones son a su vez positivas para Nes-Gfp.

\subsection{Las células Nes-GFP+ son una fuente de $\mathrm{Cxcl12}$, una quimoquina esencial para el}

\section{correcto desarrollo del órgano cardíaco}

Estudios previos habían demostrado que la población Nes-GFP+ mesenquimal presente en la médula ósea era una fuente importante de la quimoquina $C x C / 12$, esencial para la regulación de las HSCs que se liberan al torrente sanguíneo (Méndez-Ferrer et al., 2010). Con respecto al corazón en desarrollo, también parecía haber un evidente solapamiento entre población de células GFP+ marcadas con el alelo y la población de células expresando la quimoquina. En la figura 12 se muestran las comparaciones de dos embriones tempranos a E10.5 de las líneas Nes-Gfp y CXCl12 ${ }^{\text {GFP }}$ (knock-in), así como corazones de las mismas líneas a E12.5. Con la línea CXCl12 ${ }^{\mathrm{GFP}}$ lo que vemos con el reportero en verde son las células que están expresando la quimoquina en un determinado momento. Como se puede observar, el patrón de la GFP en ambos es muy parecido, lo que nos conducía a pensar que existía una gran colocalización entre las células Nes-GFP+ y las células productoras de $\mathrm{Cxc} / 12$ en esos estadios concretos del desarrollo. 

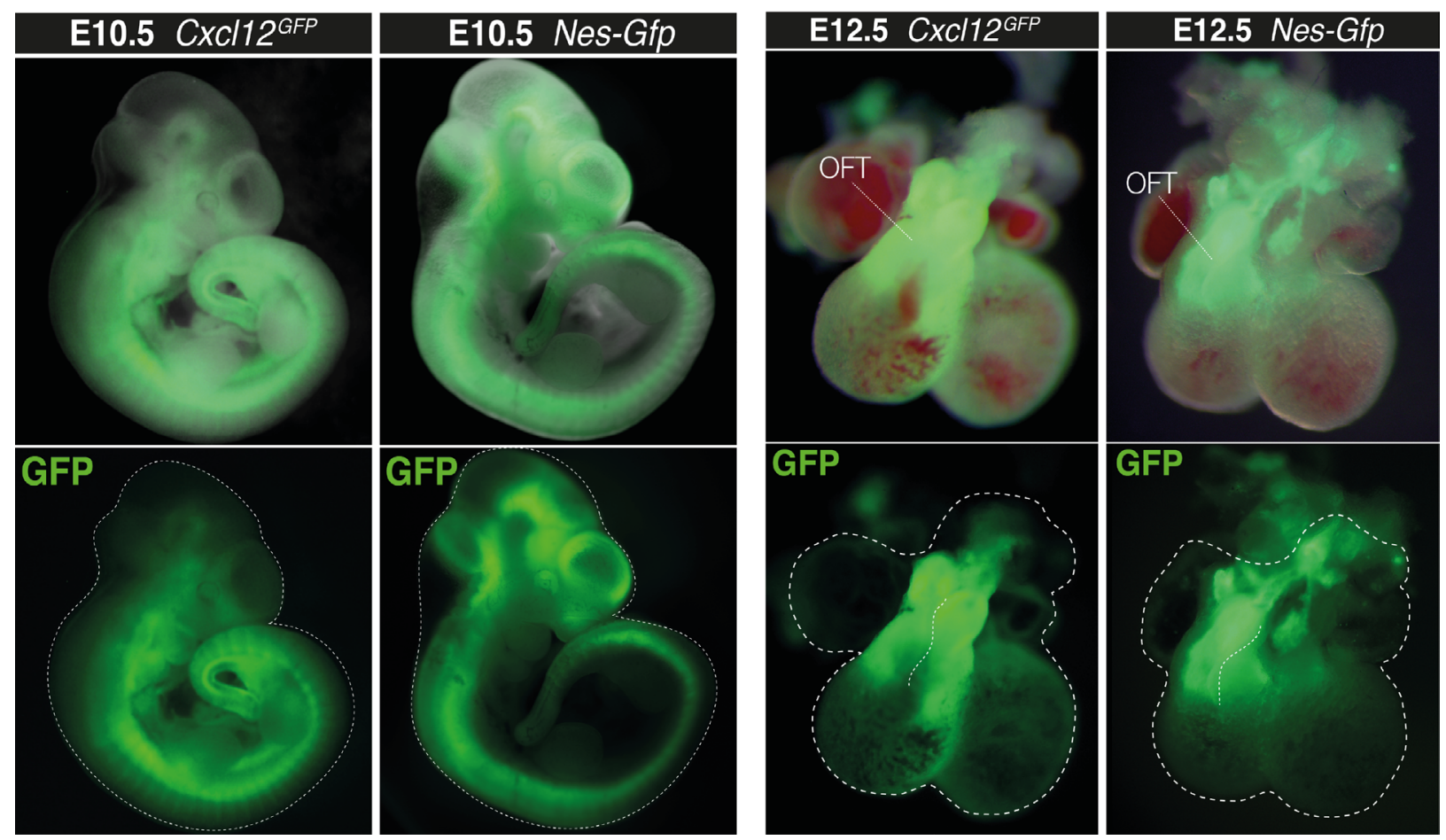

Figura 12. Comparación de patrones de expresión de la GFP en las líneas genéticas Cxcl12GFP (Knock-in) y Nes-Gfp. En el panel de la izquierda, embriones tempranos a E10.5. En ambos casos observamos expresión del reportero GFP en las células del tubo neural e intersomíticas. En la línea Nes-Gfp además la expresión en el cerebro medio es mucho mayor. En el panel de la derecha, corazones a E12.5. Los patrones de ambas líneas son casi idénticos, presentando una expresión muy elevada en las células que constituyen la región del OFT y surco interventricular, lo que sugiere que las células Nes-GFP+ podrían ser las mismas que están expresando la quimoquina Cxcl12.

Por otra parte, hacía dos décadas que se había generado el modelo de ratón nulo para el gen SDF-1 (Cxcl12). Los fenotipos descritos en este modelo, además de problemas en la linfopoyesis de los linfocitos B y la mielopoyesis en la médula ósea, presentaban defectos en la septación de los ventrículos GHQcorazón, y los embriones terminaban muriendo in utero antes GHlegar a nacer (Nagasawa et al., 1996).

Dada la relación existente entre las células Nes-GFP+ y la producción de Cxcl12, decidimos examinar el fenotipo de la deficiencia de SDF-1 en el fondo Nes-Gfp. Para ello generamos el alelo nulo de $\mathrm{CxCl} 12$ a partir de la línea condicional. Las camadas de embriones de cruces heterocigotos se analizaron principalmente a E17.5 y en algunos casos a estadios más tempranos. Los embriones deficientes de Cxcl12 eran fácilmente identificables, al mostrar generalmente grandes hemorragias, edemas, y menor tamaño que sus hermanos de camada WT o hererocigotos (Figura 13). Pero el fenotipo que nos resultó más llamativo fue que los mutantes knock-out carecían de arterias coronarias. Esto se visualizaba fácilmente en nuestros embriones ya que, al contener también el alelo Nes-Gfp,la microvaVculatura coronaria y especialmente las grandes arterias, eran muy positivas para la GFP. 

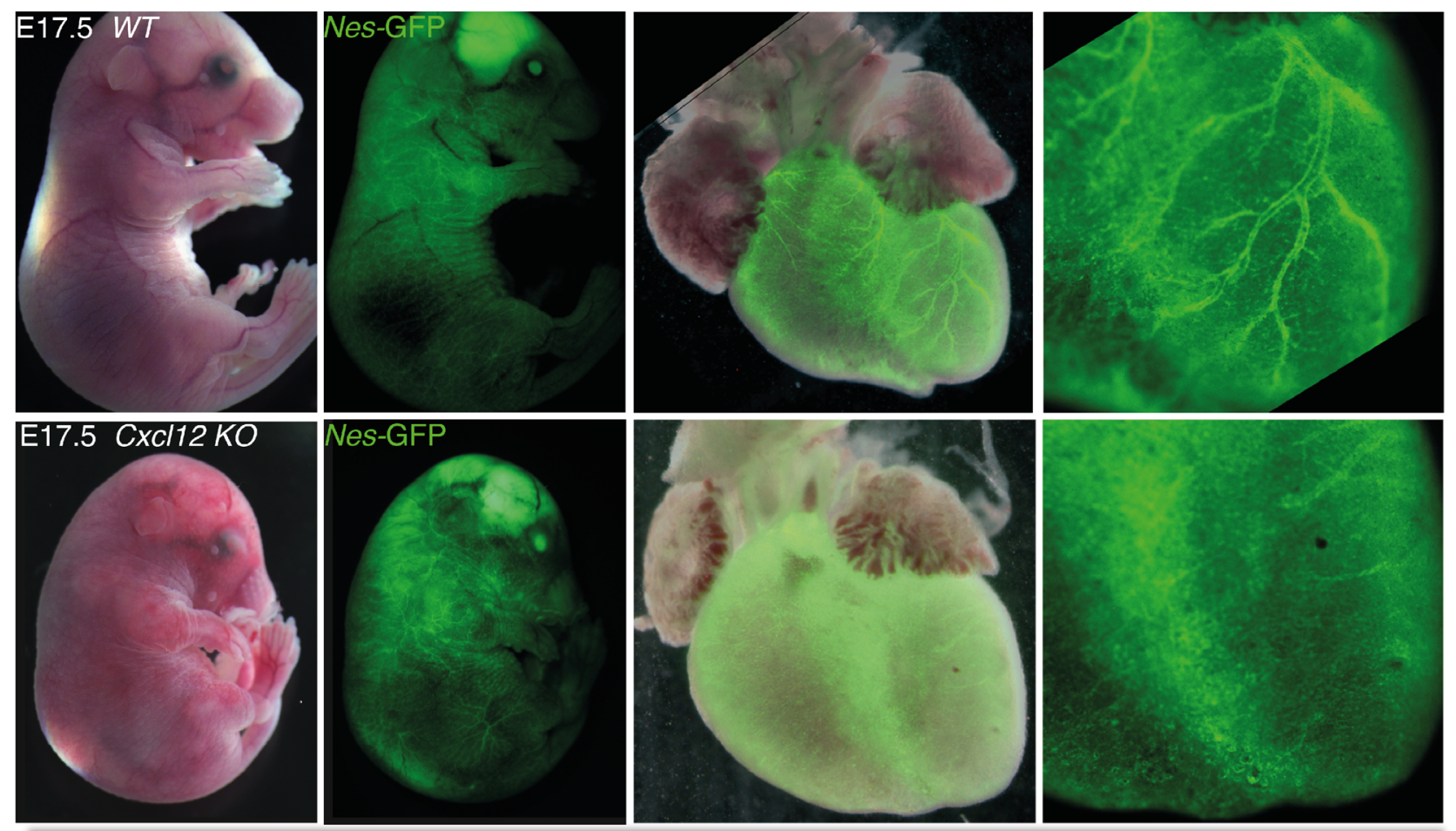

Figura 13. Embriones Cxcl12; Nes-Gfp WT y KO a E17.5. Se muestran imágenes de los embriones y sus corazones en campo claro y en el canal GFP. En el mutante de Cxcl12 KO se aprecian hemorragias con respecto al embrión WT, así como la ausencia de las arterias coronarias. WT, Wildtype; KO, Knock-out

Teniendo en cuenta que un fenotipo tan grave como la ausencia de arterias coronarias no había sido descrito en este mutante, decidimos caracterizar los embriones en mayor profundidad, centrándonos primero en el estadio más tardío posible (E17.5) y luego en estadios más tempranos para ver en qué momento comenzaban a presentar problemas por la deficiencia de Cxcl12 (Figura 14B).

En el panel de la Figura 14A se muestran cortes de corazones wildtype, heterocigoto y homocigoto para el alelo nulo de Cxcl12, respectivamente. Los corazones hemicigotos presentan aspecto normal, indicando que la reducción de la cantidad de la quimoquina producida no parecL generar estas graves alteraciones. La única diferencia con respeto al WT solía ser un mayor grosor en el miocardio compacto en algunos de los casos, pero sin llegar a manifestar alteraciones en la vasculatura. En el KO global observamos el fenotipo ya descrito sobre la incorrecta formación del septo interventricular. Pero además de las alteraciones del septo, estos corazones presentan grandes dilataciones en los vasos sanguíneos (a y a'), así como problemas en la compactación del miocardio de los ventrículos, especialmente en el ventrículo derecho, donde se aprecia su menor grosor en la zona compacta ( $b$ y b'). Analizando embriones mutantes en estadios muy tempranos (E12.5) observamos que las alteraciones en el grosor del ventrículo ya se manifiestan desde el principio del desarrollo del órgano cardíaco (Figura 14B). 


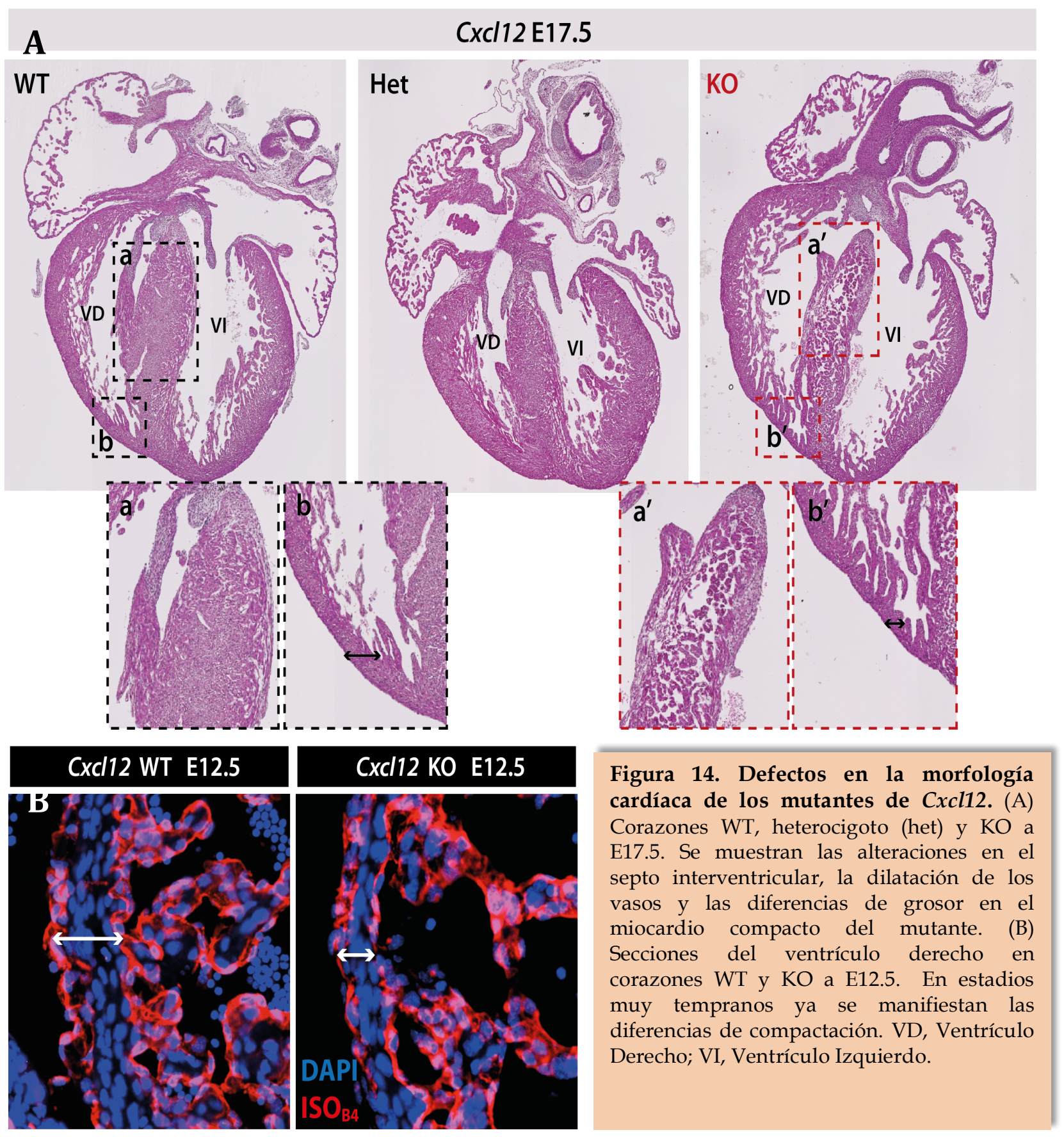

También había sido descrita la deslocalización de grandes vasos, como los presentes en el sistema gastrointestinal (Figura 15A). A su vez, tinciones con el anticuerpo TH (Tirosina Hidroxidasa) nos revelaron otro fenotipo que no había sido descrito: La carencia completa de fibras en la cara dorsal del corazón indicaba que los mutantes deficientes en Cxcl12 tenían afectados el sistema simpático (Figura 15B). 
A
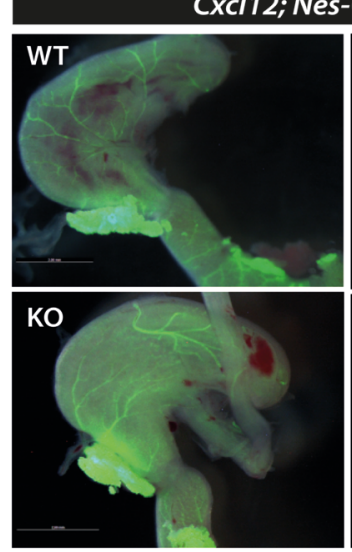

$\mathrm{KO}$

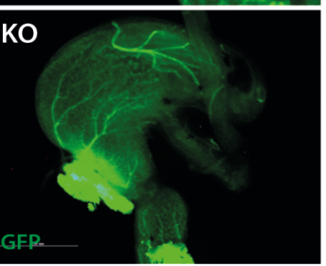

Figura 15. Los mutantes de Cxcl12 presentan deslocalización de los grandes vasos $\mathbf{y}$ ausencia del sistema simpático. (A) Estómago de embriones WT y KO donde se aprecia con la GFP el incorrecto patrón de los vasos en el caso del mutante. (B) Corazones WT y KO a E17.5 teñidos con SMA y TH. La cara dorsal muestra la completa ausencia de fibras simpáticas en los mutantes deficientes de Cxcl12 respecto a su control.
B
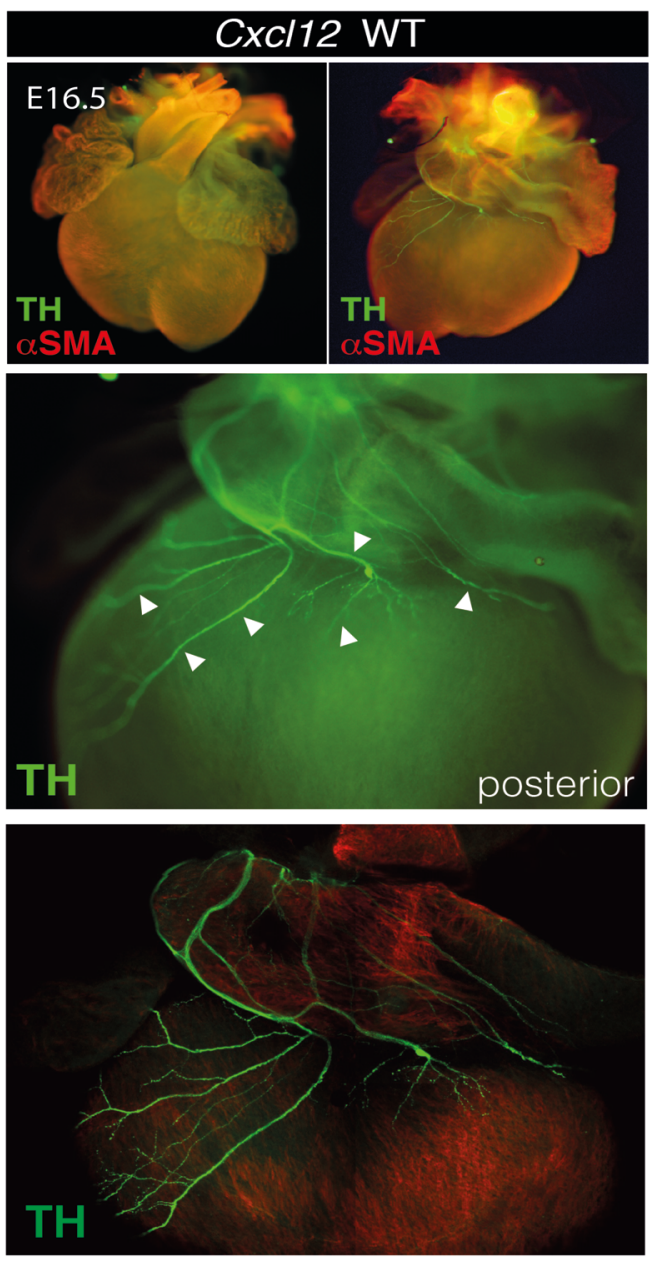
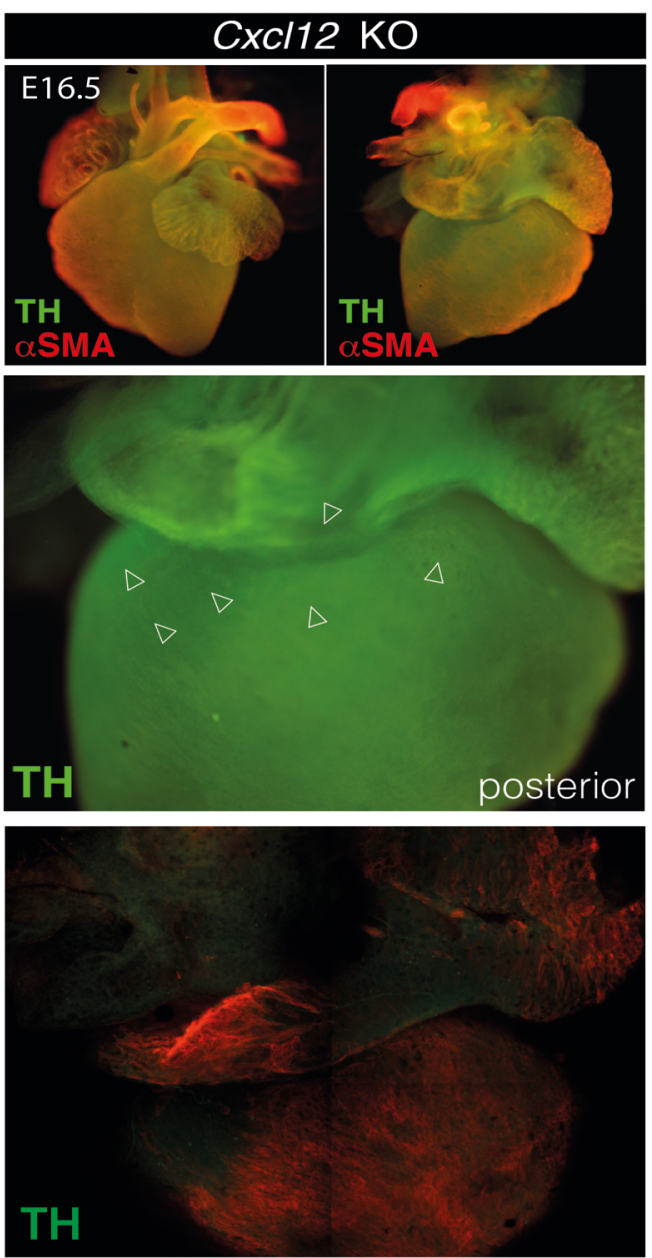

Teniendo en cuenta que los macrófagos participan en la angiogénesis degradando la matriz extracelular para permitir la expansión de la vasculatura coronaria y aprovechando que en el laboratorio disponíamos de la línea $C x_{3} C r 1-G f p$, decidimos analizar si en ausencia de la señal quimoatrayente producida por $C x c / 12$ se observaba alguna diferencia en la colonización cardíaca por estas células mieloides (Figura 16). Aunque no llegamos a profundizar en este fenotipo, se observaron diferencias en cuanto a la distribución de la población de macrófagos $C x_{3}$ Cr1-GFP+ y especialmente la morfología, ya que en ausencia de la quimoquina mostraban unas prolongaciones no presentes en la situación normal y un aspecto ameboide. 

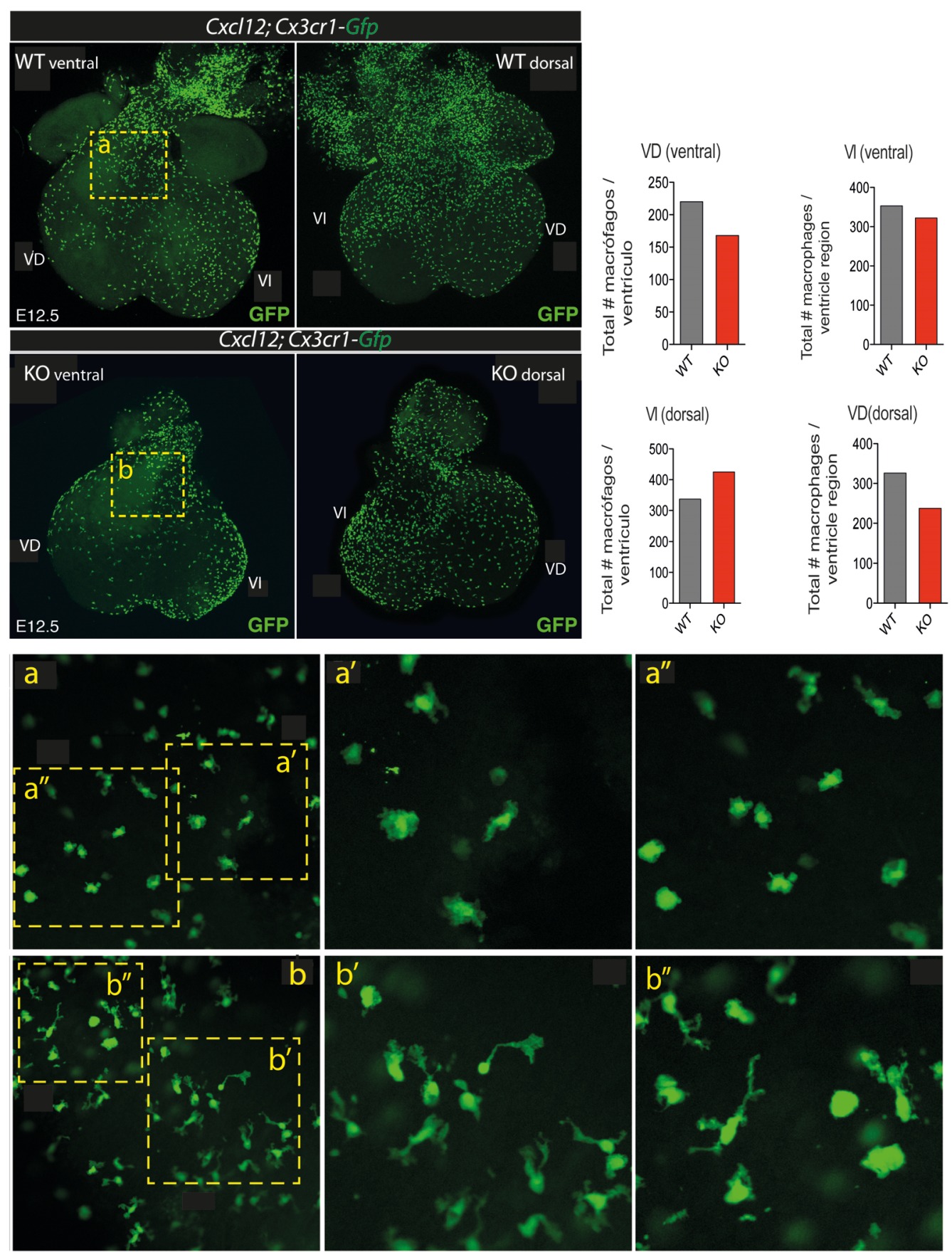

Figura 16. Comparación de la población de macrófagos en corazones WT y corazones deficientes en Cxcl12. La población de macrófagos presente en los corazones a E12.5 se encuentra marcada en GFP. Se muestran corazones WT y KO para la quimoquina Cxc12, donde se observan las diferencias en la distribución de los macrófagos (cuantificados en el panel de la derecha) así como las diferencias en morfología (amplificadas en los paneles a y b en WT y KO, respectivamente.

Con respecto al fenotipo más sorprendente, la ausencia de arterias coronarias, empleando la clarificación de tejidos adquirimos un corazón WT y un corazón KO a E17.5 a mayor resolución con microscopía confocal y observamos que el plexo vascular estaba correctamente formado en ambos casos, lo que parecía fallar en el caso del mutante era el proceso de remodelado para dar lugar a las arterias coronarias maduras. 


\section{Cxcl12; Nes-Gfp E14.5}
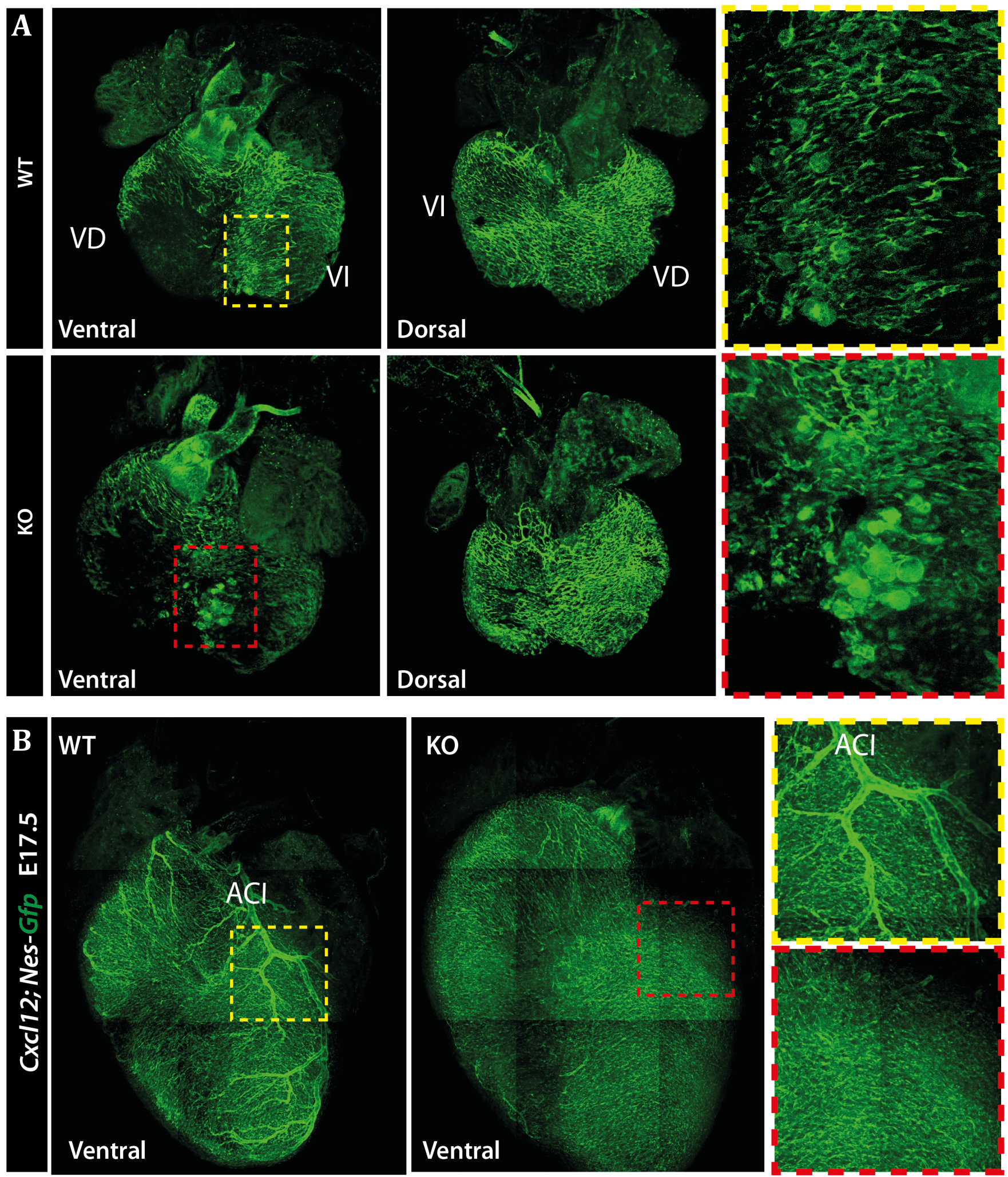

Figura 17. Vasculatura coronaria en los mutantes de Cxcl12 antes (E14.5) y después del remodelado (E17.5). (A) Corazones WT y KO a E14.5 en sus caras ventral y dorsal. No se observan alteraciones en el desarrollo del plexo primitivo en los mutantes deficientes de Cxcl12, salvo un aumento en la acumulación de islas de sangre en la región del septo interventricular. (B) Corazones WT y KO a E17.5. Se aprecia claramente el fallo en la correcta maduración del plexo vascular para dar lugar a las grandes arterias coronarias en lo mutantes. Se observan algunos vasos de mayor calibre pero carecen de verdaderas arterias. Los corazones KO presentan mayor tamaño que los WT, debido a la dilatación de su vasculatura. ACI, Arteria Coronaria Izquierda; VI, Ventrículo Izquierdo; VD, Ventrículo Derecho. 
De ser así, en los estadios previos al remodelado (E13.5-E14.5) no deberían apreciarse diferencias entre la vasculatura de los corazones WT y los mutantes. En la Figura 17 se muestran corazones control y mutante a E14.5 y E17.5, respectivamente. Tal y como se esperaba, en los mutantes a E14.5 el plexo ya expandido en la cara dorsal no presenta diferencias con respecto al control. En la cara ventral sin embargo se aprecia una mayor concentración de las estructuras conocidas como islas de sangre ("blood island"), a partir de las cuales está descrito que surgen brotes de plexo coronario derivado del endocardio (Sharma et al., 2017).

Finalmente este fenotipo terminó siendo descrito por los laboratorios de Peter J. Scambler y Henry M. Sucov (Ivins et al.,2015, Cavallero et al.,2015). En el trabajo de Cavallero et al. se describía que durante el proceso de formación de la vasculatura coronaria, los mutantes deficientes de $\mathrm{C} x \mathrm{C} / 12$ presentaban alteraciones en el plexo peritruncal que debe llegar al lumen de la aorta para formar anastomosis. Al no producirse dicha unión,el plexo primitivo no llegaba a recibir las señales de presión por el flujo sanguíneo, por lo que el remodelado a una vasculatura madura nunca llegaba a producirse. Por su parte, en el trabajo de Ivins et al.describen que las venas coronarias no estaban afectadas, desarrollándose de forma normal en estos mutantes.

En el panel de la página siguiente se muestran corazones WT y KO en los estadios E13.5 y E16.5, marcados con el anticuerpo de Caveolina 1. Aunque marcase todo el endotelio, en nuestras inmunofluorescencias de órgano completo habíamos observado previamente que Cav1 marcaba más eficientemente el plexo subepicárdico, por lo que solíamos usarlo para las venas y vasos más superficiales, sin que llegase a penetrar en los vasos intramiocárdicos. Pese a lo que había sido descrito previamente, sí parecían existir diferencias entre las venas del corazón WT con respecto del mutante KO. Si bien las venas coronarias se terminan formando en ambos casos, el plexo venoso de los embriones mutantes parece más desorganizado e inmaduro que el de sus respectivos controles (Figura 18).

Por otra parte, aunque el fallo de conexión del plexo vascular con la aorta explicase los problemas en el remodelado de las arterias, este hecho seguía sin responder a las cuestiones que se producían a estadios más tempranos e independientes al desarrollo de la vasculatura coronaria, como el problema en la formación del septo interventricular, las grandes dilataciones presentes en la microvasculatura, o los problemas en la correcta compactación del miocardio ventricular. El hecho de que la quimoquina $\mathrm{CxCl12}$ sea producida por diferentes tipos celulares y necesaria para tantos procesos en la organogénesis del embrión, hacía que su deficiencia generase un amplio panel de fenotipos, y en muchos de los cuales las causas que lo provocan aún no han podido ser identificadas. Para tratar de aislar las diferentes afectaciones, a la vez que estudiábamos los fenotipos del mutante global, realizamos mutantes de Cxcl12 condicionales empleando las diferentes líneas Cre de las que disponíamos en el laboratorio. Para ello, cruzamos el alelo Cxcl12 flox/flox con las líneas Cre para eliminar la quimoquina en las células derivadas de la cresta neural (Wnt1-Cre; Cxcl12 flox), en las células derivadas del 


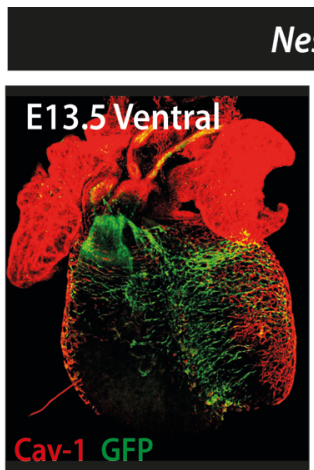

Nes-Gip; Cxcl12 (WT)
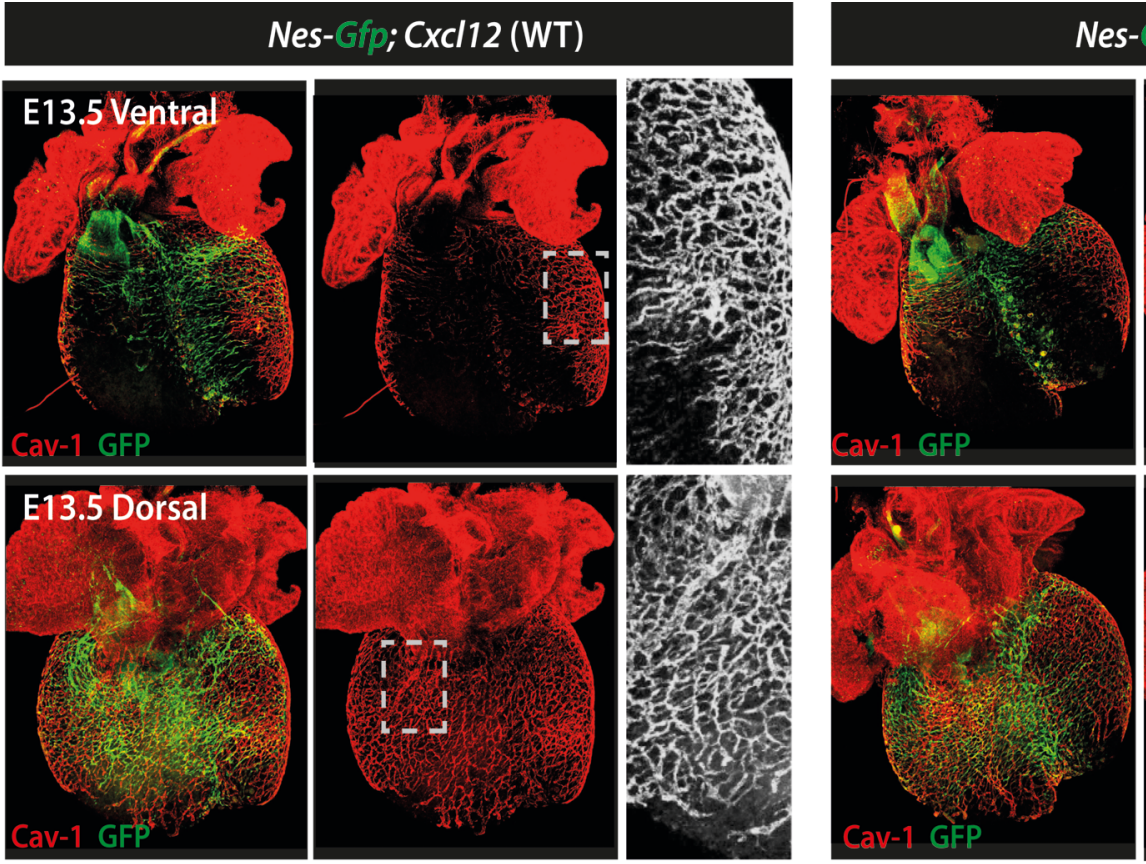

Nes-Gfp;Cxcl12 (KO)
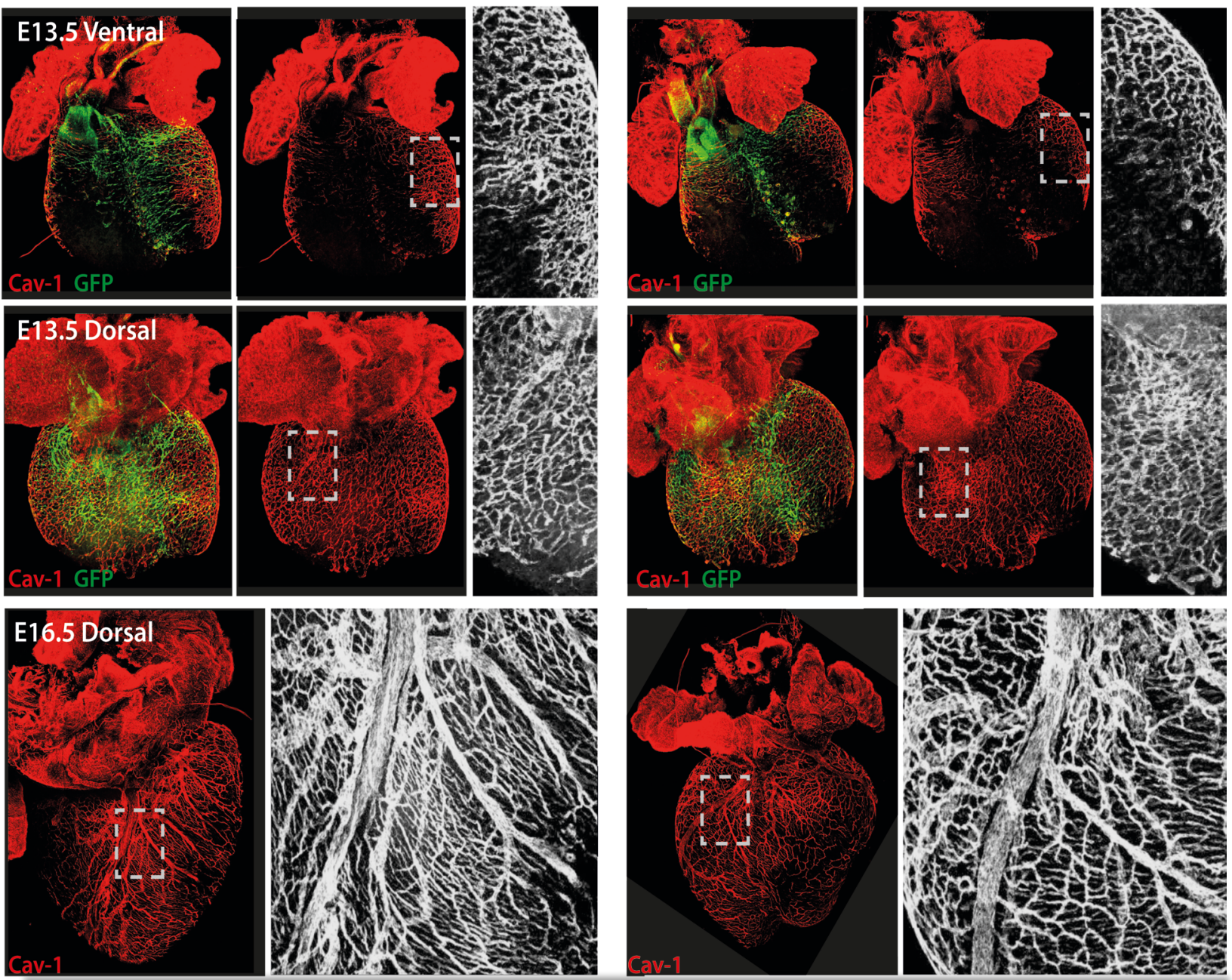

Figura 18 Inmunofluorescencia con Caveolina en corazones WT y KO a E13.5 y E16.5. Se muestran las caras ventrales/dorsales de ambos corazones a E13.5, y las caras dorsales a E16.5. Cav-1 marca el plexo venoso 1 para observar el patrón de las venas coronarias. A pesar de llegar a formarse, en el mutante parece más inmaduro que en el control.

epicardio (Wt1-Cre; Cxcl12-flox), en las células endoteliales (Tie2-Cre; Cxcl12 flox), y especialmente, en células del linaje Nestina (Nes-CreER ${ }^{T 2} ; \mathrm{CxCl}_{12}$ flox). No obstante, la anulación de $\mathrm{Cxcl12}$ con las diferentes Cre no llegó a presentar ningún fenotipo macroscópico en los mutantes condicionales.

En el siguente panel se muestra un mutante condicional en el que se ha eliminado la quimoquina en las células que recombinan con la CreER cuando se induce el tamoxifeno (Tmx) a E12.5. En el canal RCE se marcan las células que han recombinado. Como control usamos un corazón flox/+ donde se produce la pérdida de $\mathrm{Cxcl12}$ en las células que recombinan sólo en uno de los alelos, manteniendo el otro intacto. En el mutante sin embargo, un alelo ya es nulo para obtener una mayor penetrancia. No obstante, el corazón condicional no muestra ningún fenotipo visible. Si bien los mutantes en todas las camadas presentaron un mayor grosor con respecto a sus controles, indicando una posible dilatación de los vasos, las imágenes de hematoxilina/eosina muestran que la formación del septo interventricular es correcta, la 
vasculatura parece normal y las grandes arterias y coronarias están desarrolladas. Por ello concluimos que al eliminar el gen exclusivamente en unas subpoblaciones del corazón, el resto de células que sí lo producen consiguen compensar dicha deficiencia, al igual que ocurre en el caso de los heterocigotos para el alelo nulo, que no llegan a mostrar ningún fenotipo visible.

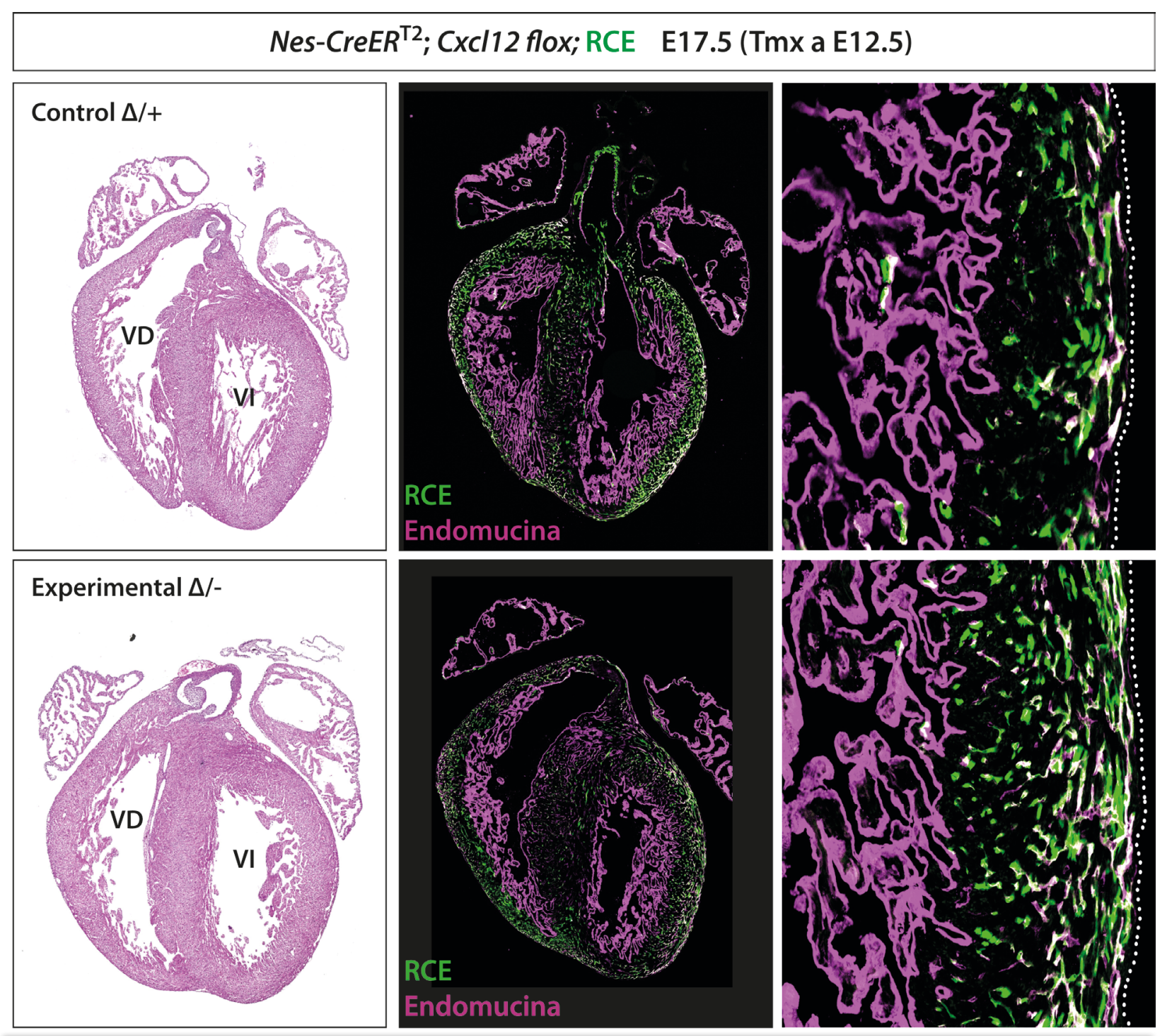

Figura 19. Mutantes condicionales de Cxcl12 en el linaje Nestina. Secciones teñidas con hematoxilina/eosina e inmunofluorescencia con Endomucina (Emcn). Se muestra una ampliación del ventrículo izquierdo (VI) para apreciar la microvasculatura. Tmx, tamoxifeno; VD, Ventrículo Derecho.

\subsection{Las células Nes-GFP+ marcan el endotelio primitivo en desarrollo y permiten} diferenciar entre las diferentes subpoblaciones de la vasculatura coronaria

En este punto es necesario recalcar que Nes-Gfp no es lo mismo que el gen Nestina endógeno. En esta línea transgénica la activación del reportero GFP depende exclusivamente de una parte del promotor $y$, especialmente, del segundo intrón del gen Nestina que contiene el 
enhancer neural. Pero al carecer del resto de señales reguladoras del gen, las células con el reportero activo no necesariamente serán las mismas que estén expresando el gen endógeno. Por este motivo, las poblaciones Nes-GFP+ que encontramos en el corazón embrionario, más que progenitores procedentes del tubo neural, son células que están recibiendo señales que específicamente regulan y activan el enhancer, independientemente del linaje celular al que pertenezcan.

Para caracterizar el patrón de expresión del alelo Nes-Gfp en la vasculatura coronaria durante el desarrollo, analizamos corazones en diferentes estadios embrionarios y posnatales. Mediante el método de clarificación empleando el reactivo CUBIC (Kolesová et al., 2016, Susaki et al., 2014, Susaki et al., 2015) conseguíamos transparentar los tejidos preservando la señal GFP endógena. Esto nos permitía adquirir la fluorescencia por microscopía confocal del órgano completo y luego realizar la proyección máxima de todo el tejido escaneado, o bien secciones ópticas a diferentes Z-stacks de alta resolución. La ventaja de este tipo de adquisición con respecto a las secciones en OCT o parafina es que al tener el corazón intacto, no se producían alteraciones ni artefactos que pudiesen afectar a la estructura de la vasculatura coronaria.

El plexo coronario comienza a desarrollarse a E11.5 a partir de los primeros brotes que surgen de la zona del SV, en la cara dorsal del corazón, y se expanden rápidamente mediante angiogénesis hacia el ápex, y lateralmente hacia la parte ventral. Inicialmente este plexo primitivo derivado del SV se encuentra justo por debajo de la capa del epicardio (plexo subepicárdico), pero a medida que el órgano cardíaco se va desarrollando, comienza a invadir y penetrar en el miocardio (plexo intramiocárdico). Por su parte, en la cara ventral, los primeros vasos que comienzan a surgir lo hacen de una zona más interna en el miocardio, en el surco interventricular. En esta zona es donde aparecen las estructuras conocidas como "islas de sangre", a partir de las cuales surge un plexo derivado de endocardio que se expande y se une al plexo procedente del SV. Así es como el músculo cardíaco se cubre totalmente por un plexo vascular primitivo complementario que, una vez se conecta a la aorta, comienza a recibir el flujo sanguíneo que desencadena su remodelado a arterias maduras, capilares y venas (Chen et al., 2014, Red-Horse et al., 2010, Tian et al., 2013).

En la Figura 20 se muestra un panel con la formación de la vasculatura a lo largo del desarrollo del embrión. A diferencia de los trabajos en los que se emplean dos líneas diferentes para marcar el plexo derivado del SV y del endocardio (Apj-CreER y Nfatc1-Cre, respectivamente), con el alelo Nes-Gfp podemos apreciar ambas poblaciones de vasculatura. A pesar de marcar los brotes endocárdicos derivados de las islas de sangre, el endocardio ventricular es negativo para la GFP, indicando que las señales que activan el reportero se producen una vez que las células dejan de formar parte del endocardio y deben migrar para unirse al resto de la vasculatura coronaria. Por otra parte, los niveles de la GFP no son uniformes en todo el plexo. Los primeros brotes que surgen del SV y se expanden por la zona del subepicardio tienen niveles equivalentes del reportero GFP, sin embargo una vez que este plexo comienza a invadir el miocardio, podemos observar cómo el plexo subepicárdico comienza 
a perder intensidad del reportero mientras que la vasculatura intramiocárdica mantiene una alta expresión del alelo Nes-Gfp (Figura 20, recuadro blanco). Con respecto a la expresión del alelo Nes-Gfp en estadios posnatales, a P1 las arterias siguen siendo muy positivas para la GFP, sin embargo esta expresión se pierde a $\mathrm{P7}$, donde quedará restringida únicamente a la microvasculatura (datos nos mostrados).
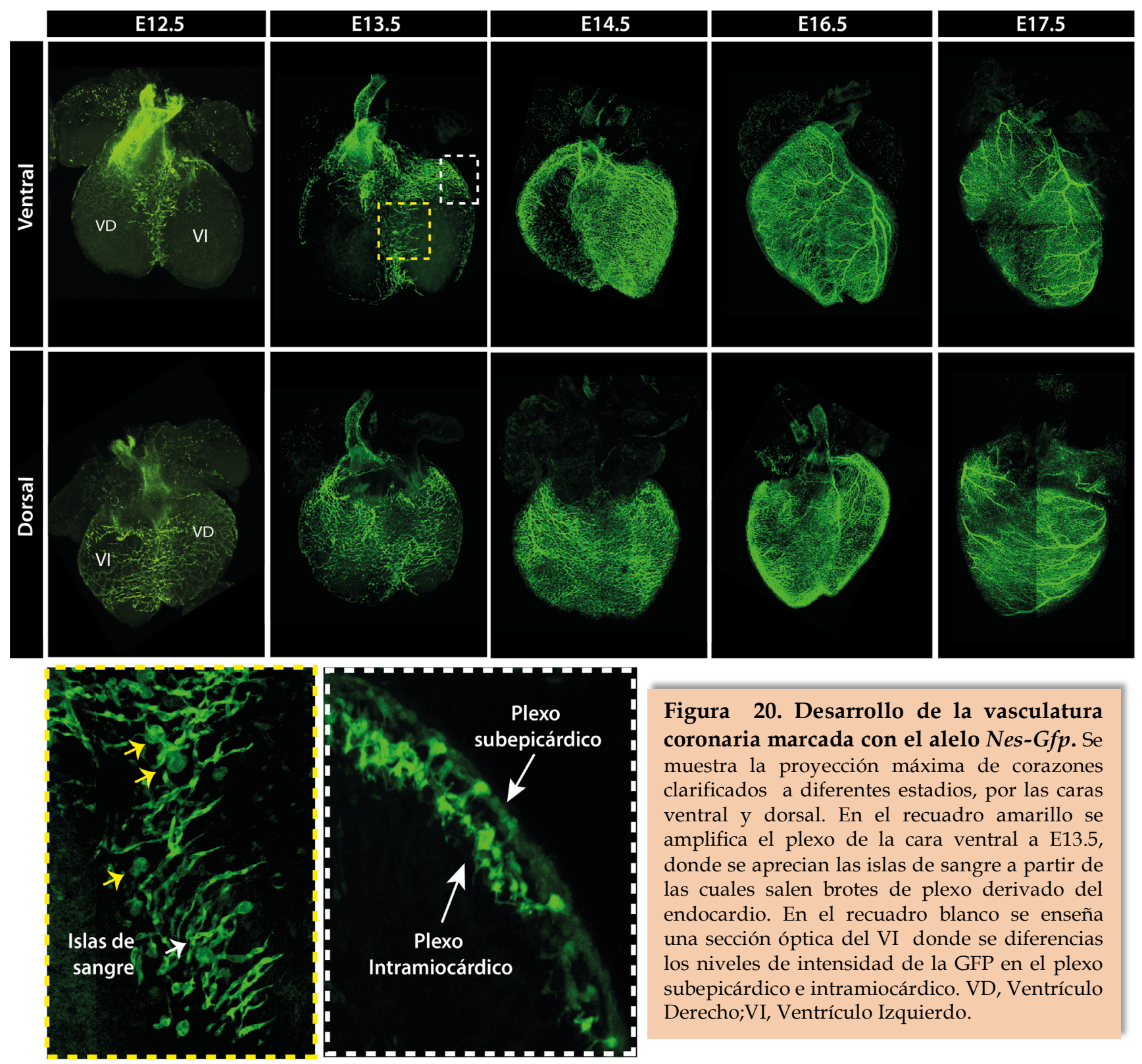

Figura 20. Desarrollo de la vasculatura coronaria marcada con el alelo Nes-Gfp. Se muestra la proyección máxima de corazones clarificados a diferentes estadios, por las caras ventral y dorsal. En el recuadro amarillo se amplifica el plexo de la cara ventral a E13.5, donde se aprecian las islas de sangre a partir de las cuales salen brotes de plexo derivado del endocardio. En el recuadro blanco se enseña una sección óptica del VI donde se diferencias los niveles de intensidad de la GFP en el plexo subepicárdico e intramiocárdico. VD, Ventrículo Derecho;VI, Ventrículo Izquierdo.

Tras el remodelado, las arterias coronarias proceden del plexo intramiocárdico y las venas del subepicárdico. Dado que a E13.5 ya observábamos diferencias en la intensidad de Nes-GFP en ambas subpoblaciones de lavasculatura, era posible que tras la maduración de los vasos coronarios viésemos diferencias entre venas y arterias. En la Figura 21 se muestra un corazón maduro a E17.5 teñido con inmunofluorescencia para marcar el recubrimiento de músculo liso 
de los grandes vasos coronarios (SMA) o exclusivamente las venas coronarias (Endomucina).En el panel de arriba se aprecia la proyección máxima del órgano completo clarificado con CUBIC. La fluorescencia endógena de la GFP colocaliza perfectamente con el marcaje de SMA en las arterias coronarias, sin embargo es negativa en las grandes venas marcadas con Endomucina. En el panel de abajo, el corazón cortado en secciones para visualizar la vasculatura en mayor detalle.

La ampliación del ventrículo derecho en el que se observa el corte transversal de una arteria y una vena coronaria, nos permite apreciar cómo en el caso de la arteria, tanto la capa endotelial como el recubrimiento de músculo liso y pericitos asociados son Nes-GFP+. Por su parte, en el caso de la vena los niveles de la GFP en el endotelio son casi inapreciables, mientras que la intensidad de fluorescencia en los peritos asociados es muy elevada. De nuevo, el endocardio ventricular es completamente negativo para el alelo Nes-Gfp, observándose células dispersas que se corresponden con el músculo liso presente en las trabéculas.
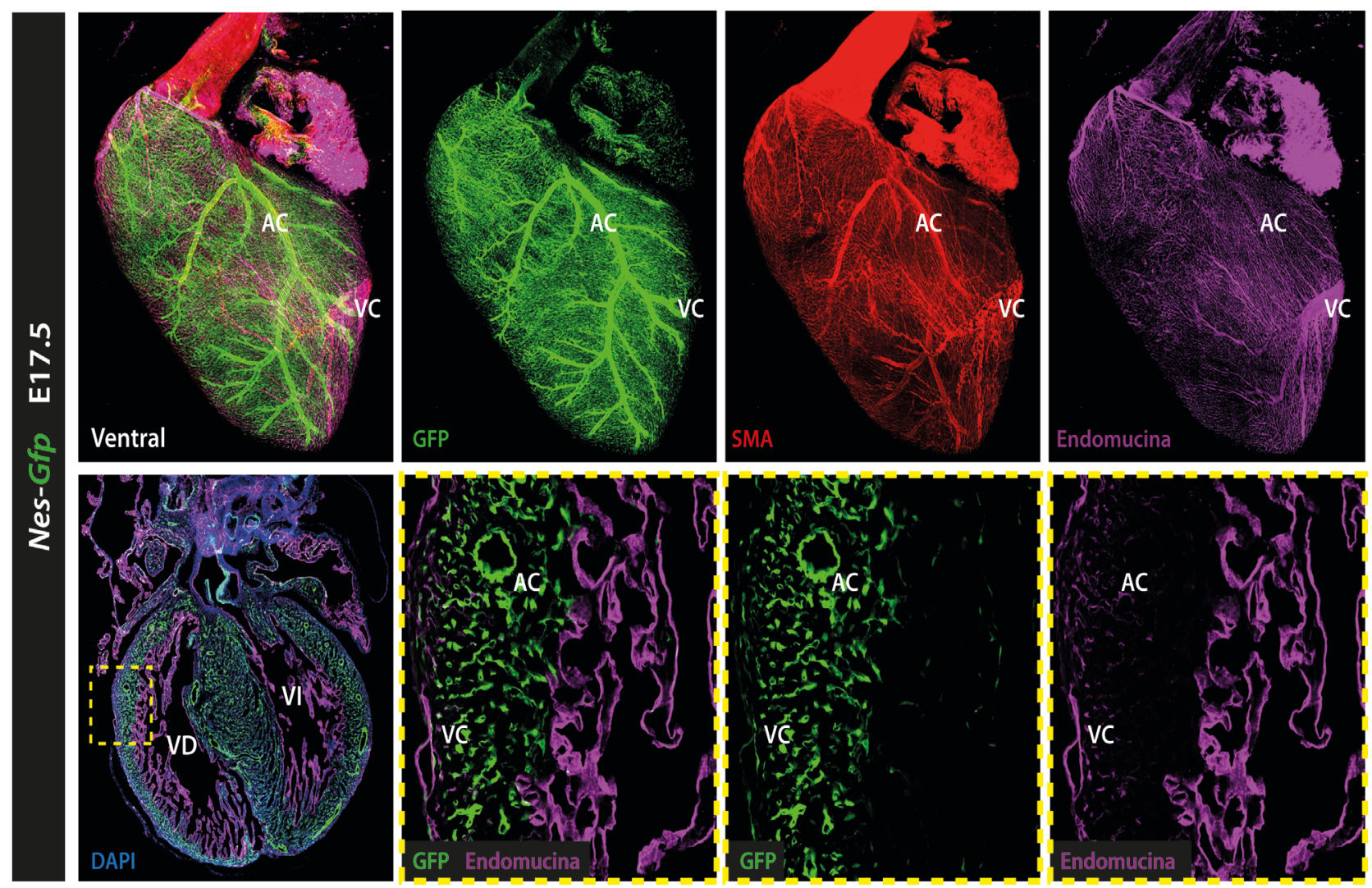

Figura 21. Corazón Nes-GFP+ tras el remodelado a E17.5. En el panel superior, la cara ventral del corazón en los diferentes canales de fluorescencia. SMA marca el recubrimiento de músculo liso de los grandes vasos, mientras que Endomucina es específico de endocardio y venas. En el panel de abajo, el mismo corazón cortado en secciones, donde se amplifica el VD para observar cómo las arterias son GFP+ mientras que el endotelio de las venas ha perdido la expresión del reportero. AC, Arteria Coronaria; VC, Vena Coronaria; VD, Ventrículo Derecho; VI, Ventrículo Izquierdo. 
Gracias a estas diferencias de expresión del alelo reportero, podemos identificar intensidades de fluorescencia GFP entre el endocardio ventricular (completamente negativo), las venas subepicárdicas (niveles muy bajos), y los capilares y arterias del intramiocardio (niveles altos). Además, el marcaje con Endomucina nos resulta muy útil ya que marca el plexo subepicárdico y el endocardio ventricular, justo las zonas más negativas para Nes-Gfp, mostrando por tanto patrones complementarios y excluyentes de expresión (Figura 22).

Aunque las diferencias de intensidades no se aprecian bien por imágenes de fluorescencia, la citometría de flujo resulta más sensible a estas variaciones, por los que diseñamos una estrategia para tratar de diferenciar entre las tres subpoblaciones endoteliales: endocardio, arterias/capilares y venas. Para ello digeríamos corazones embrionarios Nes-GFP+ entre los estadios E14.5-E16.5 y, una vez descartadas las células no viables y el linaje hematopoyético, seleccionábamos la población endotelial CD31+. De esta forma, a pesar de

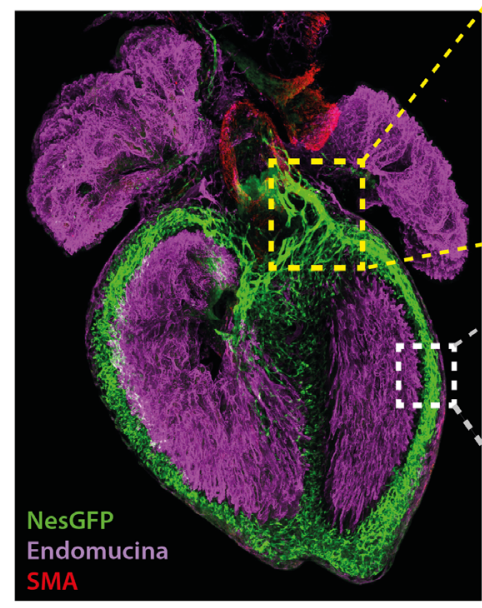

E14.5

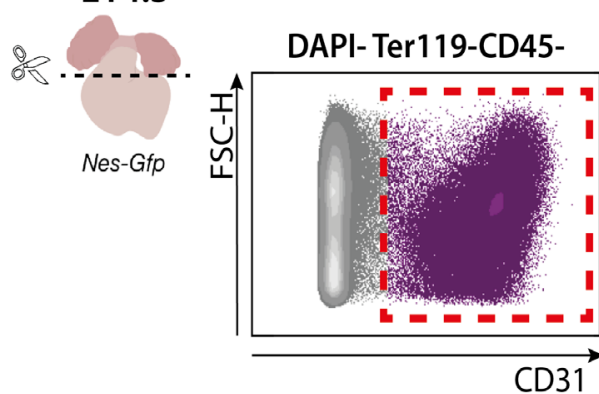

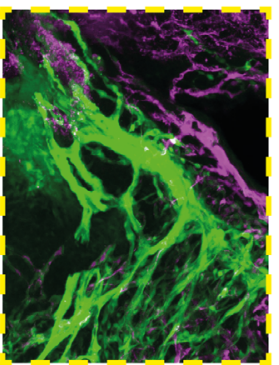
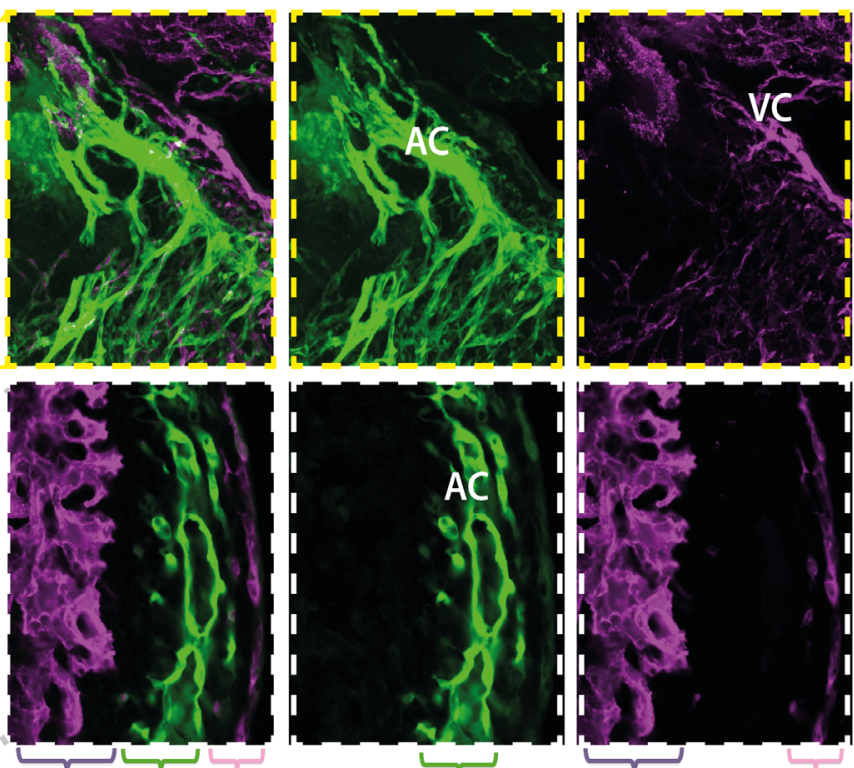

Endocardio Capilares/ Venas Arterias

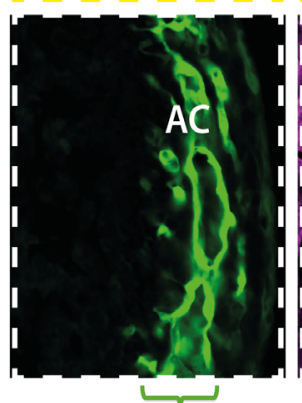

Capilares/ Arterias

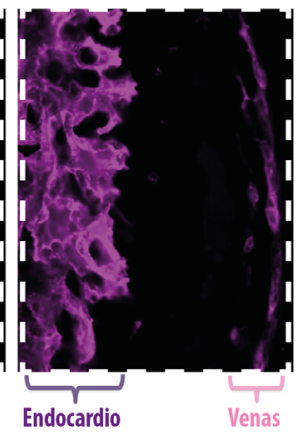

Endocardio

Venas
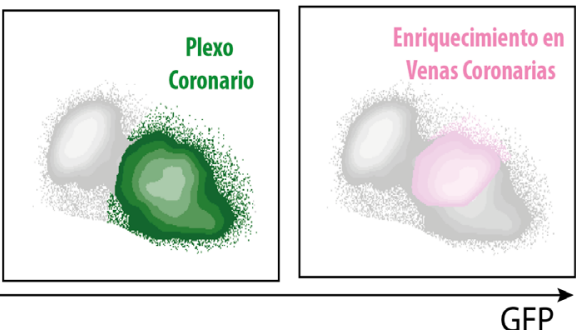

Figura 22. Los niveles de expresión relativos de GFP en combinación con CD31 y Endomucina nos permiten diferenciar por FACS endocardio, plexo coronario enriquecido en arterias, y plexo subepicárdico enriquecido en venas. (A) Proyección máxima de un corazón Nes-GFP+ a E14.5 devastado por la cara ventral y teñido con Endomucina y SMA. En el recuadro amarillo se amplifica la AC que sale de la aorta y una VC para mostrar las diferencias de expresión entre la GFP y Endomucina. En el recuadro blanco se muestran las zonas de endocardio ventricular, plexo intramiocárdico (capilares/arterias) y plexo subepicárdico (venas) que se tratarán de separar por FACS. (B) Estrategia de FACS en el que se digieren los corazones GFP+ y la población endotelial (DAPI- Ter119- CD45- CD31+) se separan en función de los niveles de fluorescencia de GFP y Endomucina, separando bien el endocardio ventricular de la vasculatura coronaria. Dentro del plexo coronario, las más positivas para Endomucina y niveles más bajos para GFP, se corresponderían con las venas. 
que el alelo Nes-Gfp marcase también una población importante de células mesenquimales, nos quedábamos exclusivamente con el endotelio coronario. Dentro de esta población endotelial, si distribuíamos las células en función de la fluorescencia para la GFP endógena y el marcaje con Endomucina, conseguíamos separar perfectamente el endocardio ventricular (Endomucina++ GFP-) del resto de vasculatura coronaria (GFP+) (Figura 22).

La separación de estas dos poblaciones ya se había conseguido con el empleo de las líneas genéticas Npr3-CreER y Fabp4-Cre para endocardio y vasculatura coronaria, respectivamente (Zhang et al., 2016). Sin embargo, lo interesante de nuestro sistema es que ambas poblaciones las adquirimos del mismo corazón, o del mismo conjunto de corazones. Además pretendíamos encontrar un método para poder diferenciar, dentro de todo el plexo coronario Nes-GFP+, la vasculatura subepicárdica e intramiocárdica. De esta forma seríamos capaces de sortear estas tres poblaciones endoteliales y realizar un perfil transcripcional de las mismas. Por ello sorteamos estas dos poblaciones basándonos en los niveles de fluorescencia. El plexo intramiocárdico que contenía los capilares y las arterias, debía ser muy positivo para la GFP y negativo para Endomucina. Por su parte, el plexo subepicárdico, que contenía las venas coronarias, debía ser positivo para Endomucina y con niveles bajos de GFP.

En la Figura 23 se muestran las 3 poblaciones que se sortearon por citometría de flujo para extraer el ARNm y realizar PCRs cuantitativas con genes conocidos para endocardio, arterias y venas que nos confirmasen si la separación que habíamos hecho en base a los niveles de fluorescencia nos serviría para discriminar, dentro de todo el plexo vascular, las venas de las arterias. La purificación del endocardio con respecto al resto de vasculatura coronaria fue muy buena (comprobado con los genes Npr3 y Endomucina). En el caso del plexo vascular, conseguimos un enriquecimiento en genes arteriales en la población intramiocárdica (Notch4,

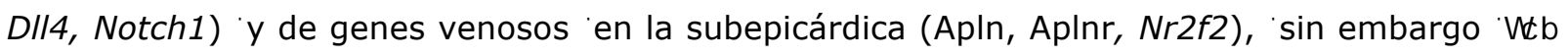
esta [estrategia de $\square$ separación aún $\square$ teníamos algunas $\square$ contaminaciones [entre $]$ ambas poblaciones vasculares, por lo que no parecía ser suficiente para discriminar bien entre venas y arterias.

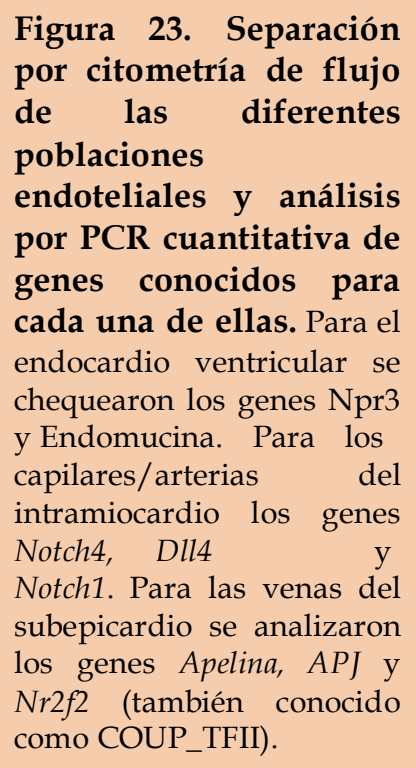

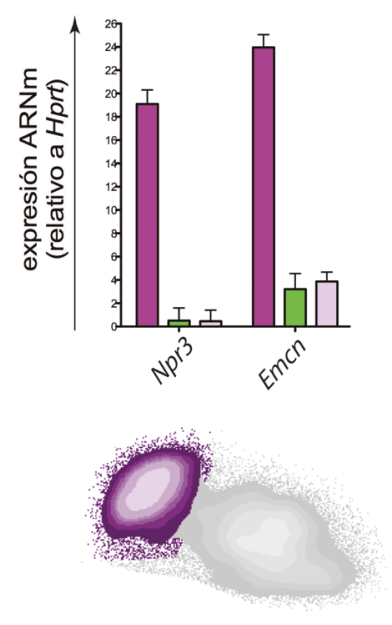

Plexo Subepicárdico (Población GFP low Emcn+)

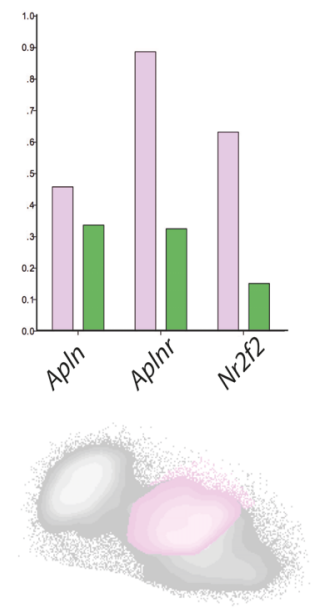

Plexo Intramiocárdico (Población GFP+Emcn low)

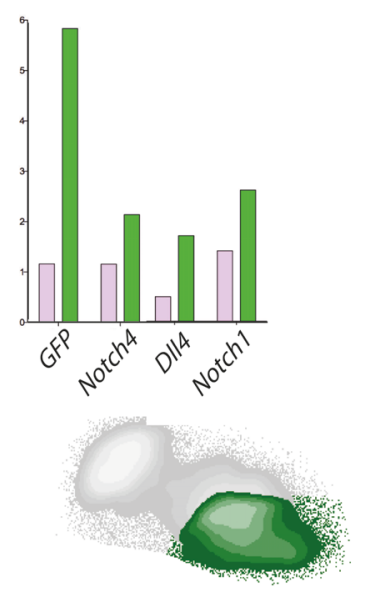




\section{2o El Trazado de linaje Nes-CreER ${ }^{T 2}$ Revela Una Especial Contribución A la}

\section{Vasculatura Coronaria En Desarrollo Pero no Al Endocardio Ventricular}

Además del alelo reportero Nes-Gfp, en el laboratorio también contábamos con la línea inducible por tamoxifeno Nes-CreER ${ }^{T 2}$ (Balordi and Fishell, 2007). En este caso, la regulación de su expresión dependía únicamente del segundo intrón del gen Nestina que contenía el enhancer neural.

En un principio la idea era inducir la recombinación a E8.5 para tratar de marcar las células GFP+ que migraban de la cresta neural cardíaca al corazón en desarrollo, pero al terminar centrando el proyecto más al estudio de la vasculatura coronaria marcada con el alelo Nes-Gfp, decidimos inocular el tamoxifeno a E10.5-E12.5, cuando los primeros brotes de células endoteliales procedentes del seno venoso y endocardio comienzan a invadir el órgano cardíaco.

La Figura 24 muestra un corazón triple transgénico Nes-CreER ${ }^{T 2}$; R26-Tomato; Nes-Gfp a E17.5 clarificado con CUBIC para ver la proyección máxima de las señales GFP y Tomato (linaje Nestina), así como un corte longitudinal. Se amplifica una región del ventrículo derecho donde hay una arteria coronaria de gran calibre y una vena coronaria. Como marcador pan-endotelial se ha empleado Isolectina B4. Se puede apreciar cómo el alelo Nes-Gfp, además de marcar el endotelio de los capilares y la arteria coronaria, también se encuentra activo en los pericitos asociados a estos vasos y el músculo liso vascular de la arteria. Sin embargo, la señal en tomato del linaje Nestina se encuentra mucho más restringida a las células endoteliales, colocalizando casi totalmente con el marcador Isolectina.
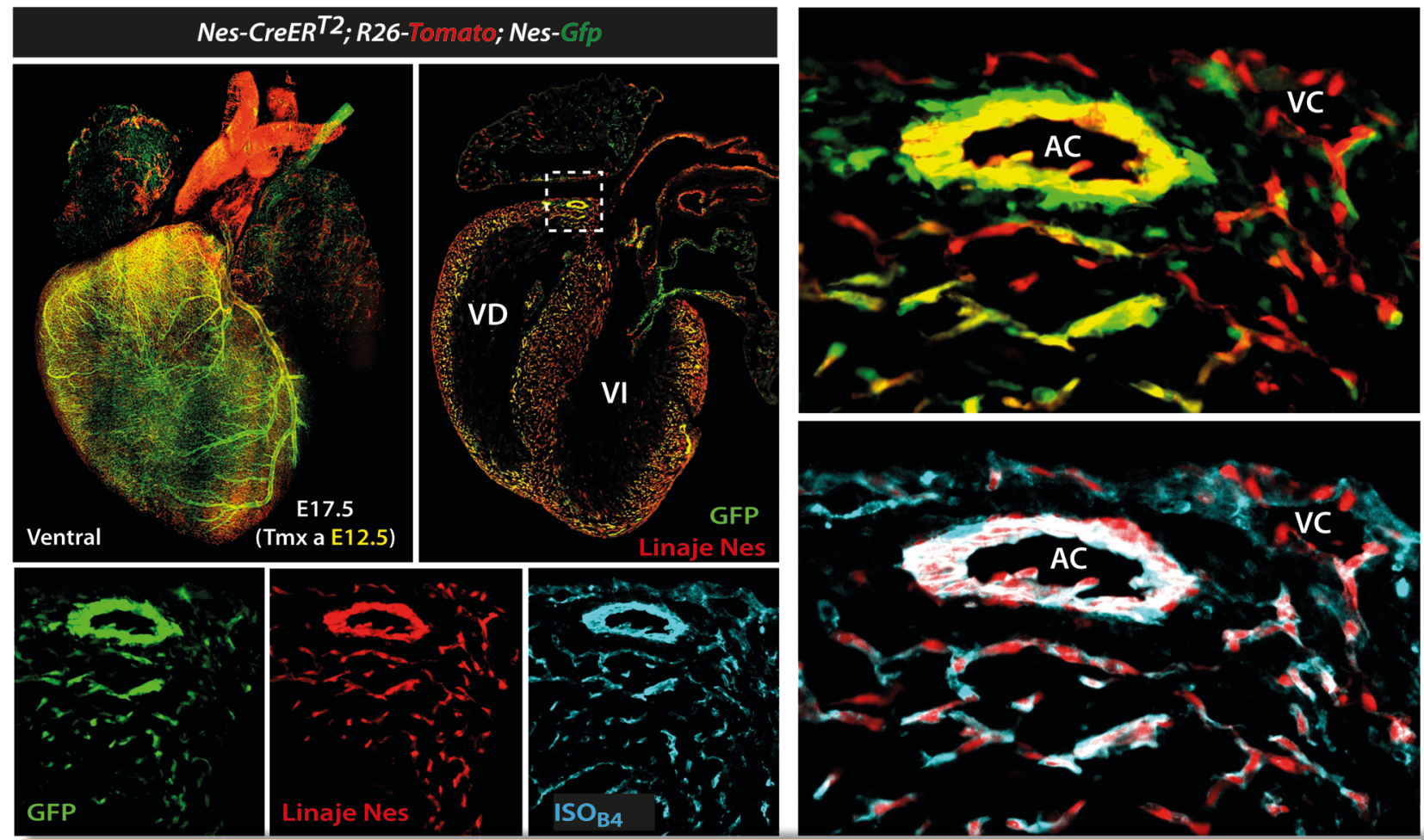

Figura 24. El trazado de linaje Nestina con el triple transgénico Nes-CreER ${ }^{T 2}$; R26-Tomato; Nes-Gfp induciendo la recombinación a E12.5 revela una principal contribución a la vasculatura coronaria excluyendo el endocardio ventricular. Se muestra la proyección máxima de un corazón a E17.5, el corte en sección longitudinal y ampliaciones de las arterias y venas coronarias (AC y VC, respectivamente). 
Esto nos indicaba que la inducción de la CreER a E12.5 restringía casi exclusivamente la recombinación de células que tienen el enhancer neural de Nestina activo en las células endoteliales, quedando excluidas la mayor parte de células mesenquimales (fundamentalmente pericitos), que de forma normal sí se encuentran marcados con el alelo Nes-Gfp. También analizamos corazones del mismo estadio donde la inducción realizada era más temprana, a E10.5, obteniendo resultados muy similares. Prácticamente la totalidad de células trazadas en tomate se correspondían con el endotelio coronario, quedando siempre excluidas las células del endocardio ventricular. La principal diferencia observada entre las inducciones a E10.5 y E12.5 era que a E10.5 se llegaba a marcar una población pequeña de los vasos presentes en el septo interventricular. Este hecho podría indicar que la aparición de estos vasos (cuyo origen está descrito que es el endocardio) sería más tardía, entre E11.5-E12.5, donde ya sí aparecen FRP SOMDP HQMATmarcados (Figura 25).
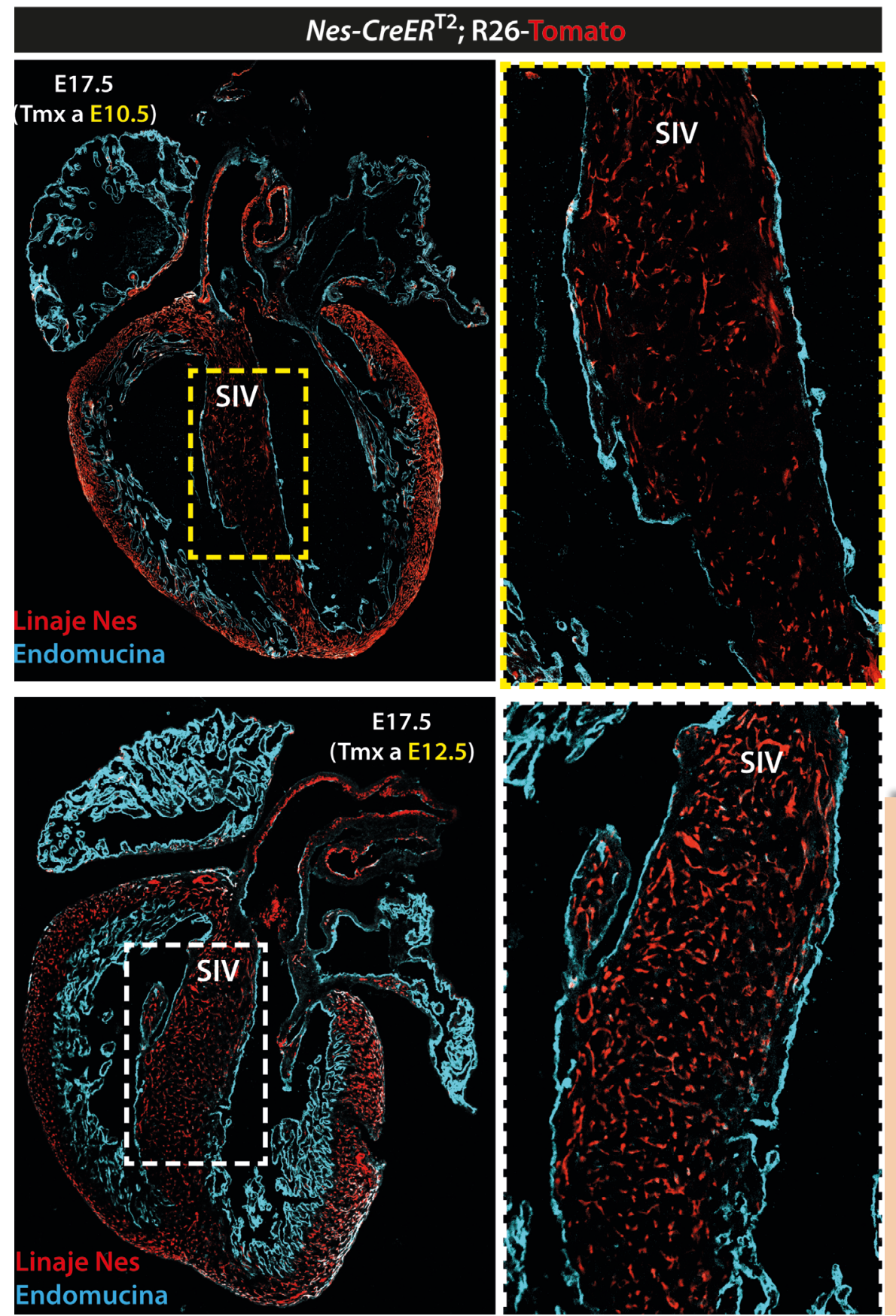

Figura 25. Comparación de los patrones del linaje Nestina en tomato cuando la recombinación se producía a E10.5 o E12.5.

En ambas situaciones se puede apreciar la recombinación del plexo coronario, pero no en el endocardio (marcado con Endomucina). La principal diferencia entre ambas situaciones es que la recombinación a E10.5 no consigue marcar toda la vasculatura del septo interventricular, mientras que la recombinación a E12.5 sí lo hace. SIV, Septo Interventricular. 
Para verificar de forma cuantitativa que el trazado de linaje con Nes-CreER ${ }^{T 2}$ marca principalmente las células de la vasculatura coronaria en desarrollo cuando la recombinación de la CreER se realiza entre la ventana temporal descrita, analizamos por FACS corazones digeridos a E17.5 inducidos a E10.5 (Tmx a E10.5) y E12.5 (Tmx a E12.5), respectivamente. Como en los casos anteriores, descartamos el linaje hematopoyético y observamos que dentro de la población Tomato+ (linaje Nestina) entre el $70-80 \%$ de las células son endoteliales $(C D 31+)$. Por su parte, el marcador Endomucina nos sirve para marcar el endocardio ventricular y el plexo subepicárdico. Dado que sabemos por las imágenes de inmunofluorescencia que el endocardio no está marcado con la Cre, toda la señal Endomucina en la población endotelial del linaje Nestina se corresponderá con la población de venas coronarias marcadas ( $30 \%$ de la población CD31+ Tom + ).
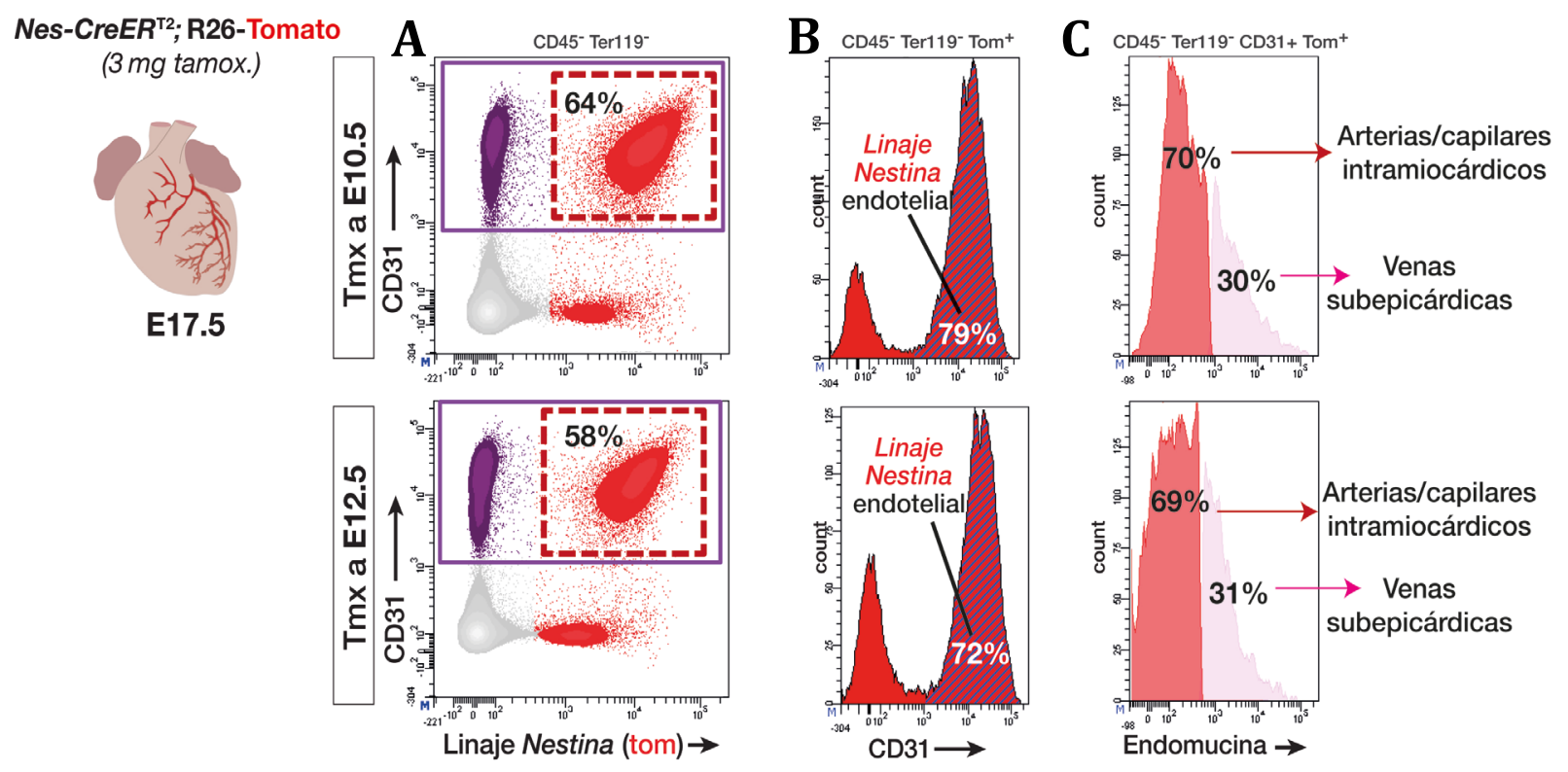

Figura 26. Análisis por FACS del trazado de linaje Nestina cuando se induce la recombinación a E10.5 y E12.5. (A) Dentro de la población endotelial (DAPI- Ter119- CD45- CD31+), el 64\% y el 58\% son linaje Nestina induciendo a E10.5 y E12.5, respectivamente. (B) Por su parte, del linaje Nestina, entre el 70$80 \%$ es endotelio coronario, correspondiendo un $30 \%$ a las venas y un $70 \%$ a los capilares y arterias (C).

Otro dato a tener en cuenta era que, a pesar de que en los corazones Nes-GFP+ vemos que la señal del reportero comienza a bajar en el plexo subepicárdico que da lugar a las venas coronarias maduras, con la línea CreER las células que recombinan quedan permanentemente marcadas en tomato, al igual que toda su progenie. Esto significa que si a E12.5 todo el plexo Nes-GFP+ recombina con la CreER, las futuras venas coronarias que derivarán de ellas también estarán marcadas en Tomato, independientemente de que el reportero Nes-Gfp se pierda en estas células. Así, podríamos utilizar la línea Nes-CreER ${ }^{T 2}$ para marcar todo el plexo coronario, incluyendo capilares, arterias y venas, pero nunca el endocardio ventricular. Además se convierte en una herramienta útil para la eliminación de genes específicamente en el endotelio coronario. 


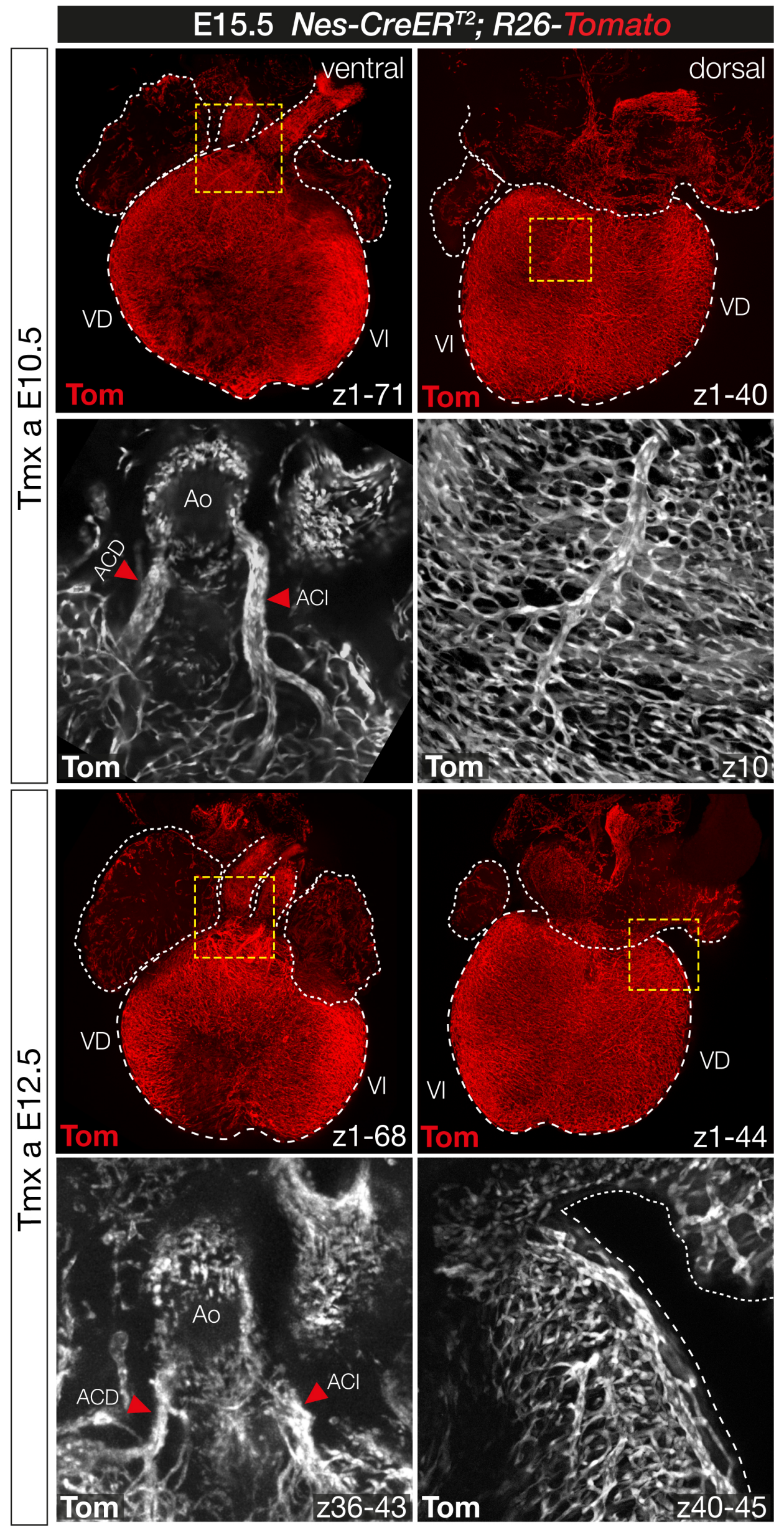

Figura 27. Trazado de linaje en corazones NesCreER ${ }^{T 2}$ a E15.5 cuando se induce la recombinación a E10.5 $y \quad$ E12.5, respectivamente. Se muestran las proyecciones máximas de todos los Z-stack de los corazones clarificados y adquiridos en el microscopio confocal para el canal Tomato (linaje Nestina). Con ambas inducciones, prácticamente la totalidad de la vasculatura coronaria se encuentra marcada. Además de las proyecciones máximas, se enseñan secciones ópticas de un único $\mathrm{Z}$ más interno para visualizar en detalle las conexiones de las arterias coronarias izquierda (ACI) y derecha $(\mathrm{ACD})$ a la aorta (Ao) en la cara ventral, o bien ampliaciones del plexo venoso que se encuentra en el subepicardio (mostrando para ello un Z más superficial). 


\section{3o Trazado de Linaje Nestina en Corazones Adultos de Ratón}

También analizamos el trazado de linajes Nestina en corazones adultos (a partir de 8 semanas) en los que se inoculaban los $3 \mathrm{mg}$ de tamoxifeno vía intraperitoneal y se obtenían los corazones $48 \mathrm{~h}$ después. Como se puede observar en la siguiente figura, conseguimos marcar toda la microvasculatura del corazón, excluyendo el endocardio y los grandes vasos. Esto concuerda con el estudio del patrón de expresión del alelo Nes-Gfp en el que veíamos que, aunque a P1 las arterias aún expresaban el reportero GFP, éste se perdía pocos días más tarde (P7). De forma complementaria, los análisis por FACS también revelan que la mayor parte de las células endoteliales que conseguíamos aislar se encontraban recombinadas en tomato. Por su parte, más del $90 \%$ del linaje de Nestina trazado correspondía con endotelio de la microvasculatura coronaria, mientras que un porcentaje muy pequeño (menor al 5\%) era células positivas para el marcador CD90.

Estudios previos demostraron que la eficiencia de recombinación en la microvasculatura coronaria de corazones adultos era mucho mayor que en otros órganos y tejidos en los que se encuentra expresada la Cre, convirtiendo al alelo $N e s-C r e E R^{T 2}$ en un excelente driver para la eliminación condicional de genes deseados en este tipo de microvasculatura cardíaca.

\section{A}
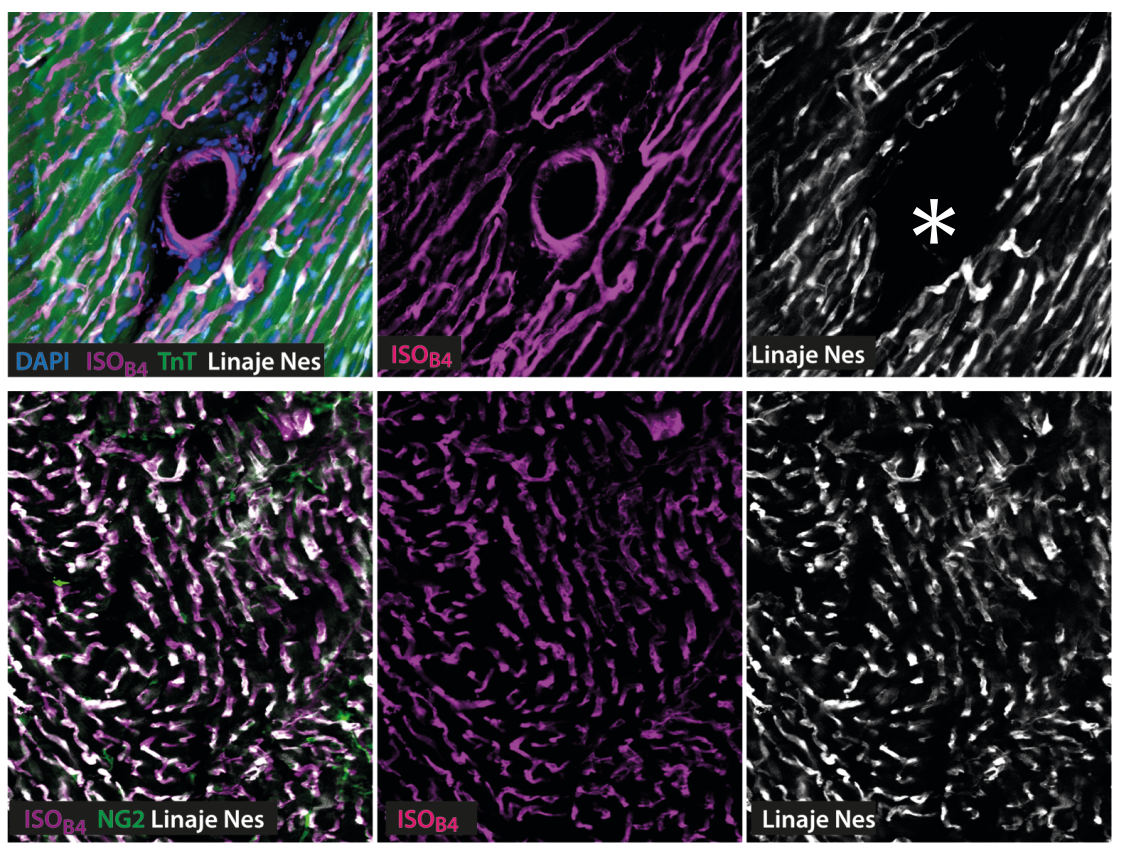

B

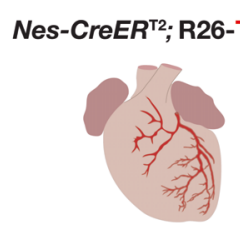

Adultos

(Tmx a 8 semanas)
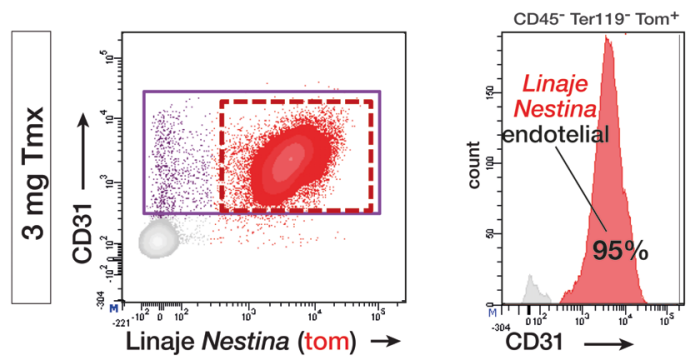

Figura 28. Trazado de linaje Nestina en corazones adultos. (A) Inmunofluorescencia con Troponina (TnT) e Isolectina para marcar cardiomiocitos y endotelio, respectivamente. El asterisco indica que el endotelio de la arteria coronaria no se encuentra marcado con tomate. Inmunofluorescencia con NG2 e isolectina para marcar pericitos y endotelio.(B)Análisis por FACS de corazones de 8 semanas digeridos $48 \mathrm{~h}$ tras la inoculación con Tmx. 


\section{4o Combinación Del Alelo Reportero Nes-GFP y El Trazado De linaje Con}

\section{Nes-CreERT2 Para el estudio Del Desarrollo Del Plexo Coronario Y la}

\section{ARTERIOGÉNESIS}

Habíamos comprobado que el trazado de linaje con el alelo Nes-CreER ${ }^{\mathrm{T2}}$ induciendo la recombinación a E12.5 nos permitía marcar prácticamente la totalidad de la vasculatura coronaria, incluyendo capilares, arterias y venas, y excluyendo en todo momento el endocardio ventricular. Por otro lado, con el alelo Nes-Gfp observamos que, a pesar de que en un principio el plexo primitivo que comenzaba a expandirse por la superficie del órgano cardíaco era GFP+, a medida que el corazón maduraba se apreciaban diferencias en la intensidad de la GFP, diferenciando la alta expresión del reportero en el plexo intramiocárdico de los bajos niveles en el plexo subepicárdico.

Teniendo en cuenta que ambas líneas genéticas compartían una regulación muy parecida, cabía la posibilidad de que, al igual que en el caso de Nes-Gfp, el alelo CreER estuviese más expresado en capilares y arterias que en el plexo venoso del subepicardio. De ser así, jugando con la ventana temporal de inducción junto con la dosis de tamoxifeno, podríamos trazar en tomato exclusivamente el plexo intramiocárdico para conseguir una separación más eficiente de venas y arterias de la que habíamos obtenido previamente con el uso exclusivo del reportero GFP y Endomucina.

Para comprobar el patrón de expresión y los niveles de la CreER, realizamos una inmunofluorecencia con el anticuerpo ESR (Estrogen Receptor) en cortes de corazones Nes$C r e E R^{T 2}+$ a E15.5, un estadio en el que ya se apreciaban las diferencias de expresión en la vasculatura en corazones Nes-GFP+.

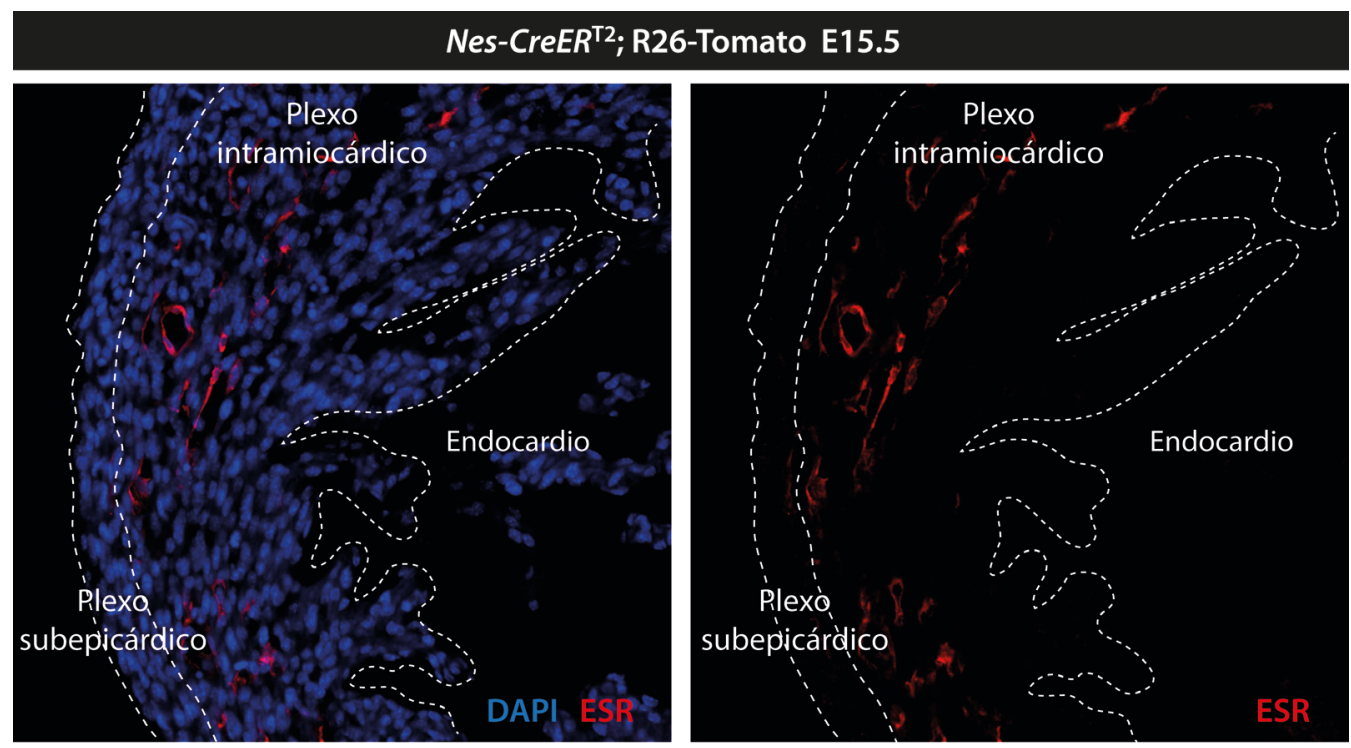

Figura 29. Tinción de células CreER ${ }^{T 2}+$. Inmunofluorescencia con el anticuerpo ESR para detectar las células que a E15.5 están expresando la CreER. Se puede observar cómo estas células se restringen al plexo intramiocárdico, siendo negativas en las células endoteliales del subepicardio. 
En la Figura 29 podemos apreciar que la tinción con ESR en el estadio E15.5 está restringida a la vasculatura intramiocárdica. Las células con el anticuerpo son las que expresan niveles altos de CreER en ese momento concreto del desarrollo, por lo que si realizamos el trazado de linaje induciendo con tamoxifeno a E15.5, al ser esas células las que recombinen exclusivamente, conseguiríamos marcar específicamente capilares y arterias coronarias, pero no venas del subepicardio.

Una vez que la ventana temporal para este trazado de linaje más específico estaba establecida, era necesario adecuar la dosis de tamoxifeno. Comprobamos que la dosis normal (3 $\mathrm{mg}$ ) era demasiado alta, ya que a pesar de realizar la inducción a E15.5, cuando los niveles de la CreER en el subepicardio eran muy bajos, estas células llegaban a recombinar. Por este motivo fuimos testando diferentes concentraciones más diluidas hasta dar con una que nos permitiese recombinar la mayor cantidad de células endoteliales posibles en el intramiocardio, pero sin que llegasen a recombinar células venosas $(0.1 \mathrm{mg})$. Usamos el análisis por FACS para cuantificar el porcentaje de venas trazadas en tomato que obteníamos en cada condición (Figura 30).

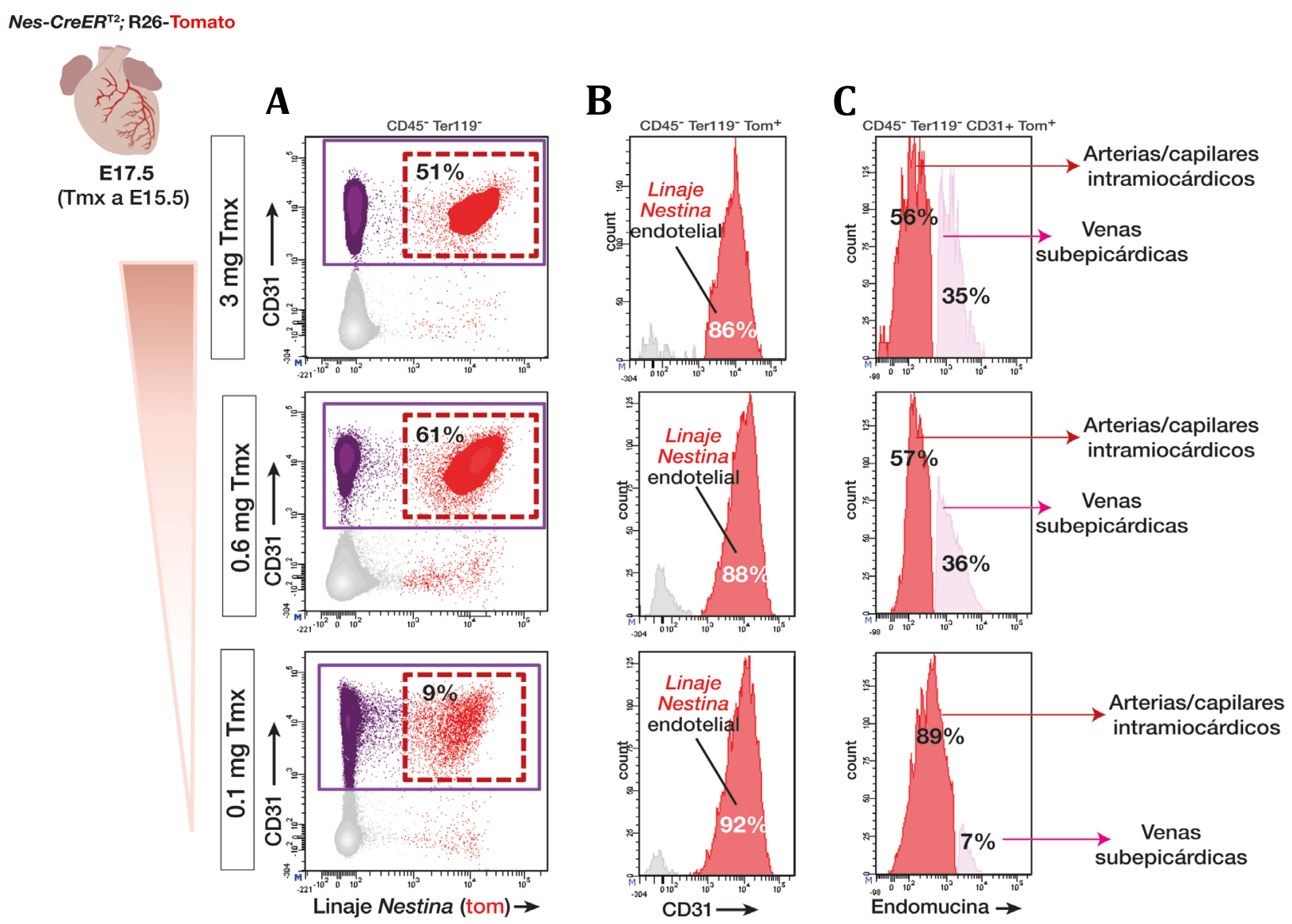

Figura 30. Comparación de la recombinación en tomato cuando se induce con diferentes dosis de tamoxifeno. (A) Se muestran datos de FACS de corazones Nes-CreERT2;R26-Tomato a E17.5 inducidos a E15.5 con $3 \mathrm{mg}, 0.6 \mathrm{mg}$ y $0.1 \mathrm{mg}$ de tamoxifeno, respectivamente. El recuadro morado muestra las células endoteliales CD31+. El recuadro rojo discontinuo, la población de células endoteliales que se marcan en Tomato. (B) En todos los casos alrededor del $90 \%$ de la población Tomato+ es endotelial. (C) Con la dosis normal de Tmx (3mg) y con la dosis diluida 5 veces $(0.6 \mathrm{mg})$ no hay diferencias en el porcentaje de venas subepicárdicas que recombinan. Sin embargo al diluir 30 veces $(0.1 \mathrm{mg})$ conseguimos que el $90 \%$ de endotelio recombinado sean arterias/capilares. 


\section{Nes-CreER ${ }^{T 2}$; R26-Tomato; Nes-Gfp E17.5 (0.1mg Tmx a E15.5)}
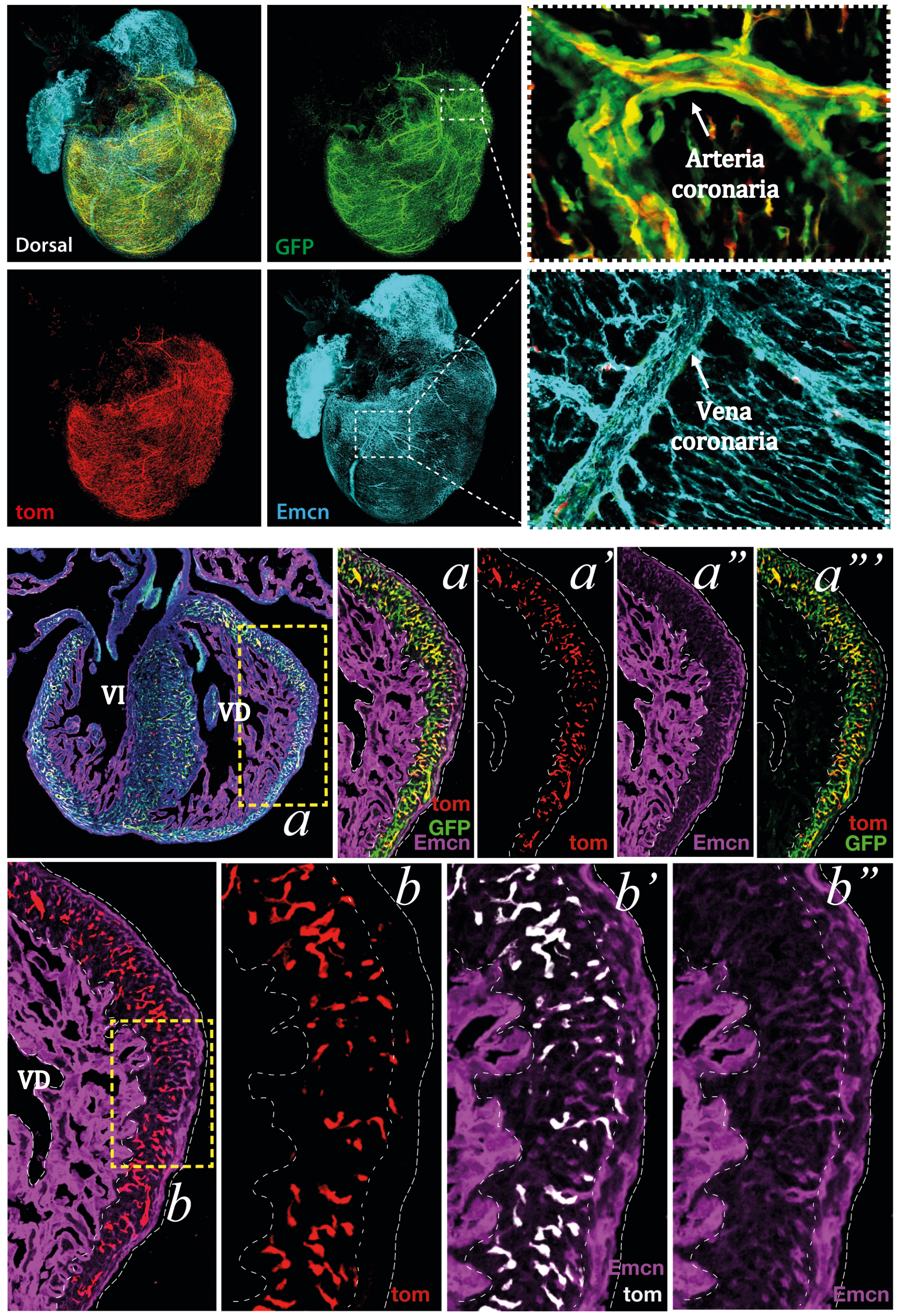
Figura 31. Trazado de linaje en corazones Nes-CreER ${ }^{T 2}$; R26-Tomato; Nes-Gfp para marcar exclusivamente el plexo intramiocárdico. En los paneles superiores se muestra la proyección máxima de la cara ventral de un corazón triple inducido a E15.5 con la dosis baja de tamoxifeno en los canales GFP, Tomato y Endomucina. Se amplifica una arteria y una vena coronaria, para mostrar la diferencia en la expresión de Tomato entre ellas, ya que en las venas no llega a recombinar en estas condiciones. En el panel inferior, el mismo corazón en secciones, donde se aprecia que las células Tomato que recombinan se restringen al plexo intramiocárdico.

En la Figura 31 tenemos un corazón Nes-CreER $R^{T 2}$; R26-Tomato; Nes-Gfp a E17.5 inducido a E15.5 con la dosis baja de tamoxifeno. En el panel superior, la proyección máxima del corazón escaneado por la cara dorsal muestra la expresión del alelo GFP, el trazado de linaje en tomato y el plexo venoso marcado con Isolectina. Para ver en detalle la expresión de los distintos marcadores en venas y arterias, se muestra una ampliación de un stack superficial del plexo venoso en el que se pueden apreciar las venas, positivas para el marcador Endomucina pero completamente negativas para Tomato. Por su parte, un stack más interno del plexo intramiocárdico demuestra que el endotelio de las arterias sí se encuentra marcado con el linaje Nestina en Tomato, mientras que el recubrimiento de músculo liso y pericitos asociados a estos grandes vasos, son GFP+ pero negativos para Tomato. En el panel inferior, el mismo corazón en secciones, donde se aprecia que la recombinación de la CreER es muy eficiente en los capilares y arterias, y una ampliación del ventrículo demuestra que el plexo subepicárdico no se encuentra marcado.

Por tanto, si con el alelo Nes-Gfp conseguíamos una buena separación de endocardio ventricular y plexo coronario, la combinación de esta línea con el alelo Nes-CreER $R^{T 2}$ en las condiciones descritas, nos permitiría lo que con las líneas genéticas y marcadores actuales no se puede conseguir eficientemente, discriminar en un mismo corazón entre las arterias/capilares del plexo intramiocárdico y las venas subepicárdicas.

\subsection{Perfil transcripcional de células del endocardio ventricular frente a la} vasculatura coronaria

Realizamos un perfil transcripcional por secuenciación de ARN (RNA-seq) entre las poblaciones de endocardio y vasculatura coronaria en corazones Nes-GFP+ en dos estadios diferentes del desarrollo: E13.5, para analizar el plexo vascular inmaduro en el momento de expansión angiogénica, y E17.5 para el plexo maduro una vez que se ha producido el remodelado que da lugar a las grandes arterias y venas coronarias. De esta forma, podríamos analizar, no sólo los genes diferencialmente expresados entre el endotelio endocárdico y coronario, sino también los cambios de expresión dentro de la misma vasculatura coronaria entre las dos fases de su desarrollo.

Para ello, agrupamos varios corazones Nes-Gfp a E13.5 y E17.5 y, siguiendo la estrategia de separación por citometría de flujo descrita anteriormente, separamos las poblaciones de endocardio ventricular y plexo coronario en estas dos condiciones para extraer el ARN y llevar a cabo el perfil transcripcional de dichas poblaciones (Figura 32A). Se realizaron cuatro réplicas 
biológicas independientes para los corazones de E13.5 y dos réplicas para los de E17.5. En la Figura 32C, el PCA de todas las muestras indica que las réplicas de cada población son muy parecidas y reproducibles. Además se muestran los valores de FPKM para genes conocidos del plexo coronario (Fabp4, Apelina y Dach1) y endocardio (Npr3, Endomucina y Gpr126), lo que nos indica el alto grado de pureza en la separación de estas dos poblaciones (Figura 32B).

\section{A Nes-Gfp

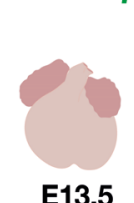

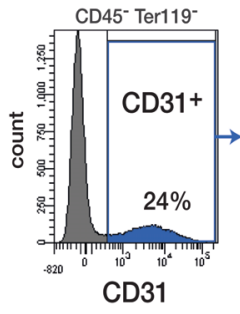
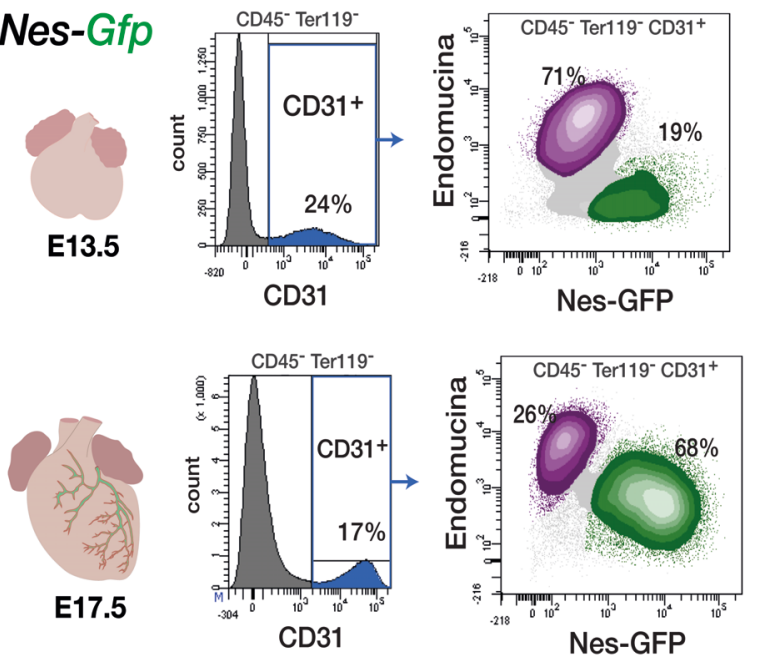

\section{D}

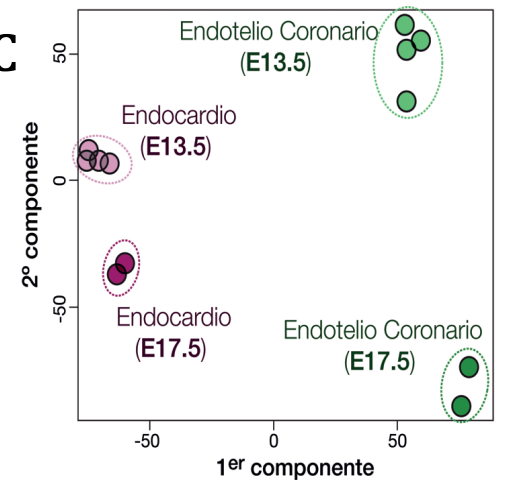

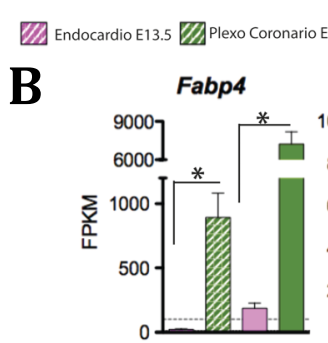
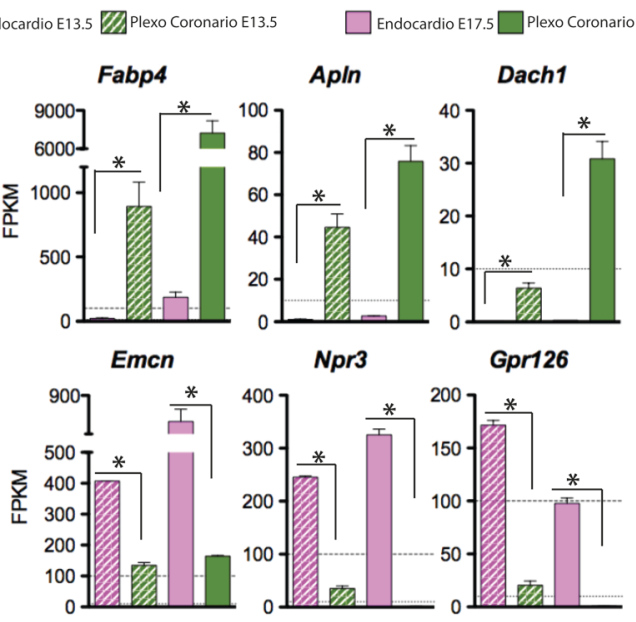

Npr3

Gpr126

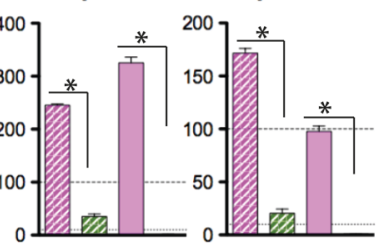

Figura 32. Separación del endocardio ventricular y el plexo coronario en los estadios E13.5 y E17.5 para el perfil transcripcional (RNAseq). (A) Estrategia de separación de ambas poblaciones por citometría de flujo. (B) Representación de la expresión de genes conocidos para cada una de las poblaciones (endocardio y plexo, respectivamente) para mostrar el grado de pureza de la separación llevada a cabo. (C) PCA mostrando las cuatro réplicas de endocardio y plexo a E13.5 y las dos réplicas a E17.5. (D) Representación gráfica de genes diferencialmente expresados entre todas las comparaciones llevadas a cabo. Se pueden comparar las poblaciones de endocardio y plexo en cada estadio del desarrollo, así como la variación de genes en una misma población entre ambos estadios. * Estadísticamente significativo p<0,05.

La comparación de perfiles de expresión mostró que entre el endocardio ventricular y el plexo coronario había 8.925 y 7.519 genes diferencialmente expresados a E13.5 y E17.5, respectivamente (Figura 32D). El Heatmap muestra los diferentes clusters que salen como resultado del análisis global. Los clusters I y $\mathrm{V}$ se corresponden con los genes expresados en 
plexo y endocardio, respectivamente, a ambos estadios, lo que indicaría que son específicos del tipo de subpoblación endotelial. Los clusters III y IV muestran genes sobreexpresados en el estadio E17.5, con mayor intensidad en plexo (III) y endocardio (IV).

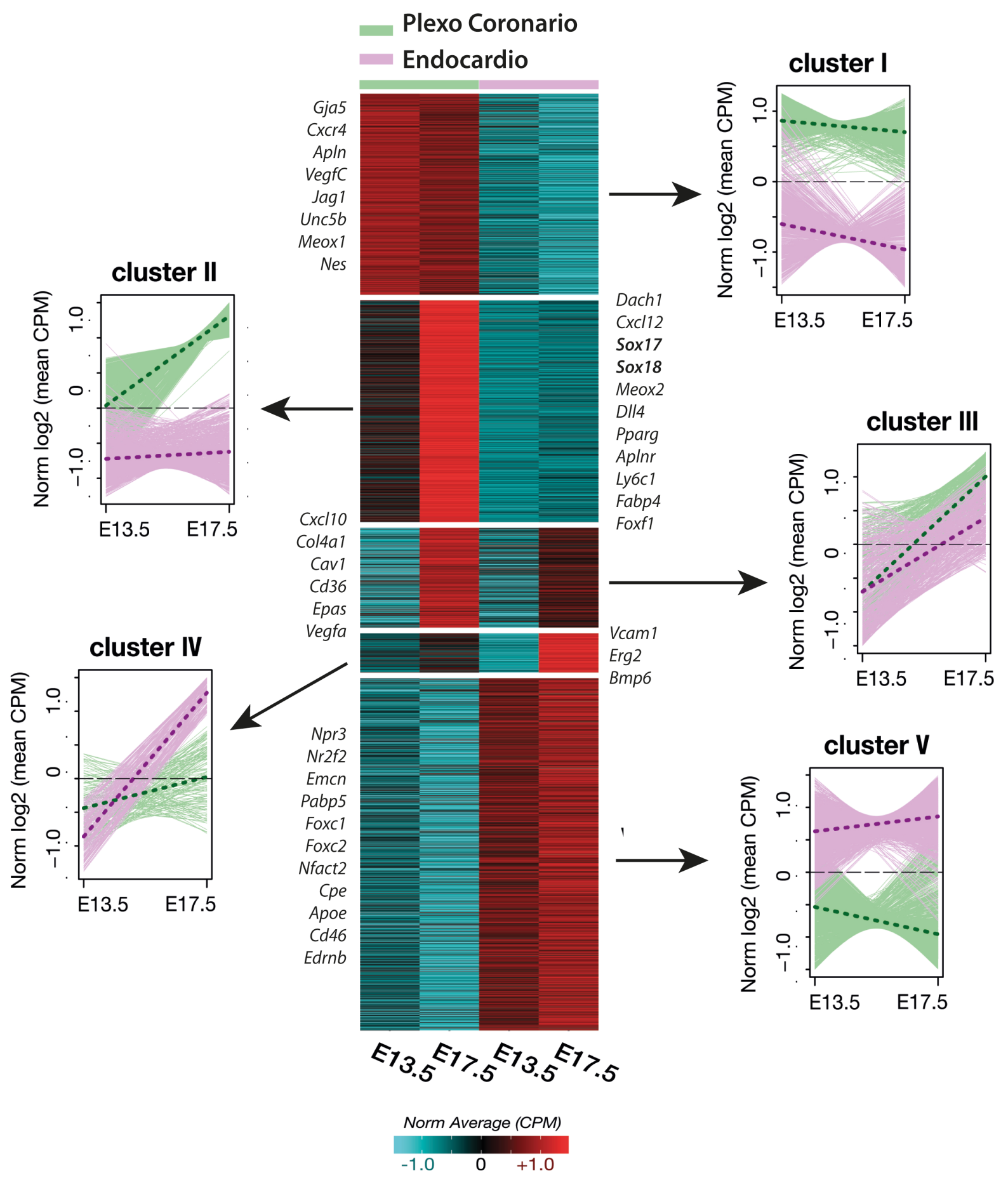

Figura 33. Heatmap resultado del perfil transcripcional de plexo coronario y endocardio a E13.5 y E17.5. Los genes diferencialmente expresados entre ambas poblaciones y estadios se pueden separar en 5 clusters según su comportamiento de expresión. En todos ellos se destacan algunos de los genes pertenecientes a cada subgrupo. 
El cluster II resulta particularmente interesante ya que contiene los genes expresados diferencialmente en el plexo coronario que a su vez se sobreexpresan de E13.5 a E17.5. Nos interesaba encontrar genes cuyo patrón de expresión fuera equivalente al de la GFP, nuestro principal reportero en este proceso. Es decir, buscábamos genes cuya expresión fuera totalmente negativa en el endocardio y presente en el plexo coronario, pero que a su vez, la expresión en la vasculatura incrementase considerablemente de E13.5 a E17.5, quedando en este estadio restringidos principalmente a arterias coronarias. De esta forma podríamos encontrar factores de transcripción o proteínas de unión al ADN candidatas a unirse al enhancer neural presente en la región reguladora del alelo Nes-Gfp para activar su expresión.
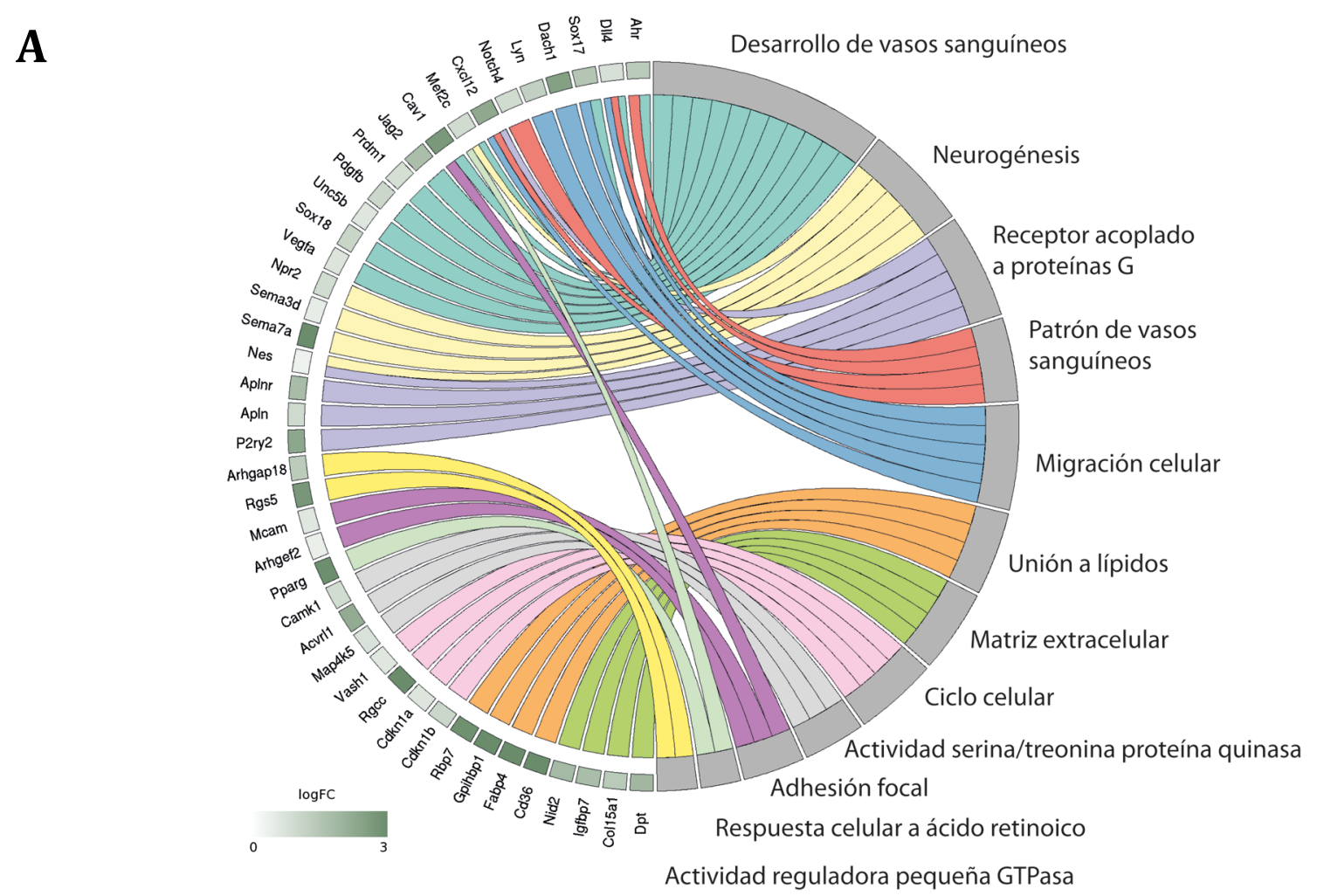

B

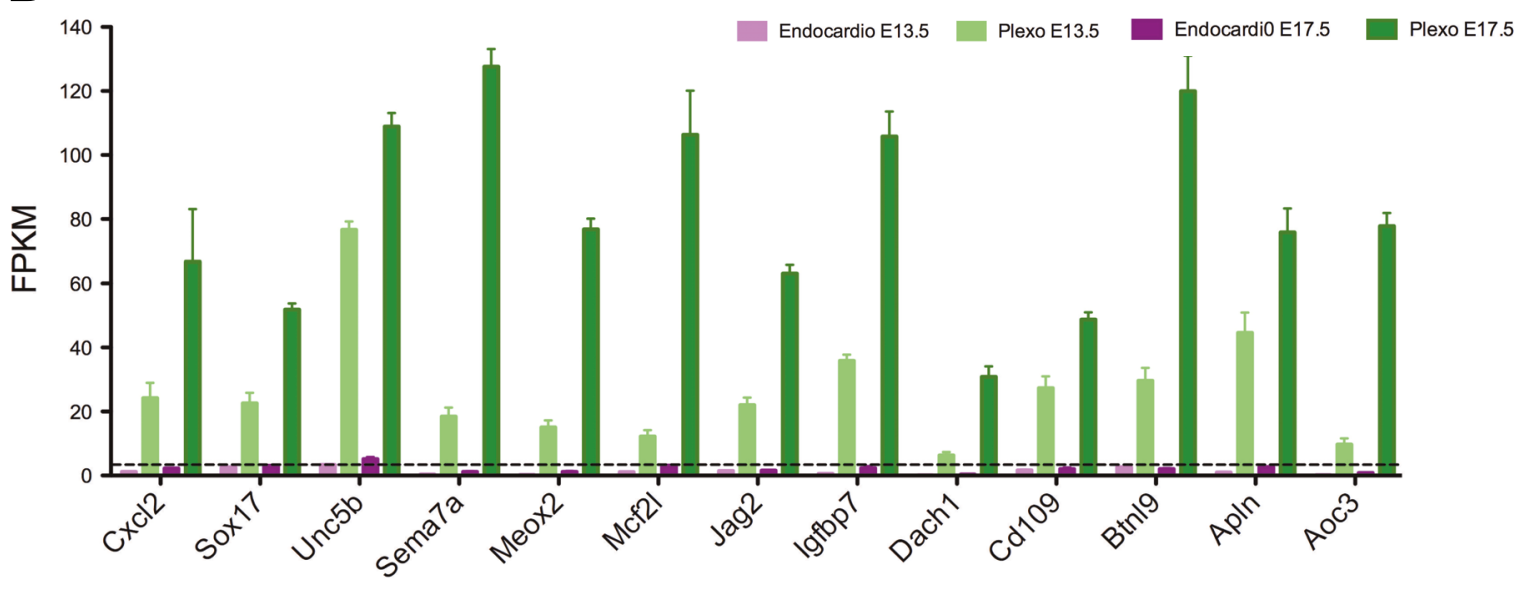

Figura 34. Genes pertenecientes al cluster II. (A) Se muestran algunos de los genes de este cluster junto con las categorías GO asociadas.(B) Representación en gráfico de barras de genes diferenciales de plexo que se sobre-expresan de E13.5 a E17.5 
En la figura anterior se muestran genes con el patrón buscado. Factores de transcripción como Sox17, Meox2 y Dach1 son posibles candidatos para regular la expresión del i2E. Además, otras vías de señalización como las de $\mathrm{Cxc} 12$ o Apelin también muestran este comportamiento (Figura 34B).

Una de las ventajas del perfil transcripcional realizado era que nos permitía encontrar marcadores de membrana para los que ya existen anticuerpos para poder separar por citometría las poblaciones de endocardio y vasculatura coronaria sin necesidad de emplear modelos genéticos de ratón. En la Figura 35 se muestran algunos ejemplos de ello. Para separar el endocardio se podría emplear el marcador CD59a, mientras que para el plexo vascular coronario existen multitud de genes diferencialmente expresados. Entre ellos seleccionamos CD36 y Ly6c, DQGLVSRQHU de RVDPMFXHUSRVPara poder hacer una prueba.
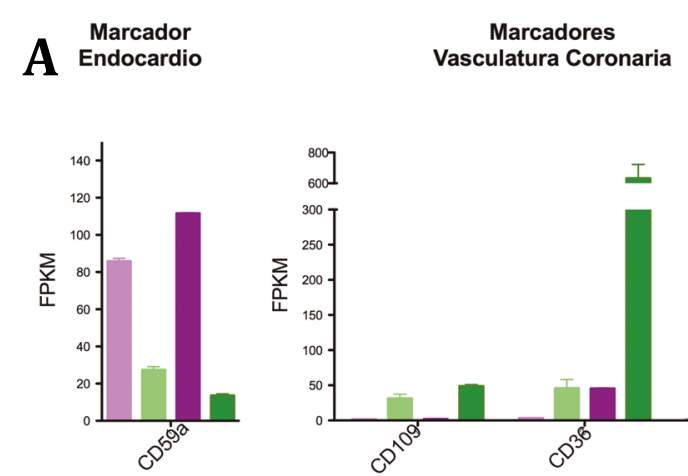

-

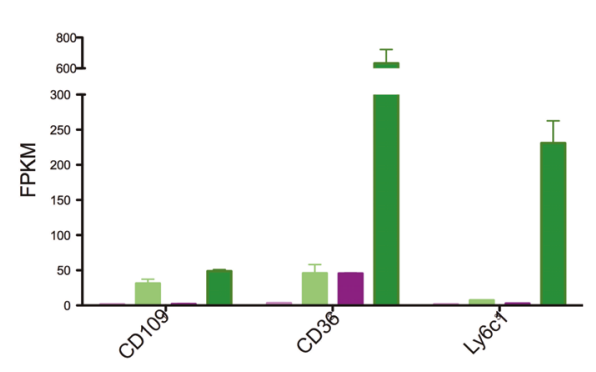

CPlexo E17.5
Figura 35. Marcadores de membrana para separar endocardio ventricular y vasculatura coronaria. (A) Se muestran algunos ejemplos de marcadores de membrana que podían emplearse para separar, dentro de la población endotelial CD31+, las subpoblaciones de endocardio y plexo coronario. Ejemplo del uso de Ly6c (C) y CD36 (D) para separar ambas poblaciones, obteniendo resultados similares a la separación realizada con el alelo Nes-Gfp (B).

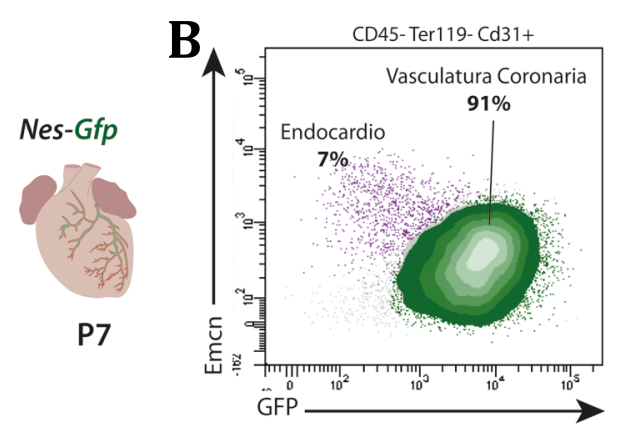

C

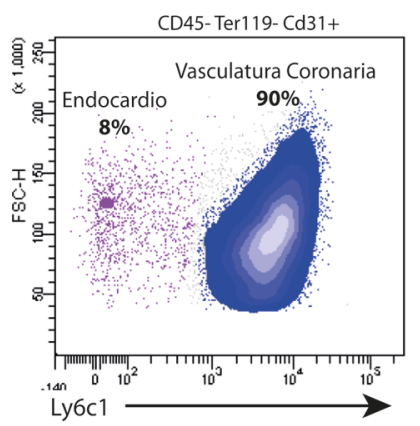

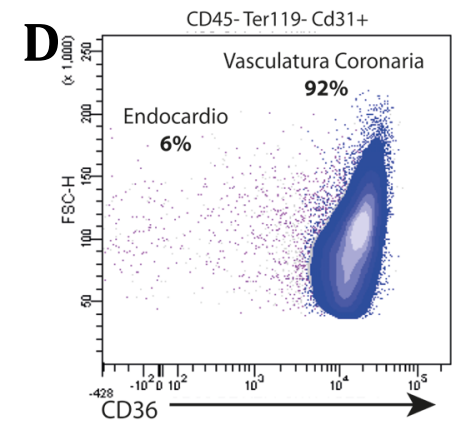

Los resultados obtenidos demuestran que sólo con el marcador Ly6c se puede obtener una separación eficiente por citometría de la población vascular coronaria con respecto al endocardio. Los resultados son similares a los obtenidos con el alelo Nes-Gfp en combinación del anticuerpo Endomucina. Por el contrario, con CD36 no se consigue una separación tan clara, ya que a pesar de estar muy expresado en la vasculatura, los bajos niveles en el endocardio dificultan la segregación de ambas poblaciones, existiendo una pequeña contaminación de células del endocardio en la población CD36+. 


\subsection{Perfil transcripcional de subpoblaciones enriquecidas en arterias/capilares del intramiocardio frente a supoblaciones enriquecidas en venas subepicárdicas}

En paralelo al perfil trancripcional realizado entre endocardio y vasculatura coronaria, se realizó otro en corazones triples Nes-CreER ${ }^{T 2}$; R26-Tomato; Nes-Gfp a E17.5, con la estrategia de trazado de linaje mencionada anteriormente (induciendo con $0.1 \mathrm{mg}$ tamoxifeno a E15.5). De esta forma, separamos por citometría las poblaciones de endocardio ventricular, plexo intramiocárdico (enriquecido en capilares y arterias) y plexo subepicárdico (enriquecido en venas). En este caso, hubo que amplificar las muestras para la secuenciación, ya que al necesitar corazones triple transgénicos, se extrajo el ARN de menores cantidades de tejido.

Nes-CreERT2; R26-Tomato; Nes-Gfp

A

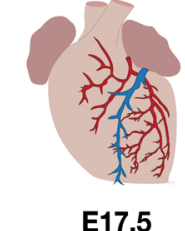

(0.1mg Tmx a E15.5)
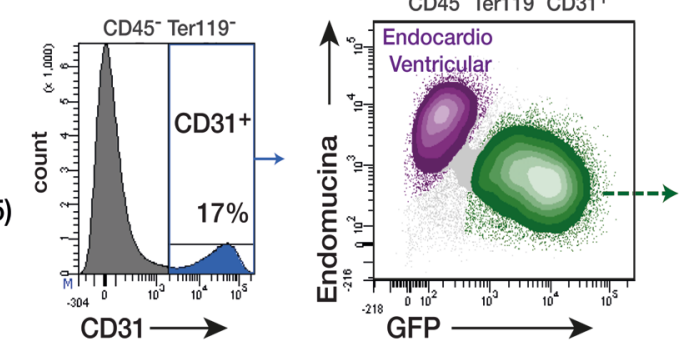

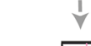

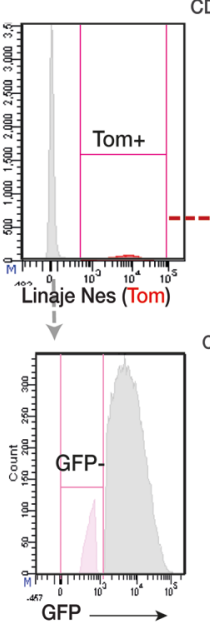

CD45- Ter119- CD31+ GFP+ ${ }^{+}$Tomato ${ }^{+}$Emcn ${ }^{-}$

Arterias/capilares Arterias/capilares
intramiocárdicos
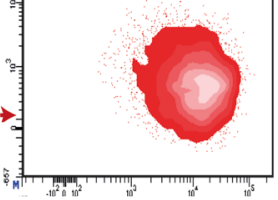

CD45" Ter119" CD31+GFP" Tomato" Emcn ${ }^{*}$

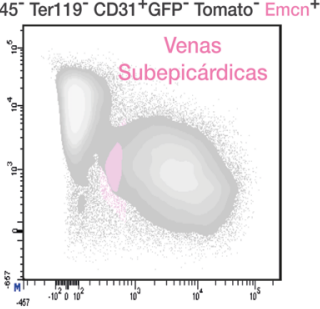

B
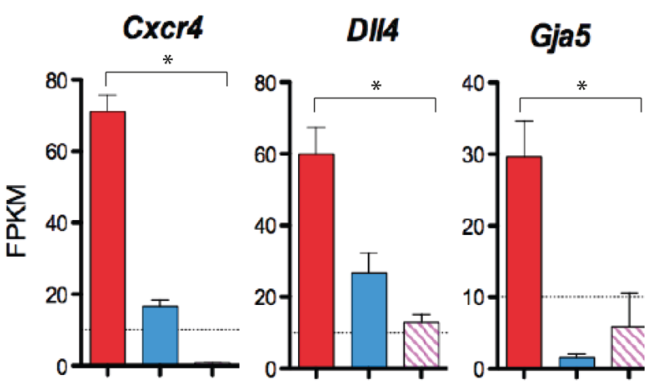

Aplnr

Edn1
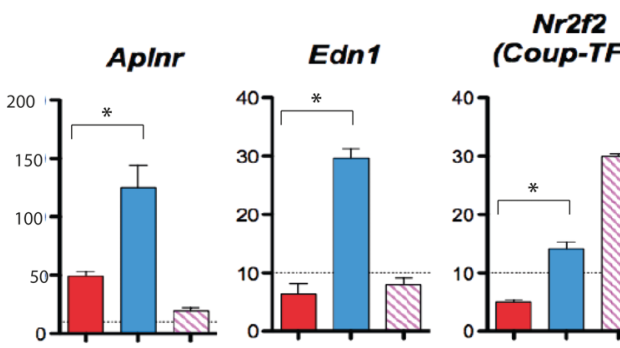

(Coup-TFII)

Arterias E17.5

Venas E17.5

(Plexo Intramiocárdico) (Plexo Subepicárdico)

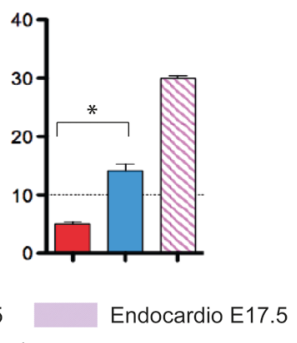

C

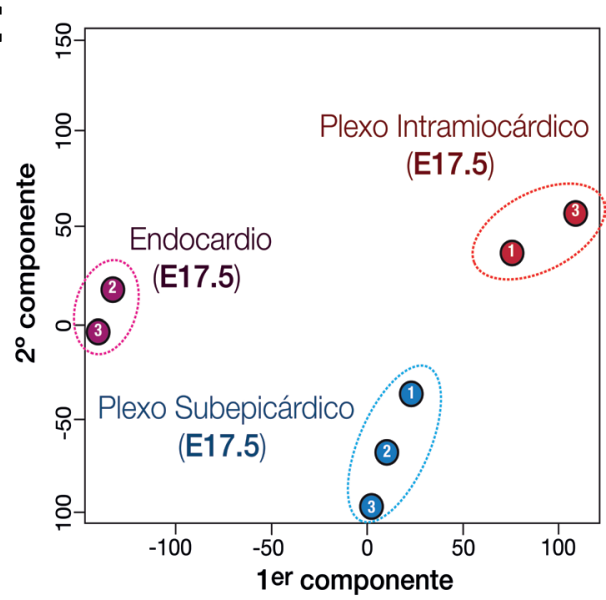

Figura 36. Separación de endocardio, capilares/arterias intramiocárdicos y venas subepicárdicas a E17.5 para el perfil transcripcional (RNAseq). (A) Estrategia de separación de las tres poblaciones por citometría de flujo. (B) Representación de la expresión de genes conocidos para arterias y venas, para mostrar el enriquecimiento en cada una de estas poblaciones. (C) PCA mostrando réplicas de cada población. * Estadísticamente significativo $\mathrm{p}<0,05$. 
De las tres réplicas de cada población, hubo una de endocardio y otra de plexo intramiocárdico que se alejaban mucho de las demás, por lo que estas dos las eliminamos para el análisis de genes diferencialmente expresados, dejando las que se muestran en el PCA .

La estrategia de separación consistía en primer lugar en separar el endocardio ventricular del resto de vasculatura coronaria, como se había realizado en experimentos anteriores. Después, de la población de plexo vascular, teníamos el trazado de linaje en tomato sólo en los capilares y arterias intramiocárdicas, por lo que se separó esta población GFP+Tom+Emcn- como arterias/capilares. Y finalmente, en la población negativa para tomato, teníamos las venas subepicárdicas y las arterias/capilares que no habían llegado a recombinar. Sin embargo éstas sabíamos que eran muy positivas para la GFP, por lo que separamos la población Tom- GFP- como venas subepicárdicas (Figura 36A). En la Figura 36B se muestran genes canónicos comúnmente empleados para la identificación de arterias (Cxcr4, DII4, Gja5) y venas coronarias (Nr2f2 o COUP_TFII, Aplnr, Edn1), respectivamente, para indicar el grado de separación entre ambas subpoblaciones coronarias. A su vez, el poder realizar la comparación de genes diferencialmente expresados en ambas subpoblaciones de un mismo pool de corazones, nos proporcionó nuevos marcadores para su identificación. Especialmente en el caso de las venas coronarias, ya que los marcadores generalmente empleados en venas adultas no necesariamente nos permiten identificar este subconjunto de vasculatura coronaria en los estadios embrionarios en los que las venas no han madurado completamente. Entre ellos destacamos los genes $D p t$ y Ogn por expresarse diferencialmente tanto de las arterias coronarias como del endocardio ventriuclar (Figura 37A).

El resultado del análisis de los genes diferenciales entre arterias y venas se representa en un GO plot circular en la Figura 37B. Algunos de los genes enriquecidos en arterias que se muestran son Cxcl12, su receptor Cxcr4, Gja5 (conexina 40), Enpp2 y la Semaforina3g. Por su parte, en la población enriquecida en venas subepicárdicas destacamos algunos como $D c n$, los colágenos Col3a1 y Col1a1, Dpt, Tbx20, Dlk1 y Plxnc1.

Otra de las comparaciones llevadas a cabo, además de la expresión de genes arteriovenosos, fue la expresión diferencial entre las subpoblaciones arterial y endocárdica. En la Figura 37C de representa un Volcano Plot con algunos de los genes más diferenciales de endocardio ventricular a E17.5 (Npr3, Gpr126, Emcn, Cldn11...) frente a genes enriquecidos en arterias coronarias y capilares intramiocárdicos (Fabp4, Dach1, Nestina, Gja5, Sox17, Cxcl12...).

Figura 37. (Página siguiente) Análisis de genes diferencialmente expresados entre venas y arterias/capilares. (A) Ejemplo de genes diferencialmente expresados en venas subepicárdicas, resaltando Ogn y Dpt por tener una expresión muy baja en el resto de poblaciones endoteliales. (B) Plot circular GO plot de genes enriquecidos en venas o arterias con las ontologías asociadas. (C) Volcano Plot con genes diferenciales entre endocardio ventricular y arterias/capilares. 

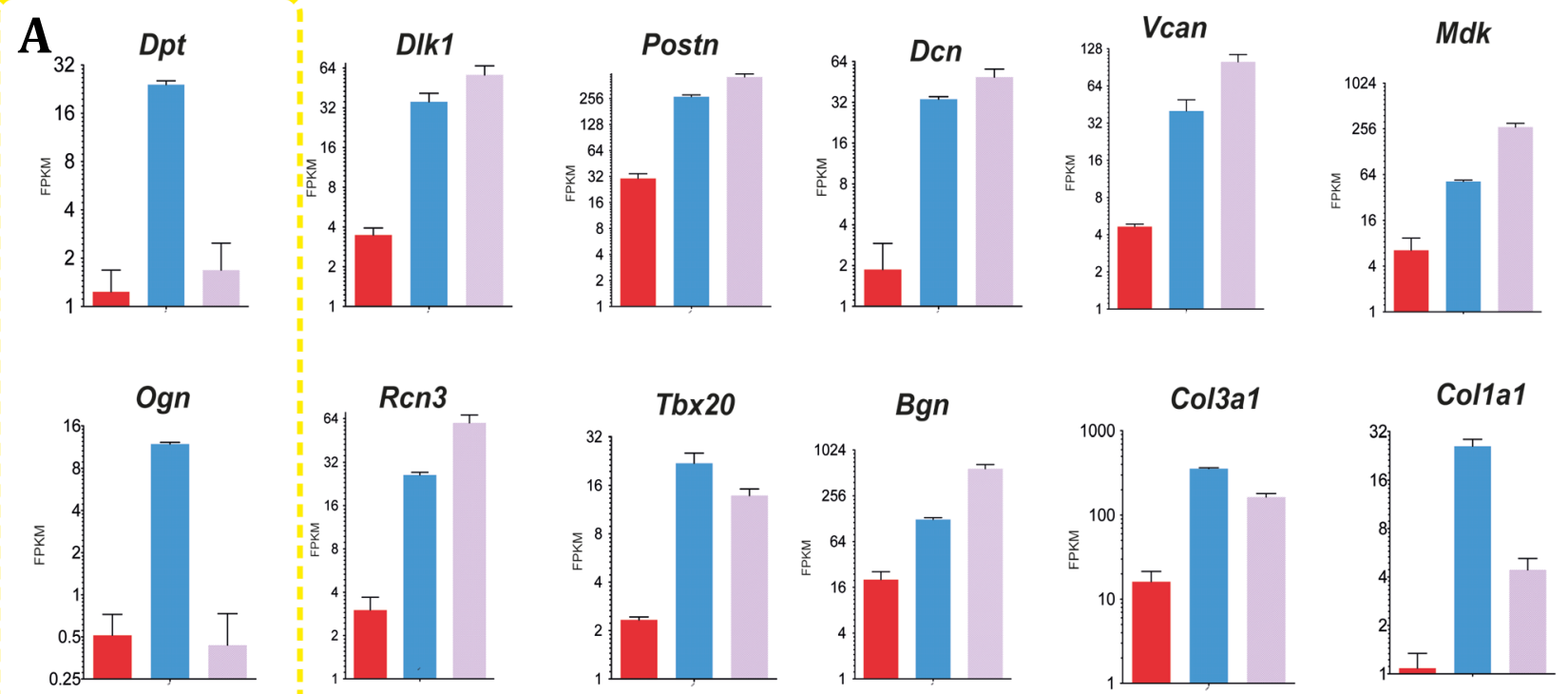

Arterias E17.5

(Plexo Intramiocárdico)

Venas E17.5

Endocardio E17.5

(Plexo Subepicárdico)

B

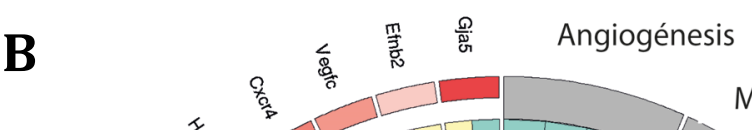
Morfogénesis Arterial
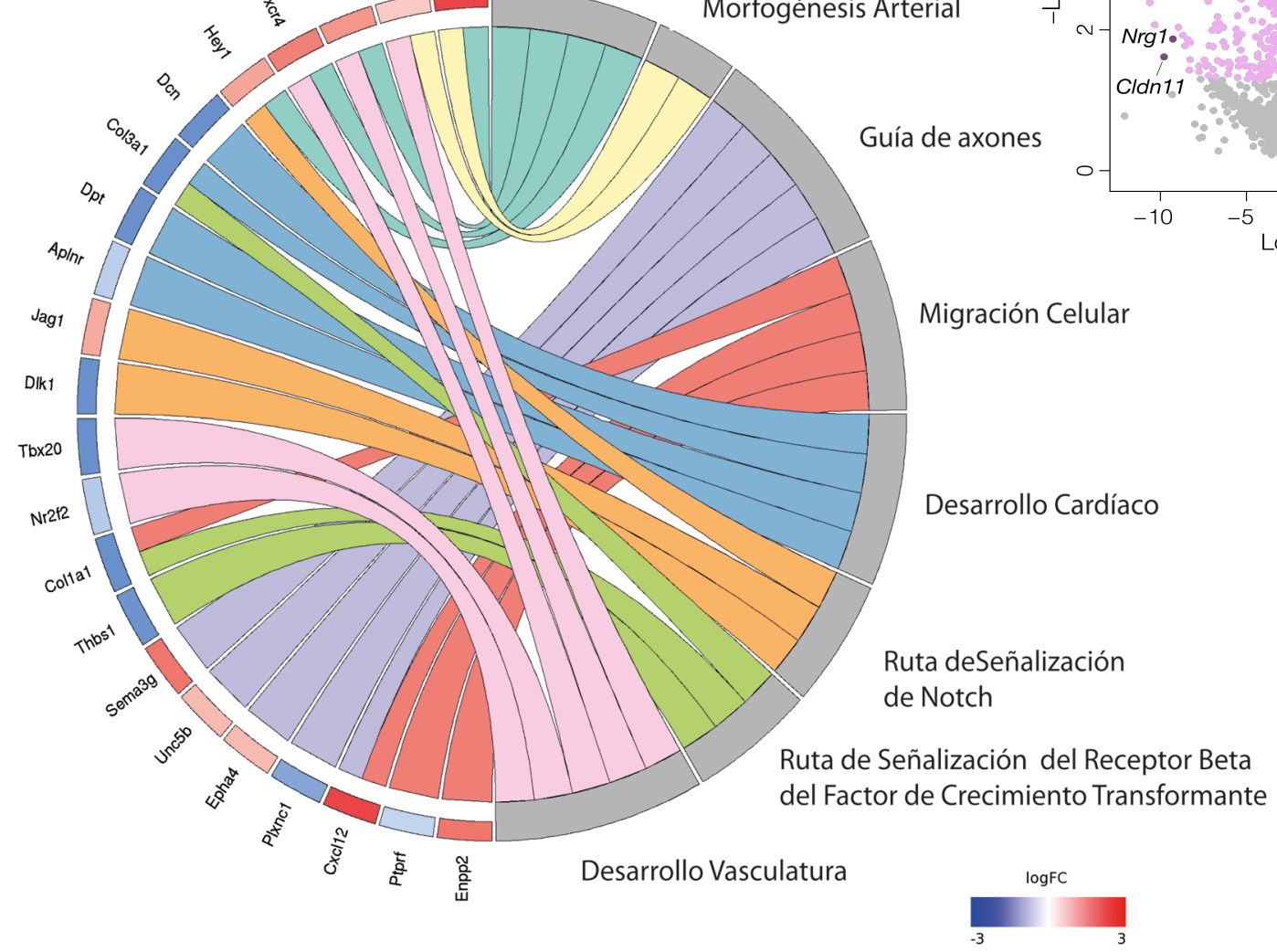


\section{5o Los Miembros de la Subfamilia Soxf Podrían Activar El Enhancer Neural}

\section{De Nestina En la Vasculatura Angiogénica}

El alelo Nes-Gfp nos permitía marcar con el reportero GFP el plexo primitivo procedente del SV y endocardio que comenzaba a invadir el órgano cardíaco a estadios tempranos del desarrollo, quedando finalmente restringida su expresión al plexo intramiocárdico que maduraba en las arterias coronarias y capilares, y perdiéndose casi por completo en las venas coronarias del subepicardio tras el remodelado de la vasculatura. Por otra parte, se sabía que la expresión de la GFP dependía casi exclusivamente de la región reguladora presente en el enhancer neural del intrón 2 del gen Nestina de rata (i2E). Por este motivo, independientemente del resto de linajes celulares en los que se encontrase activo (pericitos, músculo liso vascular, etc), particularmente en el endotelio coronario, el alelo parecía ser un buen reportero del proceso de especificación arterial de la vasculatura en desarrollo.

Dado que el enhancer neural de Nestina se correspondía con una secuencia discreta de ADN (1.6 kb), si encontrábamos factores de transcripción o proteínas de unión al ADN que se uniesen específicamente a dicha secuencia, serían candidatos a ser proteínas implicadas en la regulación de este proceso de especificación arterial. Por ello, en el análisis de genes diferencialmente expresados entre las poblaciones endoteliales, buscábamos genes que se comportasen con el mismo patrón que la GFP: sin expresión en el endocardio ventricular y expresados en la vasculatura coronaria, pero que a su vez tuviesen un incremento importante en la expresión de E13.5 a E17.5, quedando tras el remodelado vascular principalmente restringidos a arterias intramiocárdicas (cluster II). De los genes encontrados con este patrón de expresión, decidimos centrar nuestro estudio en la familia de factores de transcripción SoxF, concretamente en el FT Sox17, dada su implicación en el desarrollo del sistema cardiovascular.

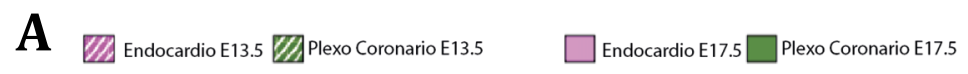

Figura $\quad 38 . \quad$ Perfil transcripcional de la familia SoxF. (A) Niveles de expresión en FPKM de los miembros de SoxF (Sox7, Sox17 y Sox18) en las poblaciones de endocardio y vasculatura coronaria a E13.5 y E17.5. (B) Destacamos Sox17 por estar diferencialmente expresado en el plexo coronario, incrementado los niveles de E13.5 a E17.5, y además presentar tras el remodelado mayor expresión en la subpoblación enriquecida en Arterias/Capilares (A) que en las venas del subepicardio (V), donde también se expresa. (C) Perfil de expresón del reportero GFP. * Estadísticamente significativo $\mathrm{p}<0,05$.
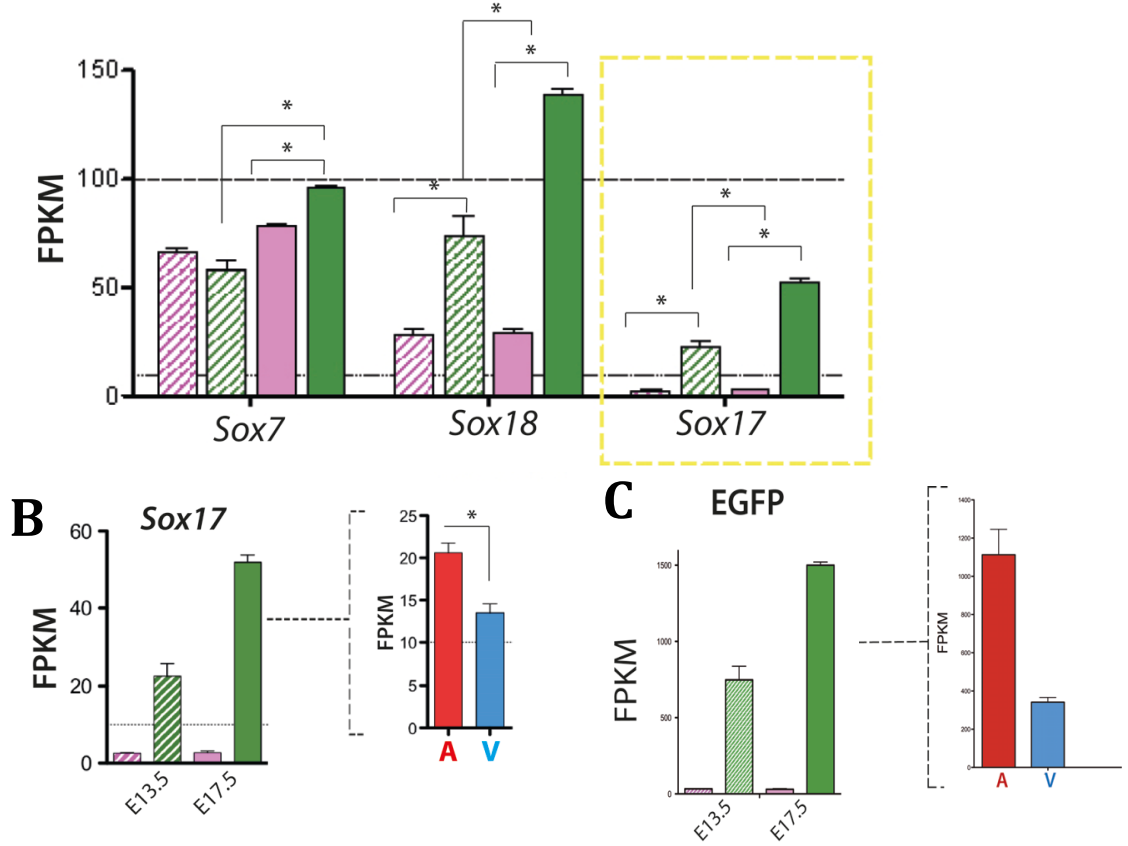
5.1 Sox17 es detectado en los primeros brotes de la vasculatura coronaria que emerge del seno venoso a E11.5

Del mismo modo que habíamos caracterizado el patrón de expresión del alelo Nes-Gfp con el uso de la microscopía confocal en los diferentes estadios del desarrollo embrionario y posnatal, tratamos de caracterizar por inmunofluorescencia el patrón de expresión de la proteína Sox17.
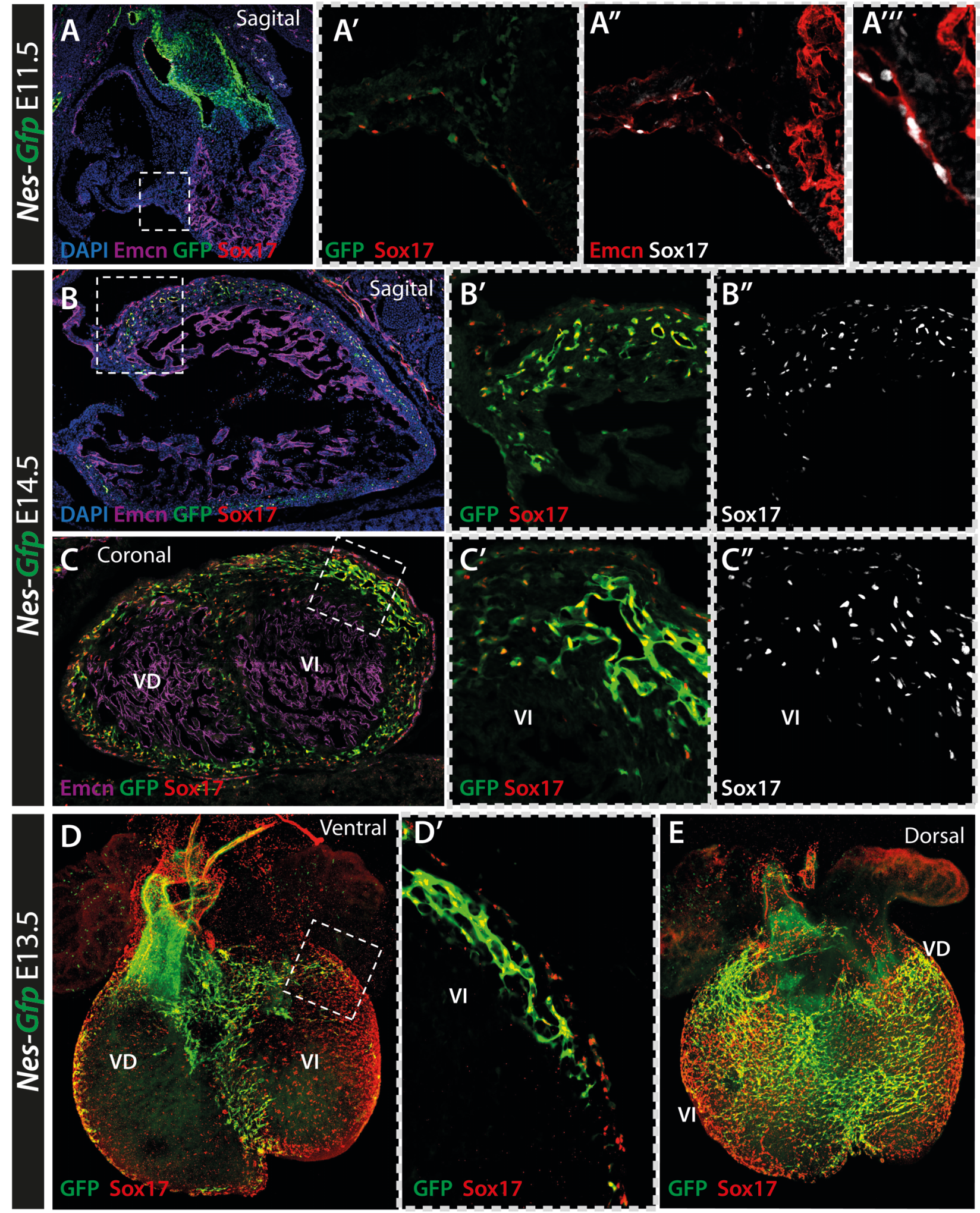
Figura 39. Expresión de Sox17 en la vasculatura durante la fase de expansión angiogénica. (A-B) Cortes sagitales de corazones a E11.5 y E14.5, respectivamente. (C) Corte coronal de corazón a E14.5. (D-E) Whole-mount de corazones enteros a E13.5 por las caras ventral y dorsal, respectivamente. VI, ventrículo izquierdo; VD, ventrículo derecho.

Tal y como se observa en la figura 39, las primeras células que brotan del seno venoso e invaden el miocardio (marcadas con endomucina en $A^{\prime \prime}$ ) ya expresan el factor de transcripción Sox17. Esta proteína se encuentra presente en todo el plexo coronario primitivo que se expande durante la fase activa de angiogénesis, pero no es detectado en las células del endocardio. Del mismo modo que ocurre con el reportero Nes-Gfp, a partir de E13.5, cuando la intensidad de la GFP comienza a reducirse en el plexo subepicárdico (que dará lugar a las futuras venas), también observamos una reducción en la expresión de Sox17 en esta población (Figura 39 B", C').
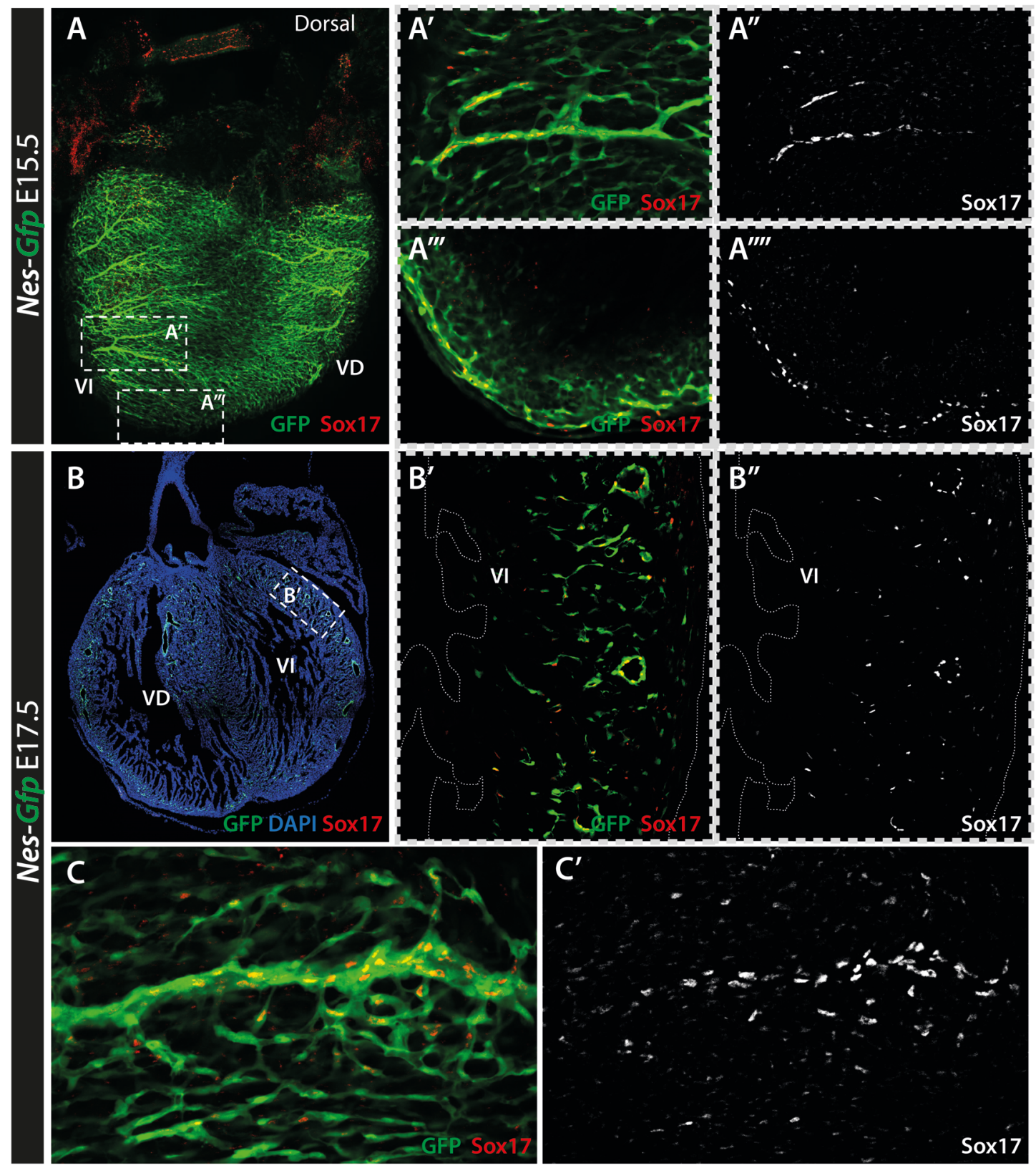

Figura 40. Expresión de Sox17 en la vasculatura remodelada. (A) Whole-mount de corazón a E15.5 donde se amplifica una arteria y el ápex. (B) Corte fino de corazón a E17.5. (C) Whole mount a E17.5 donde se amplifica una arteria coronaria madura. 
Una vez que la vasculatura se ha remodelado, el factor de transcripción queda restringido al endotelio de las arterias y arteriolas, perdiéndose en la mayor parte de capilares donde sí se expresaba durante la expansión angiogénica (Figura 40). Por este motivo, Sox17 es considerado como un marcador arterial.

Dado que el plexo primitivo en expansión parecía requerir de la presencia de esta proteína para su correcto desarrollo, decidimos examinar su patrón de expresión en los mutantes de Cxcl12 KO donde, a pesar de formarse el plexo coronario, fallaba en el remodelado de los grandes vasos. En el estadio de E13.5 no parecía haber diferencias entre los corazones mutantes y controles. Sin embargo a E15.5, cuando debería de comenzar a producirse el remodelado, observamos que en los mutantes deficientes de Cxcl12 la proteína Sox17 Ve sobreexpresa en las células del endocardio, un dominio donde de forma normal no hay expresión (Figura 41).

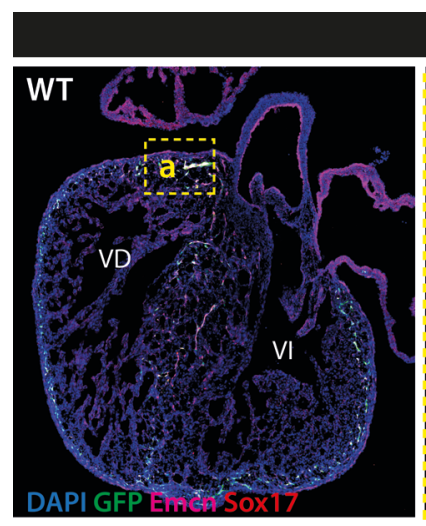

\section{Cxcl12; Nes-Gfp E16.5}
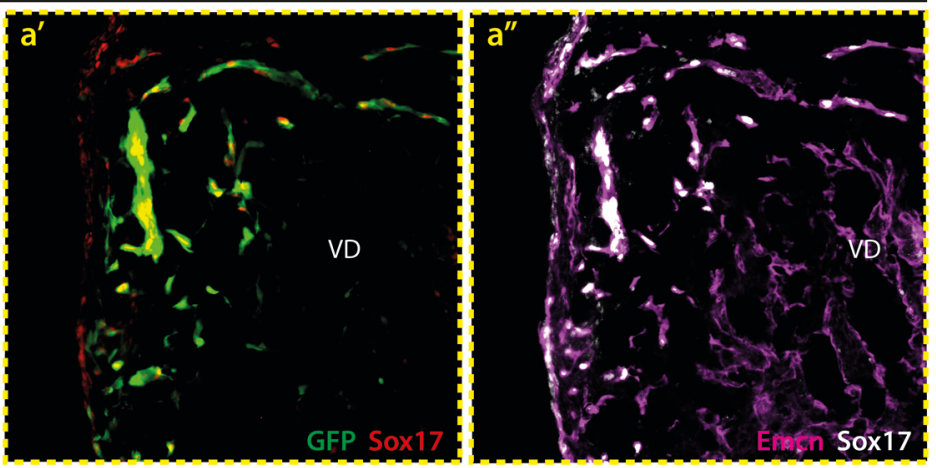

$\begin{array}{ll}\text { Figura } & 41 . \\ \text { Expresión } & \text { de }\end{array}$ Sox17 en los mutantes de Cxcl12. Se muestran cortes de corazones WT y KO a E15.5 y se amplifican las regiones del
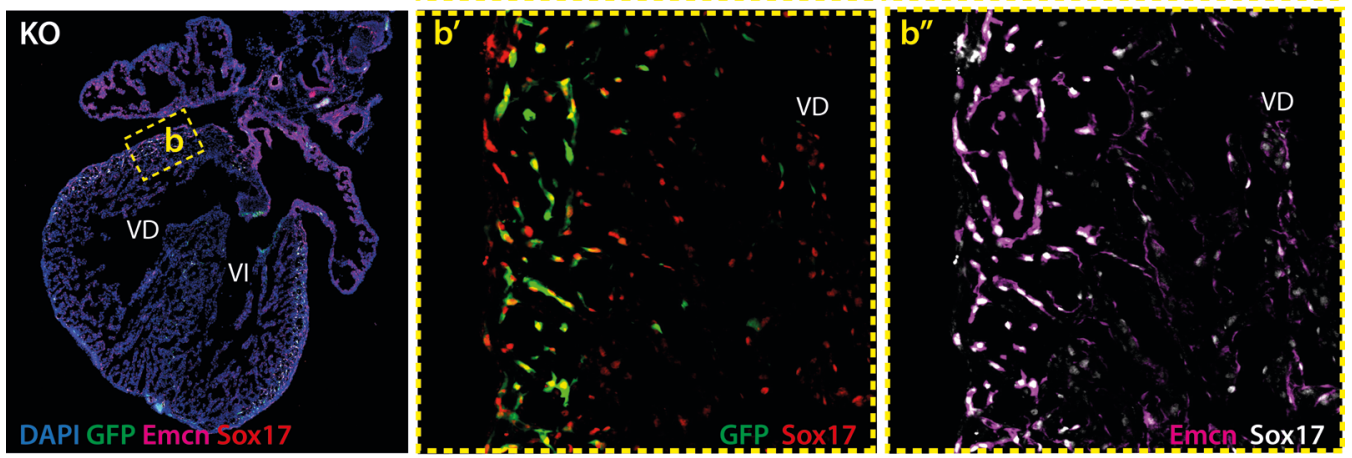
ventrículo derecho (VD) donde se observa que en el mutante Sox17 reactivado en la zona del endocardio ( $\left.b^{\prime \prime}\right)$ mientras que en el WT se restringe al plexo coronario $\left(a^{\prime \prime}\right)$

De forma paralela, en el laboratorio de Red-Horse han descrito recientemente que en el mutante de APJ, deficiente en la formación de la vasculatura coronaria procedente del seno venoso, el plexo endocárdico derivado de las islas de sangre intenta compensar la deficiencia presente en estos ratones, que llegan a ser viables por este fenómeno. Durante dicha compensación describen que el endocardio comienza a expresar también Sox17 (Sharma et al., 2017). Esto sugiere que, independientemente de cual sea la mutación que impide el correcto desarrollo vascular, el endocardio es capaz de reactivarse para tratar de suplir la ausencia de plexo coronario[SURFHGHQWH[GHRWDVGXHOMAV, y para adquirir el estado angiogénico $\square$ requiere $\square$ de (1)DFUYDFLYQTGHQI DFVRUSSOX17. 


\subsection{Generación de líneas celulares para la sobreexpresión de los factores Sox17 y}

\section{Sox18}

Los experimentos de células en cultivo in vitro se realizaron con el emplHR [GH la línea comercial de células vasculares inmortalizadas MCEC (Mouse $\underline{\text { Cardiac }}$ Endothelial Cells). Para intentar caracterizar el perfil de expresión de estas células, se extrajo ARN y se realizó una RTPCR con diferentes genes de endocardio, plexo enriquecido en arterias/capilares intramiocárdicos, y plexo enriquecido en venas. En general estas células mostraron una mezcla de expresión de marcadores de distintas subpoblaciones endoteliales. Sin embargo bajo las condiciones de cultivo, la expresión de los diferentes miembros de la familia SoxF (Sox7, Sox17 y Sox18) fue inapreciable, así como Sox13, que también se encuentra muy expresado de forma normal en la vasculatura coronaria en desarrollo.
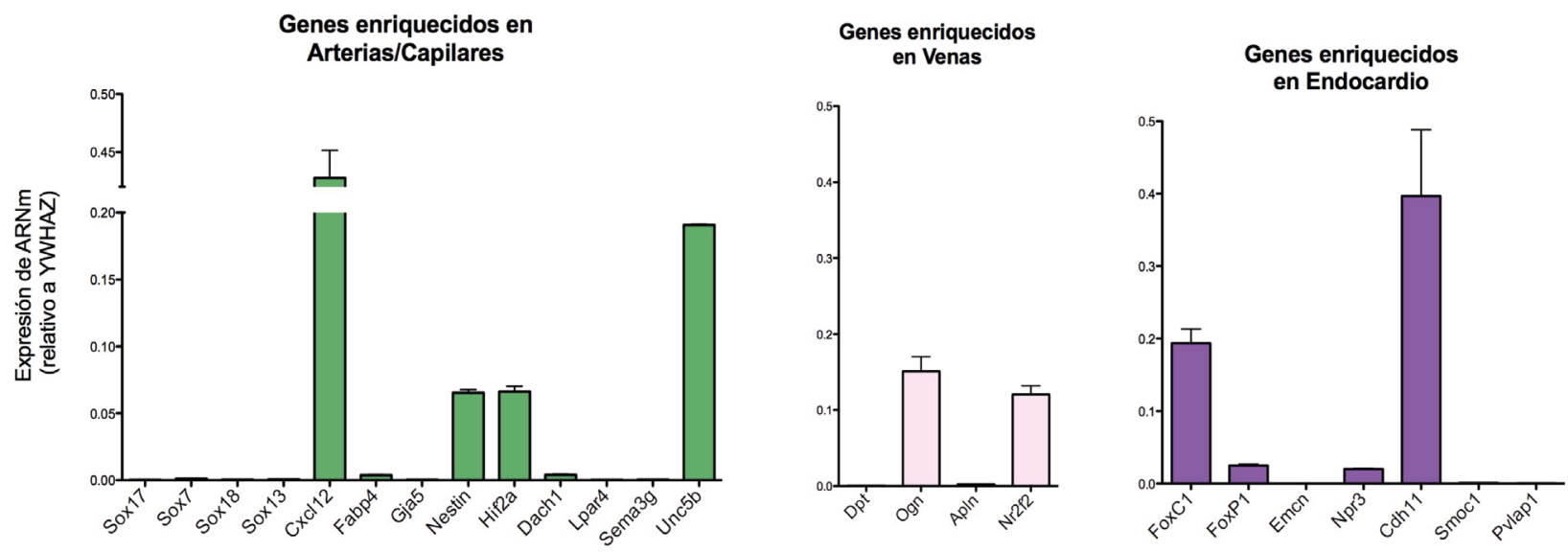

Figura 42. Análisis de expresión por RT-PCR de las MCEC. Se muestran los niveles de expresión de algunos genes seleccionados de plexo intramiocárdico, venas subepicárdicas y endocardio para ver el perfil de estas células in vitro.

Dado que las MCEC no expresaban los factores Sox, generamos dos transposones para expresar de forma inducible los genes Sox17 y Sox18 en estas células. Para ello, con el sistema de HiFi Assembly, introducimos el ORF de los genes Sox (obtenidos sintéticamente) en el vector del transposón Sleeping Beauty ( $\mathrm{pBH} / \mathrm{T} 2)$. Estas construcciones a su vez, eran inducibles por doxiciclina, contenían un reportero fluorescente BFP y resistencia a higromicina (figura 43A-B).

Figura 43. Generación de
construcciones Sleeping Beauty para
integrarlas por transposición en el
genoma de las MCEC. (A-B)
Construcciones para la sobreexpresión de
Sox17 y Sox18, respectivamente,
dependientes de doxiciclina. (C)
Construcción para la expresión del
reportero Tomato controlado por el
elemento regulador i2E del gen Nestina de
rata.

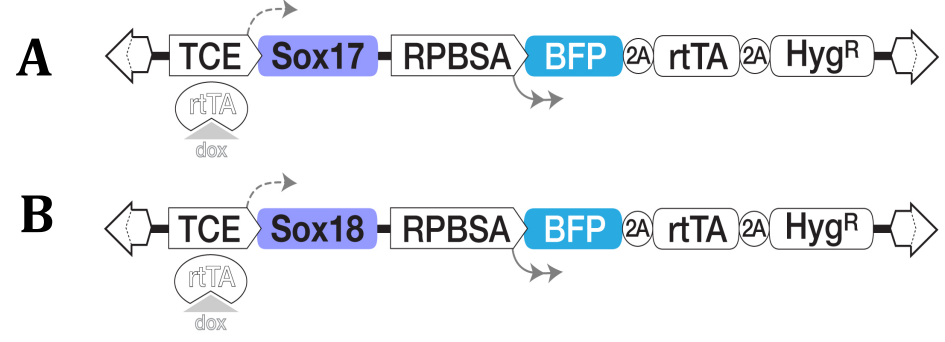

C

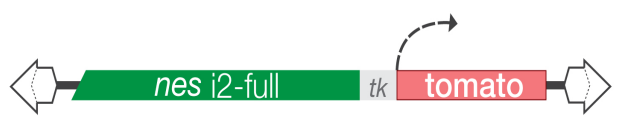


Las MCEC se transfectaron con cada uno de los transposones por separado en combinación del plásmido que codificaba para la transposasa, que al ser expresada dentro de las células, provocaría un número de integraciones al azar de los transposones en el genoma de la célula hospedadora. Para eliminar aquellas células donde no se habían producido integraciones, las MCEC transfectadas se sometieron a una selección con higromicina $B(500 \mathrm{ng} / \mathrm{mL})$ durante una semana, obteniendo así placas policlonales donde cada célula tenía un número diferente de integraciones y en distintas partes del genoma. De forma paralela, se generó una línea en la que se introdujo el transposón de sobreexpresión de Sox17 junto a otro transposón que contenía el i2E $5^{\prime}$ al reportero tdTomato (Figura 43C). En este caso, las células MCEC que los integrasen, al no expresar ninguno de los factores Sox, no encenderían el enhancer y por tanto el reportero Tomato estaría apagado. Al inducir con doxiciclina la sobreexpresión de Sox17, veríamos si este factor sería suficiente para unirse al enhancer y activar la expresión del reportero.

Pero para poder realizar estos ensayos, primero era necesario tener clones de células idénticos. Para ello las tres líneas policlonales que se habían generado (MCEC_Sox17; MCEC_Sox18 y MCEC_Sox17_i2E_Tom), se sortearon en base a la fluorescencia BFP en placas de 96 de forma que en cada pocillo hubiese una única célula y se dejaron crecer los clones. De todos los que crecieron, se chequearon varios de cada línea celular para ver los niveles de Sox con y sin inducción de doxiciclina. Para descartar el posible efecto de la doxiciclina en la expresión de los genes, reanalizamos la expresión de las MCEC con y sin dox, observando que no había grandes diferencias entre ambas condiciones (Figura 44A). A la vista de los resultados obtenidos, seleccionamos los clones MCEC_Sox17 \#2, MCEC_Sox18 \#8 y MCEC_Sox17_i2E_Tom \#56 para realizar los experimentos. En la Figura 44 se muestran los clones seleccionados en los que a su vez se analizó la expresión de genes chequeados previamente en las MCEC. La sobreexpresión de ambas proteínas Sox conllevaba a un fuerte incremento del gen Co/4a1 en todos los clones. Por otra parte, los clones en los que se sobreexpresaron Sox17 y Sox18 parecían reducir levemente la expresión de genes como Nr2f2, Cdh11 y FoxC1 (salvo en el caso del \#56), asociados a un fenotipo más venoso y endocárdico; mientras que la presencia de Sox17 incrementaba la expresión de CxCl12. Con respecto a la línea MCEC_Sox17_i2E_Tomato, se comprueba que únicamente se expresa el reportero Tomato cuando se induce la expresión de Sox17 (Figura 44D).

Para comprobar que el clon MCEC_Sox17 \#2 producía correctamente la proteína, adicionalmente se realizó una tinción de inmunofluorescencia con anti-Sox17 para comprobar que sólo detectábamos el anticuerpo nuclear cuando las células se inducían con doxiciclina (Figura 44E) 

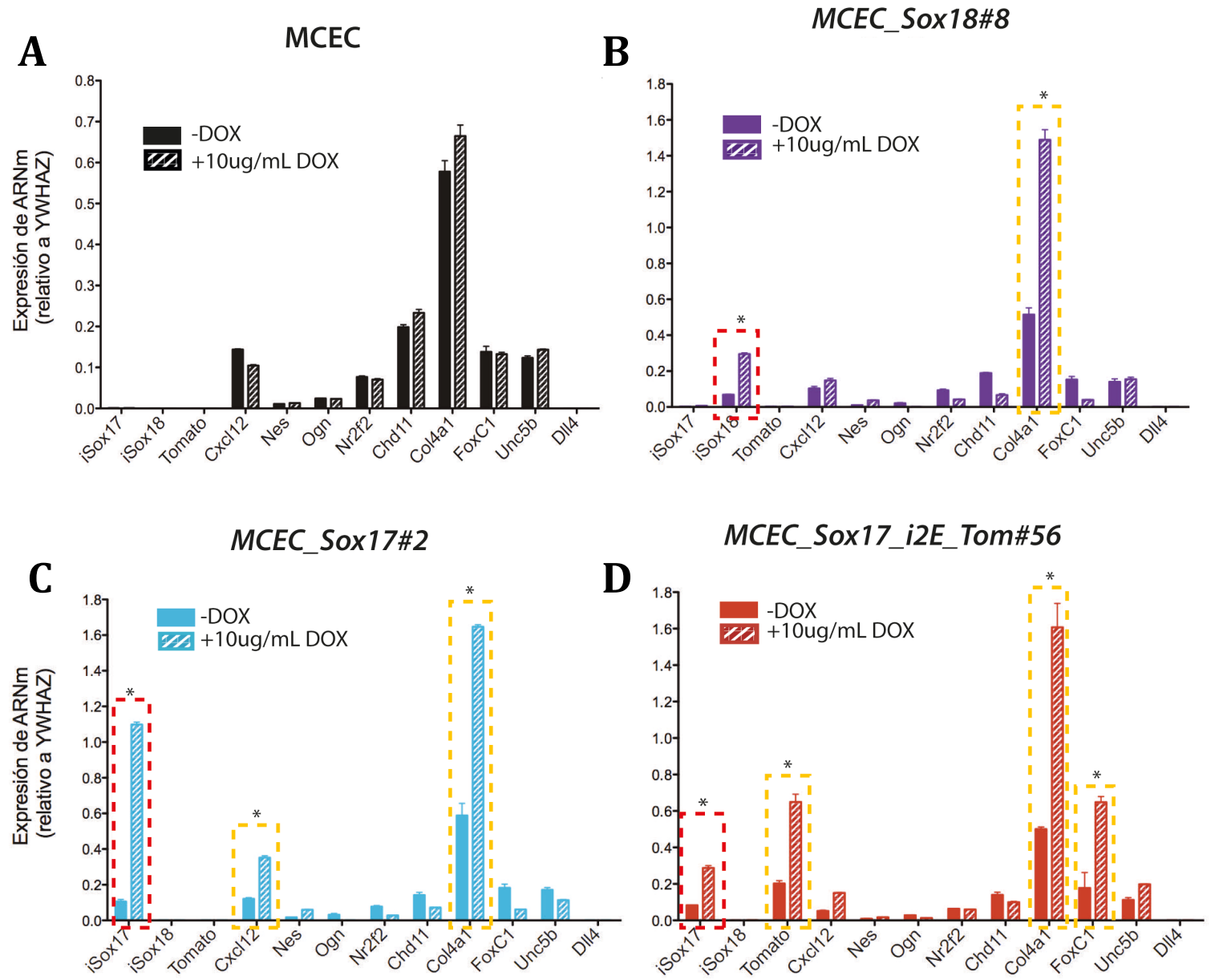

$\mathbf{E}$

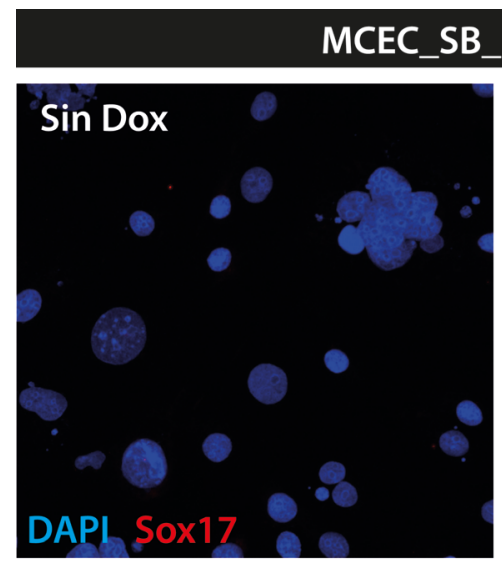

\section{B_Sox17_Clon \#2}
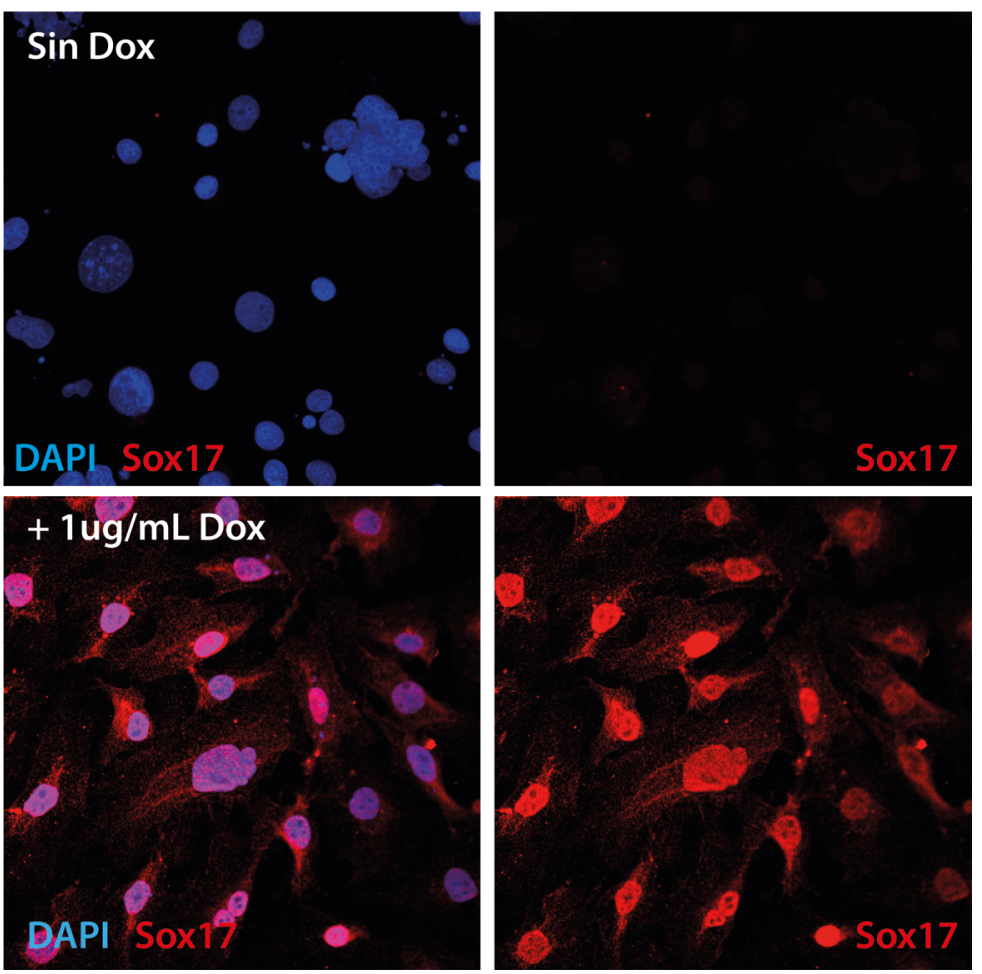

Figura 44. Análisis por RTPCR del comportamiento de los clones tras administrarles doxiciclina. (A) MCEC con y sin doxicilina en el medio (10 ug/ $\mathrm{mL}$ ).

(B) Clon MCEC_Soc18\#8. Se observa la sobreexpresión con los oligos iSox18.

(C) Clon MCEC_Sox17\#2. Se observa la sobreexpresión con los oligos iSox17. (D) Clon MCEC_Sox17_Tom\#56. Se obseva la sobreexpresión de Sox17 y Tomato, indicando que el i2E se encuentra activo únicamente en presencia de Sox17.

(E) Inmunofluorescencia con anti-Sox17 en clones sin inducción y tras la inducción de DOX. * Estadísticamente significativo $\mathrm{p}<0,05$. 


\subsection{El análisis funcional de los sitios putativos de unión los factores Sox en el i2E}

\section{demuestra que Sox17 por sí solo es capaz de activar el enhancer neural de Nestina}

Mediante el alineamiento de diferentes especies (rata, ratón, humano y oveja) de la secuencia completa del i2E encontramos distintos sitios putativos de unión para los factores SOX. Elegimos dos de ellos en base al grado de conservación entre especies, denominados CR1 y CR2 ( $C R$, de Conserved Region). Estudios realizados por el laboratorio de Kondoh en Shangai validaron in vivo que en el sistema nervioso la activación del i2E dependía de la unión de los factores de transcripción a los sitios SOX:POU contenidos en CR2. En concreto, en este tejido se producía la unión de Sox1/2/3/11 y Brn2 (Tanaka et al., 2004). Sin embargo por los datos de nuestro perfil transcripcional sabemos que en el endotelio coronario los factores POU no se encuentran presentes. Tan sólo detectamos el factor Pou6f1, pero su expresión es igual en células del endocardio (donde el enhancer permanece inactivo) y de la vasculatura coronaria. Por ese motivo pensamos que la activación del enhancer en este caso debería producirse por la combinación de Sox17 con otros co-factores diferentes.

A
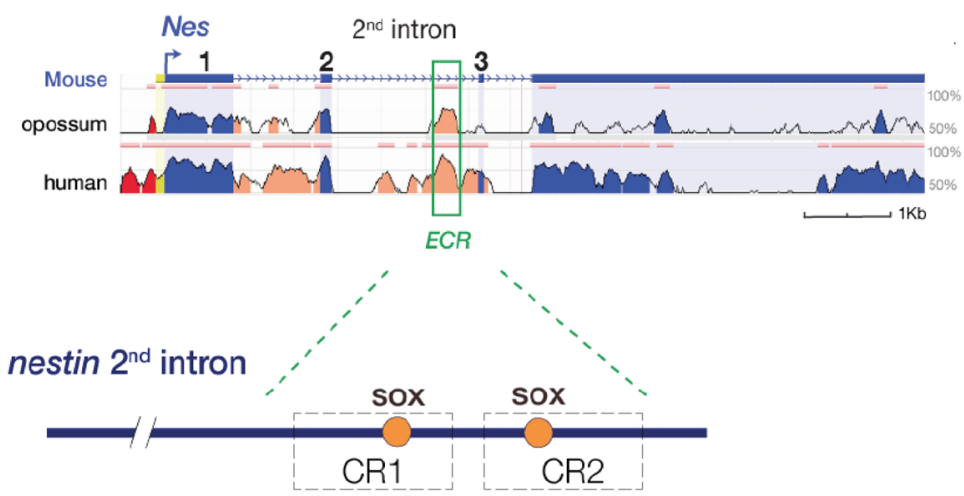

B

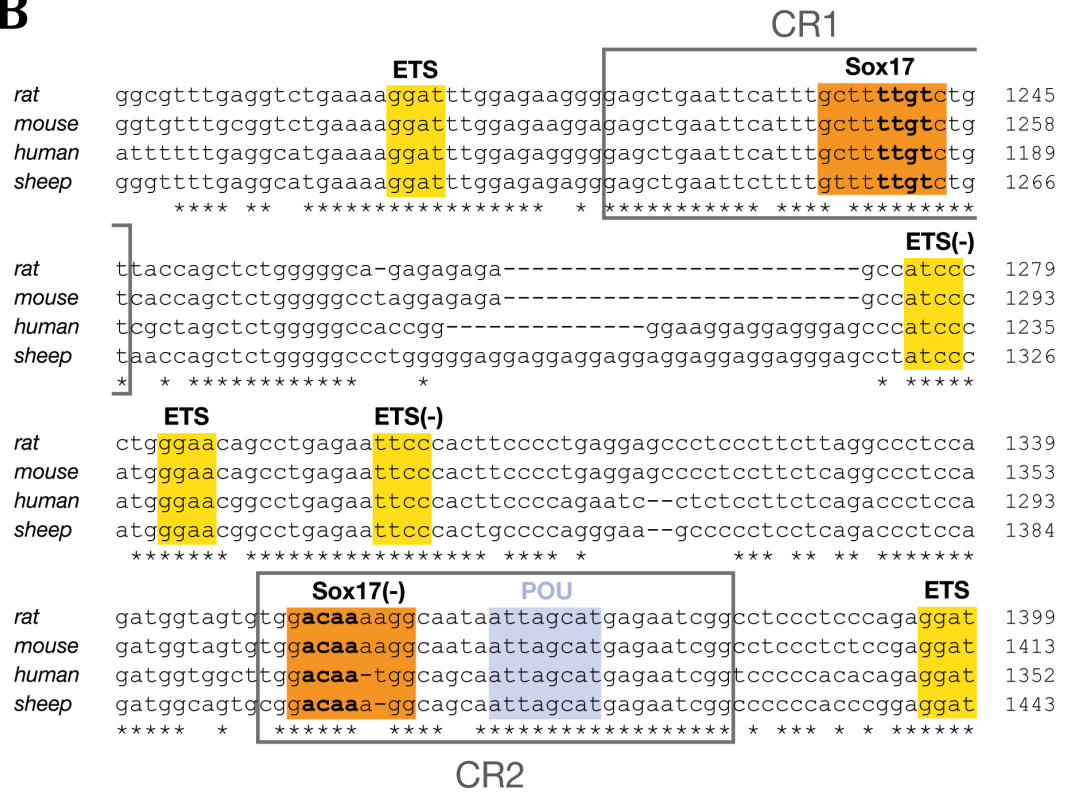

Figura 45. EL alineamiento de secuencias el i2E entre varias especies muestra regiones muy conservadas. Se muestra una parte de la secuencia del enhancer neural contenido en el segundo intrón del gen de Nestina para observar las regiones conservadas, como los sitios de unión putativos para factores ETS, y las regiones denominadas CR1 y CR2 que contienen sitios putativos de unión para los factores SOX. 
Para demostrar que Sox17 interaccionaba con las regiones CR1 y CR2 presentes en el enhancer, realizamos un ensayo de EMSA (Electrophoretic Mobility Shift $\underline{A s s a y) . ~ L a ~ p r o t e i ́ n a ~}$ Sox17 se sobreexpresó in vitro usando el clon MCEC_Sox17\#2 y se extrajo el extracto nuclear de proteínas de estas células. Se diseñaron parejas de oligos que contenían las secuencias CR1 y CR2 marcadas con fluorescencia. Para las condiciones de competición, se usaron las mismas secuencias de oligos CR1 y CR2 sin marcar. Estos se ponían 100 veces más concentrados que los oligos marcados. También se diseñaron oligos mutantes en los que se cambiaron los 6 nucleótidos necesarios para la unión de los factores Sox a sus motivos en el ADN.

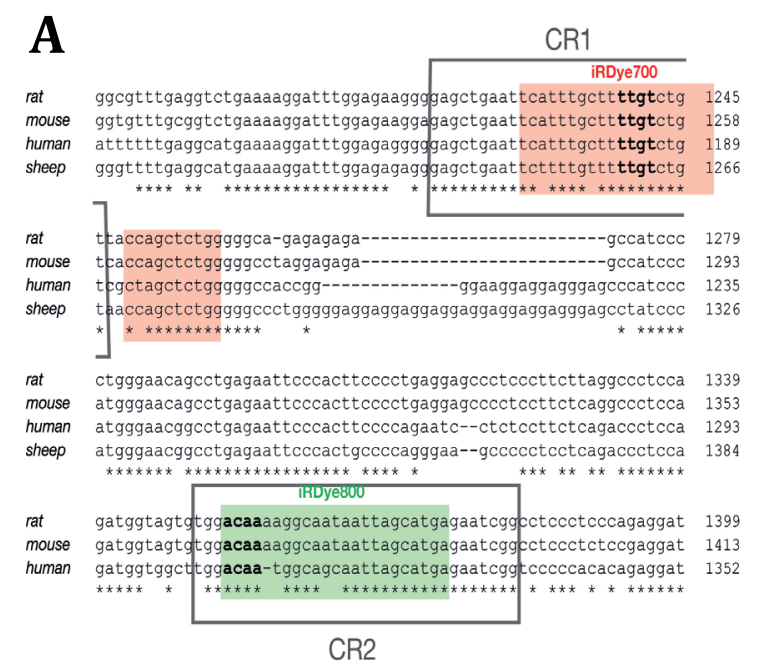

Diseño de oligos paraEMSA:

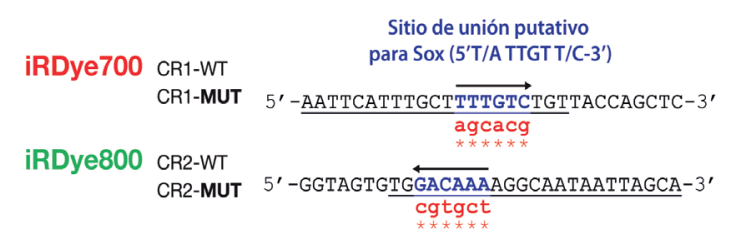

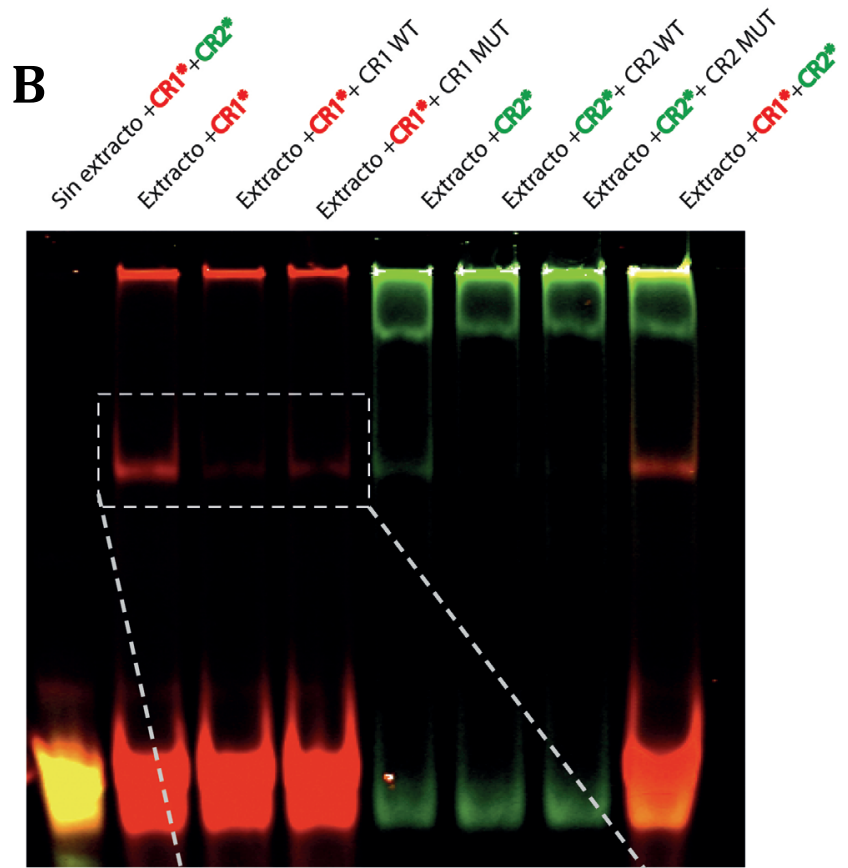

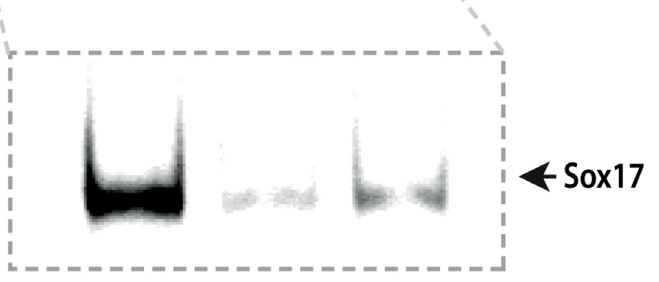

Figura 46. Análisis por EMSA de la interacción de Sox17 con los sitios putativos de unión al ADN. (A)Diseño de oligos empleados para el ensayo, tanto WT como mutantes. Se muestra en la secuencia del i2E a qué zonas de las regiones CR1 y CR2 corresponden (cajas roja y verde, respectivamente. (B) Ensayo de EMSA.

Estos datos demuestran que nuestra proteína de interés, Sox17, interacciona físicamente con los sitios de unión presentes en las regiones CR1 y CR2. Sin embargo, a pesar de los estudios previos realizados en ratón donde las proteínas Sox se unen al sitio SOX:POU contenido en el CR2, en endotelio parece que la mayor especificidad se encuentra en el CR1. Se observa el retardo de la unión Sox17 con el oligo CR1 (en rojo). Cuando se realiza la competición con el oligo CR1 sin marcar (100 veces más concentrado), perdemos la banda casi por completo. Esta 
se vuelve a recuperar cuando los oligos que compiten están mutados únicamente en los 6 nucleótidos homólogos a la secuencia consenso de unión de Sox17. En el caso del CR2 obsevamos dos tipos de retardo diferentes, indicando que se forman dos complejos distintos de proteína-ADN. El complejo de mayor tamaño parece ser completamente independiente de Sox17, ya que no se observa ninguna diferencia cuando se produce la competición con los oligos WT y mutados. Esto significaría que en nuestro extracto nuclear de proteínas hay factores, diferentes a Sox17, que se unen a la región CR2. El segundo complejo que migra a la misma altura que en el caso de CR1, sí parece ser dependiente de Sox17, sin embargo es más débil y se pierde la banda con la competencia tanto de los oligos WT como mutantes.

Este ensayo de EMSA nos indica que la proteína Sox17 puede interaccionar físicamente con los sitios SOX de unión al ADN contenidos en el i2E, sin embargo no es suficiente para predecir si dicha interacción es capaz de activar la expresión del enhancer neural de Nestina. Con el objeto de responder esto, realizamos ensayos de actividad luciferasa en células in vitro generando diferentes construcciones en las que la Gaussia luciferasa se encontraba bajo la regulación del i2E completo (i2_full), o de secuencias en las que VH[GHOHFFLRQDEDQGlas regiones conservadas

A

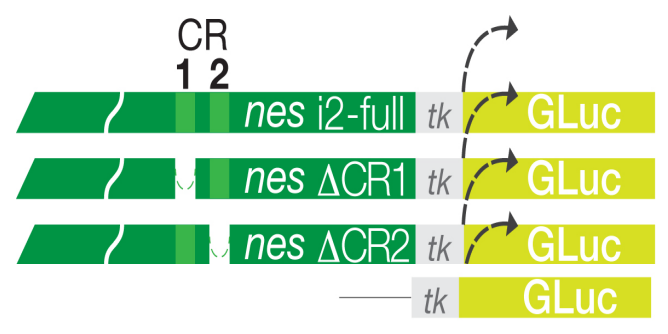

Figura 47. Estudio de la actividad del enhancer i2E mediante ensayos de actividad luciferasa en MCEC. (A) Esquema de las construcciones generadas con el enhancer completo, sus formas mutadas para CR1 y CR2, y la luciferasa sin elemento regulador en $5^{\prime}$. (B) Esquema de la estrategia de co-transfección con los plásmidos de luciferasa, fosfatasa alcalina SEAP y vector de sobreexpresión de los factores Sox. (C) Ensayo de luciferasa sobreexpresando Sox17 y (D) Sox18. URL, Unidades Relativas de Luciferasa. Estadísticamente significativo $\mathrm{p}<0,05$.
B

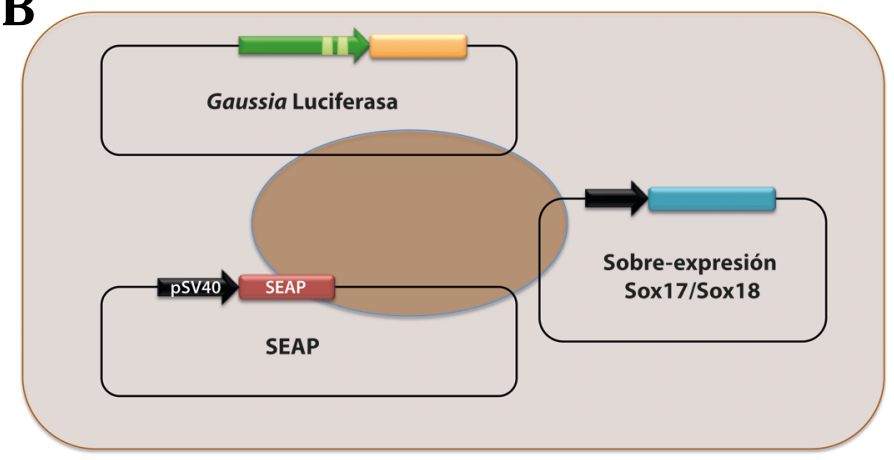

C

MCEC (pcDNA_Sox17)

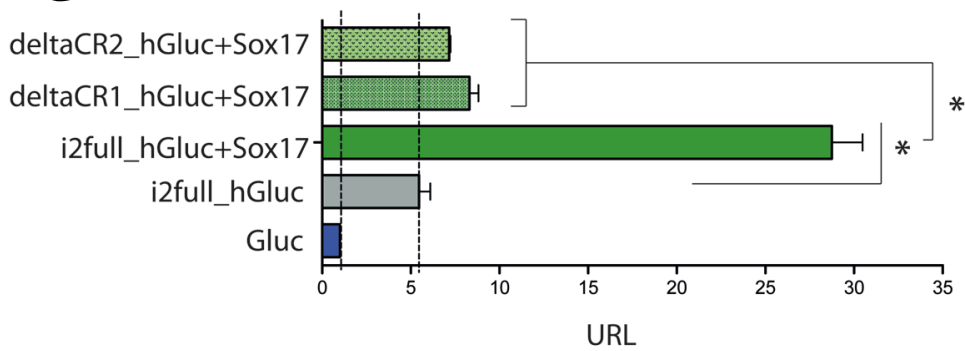

D

MCEC (pcDNA_Sox18)

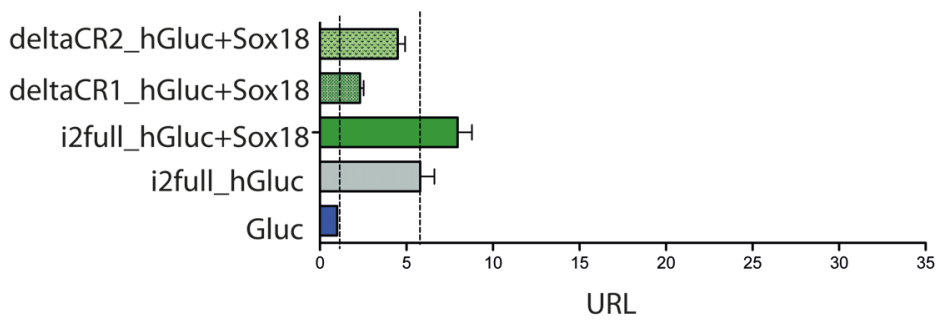


(i2full_deltaCR1, i2_full_deltaCR2). Las células se transfectaron con los plásmidos que expresaban la Gaussia luciferasa bajo cada una de las versiones del enhancer. El plásmido de la SEAP se transformaba en menor cantidad (1/5), para servirnos como control de la transfeccion. Según la condición, se transformaron también los plásmidos que sobreexpresaban las proteínas Sox17 y Sox18 de forma constitutiva (figura 47 C-D).

Los ensayos de la actividad luciferasa revelaron que la construcción i2_full_hGluc sin sobreexpresión de Sox17 aumentaba 5 veces los niveles de luciferasa con respecto al control pGluc vacío (sin enhancer clonado en $5^{\prime}$ ). Sin embargo, al sobreexpresar Sox17, los niveles de luciferasa se incrementaron casi 30 veces con respecto al Gluc vacío y 6 veces con respecto al i2full_hGluc sin Sox17. Con respecto a las versiones mutantes del enhancer, tanto al delecionar la región CR1 como la CR2 observamos un descenso en la actividad luciferasa con respecto al enhancer completo, aunque la actividad no se llegaba a perder completamente (Figura 46C). Realizamos el mismo ensayo sobre-expresando Sox18, pero en este caso no observamos la misma activación del enhancer que con la presencia de Sox17. Esto nos indicaría que, a pesar que ambos genes se encuentran diferencialmente expresados en la vasculatura coronaria donde se activa el alelo Nes-Gfp, dicha activación dependería principalmente de la unión de Sox17 a las secuencias SOX contenidas en el enhancer, posiblemente en combinación de otras proteínas activadoras (Figura 47D).

De forma paralela, además de las MCEC también empleamos el clon MCEC_ Sox17\#2 (inducible con doxiciclina). En este caso, únicamente era necesario transfectar el clon con las construcciones de las luciferasas e inducir la sobreexpresión de las proteínas Sox con la administración de doxicilina en el medio de cultivo $(10 \mu \mathrm{g} / \mathrm{mL})$. Los resultados obtenidos fueron similares, la construcción con el i2E completo tenía más actividad que el vector de la luciferasa vacío, y al inducir la sobreexpresión de Sox17 se incrementaba dicha activación. Sin embargo los ensayos de luciferasa demostraron ser muy sensibles a la presencia de antibióticos y los resultados no salían tan reproducibles administrando DOX como en el caso de las células MCEC normales.

\section{MCEC_Sox17 \#2}

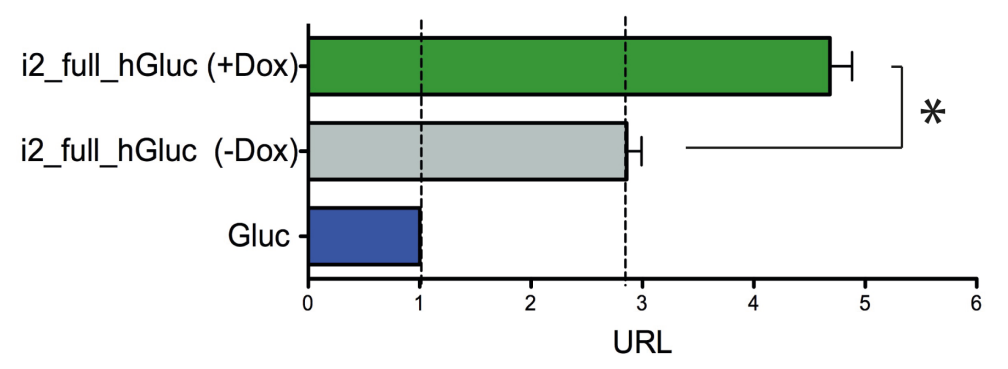

Figura 48. Ensayos de luciferasa en el clon inducible con Dox. Se muestra cómo en estas células sin inducir hay cierta actividad luciferasa, que aumenta cuando se administra doxiciclina para sobreexpresar la proteína Sox17. URL, unidades relativas de luciferasa. * Estadísticamente significativo $\mathrm{p}<0,05$. 
Otra forma de demostrar que la proteína Sox17 era capaz de activar por sí sola la expresión del i2E, fue con el uso de la línea celular MCEC_Sox17_i2full_Tomato \#56. Como ya se ha comentado, en las condiciones normales de cultivo las células MCEC no expresan los factores Sox, por lo que el enhancer permanece inactivo (células Tomato-). Al administrarse doxiciclina durante varios días, vemos cómo las células comienzan a expresar el reportero Tomato (Figura 49). A pesar de ser monoclonales, no todas las células se comportan igual a la

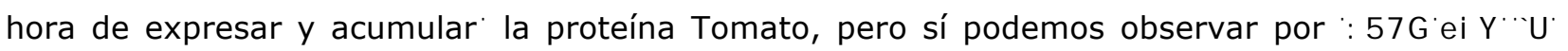
tendencia de estos clones es la de activar el reportero. Esto podría explicarse porque en concreto la inducción de Sox17 no es demasiado alta, como mostraban los datos $[\mathrm{GH} \square 57[3 \& 5$ de la Figura 44D.

Por todo lo anterior se demuestra que, si bien el enhancer requiere de la unión de Sox17 junto con otros cofactores para alcanzar la máxima activación de forma sinérgica, únicamente con este factor de transcripción ya se obtenía activación.

Una vez analizado la actividad del enhancer en modelos de células in vitro, quisimos a su vez estudiar dicha activación in vivo, mediante el modelo de "transient transgenics". En primer lugar quisimos expresar in vivo la construcción generada con el enhancer completo que regulaba la expresión del reportero tomato para reproducir el patrón de la GFP endógena en los embriones Nes-GFP+. Si esto funcionaba, generaríamos los transgénicos con las versiones mutantes del enhancer para ver si en ausencia del CR1 o CR2 perdíamos dicho patrón.

A

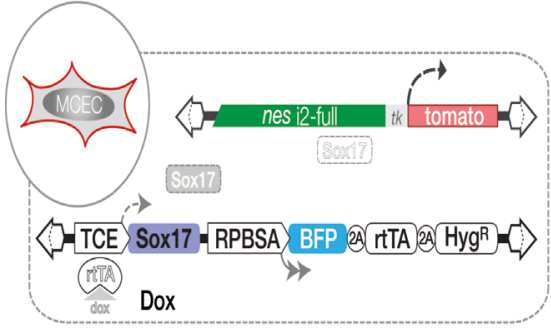

C

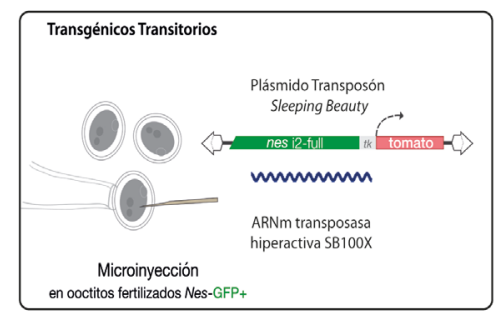

B

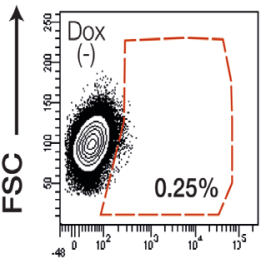

Reportero Tomato
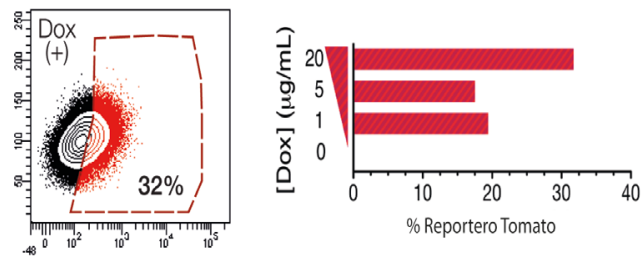

$\%$ Reportero Tomato

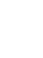


Se produjeron varias sesiones de microinyección pronuclear con el transposón del enhancer completo ( $\left.p S B(T 2) \_i 2 f u l l \_T K \_T o m a t o \_p A\right)$ en presencia del ARNm de la transposasa hiperactiva SB100X en zigotos Nes-GFP+. Los embriones transgénicos se analizaron en el estadio embrionario E14.5 y se genotiparon por PCR para detectar la presencia de integraciones del transposón en el genoma. A pesar de que la mayoría resultaron ser positivos para las integraciones (22/27), aproximadamente el 50\% mostraba fluorescencia en tomato. De los embriones positivos para el reportero, en algunos casos tuvimos mosaicismo, pero hubo varios embriones que reprodujeron a nivel macroscópico el patrón de la GFP endógena (figura 49D), especialmente en cerebro medio y tubo neural, donde el alelo Nes-Gfp se expresa con mayor intensidad. Sin embargo, cuando analizamos los corazones, la expresión de reportero Tomato obtenida con las integraciones discretas del transposón no era suficiente para visualizarse en la vasculatura coronaria. Es por ello que tuvimos que descartar esta estrategia para analizar las versiones mutantes del i2E.

\section{6o La Pérdida De Función De los Miembros de Soxf En El Endotelio} Angiogénico Podría Impedir El Correcto Desarrollo de la Vasculatura CORONARIA

Una vez mostrado bioquímicamente que Sox17 interaccionaba con los sitios SOX contenidos en las regiones C1 y CR2, y que además era capaz de encender el enhancer en células in vitro, decidimos generar un modelo de perdida de función para ver cómo afectaba la ausencia de estos factores de transcripción en el desarrollo de la vasculatura coronaria en

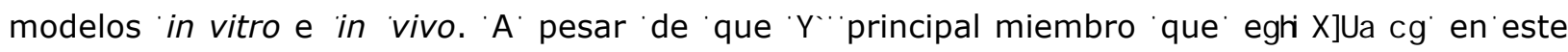
proceso era Sox17, estudios previos habían demostrado la redundancia existente entre los tres miembros de la familia SoxF y su capacidad para compensarse unos a otros en caso de deficiencia de alguno de ellos. También había sido descrita la mutación RaJ J HGOpossum generada de forma espontánea en la proteína Sox18, que aún sin conocerse exactamente el mecanismo de actuación, parecía actuar como dominante negativo del resto de proteínas Sox en las células donde se expresaba (Green and Mann, 1961, Pennisi et al., 2000, Downes and Koopman, 2001). Por este motivo, obtuvimos de forma sintética el gen mutante de Sox18 para expresar la variante Sox18-RaOp en la vasculatura coronaria.

\subsection{Ensayos de angiogénesis en explantes de corazón embrionario como modelo de pérdida de función in vitro}

Ya que con el trazado de linaje Nestina induciendo la CreER a E12.5 conseguíamos marcar toda la vasculatura coronaria (exceptuando endocardio), decidimos realizar explantes de ápex de corazones embrionarios para ver si los vasos marcados realizaban una expansión angiogénica en condiciones de cultivo in vitro. 
Para ello empleamos los ratones triples transgénicos Nes-CreER ${ }^{T 2}$; R26-Tomato; Nes-Gfp inoculando el tamoxifeno a E12.5 y sacando los corazones a E13.5-14.5. Los ápex de los corazones se colocaban en un sándwich de colágeno y se dejaba solidificar durante $30 \mathrm{~min}$ en el incubador antes de añadir el medio de cultivo M199 (suplementado con $10 \mathrm{ng} / \mathrm{mL}$ de VEGF-A). para favorecer el crecimiento de los brotes vasculares, los explantes se mantenían durante una semana en condiciones de hipoxia $\left(3 \% \mathrm{O}_{2}\right.$ y $\left.5 \% \mathrm{CO}_{2}\right)$.

Nes-CreER ${ }^{T 2}$; R26-Tomato; Nes-Gfp
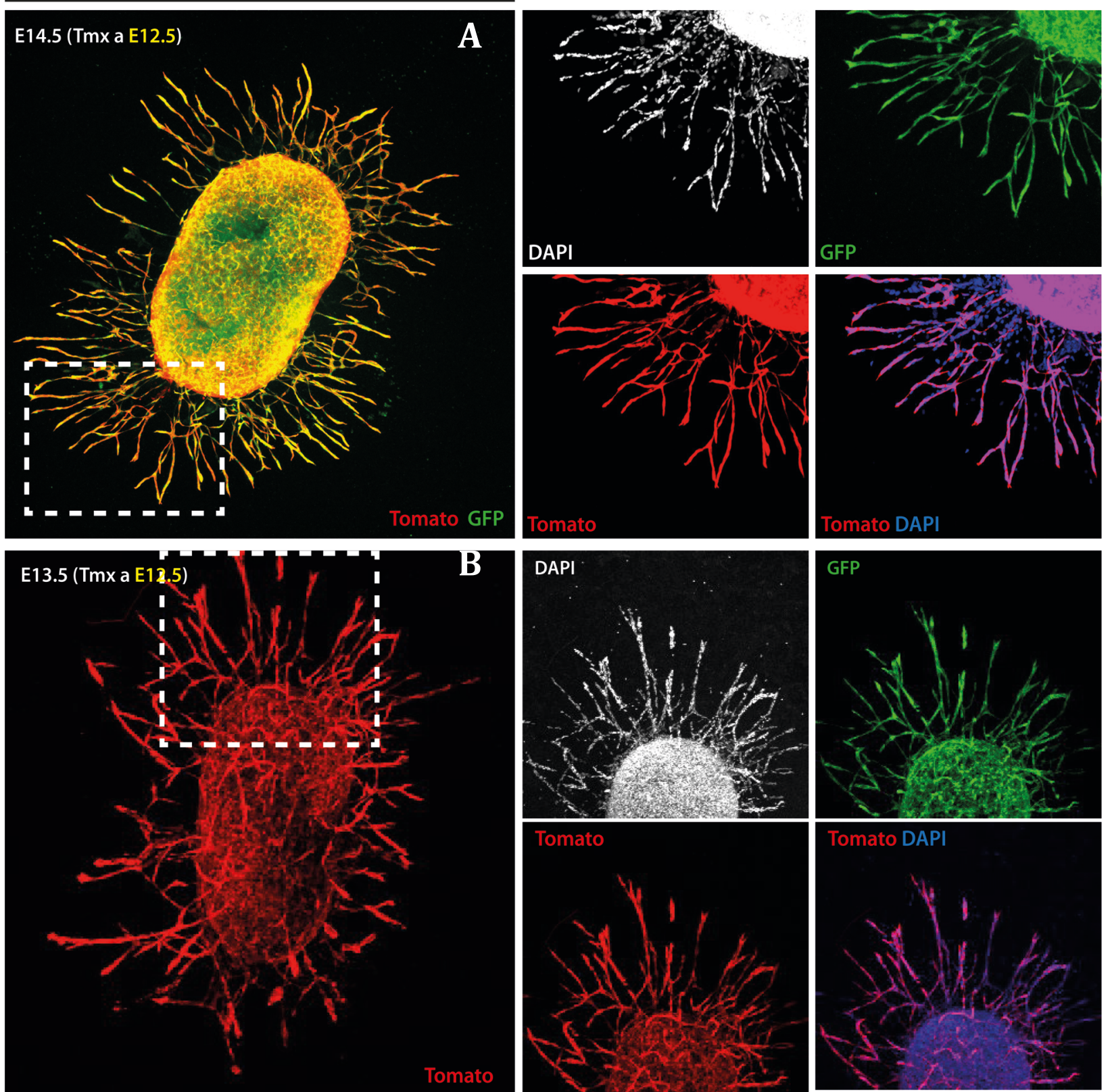

Figura 50. Explantes de ápex de corazones in vitro. (A) Explantes de ápex de corazón triple transgénico inducido con Tmx a E12.5 y extraído a E14.5. Todos los vasos que se expanden mediante angiogénesis se encuentran marcados en Tomato (linaje Nestina). (B) Explante de corazón a E13.5 inducido a E12.5 
En la figura anterior se muestra un ejemplo de explantes a E14.5 y E13.5 inducidos con tamoxifeno a E12.5. Todos los brotes endoteliales observados se encuentran marcados en tomato, debido a la eficacia de la CreER en la vasculatura coronaria. A su vez, el alelo Nes-Gfp permanece activo incluso teniendo los explantes una semana creciendo in vitro, lo que indicaría que el i2E se encuentra activo en estas células en las que la angiogénesis se encuentra activa.

Teniendo este modelo de expansión de la vasculatura coronaria in vitro, quisimos estudiar qué pasaría si eliminásemos los miembros de SoxF mediante la sobreexpresión de la proteína dominante negativa Ragged Oppossum. Para ello, generamos una construcción mediante el sistema pMule que nos permitía expresar el gen Sox18-RaOp, obtenido sintéticamente, en un vector para empaquetarlo en lentivirus. De esta forma podríamos infectar los explantes con estos virus que expresarían la proteína truncada, y veríamos si habría algún efecto en el crecimiento de los brotes angiogénicos. Como control, se produciría la infección en paralelo de explantes con lentivirus cuya construcción no contiene la proteína mutante, tan sólo el reportero fluorescente iRFP (Figura 51).
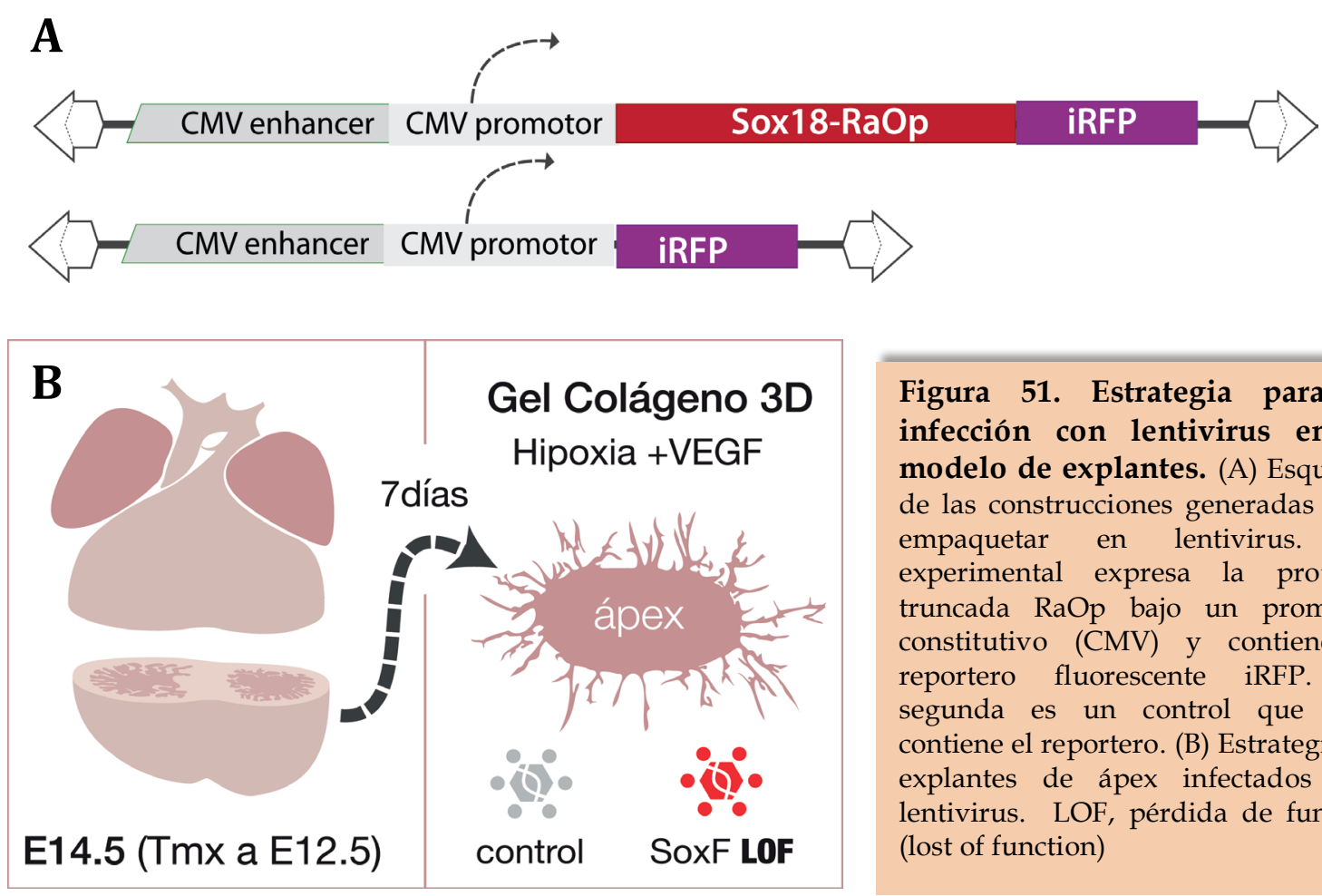

Figura 51. Estrategia para la infección con lentivirus en el modelo de explantes. (A) Esquema de las construcciones generadas para empaquetar en lentivirus. La experimental expresa la proteína truncada RaOp bajo un promotor constitutivo (CMV) y contiene el reportero fluorescente iRFP. La segunda es un control que sólo contiene el reportero. (B) Estrategia de explantes de ápex infectados con lentivirus. LOF, pérdida de función (lost of function)

La infección con lentivirus se produjo mediante la inyección de los mismos en los corazones justo antes de diseccionar los ápex para realizar los sándwich de colágeno. Desafortunadamente, aún no tenemos resultados concluyentes de estos experimentos, ya que la presencia de los virus parece afectar a la formación de los brotes angiogénicos, tanto en el caso de la proteína mutante como en el control, posiblemente por la muerte de las células ante un título demasiado elevado. 


\subsection{Expresión del dominante negativo $\mathrm{RaOp}$ en la vasculatura coronaria mediante} transgénicos transitorios ("transient transgenics")

Con el objetivo de estudiar in vivo el posible efecto de la expresión de la proteína truncada Sox18-RaOp en el correcto desarrollo de la vasculatura coronaria, empleamos transient transgenics. Para ello, generamos una construcción en la que el gen mutante de Sox18 se expresaba bajo el control del promotor Fabp4. Además la construcción, contenida dentro del transposón Sleeping Beauty, tenía como marcador la proteína SmURFP.

Se escogió el promotor del gen Fabp4 (empleado para la generación de driver Fabp4-Cre por el grupo de Bin Zhou en Shangai) para limitar la expresión de la proteína truncada a la vasculatura coronaria, ya que el fenotipo global había demostrado ser letal in utero (Figura 52J) debido a la presencia de hemorragias y dilatacón de los vasos (Downes et al., 2009).

Las microinyecciones se realizaron en zigotos Nes-GFP+, introduciendo $2-4 \mathrm{ng} / \mu \mathrm{l}$ del transposón linearizado y $5 \mathrm{ng} / \mu \mathrm{l}$ del ARNm de la transposasa. Los embriones se sacaron en el estadio E14.5. Como controles, se usaron embriones sin microinyectar que también habían sufrido el proceso de extracción y transferencia a hembras pseudogestantes. En el caso de los
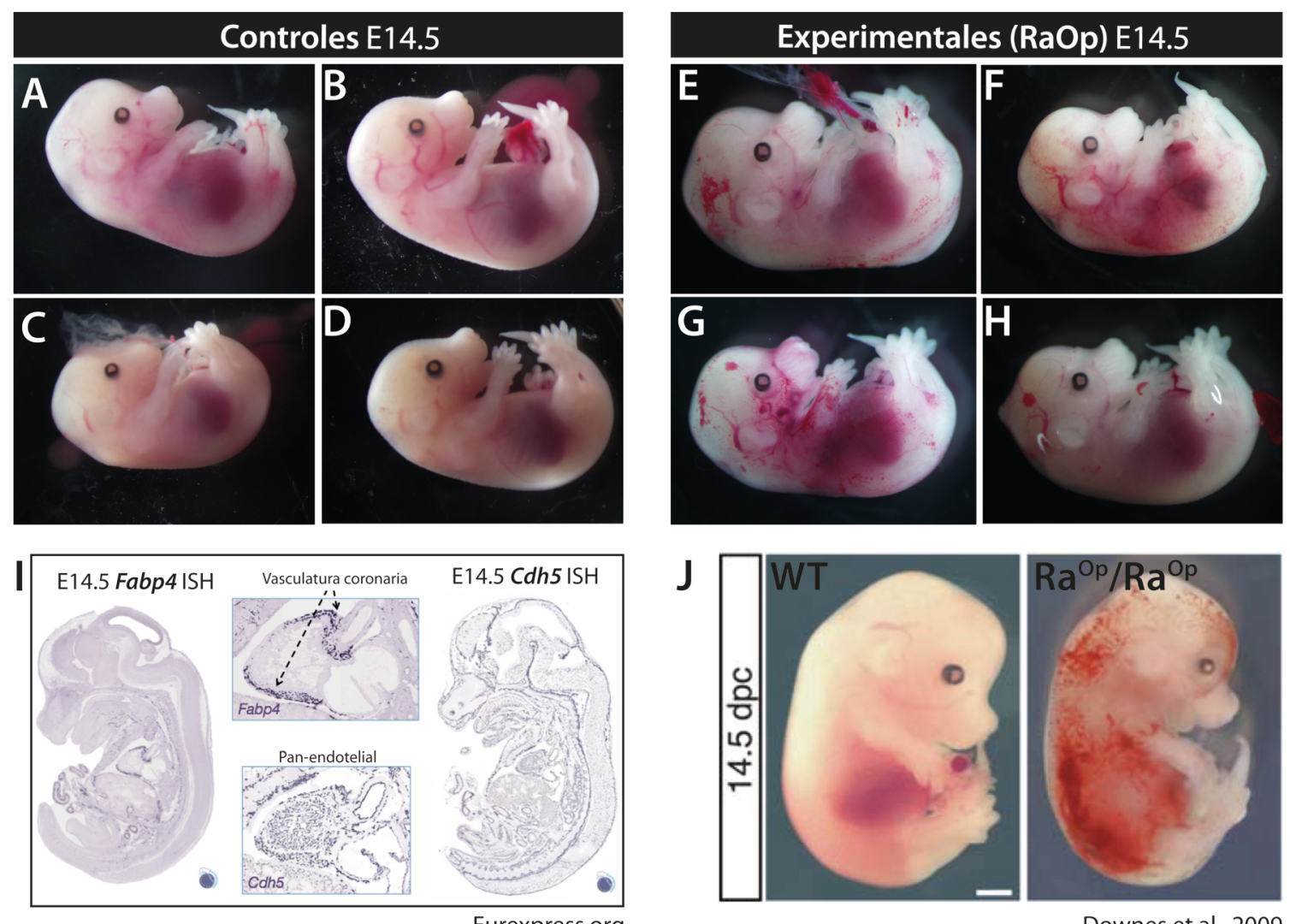

Downes et al., 2009

Figura 52. Comparación de embriones controles y experimentales (RaOp). (A-D) Se muestran embriones control sin microinyectar que se han sometido al proceso de transferencia a hembras pseudogestantes. (E-H) Embriones experimentales microinyectados con la construcción que expresa la proteína mutante RaOp bajo el control del promotor Fabp4. (I) Comparación de los perfiles de expresión por hibridación in situ entre Fabp4 y Cdh5, obtenidos de la web Eurexpress.org. (J) Imagen obtenida de Downes et al.,2009 en la que se muestra el fenotipo global de los mutantes homozigotos para la mutación RaOp. 
embriones experimentales, la frecuencia de inserción fue muy alta (70-80\%), generalmente en un número bajo de integraciones, entre 1-3 copias del transposón (datos no mostrados).

En la figura 52 se muestran algunos ejemplos de embriones control (sin microinyectar) y experimentales. El principal fenotipo observable a simple vista era la aparición de hemorragias en algunos de los embriones que integraban la construcción. Sin embargo, cuando analizamos los corazones, las afectaciones vasculares resultaron ser más sutiles. Las observaciones a la lupa en campo claro mostraron algunas anomalíaV morfológicas y alteraciones en el patrón de las venas presentes en la cara dorsal (Figura 53A, asterisco amarilo). Gracias a la presencia del alelo Nes-Gfp, pudimos escanear con detalle la vasculatura coronaria, comparando la de corazones controles con los experimentales (Figura 53B).

La expresión de la proteína RaOp en la vasculatura coronaria, que había sido descrita como dominante negativo de la subfamilia SoxF, debería afectar al correcto desarrollo del plexo vascular así como la expresión del enhancer neural de Nestina. No obstante, en este modelo lo que tenemos son integraciones al azar de bajo número de copias del transposón que expresa el gen bajo el control del promotor de Fabp4. Las principales desventajas de este sistema serían, en primer lugar, que las integraciones se produjesen en regiones del genoma donde la construcción no se expresara. En segundo lugar, en el caso de expresarse, se obtendría mosaicismo, por lo que habría células que sí expresarían los factores SoxF y el fenotipo podría verse compensado. Es por ello que buscamos diferencias sutiles en la formación de la vasculatura de estos corazones con respecto a sus controles.

Además de diferencias morfológicas como la observada en el embrión experimental \#3, observamos en bastantes corazones un importante retardo en el desarrollo del plexo vascular en el ventrículo izquierdo. En los corazones experimentales \#2 y \#4 (marcados con asterisco blanco) se observa cómo el único plexo presente es el que deriva del endocardio en la parte central, mientras que el plexo procedente del seno venoso que invade desde la parte dorsal del corazón a la ventral, se encuentra ausente. Con respecto a la cara dorsal, en algunos casos, como el corazón experimental \#4, se aprecia cierta deslocalización de los vasos que están comenzando a remodelarse para dar lugar a las arterias coronarias. El plexo venoso (subepicárdico) lo analizamos con las tinciones whole-mount de Caveolina-1. El corazón experimental \#1 por ejemplo, muestra un patrón mucho más indiferenciado que el control.

Dado que la construcción microinyectada contenía el reportero smURFP, tratamos de observar por microscopía confocal las células que estaban expresando la proteína RaOp. Desafortunadamente, la señal en rojo lejano HW tan débil que observamos mucha autofluorescencia de las células sanguíneas, lo que dificultaba en gran medida el análisis (Figura 53D). Actualmente nos encontramos estudiando estos mutantes con mayor detenimiento para caracterizar unos fenotipos que parecen ser muy sutiles al no poder conseguir la expresión de la proteína mutante en toda la vasculatura y existir por tanto compensación del resto de células que expresan correctamente los factores SoxF. 
A
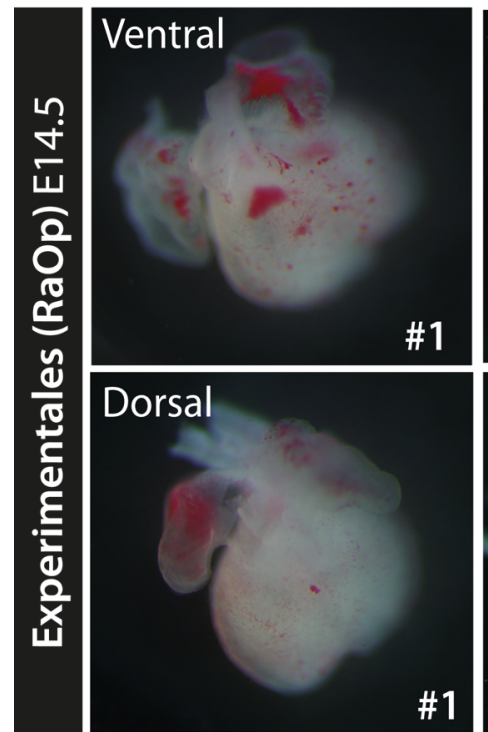

\#1
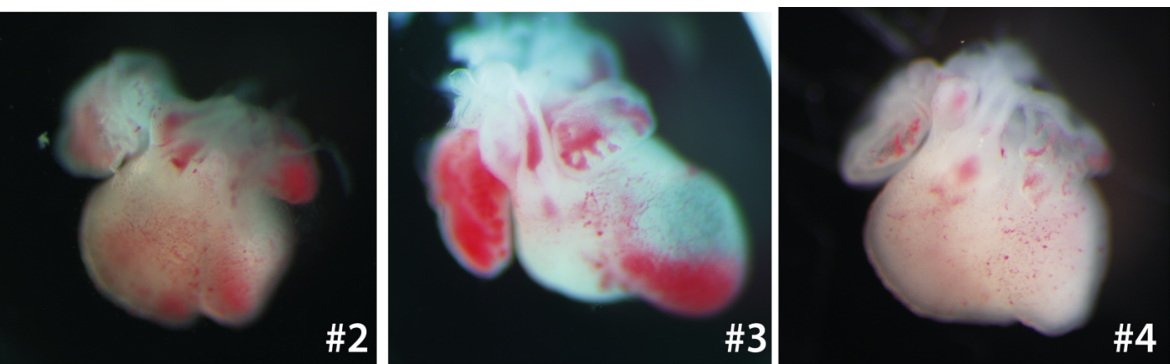

B
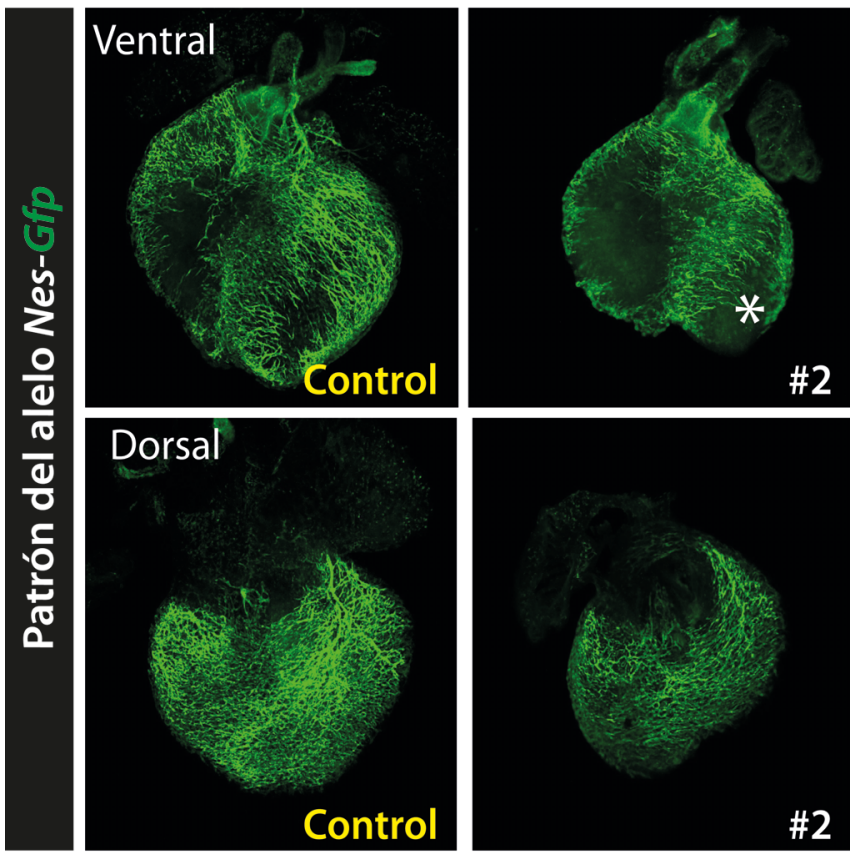

\#2
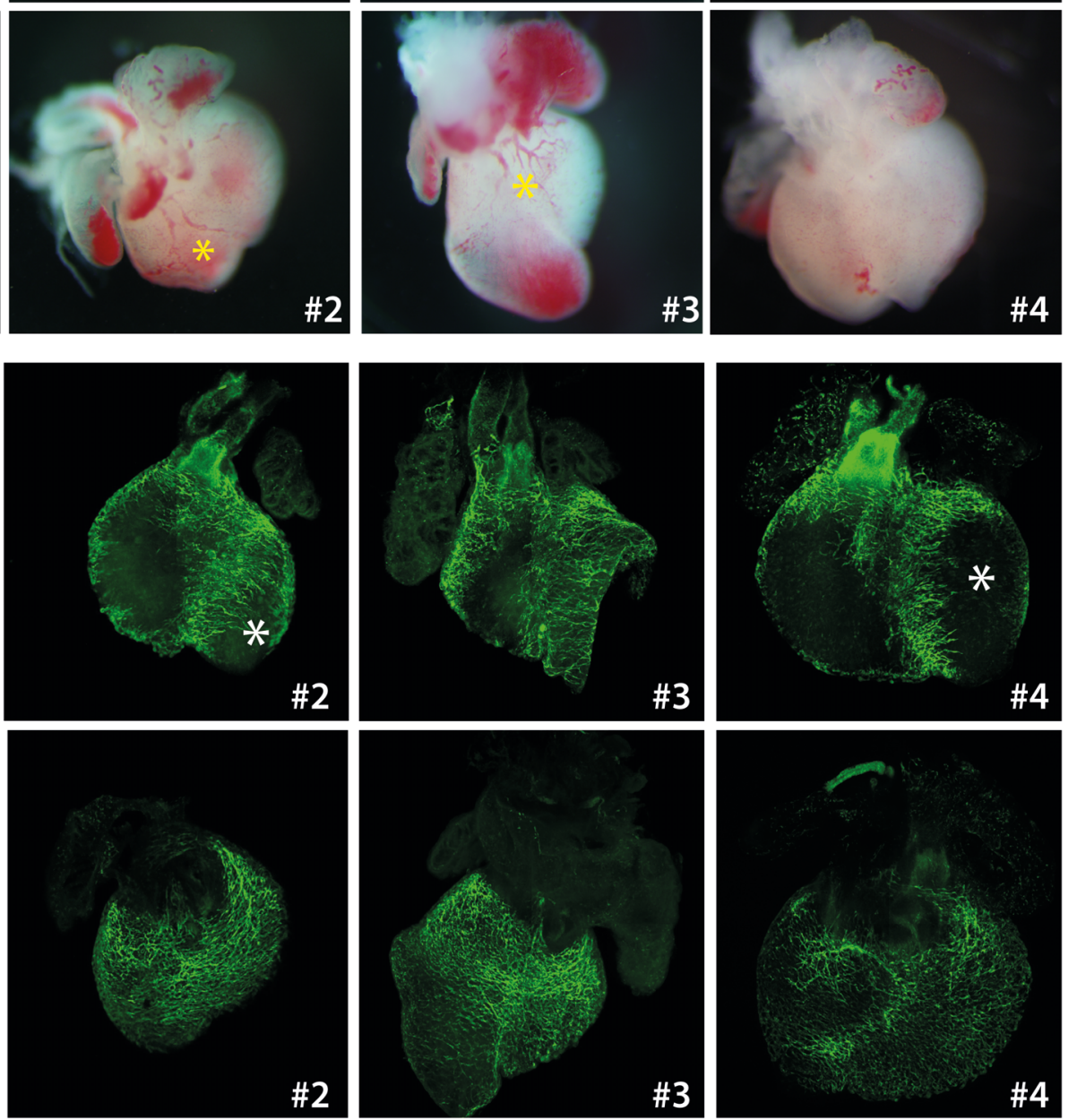

C
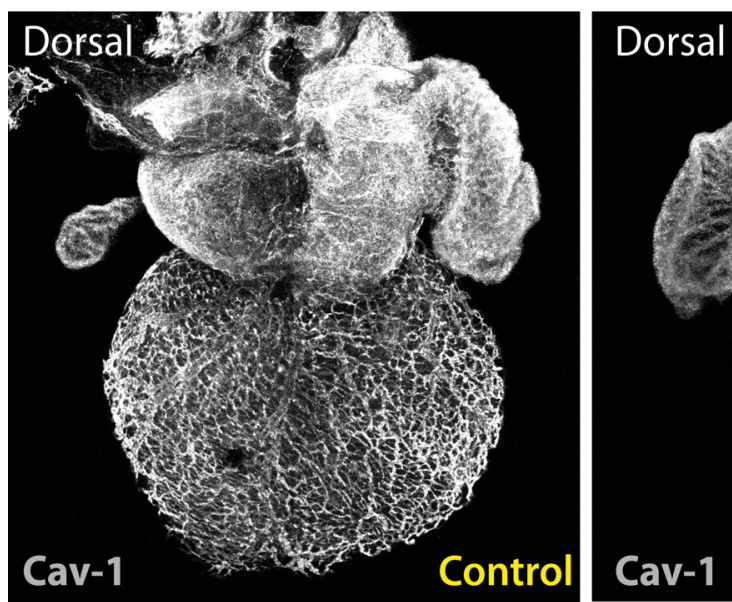

D

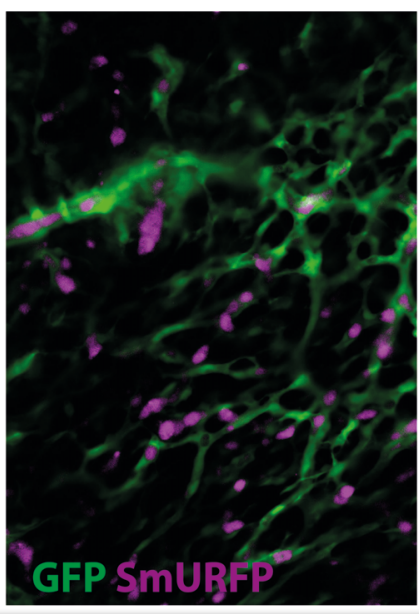

Figura 53. Alteraciones en el desarrollo de la vasculatura coronaria en los embriones experimentales (RaOp). (A)Se muestran ejemplos de corazones experimentales en los que ha habido integraciones del transposón pFabp4_RaOp_SmURFP Los asteriscos amarillos muestran alteraciones en el patrón venoso, observables a simple vista. (B) Patrón de expresión del alelo Nes-Gfp de los embriones experimentales en comparación con un corazón control. Los asteriscos blancos muestran retraso o ausencia de la vasculatura coronaria con respecto al control. (C) Se compara el plexo venoso marcado con Cav1 en el control con el experimental \#1. (D) expresión de la proteína SmURFP. 


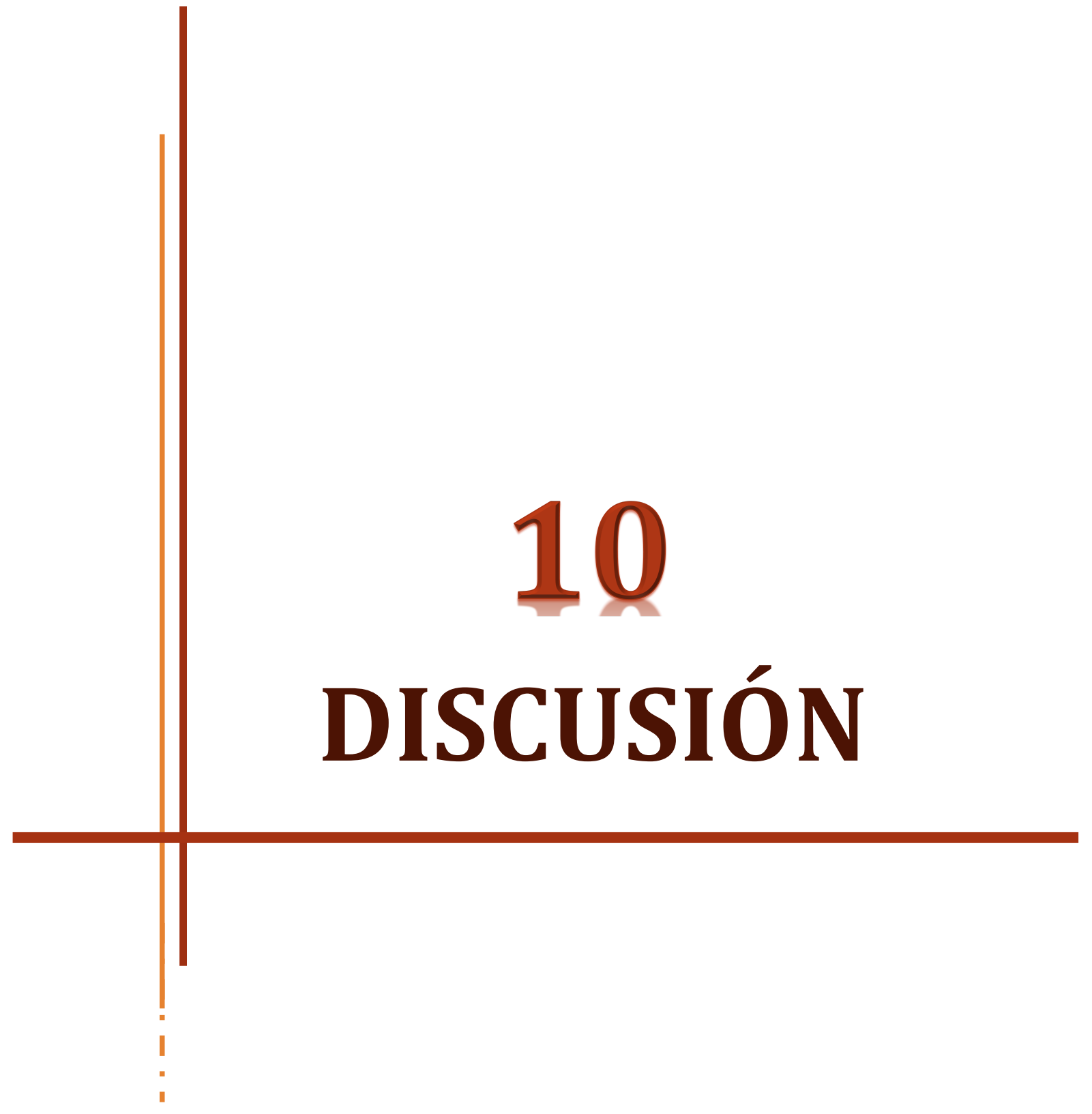





\section{El ALELo Nes-GFP SE EXPRESA DE FORMA MUY DINÁMICA EN DIVERSOS LiNAJES}

\section{CELULARES A LO LARGO DEL DESARROLLO EMBRIONARIO Y VIDA ADULTA DEL RATÓN}

El gen de Nestina codifica para un filamento intermedio del citoesqueleto que fue identificado originariamente en células progenitoras del sistema nervioso central, donde se expresa en abundancia. La posterior caracterización de sus elementos reguladores permitió desarrollar varias líneas transgénicas que recapitulaban parte del patrón endógeno de expresión del gen. Una de ellas, el alelo Nes-Gfp generado por Mignone y colaboradores $\square$ ha sido ampliamente utilizado para marcar dichos progenitores neurales, pero su expresión no está restringida únicamente al tejido neural. Fuera del SNC, también se detectó en progenitores mesenquimales y células reticulares ricas en $\mathrm{Cx} / 12$, presentes en varios órganos y sobretodo en la médula ósea. En nuestro trabajo, sin embargo, se explora por primera vez su uso como herramienta para el estudio del desarrollo de la vasculatura coronaria en ratón, aprovechando su expresión en células endoteliales durante dicho proceso.

Los módulos reguladores responsables de la expresión del transgén Nes-Gfp se encuentran potencialmente dentro del promotor $y$, especialmente, en el la secuencia proveniente del segundo intrón del gen endógeno de Nestina de rata, una secuencia de $1.8 \mathrm{~kb}$ que contiene un enhancer neural. Por este motivo, el hecho de que a lo largo del desarrollo el reportero GFP se exprese de forma dinámica pero restringida en unos determinados linajes sugiere la posibilidad de que toda esa variedad de tipos celulares tengan en común un entorno y una señalización molecular convergente que confluya activando los mismos elementos reguladores, quizás reflejo de requerimientos y funciones celulares parecidas, tanto en la neurogénesis del SNC, como durante la angiogénesis cardíaca.

La detallada caracterización que hemos llevado a cabo del patrón del alelo reportero NesGfp en las distintas poblaciones del corazón en desarrollo embrionario revela que, como cabía esperar, se encuentra activo sobretodo en una fracción importante de células no miocíticas (principalmente células de naturaleza mesenquimal/estromal, detectadas con los marcadores CD90 y MESK4). Dentro de esta población tan heterogénea figuran pericitos, fibroblastos cardíacos y células de músculo liso vascular asociadas a los vasos. El origen ontogénico de dichas células mesenquimales no es único, siendo el mesotHlio epicárdico la fuente sustancial, y entre otras, la cresta neural cardíaca, sobretodo en la región del tracto de salida. Nuestros datos revelan que más del $80 \%$ de la población no-miocítica estromal GFP+ presente en los ventrículos derivaría del epicardio, en base al trazado de linaje con el driver WT1, y se encontrarían asociadas a la vasculatura. Dichas células, posiblemente derivadas de precursores EPDCs, upregularían la expresión del transgén al adquirir el fenotipo mesenquimal y ocupar su posición mural/intersticial. Desconocemos si existe alguna fracción de pericitos, quizás derivados de otros linajes, donde no esté activo el transgén, como sí ha sido descrito en otros tejidos (Birbrair et al., 2011). Esto abre una interesante cuestión acerca de los diferentes orígenes de las células perivasculares que dan soporte a la microvasculatura del corazón y qué 
señales locales confluyen en la activación del reportero. Por otro lado, la coincidencia del patrón anatómico de expresión observado de Nes-Gfp, mayoritariamente vascular, es compatible con el hecho de que detectásemos niveles elevados del reportero GFP en el componente endotelial de los vasos. Curiosamente, la fracción de endotelio cardiaco GFP+ estaba altamente restringida a las células del plexo coronario, mientras que las células del endocardio ventricular expresaba niveles mucho más bajos, apenas detectables.

Pero, ¿qué podrían tener en común linajes tan aparentemente dispares? Los progenitores neurales el SNC expresan niveles muy elevados de Nes-Gfp, que posteriormente pierden cuando comienzan a diferenciarse. De forma similar, en este trabajo hemos observado que durante el desarrollo de la vasculatura coronaria, los primeros brotes de plexo primario y angiogénico que invaden la superficie del corazón activarían la expresión del transgén. Durante su expansión y remodelado, una vez que se adentran en el miocardio y comienzan a especificarse para adquirir la identidad arterial/venosa, se pueden distinguir las diferentes subpoblaciones vasculares en función de la intensidad de fluorescencia GFP+, siendo los niveles de GFP en las arterias coronarias y microvasculatura progresivamente downregulados en etapas postnatales. Por su parte, el conjunto de pericitos GFP+, mantienen a su vez una activación del transgén muy alta, que se extiende más allá del periodo fetal.

Teniendo en cuenta este paralelismo (revelado por la activación del alelo reportero) existente entre los progenitores neurales y las células endoteliales del plexo coronario y sus pericitos asociados, podríamos pensar que en ambos linajes se requieren funciones celulares análogas, que una vez activadas vendrían reflejadas molecularmente por la común expresión de Nes-GFP. Entre dichos fenotipos celulares podríamos mencionar la migración y motilidad, relevantes tanto en neurogénesis como en angiogénesis, y su conexión con la citocinesis. De hecho Nestina codifica para una proteína estructural del citoesqueleto que podría estar implicada en dichos procesos. En el caso de la vasculatura coronaria, tanto la expansión angiogénica del plexo primitivo como en el posterior proceso de remodelado se requiere una elevada coordinación de la emisión de procesos celulares direccionales con la migración celular y la concurrente invasión de las mismas en el tejido cardíaco, en muchos casos respondiendo a señales locales de hipoxia. Con respecto a la expresión sostenida del alelo en células murales, dichas células perivasculares asociados a las arteriolas, vénulas y capilares podrían requerir de un esqueleto filamentoso especializado, ya que producen vasoconstricción y vasodilatación para regular el diámetro vascular así como el flujo sanguíneo de los capilares (Rucker et al., 2000)

Si bien un aumento de la expresión de Nestina endógena ha sido descrito en ciertos tumores y durante procesos regenerativos, su papel molecular preciso no quedaba claro, y no necesariamente el alelo Nes-Gfp identificaría los mismos tipos/estados celulares. En el corazón, modelos de infarto de miocardio habían revelado que durante la angiogénesis activa post-infarto se expresaba el gen de forma transitoria durante el proceso de reparación. Posteriormente su expresión disminuía para dar paso a la expresión de otras proteínas estructurales como 
Vimentina en los nuevos vasos formados (Mokrý et al., 2004, Mokrý et al., 2008). De forma similar, Nestina era detectado en la vasculatura de glioblastomas agresivos, por lo que ha llegado a ser considerado un biomarcador de fenotipo invasivo así como un marcador de proliferación (Ishiwata et al., 2011).

Más allá de los procesos patológicos mencionados, en este trabajo describimos por primera la expresión del alelo Nes-Gfp en un proceso angiogénico fisiológico, encontrándose el tejido en un contexto más homeostático.

\section{2o El trazado de linaje con el alelo Nes-CreER ${ }^{T 2}$ como herramienta para el} ESTUDIO Y LA MANIPULACIÓN DE LA VASCULATURA CORONARIA EN DESARROLLO Y RATÓN ADULTO

El trazado de linaje marcado con el alelo Nes-CreER ${ }^{T 2}$ ("linaje-Nestina") ha resultado tremendamente útil para el estudio dinámico de la vasculatura coronaria, durante el desarrollo. De las diferentes líneas transgénicas existentes [http://www.informatics.jax.org/searchtool/Search.do?query=nestin\&page=featureList], en este proyecto hemos utilizado la generada por Balordi y Fishell, en la que el único elemento regulador que controla la expresión del driver inducible depende del enhancer neural del segundo intrón. Del mismo modo que en el caso del alelo Nes-Gfp, para nuestros estudios nos centramos en caracterizar de forma detallada los diferentes tipos celulares donde el transgén estaba activo y las poblaciones correspondientes que recombinaban durante diferentes ventanas de inducción. En corazón, existe una gran coincidencia entre el patrón de expresión del alelo Nes-Gfp dentro de la vasculatura con el trazado de linaje endotelial realizado con el driver Nes-CreER ${ }^{T 2}$, lo que sugiere que en este tipo celular en concreto la regulación de su expresión viene determinada por el enhancer neural que comparten ambas líneas genéticas. En la población mesenquimal/estromal GFP+, sin embargo, sí que observamos diferencias de marcaje, permaneciendo mayoritariamente poco recombinada.

\subsection{Herramienta para la manipulación génica restringida a la vasculatura} coronaria en estadios embrionarios

Como en cualquier sistema inducible, las poblaciones celulares trazadas mediante la acción del alelo $C r e E R^{T 2}$ van a depender sobretodo de sus niveles de expresión relativos en cada tipo celular en cada momento dado, y que pueden ser variables según el estadio. Por lo tanto, la ventana temporal concreta durante la que se induzca la recombinación mediada por el tamoxifeno (aparte de la dosis empleada) determinará en gran medida la naturaleza de los linajes trazados, que no necesariamente deben coincidir. En el corazón, dado que la formación del plexo endotelial coronario embrionario comienza a formarse a partir del estadio embrionario E11.5, establecimos un primer tiempo de inducción administrando a E10.5, y otro posteriormente a E12.5. 
El resultado del trazado durante estas ventanas fue el marcaje de todo el endotelio coronario emergente (incluyendo los plexos subepicárdicos, intramiocárdicos e interventriculares), pero la ausencia de contribución al endocardio ventricular. Dicho patrón de recombinación, es bastante parecido al descrito para las líneas Apelin-CreER, en ventanas de inducción semejantes (Tian et al., 2013). Otro dato a destacar era que, a diferencia de lo observado con el alelo Nes-Gfp, donde la población mayoritaria de células GFP+ era noendotelial, con el alelo Nes-CreER ${ }^{T 2}$ (período de inducción E10.5-E15.5) la situación se invierte siendo la población no endotelial solo alrededor del 10-20\%, contribuyendo mayoritariamente al endotelio coronario en un 80-90\% del total de las células marcadas. En resumen, en el corazón y durante los estadios mencionados, el driver Fishell sería un driver eminentemente endotelial, con poca contribución a linajes mesenquimales. La discrepancia entre estas dos estirpes genéticas podría residir en la presencia de secuencias críticas para su activación en células mesenquimales/murales solo en la porción de promotor, ausente en la línea Nes-CreER ${ }^{T 2}$. En contrapartida, la expresión endotelial en ambas líneas provendría de elementos situados dentro del segundo intrón, que contiene el enhancer neural, presente en los dos alelos. Con respecto a las diferencias de marcaje al recombinar a E10.5 o E12.5, la única desigualdad observada fue en el plexo interventricular. Mientras que el trazado de linaje induciendo a E10.5 marcaba sólo parte de los vasos presentes en el septo interventricular (de origen endocárdico principalmente), induciendo a E12.5 ya sí se observaban todos los vasos marcados, lo que sugiere que la población vascular coronaria presente en el septo termine de surgir entre E11.5E12.5. Esta contribución diferencial de marcaje, se ha descrito de manera análoga con el uso de la línea Fabp4-CreER (He et al., 2014).

La principal ventaja de esta herramienta genética aplicada al corazón es que nos permite modular las poblaciones endoteliales marcadas para separarlas por citometría de flujo, o eliminación de genes específicos en las poblaciones deseadas con una eficiencia de recombinación muy alta. A diferencia de otras Cre pan-endoteliales (tales como Tie2-Cre, Cdh5CreER, etc.), con el alelo Nes-CreER ${ }^{T 2}$ somos capaces de trazar de forma específica toda la vasculatura coronaria en desarrollo, incluyendo los capilares, las arterias/arteriolas y las venas, sin afectar el endocardio ventricular. En este trabajo también hemos determinado que, del mismo modo que la expresión del alelo Nes-Gfp se reduce significativamente tras la fase de expansión angiogénica en el plexo subepicárdico que da lugar a las futuras venas coronarias, la expresión de CreER se encuentra correlativamente menos expresada en dicha subpoblación endotelial. Este hecho diferencial nos ha permitido que seleccionando la ventana de inducción a E15.5 (y reduciendo la dosis de tamoxifeno), podamos trazar de forma exclusiva la vasculatura coronaria del intramiocardio, incluyendo capilares y arterias prospectivas, y descartando selectivamente las venas coronarias y el endocardio. Gracias a ello podemos realizar una separación única hasta el momento de las tres subpoblaciones vasculares presentes en un mismo corazón: endocardio ventricular, arterias/capilares intramiocárdicas y venas subepicárdicas. 


\subsection{Herramienta para el marcaje/modificación génica restringida a la micro-}

\section{vasculatura coronaria en adultos}

Si bien una vez el endotelio ha madurado la expresión de muchos genes activos disminuye respecto a las fases angiogénicas fetales, el trazado de linaje con el driver induciendo esta vez en animales adultos (8-12 semanas de edad) ha revelado que la expresión endotelial del alelo Nes-CreER ${ }^{T 2}$ se mantiene postnatalmente. De manera muy eficiente, logramos marcar solo la microvasculatura coronaria (alrededor del 95\% del total de células que recombinan), quedando excluidos el endotelio de los grandes vasos (arterias y venas coronarias) y, al igual que durante el desarrollo, el endocardio ventricular. Esto supone la posibilidad de modificación genética de forma específica en esta población endotelial microvascular sin afectar a las arterias ni las venas de mayor calibre. En este sentido esta línea recapitularía en cierto sentido la actividad del alelo Apln-CreER descrita en corazón adulto (Liu et al., 2015a), aunque en otros órganos o contextos patofisiológicos, el solapamiento de ambos drivers no necesariamente debería coincidir, extendiéndose a linajes extra-endoteliales. En todo caso, en homeostasis y en animales adultos jóvenes, la actividad del alelo Nes-CreER $R^{T 2}$ tendría principalmente un carácter de driver endotelial puro, y con preferencia por los capilares cardíacos.

Un ejemplo de ello es un segundo proyecto llevado a cabo en el grupo en el que hemos delecionado el gen de VHL ( $\underline{\text { Von }}$ Hippel-Lindau) en el endotelio coronario sin afectar a las arterias ni venas del corazón. Como consecuencia de la pérdida del alelo VHL floxeado en esta población, se consigue la estabilización de los diferentes Hif, lo que conlleva a una reactivación del programa angiogénico en la microvasculatura produciendo un fenotipo de cardiomegalia. A pesar de la dilatación de los vasos y el aumento de tamaño del órgano, los patrones analizados por ecocardiografías resultaron normales, teniendo incluso una mejora en valores como la fracción de eyección. Por su parte, la eliminación conjunta de los genes floxeados VHL y Hif2a produce el rescate completo del fenotipo cardíaco, donde los corazones experimentales recuperan su tamaño normal, indicando por tanto que la reactivación del programa angiogénico en esta población endotelial depende únicamente de la estabilización del factor Hif2a (Manuscrito en preparación).

Hay que tener presente que al eliminar un gen de forma condicional en la microvasculatura no estamos recombinando sólo en el corazón, también en la vasculatura de otros tejidos como pulmón, hígado y riñón, sin embargo hemos observado que la eficiente tasa de recombinación de este driver sólo se da en el órgano cardíaco. A pesar de poder eliminar el alelo floxeado de VHL en las microvasculatura de otros tejidos, lo cierto es que sólo se observa un fenotipo en el corazón, convirtiendo al alelo Nes-CreER ${ }^{T 2}$ Fishell en una herramienta excelente para la eliminación eficiente de forma muy selectiva en la vasculatura coronaria. 


\title{
Tabla 18. Poblaciones marcadas con los alelos Nes-Gfp y Nes-CreER ${ }^{\text {T2 }}$
}

\begin{tabular}{|c|c|c|c|c|}
\hline \multirow{2}{*}{ Alelo } & \multirow{2}{*}{ Inducción } & \multicolumn{2}{|c|}{ Poblaciones marcadas } & \multirow[t]{2}{*}{ Poblaciones excluidas } \\
\hline & & Endotelial & Estromal & \\
\hline Nes-Gfp & & Vasculatura coronaria & $\begin{array}{c}\text { Pericitos, células murales y } \\
\text { fibroblastos }\end{array}$ & Endocardio ventricular \\
\hline \multirow{4}{*}{$\begin{array}{c}\text { Nes- } \\
\text { CreER }^{T 2}\end{array}$} & Tmx a E10.5 & $\begin{array}{l}\text { Vasculatura coronaria } \\
\text { (sub/intramiocárdica) }\end{array}$ & $20 \%$ & $\begin{array}{c}\text { Endocardio ventricular, } \\
\text { vasos SIV }\end{array}$ \\
\hline & Tmx a E12.5 & $\begin{array}{l}\text { Vasculatura coronaria } \\
\text { (sub/intramiocárdica) }\end{array}$ & $20 \%$ & Endocardio ventricular \\
\hline & Tmx a E15.5 & Vasculatura intramiocárdica & $<5 \%$ & $\begin{array}{c}\text { Endocardio ventricular, } \\
\text { plexo subepicárdico }\end{array}$ \\
\hline & Tmx en adultos & Microvasculatura & No detectable & $\begin{array}{c}\text { Endocardio, arterias, } \\
\text { venas }\end{array}$ \\
\hline
\end{tabular}

\section{GENES DIFERENCIALMENTE EXPRESADOS EN LAS SUBPOBLACIONES ENDOTELIALES}

\author{
DEL CORAZÓN E IDENTIFICACIÓN DE NUEVOS MARCADORES CORONARIOS
}

\subsection{Comparación de perfiles transcripcionales entre endocardio ventricular y vasculatura coronaria en las fases de angiogénesis (E13.5) y remodelado $(\mathrm{E} 17.5)$}

La dinámica expresión del alelo Nes-Gfp en la población endotelial del corazón presenta unas características únicas, convirtiéndose en una gran herramienta para el estudio de un proceso biológico con el que nunca había sido relacionado este reportero, como es el desarrollo de la vasculatura coronaria y posterior especificación arterio-venosa.

Al expresarse en todo el plexo vascular naciente (tanto el que surge del SV como el que deriva de endocardio) pero no en el endocardio ventricular propiamente, la primera gran aplicación de este transgén es que nos permite una fácil separación mediante citometría de flujo de estas dos subpoblaciones endoteliales con una excelente pureza para realizar perfiles transcripcionales y estudiar los genes diferencialmente expresados entre ellas. Ya existían perfiles de expresión de las poblaciones endoteliales de corazones enteros, sin embargo el poder separar el endocardio del plexo vascular sólo había sido llevado a cabo recientemente por el grupo de Bin Zhou (Shangai) empleando las líneas Npr3-CreER y Fabp4-Cre, para el marcaje de endocardio ventricular y vasculatura coronaria, respectivamente (Zhang et al., 2016). Si bien Fabp4 se expresa en el endotelio coronario, su expresión no es exclusiva de células endoteliales y con el uso de un driver no inducible se corre el riesgo de marcar conjunto más heterogéneo de células, no estrictamente endoteliales. Además en dicho trabajo se asilaron las poblaciones marcadas genéticamente en base únicamente a la presencia del reportero de recombinación. En nuestro caso, aparte de descartar posibles células sanguíneas contaminantes (CD45/Ter119), hemos seleccionado únicamente células positivas además para el marcador pan-endotelial CD31, para obtener unas subpoblaciones mucho más definidas. Otra ventaja de nuestro método, es que 
podemos aislar todas las distintas subpoblaciones a partir de los mismos corazones, es decir plenamente sincrónicas entre ellas y de un fondo genético más homogéneo, reduciendo las variabilidad debido a estados gestacionales dispares en el caso de usar pools distintos de corazones para cada caso.

Aprovechando este método de separación, obtuvimos los perfiles transcripcionales del endocardio y vasculatura coronaria durante la fase indiferenciada de expansión angiogénica (E13.5) y tras el remodelado, en una fase de maduración vascular (E17.5). De esta forma no sólo podríamos comparar los genes diferencialmente expresados entre ambas subpoblaciones endoteliales, sino que además, dentro de la misma población, podríamos examinar qué genes cambiaban entre los dos momentos del desarrollo. En la tabla 19 se sintetizan algunas de las familias de genes diferencialmente expresadas entre ambas subpoblaciones endoteliales.

Entre otros, existen familias de genes que se encuentran exclusivamente expresados en el endocardio ventricular durante los diferentes estadios del desarrollo, como son miembros de la familia GATA (Gata2/3/6) y miembros de la familia Iroquois (Irx3/4/6). También se aprecian claras diferencias en la expresión de protocaderinas (PCDH). Mientras que en el endocardio se expresan la mayoría de miembros de la subfamilia $\beta$, en el plexo coronario tan sólo hay miembros de las protocaderinas sin clusterizar. Se cree que estas PCDH no clusterizadas se relacionan con otras funciones como promover la motilidad, en lugar de establecer la adhesión célula-célula que podría estar regulando la subfamilia $\beta$ en el endocardio (Hayashi and Takeichi, 2015).

Otra familia interesante de genes expresados en el endotelio son las semaforinas. Compuesta por un conjunto de proteínas involucradas en la transmisión de señales de guía axonal que controlan el desarrollo del SNC, las semaforinas también han demostrado jugar un papel crítico en la guía de los vasos sanguíneos durante los procesos de angiogénesis. A pesar de que en un principio fueron identificadas por su potencial quimo-repelente, estas proteínas pueden proporcionar moléculas atrayentes o repelentes en función del contexto biológico en el que se encuentren (Sakurai et al., 2012). En el endocardio se encuentran enriquecidas las Sema3a y Sema4d. Está descrito que Sema3a aumenta la permeabilidad vascular e inhibe la proliferación de células endoteliales. La señalización de Sema4d por el contrario, parece promover la migración endotelial y la formación de tubos, indicando funciones contradictorias expresadas en el mismo subconjunto de células endoteliales (Sakurai et al., 2012). Por su parte, en el plexo coronario se encuentran diferencialmente expresadas varias semaforinas. En el cluster II de genes de plexo coronario que se sobreexpresan de la fase angiogénica (E13.5) a la fase de vasculatura remodelada (E17.5), encontramos los genes Sema3g y Sema7a. Parece existir una conexión entre el factor de transcripción HLX, la Semaforina $3 g$, la Plexina $A$ y el receptor Unc5b, todos ellos sobreexpresados en el plexo coronario, especialmente tras la fase de remodelado. Se ha descrito que la señalización de Vegfa en las células endoteliales activa a HLX, que a su vez incrementa la expresión de proteínas de guía celular repulsivas, entre las que se encuentran Unc5b, Plexina A1 y Sema $3 g$, inhibiendo la migración de células endoteliales, 
angiogénesis y formación de vasos (Testori et al., 2011). Esto podría ser explicado porque la vasculatura coronaria a E17.5 ya se encuentra remodelada, con la correcta formación de las arterias coronarias y capilares que nutren de oxígeno el tejido cardíaco. Frente a estas condiciones, la ausencia de hipoxia local reduce las señales de expansión angiogénica.

Sin embargo existen datos contradictorios sobre la acción pro/anti-angiogénica de algunos de estos genes. En el caso de Unc5b, diferentes trabajos han mostrado su papel crucial para promover la expansión angiogénica de las células endoteliales durante el desarrollo embrionario (Navankasattusas et al., 2008). Del mismo modo, un estudio reciente relaciona Sema3g con inducción de la migración de células endoteliales actuando como efector de la señalización vía Ppar-y (Liu et al., 2015b). Por lo que la señalización de estos factores, a pesar de ser ampliamente estudiados en SNC, aún no se conoce por completo su función en las células endoteliales del órgano cardíaco.

El perfil transcripcional de las poblaciones de endocardio ventricular y vasculatura coronaria también nos ha permitido identificar marcadores de membrana potencialmente útiles para separar por citometría ambas poblaciones, sin necesidad de usar líneas transgénicas de ratón. En endocardio por ejemplo, hemos identificado el marcador CD59a, que a pesar de ser una glicoproteína presente mayoritariamente en células de la sangre, dentro de la población endotelial podría servir para definir el endocardio ventricular. Con respecto al endotelio coronario, hemos validado la expresión a nivel de proteína de los transcritos de Cd36 y $L y 6 c 1$, no habituales para células endoteliales de otros tejidos. Si bien el primero también tiene algo de expresión en el endocardio maduro, el segundo ha resultado excelente para la separación del plexo coronario obteniendo resultados equivalentes a la separación que realizamos con el alelo Nes-Gfp y el marcador Endomucina.

Finalmente, es conocido que los factores de transcripción Fox, Sox y Ets juegan un papel fundamental en el desarrollo de la vasculatura, y se discutirán en mayor profundidad en el siguiente apartado. Los distintos miembros de la familia Ets se encuentran expresados en todas las subpoblaciones de células endoteliales. Por su parte, mientras que Sox7 se expresa en niveles muy altos tanto en endocardio como en plexo coronario en los distintos estadios del desarrollo, los factores Sox13, Sox17 y Sox18 se encuentran diferencialmente expresados en la vasculatura coronaria, incrementando sus niveles de E13.5 a E17.5. 3or su parte, los datos obtenidos sobre la expresión de los factores Fox resultaron muy interesantes. A diferencia de lo esperado, los genes Foxc1/c2 son completamente diferenciales del endocardio ventricular. Por el contrario, en el plexo coronario encontramos los miembros Foxm1, Foxp1, Foxd2 y Foxs1. Esto resultaba curioso, teniendo en cuenta que Foxc1/c2 habían sido descritos como reguladores de la transcripción mediante la unión a los promotores de los genes DIl4 y Hey2 para promover la especificación arterial, en estadios muy tempranos (Hayashi and Kume, 2008, Seo et al., 2006). Sin embargo los datos obtenidos en este proyecto demuestran que, al menos en corazón, el dominio de expresión de estos factores se encuentra restringido al endocardio ventricular y no a la vasculatura coronaria. 


\begin{tabular}{|c|c|c|c|c|}
\hline & $\begin{array}{c}\text { Endocardio General } \\
\text { (E13.5/E17.5) }\end{array}$ & $\begin{array}{c}\text { Endocardio E13.5-> } \\
\text { E17.5UP }\end{array}$ & $\begin{array}{l}\text { Plexo General } \\
\text { (E13.5/E17.5) }\end{array}$ & Plexo E13.5->E17.5UP (cluster II) \\
\hline $\begin{array}{l}\text { Marcadores } \\
\text { membrana }\end{array}$ & & $C D 59 a$ & & CD36, CD109, Ly6c1, \\
\hline Colágenos & Col14a1, Col23a1, Col26a1 & & Col1a1, Col15a1 & \\
\hline Semaforinas & Sema3a, Sema $4 d$ & & Sema3f & Sema $3 g$, Sema $7 a$ \\
\hline $\begin{array}{l}\text { Señalización } \\
\text { de Notch }\end{array}$ & Dll1 & & Jag1, Heyl & Jag2, Dll4, Hey1, Notch4 \\
\hline $\begin{array}{l}\text { Caderinas y } \\
\text { PCDH }\end{array}$ & $\begin{aligned} C d h 11 ; & P c d h 7, P c d h \beta 3, \\
P c d h \beta 4, & P c d h \beta 5, P c d h \beta 7, \\
& P c d h \beta 9\end{aligned}$ & & & Pcdh1, Pch12 \\
\hline Familia FOX & Foxc1, Foxc2, Foxp1 & & Foxm1 & \\
\hline Familia SOX & & & & Sox13, Sox17, Sox18 \\
\hline Familia ETS & $\mathrm{Fev}$ & Egr1, Egr2 & Erg, Etv4 & Fli1 \\
\hline Familia Fabp & Fabp5 & & & Fabp4, Fabp7, Rbp7 \\
\hline $\begin{array}{l}\text { Otros } \\
\text { Factores de } \\
\text { transcripción }\end{array}$ & & & Meox1, Snai2 & Meox2, Mef2c, Dach1, HLX \\
\hline $\begin{array}{l}\text { Otros genes } \\
\text { relevantes }\end{array}$ & $\begin{array}{l}\text { Nr2f2 (COUP_TFII), } \\
\text { Nfatc2, Hif3 } \alpha, \text { Vegfb, }\end{array}$ & Npr3, Emcn, & Vegfc, Nes, Cxcr 4 & $\begin{array}{c}\text { Lpar4, Wt1, Aplnr, APln, Cxcl12, } \\
\text { Ppag, Cav1, Epas (Hif2 } \alpha \text { ), Plxna2, } \\
\text { Vegfa, Unc5b }\end{array}$ \\
\hline
\end{tabular}

\subsection{Comparación de perfiles transcripcionales entre endocardio ventricular,} arterias/capilares intramiocárdicos y venas subepicárdicas tras remodelar

El plexo primitivo que comienza a invadir la superficie dorsoventral del corazón es robustamente Nes-GFP+. Más adelante, cuando se extiende penetrando por el miocardio se comienzan a distinguir dos subpoblaciones en base a la intensidad de reportero: el plexo intramiocárdico, que tras el remodelado dará lugar a las futuras arterias y capilares, mantiene altos niveles de GFP. Por su parte, el plexo subepicárdico, que se remodelará en las futuras venas coronarias, va perdiendo progresivamente la fluorescencia. Estas diferencias en la expresión del alelo se reproducen también en el driver Nes-CreER ${ }^{T 2}$, por lo que la combinación de ambas herramientas genéticas nos permite una buena separación de las tres subpoblaciones endoteliales en un mismo conjunto de corazones, en base a los niveles celulares relativos de cada uno de los transgenes. Gracias a ello hemos podido caracterizar el perfil transcripcional de las mismas en el estadio embrionario E17.5.

La mayor parte de la información en la literatura que se tiene en cuanto a perfiles transcripcionales entre arterias y venas se han obtenido sobre todo a partir de endotelio de grandes vasos, como la aorta o las arterias y venaV umbilicales (Aranguren et al.,2013), que no tienen por qué ser los mismos para el endotelio análogo de un órgano tan especial como el corazón. Además, el endocardio, si no se descarta, puede introducir "ruido" en las 
comparativas. Este problema lo encontramos principalmente con los marcadores canónicos venosos, ya que las venas comparten una expresión de genes muy similar al de las células del endocardio. Ejemplo de ello es el gen Nr2f2 (COUP_TFII), que a pesar de estar diferencialmente expresado entre venas y arterias, los niveles en endocardio también son muy altos. Por ello identificamos otros transcritos que, al menos en este estadio del desarrollo, pudiesen ser más exclusivos de venas subepicárdicas, como son los genes Ogn y Dpt (Figura 54B). Con respecto a los marcadores enriquecidos en arterias también hemos encontrado discrepancias en la expresión de genes como Notch4, Pparg o Pdgfb, donde encontramos los mismos niveles entre plexo intramiocárdico (enriquecido en arterias/capilares) y plexo subepicárdico (enriquecido en venas) (Figura 54A).

Por todo ello, nuestra estrategia de separación puede ayudar a aportar nueva información molecular sobre algunos de los genes y pathways activas en unas poblaciones de células endoteliales que, al menos durante los estadios embrionarios, no se encontraban bien caracterizadas.

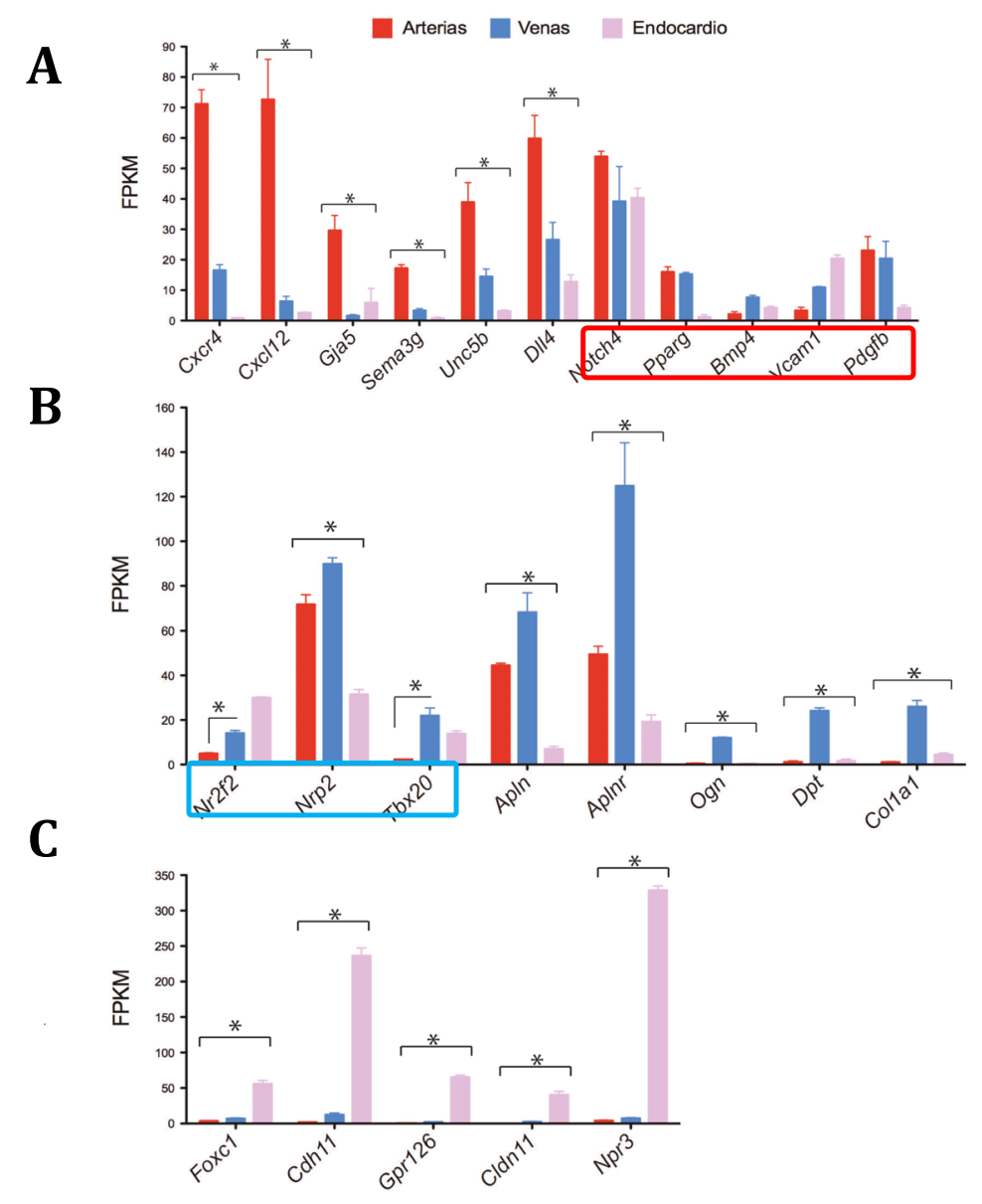

Figura 54. Perfil de genes marcadores para las diferentes subpoblaciones endoteliales a E17.5. (A) se muestran genes marcadores para la población arterial, con aquellos que no son específicos de arterial marcados con un recuadro rojo. (B) Genes marcadores de la población venosa, resaltando en el recuadro azul los que nos son diferenciales de venas. (C) Marcadores diferencialmente expresados en el endocardio ventricular. * Estadísticamente significativo $\mathrm{p}<0,05$. 
4o Caracterización del enhancer neural de Nestina PARA El ESTUdio de LA Vasculatura coronaria: Papel de los factores Soxf en la Regulación de la EXPANSIÓN VASCULAR CORONARIA Y POSTERIOR ESPECIFICACIÓN ARTERIO-VENOSA

\subsection{La activación del i2E de Nestina en SNC depende principalmente de los factores POU, en combinación con miembros de la familia SOX}

Una vez establecida la posible relación entre distintos linajes a través de requerimientos

y funciones celulares convergentes como migración, proliferación, motilidad direccional, etc, lo siguiente sería pensar que si coinciden en las mismas funciones, deberían compartir a su vez las mismas familias de factores de transcripción implicadas en la regulación de la activación de dichos procesos. Dado que la expresión del alelo depende principalmente de la activación del enhancer neural de Nestina (i2E), el estudio de los factores de transcripción implicados en su regulación podían acotarse a aquellos con dominios de unión al ADN contenidos en el enhancer. ' HELGRDOpatrón similar dęexpresión/activación espaciotemporal de las líneas Apelin-CreER, Aplnr-CreER, Fabp4-Cre, con los alelos Nes-Gfp y Nes-CreER ${ }^{T 2}$ descritos en esta Tesis, es atractivo pensar que a nivel upstream, podrían compartir pathways similares implicadas en la up-regulación coordinada de factores que desembocasen en la activación de un número discreto de efectores transcripcionales equivalentes, uniéndose a los respectivos enhancers de cada gen.

La comparación de secuencias de diferentes organismos demuestra que el segundo intrón contiene varias regiones muy conservadas evolutivamente entre diferentes especies, donde se aprecian dominios putativos de unión al ADN para diferentes familias de FT, entre las que se encuentran los factores Ets, Sox y POU. Entre todas ellas, en este trabajo nos centramos particularmente en analizar dos de las regiones conservadas que contienen sitios de unión a los factores Sox, denominadas CR1 y CR2, respectivamente.

Estudios previos habían demostrado que los factores de transcripción POU controlaban la expresión de ciertos genes en células progenitoras del SNC, entre los que se encontraba el gen Nestina. El fragmento mínimo de 257 pb de enhancer neural localizado en el segundo intrón, capaz de recapitular la expresión del gen en neuroepitelio, contenía dos sitios de unión al ADN para los factores POU. Entre ellos, sólo uno requerido para la expresión en SNC (Josephson et al., 1998). Posteriormente se concretó que en las células del primordio neural, el enhancer de Nestina se activaba de forma sinérgica por las interacciones de los factores Sox de grupo B1/C (Sox1/2/3/11) con los factores POU de clase III (Brn1/2/4 y Oct6), demostrado así la unión de los factores Sox en la región $5^{\prime}$ del sitio de unión para POU (Tanaka et al., 2004).

La relación entre factores de transcripción de las familias Sox y POU ya había sido observada previamente en la regulación del enhancer del factor de crecimiento de fibroblastos 4 
(FGF-4), cuya activación dependía de la unión del complejo formado por Sox2 y Oct-3/4 (Ambrosetti et al., 1997), al igual que en la regulación de células gliales procedentes del linaje oligodentrocítico, donde se mostraba la acción sinérgica de Sox11 y el factor Brn-1 (Kuhlbrodt et al., 1998). Por este motivo se concluyó que las familias de proteínas Sox y POU estaban fuertemente implicadas en el desarrollo del sistema nervioso.

El sitio de unión al ADN SOX:POU responsable de la activación del enhancer neural de Nestina descrito por Tanaka y colaboradores se corresponde en realidad con la región que denominamos como CR2. Si la unión de ambos factores era necesaria para la activación del enhancer en las células del SNC, cabía la posibilidad de que para su activación en el resto de linajes celulares dependiese de miembros de las mismas familias de factores de transcripción.

\subsection{En la vasculatura coronaria angiogénica, la activación del i2E depende del} factor Sox17 en combinación con otros factores no pertenecientes a la familia POU, a diferencia de las células neurales

En este trabajo nos hemos centrado en el estudio de la regulación del i2E en el endotelio coronario en desarrollo. Tras los perfiles transcripcionales realizados entre endocardio ventricular y vasculatura coronaria en los estadios de E13.5 y E17.5, pudimos encontrar genes de la familia Soxf diferencialmente expresados entre ambas poblaciones. En concreto, el factor Sox17 parecía ser un excelente candidato en la activación del alelo Nes-Gfp, ya que con el uso del anticuerpo anti-Sox17 examinamos que el plexo primitivo de células GFP+ que comienza a invadir el corazón, era a su vez positivo para esta proteína. Esto resultaba muy interesante, ya que Sox17 siempre había sido empleado como marcador arterial, y sin embargo en este proceso del desarrollo lo veíamos fuertemente expresado en el plexo primitivo e indiferenciado a partir del cual surgirían las futuras venas y arterias coronarias. Posteriormente, con el comienzo de la especificación arterio-venosa, el plexo subepicárdico que apaga la expresión del alelo Gfp también pierde la expresión del factor de transcripción, que queda finalmente restringido al endotelio de las principales arterias y arteriolas coronarias. Con respecto a su compañero POU, los datos del perfil transcripcional revelaron que no había ningún miembro de la familia expresado de forma diferencial en la vasculatura coronaria, tan solo detectamos la expresión del gen Pou6f1 por igual en todas las células endoteliales. Por este motivo pensamos que, al menos en este tejido en concreto, la regulación de los factores de transcripción responsables de activar el enhancer neural de Nestina debía producirse a partir de una combinación diferente a la descrita en SNC.

Teniendo en cuenta a Sox17 como un firme candidato para la regulación del enhancer, se establecieron las regiones conservadas CR1 y CR2 en base a que contenían sitios putativos de unión al ADN para los miembros de la familia SOX. Ya habían validado in vivo que, al menos en SNC, el sitio SOX contenido en la región CR2 era ocupado por los factores Sox1/2/3/11, sin embargo dichos miembros no se encontraban expresados en las células endoteliales de la 
vasculatura. Nuestros ensayos de EMSA revelaron que Sox17 se unía bioquímicamente a ambos sitios SOX, sin embargo, y en contra de lo esperado, parecía presentar una mayor afinidad al lugar SOX contenido en el CR1 que al del CR2, donde observábamos un segundo complejo de proteínas-ADN de mayor tamaño independiente a Sox17.

La unión producida en el CR1 parecía ser específica, ya que en las condiciones de competencia con exceso de oligo WT sin marcar, perdíamos señal en la banda retardada. Esta señal se volvía a recuperar cuando la competencia se realizaba con exceso de oligo mutante que tenía afectados los 6 nucleótidos homólogos al dominio HMG de Sox. Por su parte, en el CR2 encontramos que se producían dos complejos diferentes de proteínas. Uno de ellos migraba a la misma altura que con los oligos del CR1, pero el otro parecía ser un complejo de mayor tamaño que no variaba en las condiciones de competencia. Esto podría indicar dos alternativas: la primera supondría que el complejo de proteínas presente en el extracto unido a la secuencia de ADN fuera independiente del factor Sox17, lo que explicaría que no se observase fenómeno de competición al poner los oligos sin marcar en exceso. La segunda alternativa sería que se produjese primero una interacción proteína-proteína que posteriormente se uniese al ADN, de manera que la afinidad de la unión dependiese de las otras proteínas co-factoras que no estábamos compitiendo.

A pesar de desconocer qué otras proteínas estaban interaccionando con las secuencias CR1 y CR2 para regular de forma conjunta el enhancer neural de Nestina, quisimos determinar si Sox17 era suficiente para activar por sí solo su expresión. Los ensayos de luciferasa revelaron que la sobreexpresión de Sox17 era suficiente para aumentar la actividad del i2E in vitro, y que dicha activación se reducía con las construcciones mutantes en las que le faltaban la regiones CR1 o CR2, determinando que la ausencia de cualquiera de ellas afectaba a la señal luciferasa. Otra forma de demostrar que Sox17 era capaz de activar la expresión del enhancer fue mediante el clon MCEC_i2E_Tomato\#56. Estas células carecían de Sox17 cuando se cultivaban de forma normal, por lo que el i2E permanecía inactivo y no se detectaba la señal del reportero Tomato. Sin embargo, cuando se cultivaban en presencia de doxiciclina, se inducía la expresión de Sox17, de manera que se activaba el enhancer y este a su vez, la expresión del reportero fluorescente. Por su parte, la sobreexpresión de Sox18, otro de los factores diferencialmente expresados en la vasculatura coronaria, no pareció ser suficiente para encender por sí solo la actividad del reportero, si bien no podemos descartar que in vitro también se produzca la unión de esta proteína al lugar SOX.

Por todo lo anterior proponemos un modelo en el que, el enhancer neural que dirige principalmente la regulación del alelo Nes-Gfp contiene secuencias muy conservadas evolutivamente con sitios de unión a factores Ets, Sox y POU, entre otros. En SNC se ha validado in vitro e in vivo que la activación del reportero depende especialmente de la unión sinérgica de los factores SOX/POU a sus secuencias consenso respectivas contenidas en la región CR2. Por su parte, en la vasculatura coronaria no parece que los factores POU tengan un papel relevante para la activación de alelo, por lo que su regulación debe depender de los otros 
factores de transcripción capaces de unirse a su secuencia. En concreto, Sox17 se encuentra expresado en las primeras células endoteliales que invaden la superficie dorsal del corazón y, mediante una rápida expansión angiogénica, forman el plexo primitivo que se remodelará para dar lugar a las futuras venas, arterias coronarias y capilares. Es tras este proceso cuando su expresión ya parece restringirse al fenotipo arterial, perdiéndose en el resto de la microvasculatura que permanece siendo GFP+. Qué señales están implicadas en el mantenimiento del alelo Gfp activo en los capilares durante el resto del desarrollo embrionario y posnatal permanecen desconocidas. Parece que el papel de la proteína Sox17 juega mayor importancia en todo el plexo durante la fase angiogénica, posiblemente respondiendo a señales de hipoxia. Esta teoría se ver reforzada por los modelos mutantes de ratón en los que la vasculatura coronaria se encuentra afectada, como los mutantes de APJ (Sharma et al., 2017) o los de $\mathrm{Cxcl12}$ (este trabajo). Es en estas situaciones cuando el endocardio trata de compensar las deficiencias del plexo vascular (mayoritariamente derivado del SV) y debe expandirse rápidamente. Esto parece provocar la activación en sus células la expresión de Sox17, un dominio en el que de forma normal no se encuentra expresado.

Lo que parece evidente es que el alelo Nes-Gfp se encuentra expresado en una amplia variedad de linajes celulares que, a pesar de ser muy diferentes entre ellos, comparten las mismas familias de factores de transcripción para regular su actividad respondiendo a funciones concretas, como son la motilidad y migración. En el caso del endocardio ventricular, las células endoteliales que lo componen no encienden el alelo Nes-Gfp, posiblemente porque las funciones realizadas por este subgrupo concreto de endotelio no lo requieren. No obstante, el plexo que vemos en la cara ventral de los corazones en desarrollo expandirse a partir de las denominadas "islas de sangre" sí que enciende el reportero, confirmando que, a pesar de derivar de unas células GFP-, una vez que dejan de formar parte del endocardio ventricular y deben expandirse para unirse al resto de la vasculatura, las señales implicadas en regular el proceso de angiogénesis de esas células también encienden el reportero GFP.

\subsection{Posible regulación por mecanismos activadores/represores del enhancer neural de Nestina en las célullas endoteliales del corazón}

Los perfiles transcripcionales realizados entre endocardio y vasculatura coronaria nos muestran multitud de genes diferencialmente expresados entre ambas poblaciones. El hecho de que en el endocardio el alelo no se encienda podría deberse a que en estas células no estuviesen presente las señales necesarias para su activación (como por ejemplo la ausencia de Sox17) o que además existan factores represores de dicha activación.

Nos resulta particularmente interesante el patrón de expresión de los factores Fox, ya que algunos de sus miembros parecen ser diferenciales de endocardio ventricular ( $F o x c / c 2$ ) mientras que otros lo serían de la vasculatura coronaria (Foxm1). En concreto, los genes Foxc1 y Foxc2 presentan un patrón de expresión totalmente contrario al de Sox17, con mucha 
expresión en el endocardio ventricular y muy baja en el plexo coronario. Esto nos hizo plantearnos si estos dos factores podrían estar actuando como inhibidores en el endocardio. Además, el análisis con JASPAR mostraba que en el CR2 existía un sitio putativo de unión para los factores FoxC solapando con el sitio de unión para el factor Sox17. Esto podría sugerir una situación de competencia, en la que en función de las cantidades de factores Sox/Fox, se unan uno u otro para activar o reprimir la activación del enhancer neural de Nestina.

Con respecto a los factores que puedan promover la activación del enhancer, el patrón del alelo Nes-Gfp en la vasculatura es muy similar al de otros genes como Fabp4, Fabp7, Dach1, y Ppary. Ya había sido descrito que en SNC, la regulación de los genes B-Fabp (brain fatty acid binding protein) era análoga a la del gen Nestina, por lo que en endotelio coronario es posible que Fabp4/7 estén siendo activados por los mismos elementos reguladores que el i2E. Con respecto a los factores de transcripción, Dach1 también podría estar regulando directamente la expresión del enhancer. Aunque no se conoce exactamente la secuencia de unión de este factor al ADN, se ha descrito que su secuencia consenso sería muy similar a la del factor Foxm1 (Sanders et al., 2015), que también se expresa diferencialmente en la vasculatura coronaria. Por este motivo podría ser que en los dominios de unión putativos para los factores Fox, pudiese estar uniéndose Dach1 específicamente en la vasculatura coronaria, activando así al i2E. Recientemente se publicó un trabajo que mostraba la participación de Dach1 de forma activa en el proceso de remodelado arterial, coordinando a su vez el axis de señalización $C x c / 12 / C x c r 4$ en las células endoteliales de la vasculatura coronaria (Chang et al., 2017). Finalmente, en la región 5' del CR2 encontramos un sitio de unión $R A R / R X R$, donde la proteína Ppary podría estar uniéndose en combinación con Sox17 para activar el enhancer neural de Nestina.

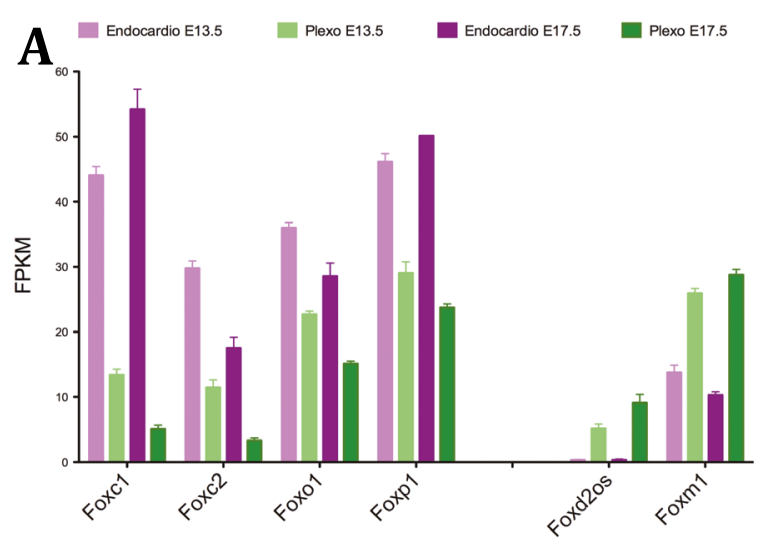

Figura 55. Posibles factores co-reguladores de la actividad del i2E. (A) Se muestra el perfil de expresión de los diferentes miembros de la familia Fox en endocardio y plexo coronario a E13.5 y E17.5. (B) Sitios putativos de unión al ADN del i2E para factores Fox y receptores RAR/RXR. (C) Perfil de expresión de posibles genes candidatos para la regulación del enhancer neural de Nestina a E17.5. * Estadísticamente significativo $\mathrm{p}<0,05$.

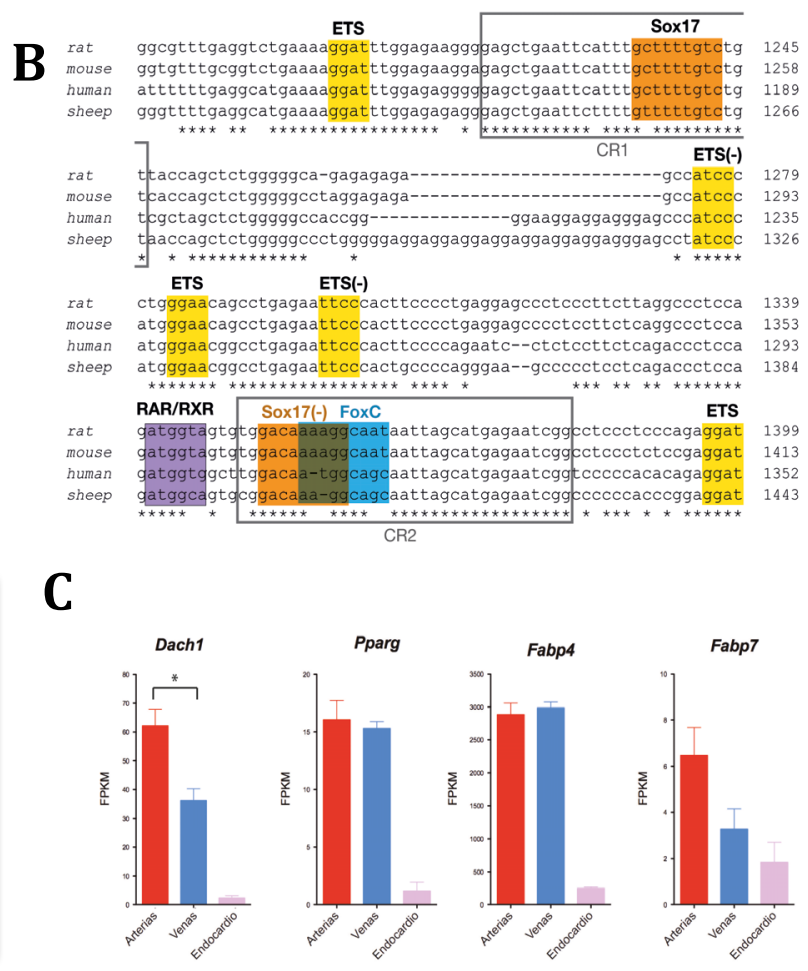




\section{Sistema Nervioso Central}

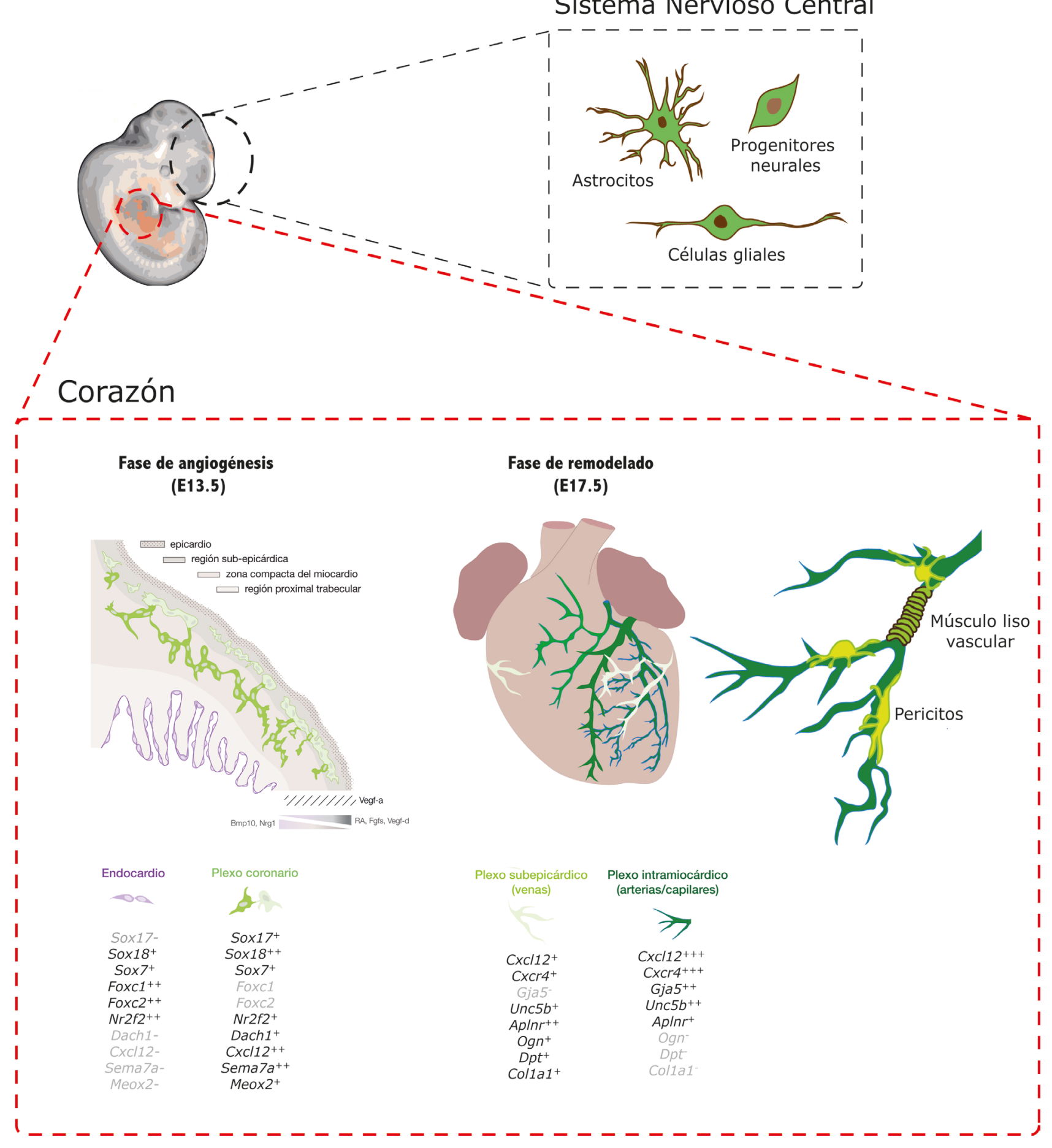

Figura 56. Resumen de poblaciones marcadas con el alelo Nes-Gfp en sistema nervioso central y corazón. El alelo Nes-Gfp ha sido ampliamente usado como herramienta para el marcaje de progenitores neurales en SNC, sin embargo también se encuentra muy expresado durante el desarrollo cardíaco. En corazón observamos poblaciones mesenquimales como pericitos, músculo liso vascular y fibroblastos GFP+. Con respecto a la vasculatura, en endocardio ventricular no se encuentra expresado, pero sí en el plexo primitivo que, tras diferenciarse en subepicárdico e intramiocárdico, los niveles descienden en las futuras venas para quedar únicamente expresado en los capilares y arterias coronarias. Estas diferencias en el patrón de expresión nos permiten separar las distintas subpoblaciones endoteliales y realizar perfiles transcripcionales de las mismas. 


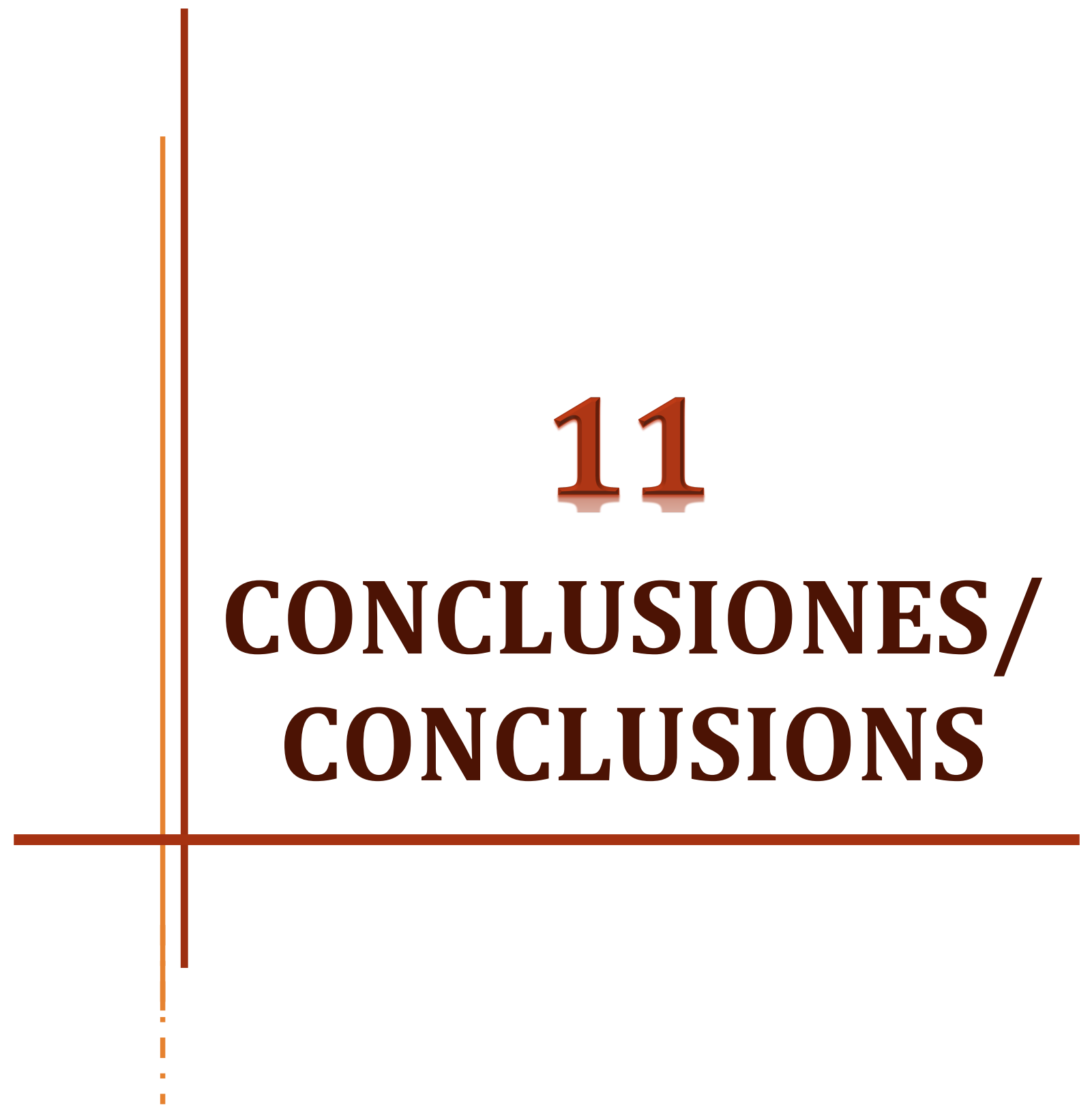



1. Durante el desarrollo cardíaco de ratón, el alelo Nestin-Gfp se expresa dinámicamente en distintas poblaciones no miocíticas, incluyendo células mesenquimales y murales, en células endoteliales del plexo vascular naciente y en las zonas de remodelado coronario arterial.

2. La activación del reportero GFP en los vasos coronarios angiogénicos, junto al empleo de técnicas de clarificación óptica (CUBIC), permite el estudio de la formación del plexo coronario mediante microscopia confocal a alta resolución en corazones intactos. Entre E11.5-E13.5 el reportero se puede detectar en el conjunto de la vasculatura coronaria. Posteriormente, esta expresión disminuye progresivamente en los vasos subepicárdicos, manteniendo sus niveles de expresión en los vasos intramiocárdicos de la pared ventricular.

3. La fuerte inducción de GFP en las arterias coronarias emergentes de corazones Nes-GFP+ facilita la visualización directa de posibles malformaciones vasculares en mutantes letales como los embriones deficientes en $\mathrm{CxCl12}$. Los corazones $\mathrm{CxCl12} \mathrm{KO}$ presentan retrasos en la formación del plexo vascular y consecuente remodelado, careciendo de arterias coronarias apreciables. A su vez, exhiben déficit de fibras neurales simpáticas en la cara dorsal y defectos en el reclutamiento (junto a alteraciones morfológicas) de la población de macrófagos primitivos subepicárdica.

4. El trazado de linaje con el alelo Nes-CreER ${ }^{T 2}$ nos permite marcar selectivamente la mayoría del endotelio coronario (durante la ventana E10.5/12.5), o de forma más específica, preferencialmente los vasos intramurales (capilares y arterias coronarias) en función del estadio en que se induzca la recombinación. En adultos la actividad del driver en corazón se encuentra restringida mayoritariamente a la microvasculatura ventricular y septal.

5. La combinación de los alelos Nes-Gfp y Nes-CreER ${ }^{T 2}$, junto a los niveles de expresión del marcador Endomucina, nos permite distinguir entre distintas subpoblaciones endoteliales cardíacas: el endocardio, los vasos intramiocárdicos (enriquecido en arterias/capilares) y los vasos subepicárdicos (enriquecido en venas coronarias). Esto posibilita separarlas y realizar un perfil transcripcional de los genes distintivos entre los distintos subtipos. También ha sido posible identificar los transcritos que cambian, dentro del endotelio coronario, durante la fase de expansión angiogénica (E13.5) y la fase de remodelado del plexo primitivo y maduración arteriogénica (E17.5).

6. Entre los genes diferencialmente expresados entre plexo y endocardio, hemos identificado el factor de transcripción Sox17. La proteína se encuentra localizada en los núcleos de las primeras células endoteliales procedentes del SV que invaden la pared ventricular. Posteriormente, durante la fase de remodelado, su expresión queda restringida principalmente en el endotelio de las arterias y arteriolas intramurales. 
7. Existe una elevada correspondencia entre la expresión del factor Sox17 y la inducción del alelo Nes-Gfp o Nes-CreER ${ }^{T 2}$. Ambos transgenes contienen el segundo intrón del gen Nestina donde se han localizado 2 sitios putativos de unión a factores Sox altamente conservados evolutivamente (denominados CR1 y CR2). Ensayos bioquímicos de EMSA revelan que extractos de células endoteliales cardíacas que sobreexpresan Sox17, son capaces de unirse a ambas regiones, presentando mayor especificidad por el lugar CR1.

8. Ensayos de actividad luciferasa in vitro con una línea celular endotelial cardíaca han revelado que Sox17 es capaz de inducir el enhancer neural del segundo intrón de Nestina.

9. Por todo lo anterior, proponemos un modelo en el cual durante la fase angiogénica activa, el conjunto del plexo coronario up-regularta Sox17 -concomitantemente a otros factores-, activando un programa génico que durante el remodelado quedaría restringido y refinado a las arteriolas y arterias intramurales. El enhancer neural del segundo intrón de Nestina, permitiría sensar esta activación, a través de los sitios de unión específicos. 
1. During mouse cardiac development, the Nestin-Gfp allele is expressed dynamically in different non-myocytic populations, including mesenchymal and mural cells, in endothelial cells of the nascent vascular plexus and in areas of arterial coronary remodeling.

2. The activation of the GFP reporter in the coronary angiogenic vessels, together with the use of optical clarification techniques (CUBIC), allows the study of the formation of the coronary plexus by confocal microscopy at high resolution in intact hearts. Between E11.5-E13.5 the reporter can be detected in the whole of the coronary vasculature. Subsequently, this expression decreases progressively in the subepicardial vessels, maintaining their levels of expression in the intramyocardial vessels of the ventricular wall.

3. The strong induction of GFP in the emergent coronary arteries of Nes-GFP+ hearts facilitates the direct visualization of possible vascular malformations in lethal mutants such as embryos deficient in $\mathrm{CxCl} 12$. The $\mathrm{CxCl} 12 \mathrm{KO}$ hearts show delays in the formation of the vascular plexus and consequent remodeling, lacking appreciable coronary arteries. In turn, they show a deficit of sympathetic neural fibers in the dorsal aspect and defects in the recruitment (together with morphological alterations) of the population of subepicardial primitive macrophages.

4. Lineage tracing with the Nes-CreER ${ }^{T 2}$ allele allows us to selectively mark most of the coronary endothelium (during E10.5/12.5), or more specifically, preferentially intramural vessels (capillaries and coronary arteries) depending on the stage in which recombination is induced. In adults, the activity of the driver is mainly restricted to the ventricular and septal microvasculature.

5. The combination of the Nes-Gfp and Nes-CreER ${ }^{T 2}$ alleles, together with the expression levels of the Endomucin marker, allows us to distinguish between different cardiac endothelial subpopulations: the endocardium, the intramyocardial vessels (arteries / capillaries-enriched) and the subepicardial vessels (enriched in coronary veins). This makes it possible to separate them and make a transcriptional profile of the distinctive genes between the different subtypes. It has also been possible to identify the transcripts that change, within the coronary endothelium, during the angiogenic phase (E13.5) and the remodeling phase of the primitive plexus and arteriogenic maturation (E17.5).

6. Among the genes differentially expressed between plexus and endocardium, we have identified the transcription factor Sox17. The protein is located in the nuclei of the first endothelial cells from the SV that invade the ventricular wall. Later, during the remodeling phase, its expression is restricted mainly in the endothelium of the intramural arteries and arterioles. 
7. There is a high correspondence between the expression of the Sox17 factor and the induction of the Nes-Gfp or Nes-CreER ${ }^{T 2}$ allele. Both transgenes contain the second intron of the Nestin gene where 2 putative binding sites evolutionarily highly conserved Sox factors (called CR1 and CR2) have been located. EMSA biochemical assays reveal that extracts of cardiac endothelial cells overexpressing Sox17 are able of binding to both regions, presenting greater specificity for the CR1 site.

8. In vitro luciferase activity assays with a cardiac endothelial cell line have revealed that Sox17 is able of inducing the neural enhancer of the Nestin second intron.

9. For all the above, we propose a model in which during the active angiogenic phase, the whole of the upregulating coronary plexus Sox17 -concomitantly to other factors-, is activating a gene program that during the remodeling would be restricted and refined to the arterioles and arteries intramurals. The neural enhancer of the Nestin second intron, would allow sensing this activation, through the specific binding sites. 


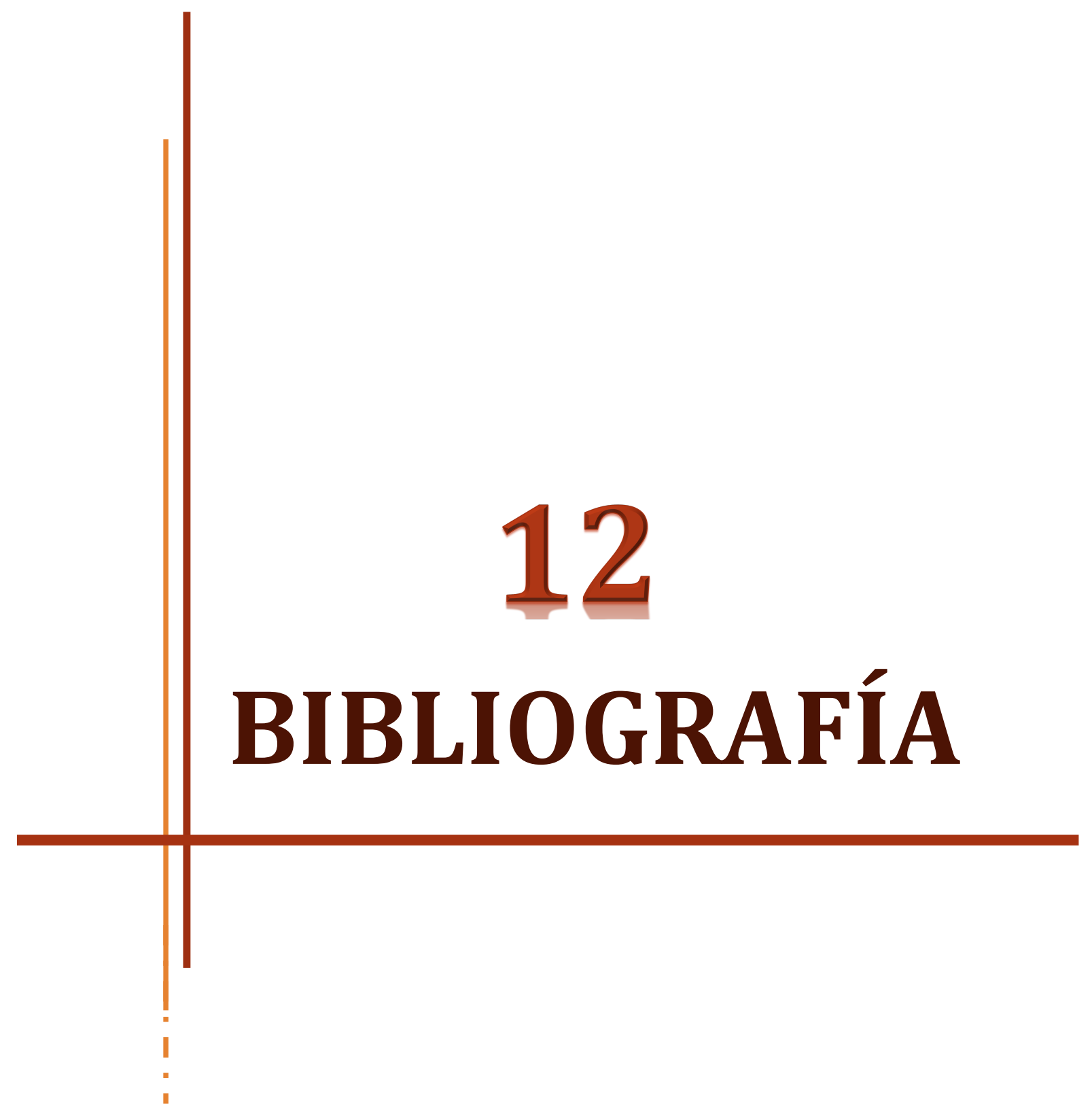



AIHARA, M., SUGAWARA, K.-I., TORII, S., HOSAKA, M., KURIHARA, H., SAITO, N. \& TAKEUCHI, T. 2004. Angiogenic endothelium-specific nestin expression is enhanced by the first intron of the nestin gene. Lab Invest.

AMBROSETTI, D. C., BASILICO, C. \& DAILEY, L. 1997. Synergistic activation of the fibroblast growth factor 4 enhancer by Sox2 and Oct-3 depends on protein-protein interactions facilitated by a specific spatial arrangement of factor binding sites. $\mathrm{Mol}$ Cell Biol.

AMOH, Y., YANG, M., LI, L., REYNOSO, J., BOUVET, M., MOOSSA, A. R., KATSUOKA, K. \& HOFFMAN, R. M. 2005. Nestin-linked green fluorescent protein transgenic nude mouse for imaging human tumor angiogenesis. Cancer Res.

ANDREWS, S. 2010. FastQC: A quality control tool for high throughput sequence data. [WWW Document]. http://www.bioinformatics.babraham.ac.uk/projects/fastqc/.

ANTHONY, B. A. \& LINK, D. C. 2014. Regulation of hematopoietic stem cells by bone marrow stromal cells. Trends in Immunology.

ARA, T., ITOI, M., KAWABATA, K., EGAWA, T., TOKOYODA, K., SUGIYAMA, T., FUJII, N., AMAGAI, T. \& NAGASAWA, T. 2003. A role of CXC chemokine ligand 12/stromal cell-derived factor-1/pre-B cell growth stimulating factor and its receptor CXCR4 in fetal and adult $\mathrm{T}$ cell development in vivo. J Immunol.

ARANGUREN, X. L., AGIRRE, X., BEERENS, M., COPPIELLO, G., URIZ, M., VANDERSMISSEN, I., BENKHEIL, M., PANADERO, J., AGUADO, N., PASCUAL-MONTANO, A., SEGURA, V., PRÓSPER, F. \& LUTTUN, A. 2013. Unraveling a novel transcription factor code determining the human arterial-specific endothelial cell signature. Blood.

ARIMA, Y., MIYAGAWA-TOMITA, S., MAEDA, K., ASAI, R., SEYA, D., MINOUX, M., RIJLI, F. M., NISHIYAMA, K., KIM, K.-S., UCHIJIMA, Y., OGAWA, H., KURIHARA, Y. \& KURIHARA, H. 2012. Preotic neural crest cells contribute to coronary artery smooth muscle involving endothelin signalling. Nature Communications.

ARITA, Y., NAKAOKA, Y., MATSUNAGA, T., KIDOYA, H., YAMAMIZU, K., ARIMA, Y., KATAOKA-HASHIMOTO, T., IKEOKA, K., YASUI, T., MASAKI, T., YAMAMOTO, K., HIGUCHI, K., PARK, J.-S., SHIRAI, M., NISHIYAMA, K., YAMAGISHI, H., OTSU, K., KURIHARA, H., MINAMI, T., YAMAUCHI-TAKIHARA, K., KOH, G. Y., MOCHIZUKI, N., TAKAKURA, N., SAKATA, Y., YAMASHITA, J. K. \& KOMURO, I. 2014. Myocardiumderived angiopoietin-1 is essential for coronary vein formation in the developing heart. Nature Communications.

BALORDI, F. \& FISHELL, G. 2007. Mosaic removal of hedgehog signaling in the adult SVZ reveals that the residual wild-type stem cells have a limited capacity for selfrenewal. J Neurosci.

BARBIERI, S. S. \& WEKSLER, B. B. 2007. Tobacco smoke cooperates with interleukin-1beta to alter beta-catenin trafficking in vascular endothelium resulting in increased permeability and induction of cyclooxygenase- 2 expression in vitro and in vivo. FASEB J.

BÉGUIN, P. C., GOSSELIN, H., MAMARBACHI, M. \& CALDERONE, A. 2011. Nestin expression is lost in ventricular fibroblasts during postnatal development of the rat heart and re-expressed in scar myofibroblasts. J Cell Physiol.

BENNETT, H. 1936. The development of the blood supply to the heart in the embryo pig. Am J Anat, 60, 27.

BIRBRAIR, A., WANG, Z.-M., MESSI, M. L., ENIKOLOPOV, G. N. \& DELBONO, 0. 2011. NestinGFP transgene reveals neural precursor cells in adult skeletal muscle. PLoS ONE.

BUCKINGHAM, M., MEILHAC, S. \& ZAFFRAN, S. 2005. Building the mammalian heart from two sources of myocardial cells. Nat Rev Genet. 
CAI, C.-L., MARTIN, J. C., SUN, Y., CUI, L., WANG, L., OUYANG, K., YANG, L., BU, L., LIANG, X., ZHANG, X., STALLCUP, W. B., DENTON, C. P., MCCULLOCH, A., CHEN, J. \& EVANS, S. M. 2008. A myocardial lineage derives from Tbx18 epicardial cells. Nature.

CALDERONE, A. 2012. Nestin+ cells and healing the infarcted heart. AJP: Heart and Circulatory Physiology.

CARTER, T. C. \& PHILLIPS, J. S. 1954. Ragged, a semidominant coat texture mutant in the house mouse. Journal of Heredity, 45, 151-154.

CAVALLERO, S., SHEN, H., YI, C., LIEN, C.-L., KUMAR, S. R. \& SUCOV, H. M. 2015. CXCL12 Signaling Is Essential for Maturation of the Ventricular Coronary Endothelial Plexus and Establishment of Functional Coronary Circulation. Dev Cell.

CERMENATI, S., MOLERI, S., CIMBRO, S., CORTI, P., DEL GIACCO, L., AMODEO, R., DEJANA, E., KOOPMAN, P., COTELli, F. \& BELTRAME, M. 2008. Sox18 and Sox7 play redundant roles in vascular development. Blood.

CHANG, A. H., RAFTREY, B. C., D'AMATO, G., SURYA, V. N., PODURI, A., CHEN, H. I., GOLDSTONE, A. B., WOO, J., FULLER, G. G., DUNN, A. R. \& RED-HORSE, K. 2017. DACH1 stimulates shear stress-guided endothelial cell migration and coronary artery growth through the CXCL12-CXCR4 signaling axis. Genes Dev.

CHEN, H. I., SHARMA, B., AKERBERG, B. N., NUMI, H. J., KIVELÄ, R., SAHARINEN, P., AGHAJANIAN, H., MCKAY, A. S., BOGARD, P. E., CHANG, A. H., JACOBS, A. H., EPSTEIN, J. A., STANKUNAS, K., ALITALO, K. \& RED-HORSE, K. 2014. The sinus venosus contributes to coronary vasculature through VEGFC-stimulated angiogenesis. Development.

CHEN, K. G., JOHNSON, KORY R. \& ROBEY, PAMELA G. 2017. Mouse Genetic Analysis of Bone Marrow Stem Cell Niches: Technological Pitfalls, Challenges, and Translational Considerations. Stem Cell Reports.

CHRISTOFFELS, V. M., HABETS, P. E., FRANCO, D., CAMPIONE, M., DE JONG, F., LAMERS, W. H., BAO, Z. Z., PALMER, S., BIBEN, C., HARVEY, R. P. \& MOORMAN, A. F. 2000. Chamber formation and morphogenesis in the developing mammalian heart. Dev Biol.

CORADA, M., ORSENIGO, F., MORINI, M. F., PITUlESCU, M. E., BHAT, G., NYQVIST, D., BREVIARIO, F., CONTI, V., BRIOT, A., IRUELA-ARISPE, M. L., ADAMS, R. H. \& DEJANA, E. 2013. Sox17 is indispensable for acquisition and maintenance of arterial identity. Nature Communications.

CREAZZO, T. L., GODT, R. E., LEATHERBURY, L., CONWAY, S. J. \& KIRBY, M. L. 1998. Role of cardiac neural crest cells in cardiovascular development. Annu. Rev. Physiol.

DAS, S. \& RED-HORSE, K. 2017. Cellular plasticity in cardiovascular development and disease. Dev. Dyn.

DE VAL, S. \& BLACK, B. L. 2009. Transcriptional control of endothelial cell development. Dev Cell.

DE VAL, S., CHI, N. C., MEADOWS, S. M., MINOVITSKY, S., ANDERSON, J. P., HARRIS, I. S., EHLERS, M. L., AGARWAL, P., VISEL, A., XU, S.-M., PENNACCHIO, L. A., DUBCHAK, I., KRIEG, P. A., STAINIER, D. Y. R. \& BLACK, B. L. 2008. Combinatorial regulation of endothelial gene expression by ets and forkhead transcription factors. Cell.

DEJANA, E., TADDEI, A. \& RANDI, A. M. 2007. Foxs and Ets in the transcriptional regulation of endothelial cell differentiation and angiogenesis. Biochim Biophys Acta.

DEL MONTE, G., CASANOVA, J. C., GUADIX, J. A., MACGROGAN, D., BURCH, J. B. E., PÉREZPOMARES, J. M. \& DE LA POMPA, J. L. 2011. Differential Notch signaling in the epicardium is required for cardiac inflow development and coronary vessel morphogenesis. Circ Res. 
DOWNES, M., FRANÇOIS, M., FERGUSON, C., PARTON, R. G. \& KOOPMAN, P. 2009. Vascular defects in a mouse model of hypotrichosis-lymphedema-telangiectasia syndrome indicate a role for SOX18 in blood vessel maturation. Hum Mol Genet.

DOWNES, M. \& KOOPMAN, P. 2001. SOX18 and the transcriptional regulation of blood vessel development. Trends Cardiovasc Med.

DYER, L., PI, X. \& PATTERSON, C. 2014. Connecting the coronaries_ How the coronary plexus develops and is functionalized. Dev Biol.

EL-HELOU, V., BEGUIN, P. C., ASSIMAKOPOULOS, J., CLEMENT, R., GOSSELIN, H., BRUGADA, R., AUMONT, A., BIERNASKIE, J., VILLENEUVE, L., LEUNG, T. K., FERNANDES, K. J. L. \& CALDERONE, A. 2008. The rat heart contains a neural stem cell population; role in sympathetic sprouting and angiogenesis. J Mol Cell Cardiol.

EL-HELOU, V., CHABOT, A., GOSSELIN, H., VILLENEUVE, L., CLAVET-LANTHIER, M.-E., TANGUAY, J.-F., ENIKOLOPOV, G., FERNANDES, K. J. L., JASMIN, J.-F. \& CALDERONE, A. 2013. Cardiac resident nestin +cells participate in reparative vascularisation. $J$ Cell Physiol.

EL-HElOU, V., DUPUIS, J., PROULX, C., DRAPEAU, J., CLEMENT, R., GOSSELIN, H., VILLENEUVE, L., MANGANAS, L. \& CALDERONE, A. 2005. Resident nestin+ neurallike cells and fibers are detected in normal and damaged rat myocardium. Hypertension.

FEIL, R., WAGNER, J., METZGER, D. \& CHAMBON, P. 1997. Regulation of Cre recombinase activity by mutated estrogen receptor ligand-binding domains. Biochem Biophys Res Commun.

FLAHT, A., JANKOWSKA-STEIFER, E., RADOMSKA, D. M., MADEJ, M., GULA, G., KUJAWA, M. \& RATAJSKA, A. 2012. Cellular phenotypes and spatio-temporal patterns of lymphatic vessel development in embryonic mouse hearts. Dev Dyn.

FLAMME, I., FRÖLICH, T. \& RASAU, W. 1997. Molecular mechanisms of vasculogenesis and embryonic angiogenesis. J Cell Physiol., 173, 206-2010.

FRANÇOIS, M., CAPRINI, A., HOSKING, B., ORSENIGO, F., WILHELM, D., BROWNE, C., PAAVONEN, K., KARNEZIS, T., SHAYAN, R., DOWNES, M., DAVIDSON, T., TUTT, D., CHEAH, K. S. E., STACKER, S. A., MUSCAT, G. E. O., ACHEN, M. G., DEJANA, E. \& KOOPMAN, P. 2008. Sox18 induces development of the lymphatic vasculature in mice. Nature.

FRANCOIS, M., KOOPMAN, P. \& BELTRAME, M. 2010. SoxF genes: Key players in the development of the cardio-vascular system. Int J Biochem Cell Biol.

FREDERIKSEN, K. \& MCKAY, R. D. 1988. Proliferation and differentiation of rat neuroepithelial precursor cells in vivo. J Neurosci.

FRENETTE, P. S., PINHO, S., LUCAS, D. \& SCHEIERMANN, C. 2013. Mesenchymal stem cell: keystone of the hematopoietic stem cell niche and a stepping-stone for regenerative medicine. Annu Rev Immunol.

FRIEDRICH, G. \& SORIANO, P. 1991. Promoter traps in embryonic stem cells: a genetic screen to identify and mutate developmental genes in mice. Genes Dev.

GITTENBERGER-DE GROOT, A. C., WINTER, E. M. \& POELMANN, R. E. 2010. Epicardiumderived cells (EPDCs) in development, cardiac disease and repair of ischemia.J Cell Mol Med.

GOLDSMITH, J. \& BUTLER, H. 1937. The development of the cardiac-coronary circulatory system. Am J Anat, 60, 185.

GREEN, E. L. \& MANN, S. J. 1961. Opossum, a semi-dominant lethal mutation affecting hair and other characteristics of mice. J. Hered., 52. 
GREGO-BESSA, J., LUNA-ZURITA, L., DEL MONTE, G., BOLÓS, V., MELGAR, P., ARANDILLA, A., GARRATT, A. N., ZANG, H., MUKOUYAMA, Y.-S., CHEN, H., SHOU, W., BALLESTAR, E., ESTELLER, M., ROJAS, A., PÉREZ-POMARES, J. M. \& DE LA POMPA, J. L. 2007. Notch signaling is essential for ventricular chamber development. Dev Cell.

HAMILTON, D. L. \& ABREMSKI, K. 1984. Site-specific recombination by the bacteriophage P1 lox-Cre system. Cre-mediated synapsis of two lox sites. J Mol Biol.

HAYASHI, H. \& KUME, T. 2008. Foxc transcription factors directly regulate Dll4 and Hey2 expression by interacting with the VEGF-Notch signaling pathways in endothelial cells. PLOS ONE.

HAYASHI, S. \& TAKEICHI, M. 2015. Emerging roles of protocadherins: from self-avoidance to enhancement of motility. J Cell Sci.

HE, L., TIAN, X., ZHANG, H., WYTHE, J. D. \& ZHOU, B. 2014. Fabp4-CreER lineage tracing reveals two distinctive coronary vascular populations. J Cell Mol Med.

HOCKFIELD, S. \& MCKAY, R. D. 1985. Identification of major cell classes in the developing mammalian nervous system. J Neurosci.

HOLLENHORST, P. C., JONES, D. A. \& GRAVES, B. J. 2004. Expression profiles frame the promoter specificity dilemma of the ETS family of transcription factors. Nucleic Acids Res.

HOLLENHORST, P. C., SHAH, A. A., HOPKINS, C. \& GRAVES, B. J. 2007. Genome-wide analyses reveal properties of redundant and specific promoter occupancy within the ETS gene family. Genes Dev.

HOSKING, B., FRANÇOIS, M., WILHELM, D., ORSENIGO, F., CAPRINI, A., SVINGEN, T., TUTT, D., DAVIDSON, T., BROWNE, C., DEJANA, E. \& KOOPMAN, P. 2009. Sox7 and Sox17 are strain-specific modifiers of the

lymphangiogenic defects caused by Sox18 dysfunction in mice. Development.

HOSKING, B. M., WANG, S. C., CHEN, S. L., PENNING, S., KOOPMAN, P. \& MUSCAT, G. E. 2001a. SOX18 directly interacts with MEF2C in endothelial cells. Biochem Biophys Res Commun.

HOSKING, B. M., WYETH, J. R., PENNISI, D. J., WANG, S. C., KOOPMAN, P. \& MUSCAT, G. E. 2001b. Cloning and functional analysis of the Sry-related HMG box gene, Sox18. Gene.

HOU, L., SRIVASTAVA, Y. \& JAUCH, R. 2016. Molecular basis for the genome engagement by Sox proteins. Semin Cell Dev Biol.

HUSTON, M. R. \& KIRBY, M. L. 2003. Neural crest and cardiovascular development: a 20year perspective. . Birth Defects Res C Embryo Today., 69, 2-13.

HUTCHINS, G. M., KESSLER-HANNA, A. \& MOORE, G. W. 1988. Development of the coronary arteries in the embryonic human heart. Circulation.

IRRTHUM, A., DEVRIENDT, K., CHITAYAT, D., MATTHIJS, G., GLADE, C., STEIJLEN, P. M., FRYNS, J.-P., VAN STEENSEL, M. A. M. \& VIKKULA, M. 2003. Mutations in the transcription factor gene SOX18 underlie recessive and dominant forms of hypotrichosis-lymphedema-telangiectasia. Am J Hum Genet.

ISERN, J., GARCÍA-GARCÍA, A., MARTÍN, A. M., ARRANZ, L., MARTÍN-PÉREZ, D., TORROJA, C., SÁNCHEZ-CABO, F. \& MÉNDEZ-FERRER, S. 2014. The neural crest is a source of mesenchymal stem cells with specialized hematopoietic stem cell niche function. Elife.

ISERN, J. \& MÉNDEZ-FERRER, S. 2011. Stem cell interactions in a bone marrow niche. Curr Osteoporos Rep. 
ISHIWATA, T., TEDUKA, K., YAMAMOTO, T., KAWAHARA, K., MATSUDA, Y. \& NAITO, Z. 2011. Neuroepithelial stem cell marker nestin regulates the migration, invasion and growth of human gliomas. Oncol Rep.

IVICS, Z., HIRIPI, L., HOFFMANN, O. I., MÁTÉS, L., YAU, T. Y., BASHIR, S., ZIDEK, V., LANDA, V., GEURTS, A., PRAVENEC, M., RÜLICKE, T., BÖSZE, Z. \& IZSVÁK, Z. 2014. Germline transgenesis in rabbits by pronuclear microinjection of Sleeping Beauty transposons. Nat Protoc.

IVINS, S., CHAPPELL, J., VERNAY, B., SUNTHARALINGHAM, J., MARTINEAU, A., MOHUN, T. J. \& SCAMBLER, P. J. 2015. The CXCL12/CXCR4 Axis Plays a Critical Role in Coronary Artery Development. Dev Cell.

JAMES, K., HOSKING, B., GARDNER, J., MUSCAT, G. E. O. \& KOOPMAN, P. 2003. Sox18 mutations in the ragged mouse alleles ragged-like and opossum. Genesis.

JOSEPHSON, R., MÜLLER, T., PICKEL, J., OKABE, S., REYNOLDS, K., TURNER, P. A., ZIMMER, A. \& MCKAY, R. D. 1998. POU transcription factors control expression of CNS stem cell-specific genes. Development.

KANAI-AZUMA, M., KANAI, Y., GAD, J. M., TAJIMA, Y., TAYA, C., KUROHMARU, M., SANAI, Y., YONEKAWA, H., YAZAKI, K., TAM, P. P. L. \& HAYASHI, Y. 2002. Depletion of definitive gut endoderm in Sox17-null mutant mice. Development.

KATZ, T. C., SINGH, M. K., DEGENHARDT, K., RIVERA-FELICIANO, J., JOHNSON, R. L., EPSTEIN, J. A. \& TABIN, C. J. 2012. Distinct compartments of the proepicardial organ give rise to coronary vascular endothelial cells. Dev Cell.

KELLY, R. G. \& BUCKINGHAM, M. E. 2002. The anterior heart-forming field: voyage to the arterial pole of the heart. Trends Genet.

KILBY, N. J., SNAITH, M. R. \& MURRAY, J. A. H. 1993. Site-specific recombinases: tools for genome engineering. Trends Genet, 9, 413-421.

KIM, I., SAUNDERS, T. L. \& MORRISON, S. J. 2007. Sox17 dependence distinguishes the transcriptional regulation of fetal from adult hematopoietic stem cells. Cell.

KIM, K., KIM, I.-K., YANG, J. M., LEE, E., KOH, B. I., SONG, S., PARK, J., LEE, S., CHOI, C., KIM, J. W., KUBOTA, Y., KOH, G. Y. \& KIM, I. 2016. SoxF Transcription Factors Are Positive Feedback Regulators of VEGF Signaling. Circ Res.

KIRBY, M. L. 1999. Contribution of neural crest to heart and vessel morphology. Heart development. Academic Press, 179-193.

KIRBY, M. L. 2002. Molecular embryogenesis of the heart. Pediat Dev Pathol, 5, 516-543.

KISANUKI, Y. Y., HAMMER, R. E., MIYAZAKI, J., WILLIAMS, S. C., RICHARDSON, J. A. \& YANAGISAWA, M. 2001. Tie2-Cre transgenic mice: a new model for endothelial cell-lineage analysis in vivo. Developmental Biology

KLOTZ, L., NORMAN, S., VIEIRA, J. M., MASTERS, M., ROHLING, M., DUBÉ, K. N., BOLLINI, S., MATSUZAKI, F., CARR, C. A. \& RILEY, P. R. 2015. Cardiac lymphatics are heterogeneous in origin and respond to injury. Nature.

KOLESOVÁ, H., ČAPEK, M., RADOCHOVÁ, B., JANÁČEK, J. \& SEDMERA, D. 2016. Comparison of different tissue clearing methods and 3D imaging techniques for visualization of GFP-expressing mouse embryos and embryonic hearts. Histochem Cell Biol.

KRETZSCHMAR, K. \& WATT, F. M. 2012. Lineage tracing. Cell.

KUHLBRODT, K., HERBARTH, B., SOCK, E., ENDERICH, J., HERMANS-BORGMEYER, I. \& WEGNER, M. 1998. Cooperative function of POU proteins and SOX proteins in glial cells. J Biol Chem.

LAVINE, K. \& ORNITZ, D. M. 2010. Chapter 5.2 -The Epicardial Signaling Center in Development and Disease. Heart Development and Regeneration, 345-359. 
LAWSON, N. D., VOGEL, A. M. \& WEINSTEIN, B. M. 2002. sonic hedgehog and vascular endothelial growth factor act upstream of the Notch pathway during arterial endothelial differentiation. Dev Cell.

LENDAHL, U., ZIMMERMAN, L. B. \& MCKAY, R. D. 1990. CNS stem cells express a new class of intermediate filament protein. Cell.

LEWIS, A. E., VASUDEVAN, H. N., O'NEILL, A. K., SORIANO, P. \& BUSH, J. O. 2013. The widely used Wnt1-Cre transgene causes developmental phenotypes by ectopic activation of Wnt signaling. Dev Biol.

LI, B. \& DEWEY, C. N. 2011. RSEM: accurate transcript quantification from RNA-Seq data with or without a reference genome. BMC Bioinformatics.

LILLY, A. J., LACAUD, G. \& KOUSKOFF, V. 2016. SOXF transcription factors in cardiovascular development. Semin Cell Dev Biol.

LIU, Q., HU, T., HE, L., HUANG, X., TIAN, X., ZHANG, H., HE, L., PU, W., ZHANG, L., SUN, H., FANG, J., YU, Y., DUAN, S., HU, C., HUI, L., ZHANG, H., QUERTERMOUS, T., XU, Q., RED-HORSE, K., WYTHE, J. D. \& ZHOU, B. 2015a. Genetic targeting of sprouting angiogenesis using Apln-CreER. Nature Communications.

LIU, W., LI, J., LIU, M., ZHANG, H. \& WANG, N. 2015b. PPAR- $\gamma$ promotes endothelial cell migration by inducing the expression of Sema3g. J Cell Biochem.

LOTHIAN, C. \& LENDAHL, U. 1997. An evolutionarily conserved region in the second intron of the human nestin gene directs gene expression to CNS progenitor cells and to early neural crest cells. Eur J Neurosci.

LOTHIAN, C., PRAKASH, N., LENDAHL, U. \& WAHLSTRÖM, G. M. 1999. Identification of both general and region-specific embryonic CNS enhancer elements in the nestin promoter. Exp Cell Res.

MADISEN, L., ZWINGMAN, T. A., SUNKIN, S. M., OH, S. W., ZARIWALA, H. A., GU, H., NG, L. L., PALMITER, R. D., HAWRYLYCZ, M. J., JONES, A. R., LEIN, E. S. \& ZENG, H. 2010. A robust and high-throughput Cre reporting and characterization system for the whole mouse brain. Nat Neurosci.

MANASEK, F. J. 1969. Embryonic development of the heart. II. Formation of the epicardium. J Embryol Exp Morphol.

MÄNNER, J. 1999. Does the subepicardial mesenchyme contribute myocardioblasts to the myocardium of the chick embryo heart? A quail-chick chimera study tracing the fate of the epicardial primordium. Anat Rec.

MÄNNER, J., PÉREZ-POMARES, J. M., MACÍAS, D. \& MUÑOZ-CHÁPULI, R. 2001. The origin, formation and developmental significance of the epicardium: a review. Cells Tissues Organs (Print).

MAROULAKOU, I. G. \& BOWE, D. B. 2000. Expression and function of Ets transcription factors in mammalian development: a regulatory network. Oncogene.

MARTIN, M. 2011. Cutadapt removes adapter sequences from high-throughput sequencing reads. EMBnet.journal, 10-12.

MARTINEZ-CORRAL, I., ULVMAR, M. H., STANCZUK, L., TATIN, F., KIZHATIL, K., JOHN, S. W. M., ALITALO, K., ORTEGA, S. \& MAKINEN, T. 2015. Nonvenous origin of dermal lymphatic vasculature. Circ Res.

MASCHHOFF, K. L. \& BALDWIN, H. S. 2001. Molecular determinants of neural crest migration. Am J Med Genet, 97, 280-288.

MATSUI, T., KANAI-AZUMA, M., HARA, K., MATOBA, S., HIRAMATSU, R., KAWAKAMI, H., KUROHMARU, M., KOOPMAN, P. \& KANAI, Y. 2006. Redundant roles of Sox17 and Sox18 in postnatal angiogenesis in mice. J Cell Sci. 
MEILHAC, S. M., LESCROART, F., BLANPAIN, C. \& BUCKINGHAM, M. E. 2014. Cardiac cell lineages that form the heart. Cold Spring Harb Perspect Med.

MÉNDEZ-FERRER, S., MICHURINA, T. V., FERRARO, F., MAZLOOM, A. R., MACARTHUR, B. D., LIRA, S. A., SCADDEN, D. T., MA'AYAN, A., ENIKOLOPOV, G. N. \& FRENETTE, P. S. 2010. Mesenchymal and haematopoietic stem cells form a unique bone marrow niche. Nature.

MERKI, E., ZAMORA, M., RAYA, A., KAWAKAMI, Y., WANG, J., ZHANG, X., BURCH, J., KUBALAK, S. W., KALIMAN, P., IZPISUA BELMONTE, J. C., CHIEN, K. R. \& RUIZLOZANO, P. 2005. Epicardial retinoid X receptor alpha is required for myocardial growth and coronary artery formation. Proc Natl Acad Sci USA.

MIGNONE, J., PEUNOVA, N. \& ENIKOLOPOV, G. 2016. Nestin-based reporter transgenic mouse lines. Methods Molecular Biology

MIGNONE, J. L., KUKEKOV, V., CHIANG, A.-S., STEINDLER, D. \& ENIKOLOPOV, G. 2004. Neural stem and progenitor cells in nestin-GFP transgenic mice. J. Comp. Neurol.

MIKAWA, T. \& BRAND, T. 2010. Chapter 5.1 - Epicardial Lineage: Origins and Fates. Heart Development and Regeneration, 325-344.

MIKAWA, T. \& FISCHMAN, D. A. 1992. Retroviral analysis of cardiac morphogenesis: Discontinuous formation of coronary vessels. Proc. Natl. Acad. Sci. USA 89, 95049508.

MIKAWA, T. \& GOURDIE, R. G. 1996. Pericardial mesoderm generates a population of coronary smooth muscle cells migrating into the heart along with ingrowth if the epicardial organ. Developmental Biology, 174, 221-232.

MIQUEROL, L. \& KELLY, R. G. 2013. Organogenesis of the vertebrate heart. WIREs Dev Biol. MIQUEROL, L., THIREAU, J., BIDEAUX, P., STURNY, R., RICHARD, S. \& KELLY, R. G. 2015. Endothelial plasticity drives arterial remodeling within the endocardium after myocardial infarction. Circ Res.

MOKRÝ, J., CÍZKOVÁ, D., FILIP, S., EHRMANN, J., OSTERREICHER, J., KOLÁR, Z. \& ENGLISH, D. 2004. Nestin expression by newly formed human blood vessels. Stem Cells Dev.

MOKRÝ, J., EHRMANN, J., KARBANOVÁ, J., CÍZKOVÁ, D., SOUKUP, T., SUCHÁNEK, J., FILIP, S. \& KOLÁR, Z. 2008. Expression of intermediate filament nestin in blood vessels of neural and non-neural tissues. Acta Medica (Hradec Kralove).

MUÑOZ-CHÁPULI, R., GONZÁLEZ-IRIARTE, M., CARMONA, R., ATENCIA, G., MACÍAS, D. \& PÉREZ-POMARES, J. M. 2002. Cellular precursors of the coronary arteries. Tex Heart Inst J.

NAGASAWA, T., HIROTA, S., TACHIBANA, K., TAKAKURA, N., NISHIKAWA, S., KITAMURA, Y., YOSHIDA, N., KIKUTANI, H. \& KISHIMOTO, T. 1996. Defects of B-cell lymphopoiesis and bone-marrow myelopoiesis in mice lacking the CXC chemokine PBSF/SDF-1. Nature, 382, 635-638.

NARLIKAR, L. \& OVCHARENKO, I. 2009. Identifying regulatory elements in eukaryotic genomes. Brief Funct Genomic Proteomic.

NAVANKASATTUSAS, S., WHITEHEAD, K. J., SULI, A., SORENSEN, L. K., LIM, A. H., ZHAO, J., PARK, K. W., WYTHE, J. D., THOMAS, K. R., CHIEN, C.-B. \& LI, D. Y. 2008. The netrin receptor UNC5B promotes angiogenesis in specific vascular beds. Development.

NIAKAN, K. K., JI, H., MAEHR, R., VOKES, S. A., RODOLFA, K. T., SHERWOOD, R. I., YAMAKI, M., DIMOS, J. T., CHEN, A. E., MELTON, D. A., MCMAHON, A. P. \& EGGAN, K. 2010. Sox17 promotes differentiation in mouse embryonic stem cells by directly regulating extraembryonic gene expression and indirectly antagonizing selfrenewal. Genes Dev. 
OCAÑA, O. H., COSKUN, H., MINGUILLÓN, C., MURAWALA, P., TANAKA, E. M., GALCERÁN, J., MUÑOZ-CHÁPULI, R. \& NIETO, M. A. 2017. A right-handed signalling pathway drives heart looping in vertebrates. Nature.

OLIVEY, H. E. \& SVENSSON, E. C. 2010. Epicardial-myocardial signaling directing coronary vasculogenesis. Circ Res.

PATAN, S. 2004. Vasculogenesis and angiogenesis. Cancer Treat Res., 117, 3-32.

PENNACCHIO, L. A., AHITUV, N., MOSES, A. M., PRABHAKAR, S., NOBREGA, M. A., SHOUKRY, M., MINOVITSKY, S., DUBCHAK, I., HOLT, A., LEWIS, K. D., PLAJZERFRICK, I., AKIYAMA, J., DE VAL, S., AFZAL, V., BLACK, B. L., COURONNE, O., EISEN, M. B., VISEL, A. \& RUBIN, E. M. 2006. In vivo enhancer analysis of human conserved non-coding sequences. Nature.

PENNACCHIO, L. A., BICKMORE, W., DEAN, A., NOBREGA, M. A. \& BEJERANO, G. 2013. Enhancers: five essential questions. Nat Rev Genet.

PENNISI, D., GARDNER, J., CHAMBERS, D., HOSKING, B., PETERS, J., MUSCAT, G., ABBOTT, C. \& KOOPMAN, P. 2000. Mutations in Sox18 underlie cardiovascular and hair follicle defects in ragged mice. Nat Genet.

PÉREZ-POMARES, J.-M., CARMONA, R., GONZÁLEZ-IRIARTE, M., ATENCIA, G., WESSELS, A. \& MUÑOZ-CHÁPULI, R. 2002. Origin of coronary endothelial cells from epicardial mesothelium in avian embryos. Int J Dev Biol.

PÉREZ-POMARES, J. M. \& DE LA POMPA, J. L. 2011. Signaling during epicardium and coronary vessel development. Circ Res.

PÉREZ-POMARES, J. M., MACÍAS, D., GARCÍA-GARRIDO, L. \& MUÑOZ-CHÁPULI, R. 1998. The origin of the subepicardial mesenchyme in the avian embryo: an immunohistochemical and quail-chick chimera study. Dev Biol.

PESHKOVSKY, C., TOTONG, R. \& YELON, D. 2011. Dependence of cardiac trabeculation on neuregulin signaling and blood flow in zebrafish. Dev Dyn.

PINTO, A. R., ILINYKH, A., IVEY, M. J., KUWABARA, J. T., D'ANTONI, M. L., DEBUQUE, R., CHANDRAN, A., WANG, L., ARORA, K., ROSENTHAL, N. A. \& TALLQUIST, M. D. 2016. Revisiting Cardiac Cellular Composition. Circ Res.

POELMANN, R. E., GITTENBERGER-DE GROOT, A. C., MENTINK, M. M., BÖKENKAMP, R. \& HOGERS, B. 1993. Development of the cardiac coronary vascular endothelium, studied with antiendothelial antibodies, in chicken-quail chimeras. Circ Res.

PRABHAKAR, S., POULIN, F., SHOUKRY, M., AFZAL, V., RUBIN, E. M., COURONNE, 0. \& PENNACCHIO, L. A. 2006. Close sequence comparisons are sufficient to identify human cis-regulatory elements. Genome Res.

RATAJSKA, A., CZARNOWSKA, E. \& CISZEK, B. 2008. Embryonic development of the proepicardium and coronary vessels. Int J Dev Biol.

RATAJSKA, A., CZARNOWSKA, E., KOŁODZIŃSKA, A., JABŁOŃSKA, A. \& STACHURSKA, E. 2009. New morphological aspects of blood islands formation in the embryonic mouse hearts. Histochem Cell Biol.

RED-HORSE, K., UENO, H., WEISSMAN, I. L. \& KRASNOW, M. A. 2010. Coronary arteries form by developmental reprogramming of venous cells. Nature.

RILEY, P. R. \& SMART, N. 2011. Vascularizing the heart. Cardiovasc Res.

RITCHIE, M. E., PHIPSON, B., WU, D., HU, Y., LAW, C. W., SHI, W. \& SMYTH, G. K. 2015. limma powers differential expression analyses for RNA-sequencing and microarray studies. Nucleic Acids Res.

ROBINSON, A. S., MATERNA, S. C., BARNES, R. M., DE VAL, S., XU, S.-M. \& BLACK, B. L. 2014. An arterial-specific enhancer of the human endothelin converting enzyme 1 (ECE1) gene is synergistically activated by Sox17, FoxC2, and Etv2. Dev Biol. 
RUBANYI, G. M. 2013. Mechanistic, technical, and clinical perspectives in therapeutic stimulation of coronary collateral development by angiogenic growth factors. Mol Ther.

RUCKER, H. K., WYNDER, H. J. \& THOMAS, W. E. 2000. Cellular mechanisms of CNS pericytes. Brain Res Bull.

SAKAMOTO, Y., HARA, K., KANAI-AZUMA, M., MATSUI, T., MIURA, Y., TSUNEKAWA, N., KUROHMARU, M., SAIJOH, Y., KOOPMAN, P. \& KANAI, Y. 2007. Redundant roles of Sox17 and Sox18 in early cardiovascular development of mouse embryos. Biochem Biophys Res Commun.

SAKURAI, A., DOÇI, C. L., DOCI, C. \& GUTKIND, J. S. 2012. Semaphorin signaling in angiogenesis, lymphangiogenesis and cancer. Cell Res.

SANDERS, D. A., GORMALLY, M. V., MARSICO, G., BERALDI, D., TANNAHILL, D. \& BALASUBRAMANIAN, S. 2015. FOXM1 binds directly to non-consensus sequences in the human genome. Genome Biol.

SATO, Y. 2001. Role of ETS family transcription factors in vascular development and angiogenesis. Cell Struct Funct.

SAUER, B. 1998. Inducible gene targeting in mice using the cre/lox system. Methods, 14, 381-92.

SEO, S., FUJITA, H., NAKANO, A., KANG, M., DUARTE, A. \& KUME, T. 2006. The forkhead transcription factors, Foxc1 and Foxc2, are required for arterial specification and lymphatic sprouting during vascular development. Dev Biol.

SHARMA, B., CHANG, A. \& RED-HORSE, K. 2016. Coronary Artery Development: Progenitor Cells and Differentiation Pathways. Annu. Rev. Physiol.

SHARMA, B., HO, L., FORD, G. H., CHEN, H. I., GOLDSTONE, A. B., WOO, Y. J., QUERTERMOUS, T., REVERSADE, B. \& RED-HORSE, K. 2017. Alternative Progenitor Cells Compensate to Rebuild the Coronary Vasculature in Elabela- and ApjDeficient Hearts. Dev Cell.

SIMÕES, F. C. \& RILEY, P. R. 2018. The ontogeny, activation and function of the epicardium during heart development and regeneration. Development.

SLEE, J. 1957. The morphology and development of Ragged-a mutant affecting the skin and hair of the mouse. J. Genet., 55, 100-121.

SMITH, M. F. \& DELBARY-GOSSART, S. 2001. Electrophoretic Mobility Shift Assay (EMSA). Methods Mol Med.

SNIDER, P., STANDLEY, K. N., WANG, J., AZHAR, M., DOETSCHMAN, T. \& SIMON, J. C. 2009. Origin of cardiac fibroblasts and the role of periostin. Circ Res, 105, 934-347.

SOUSA, V. H., MIYOSHI, G., HJERLING-LEFFLER, J., KARAYANNIS, T. \& FISHELL, G. 2009. Characterization of Nkx6-2-derived neocortical interneuron lineages. Cereb Cortex.

SPENCE, J. R., LANGE, A. W., LIN, S.-C. J., KAESTNER, K. H., LOWY, A. M., KIM, I., WHITSETT, J. A. \& WELLS, J. M. 2009. Sox17 regulates organ lineage segregation of ventral foregut progenitor cells. Dev Cell.

SPITZ, F. \& FURLONG, E. E. M. 2012. Transcription factors: from enhancer binding to developmental control. Nature Reviews Genetics, 13, 613-626.

SRINIVASAN, R. S., DILlaRD, M. E., LAGUTIN, O. V., LIN, F.-J., TSAI, S., TSAI, M.-J., SAMOKHVALOV, I. M. \& OLIVER, G. 2007. Lineage tracing demonstrates the venous origin of the mammalian lymphatic vasculature. Genes Dev.

SUCOV, H. M., GU, Y., THOMAS, S., LI, P. \& PASHMFOROUSH, M. 2009. Epicardial control of myocardial proliferation and morphogenesis. Pediatr Cardiol.

SUSAKI, E. A., TAINAKA, K., PERRIN, D., KISHINO, F., TAWARA, T., WATANABE, T. M., YOKOYAMA, C., ONOE, H., EGUCHI, M., YAMAGUCHI, S., ABE, T., KIYONARI, H., 
SHIMIZU, Y., MIYAWAKI, A., YOKOTA, H. \& UEDA, H. R. 2014. Whole-brain imaging with single-cell resolution using chemical cocktails and computational analysis. Cell.

SUSAKI, E. A., TAINAKA, K., PERRIN, D., YUKINAGA, H., KUNO, A. \& UEDA, H. R. 2015. Advanced CUBIC protocols for whole-brain and whole-body clearing and imaging. Nat Protoc.

TANAKA, S., KAMACHI, Y., TANOUCHI, A., HAMADA, H., JING, N. \& KONDOH, H. 2004. Interplay of SOX and POU factors in regulation of the Nestin gene in neural primordial cells. Mol Cell Biol.

TESTORI, J., SCHWEIGHOFER, B., HELFRICH, I., STURTZEL, C., LIPNIK, K., GESIERICH, S., NASARRE, P., HOFER-WARBINEK, R., BILBAN, M., AUGUSTIN, H. G. \& HOFER, E. 2011. The VEGF-regulated transcription factor HLX controls the expression of guidance cues and negatively regulates sprouting of endothelial cells. Blood.

TIAN, X., HU, T., ZHANG, H., HE, L., HUANG, X., LIU, Q., YU, W., HE, L., YANG, Z., YAN, Y., YANG, X., ZHONG, T. P., PU, W. T. \& ZHOU, B. 2014. Vessel formation. De novo formation of a distinct coronary vascular population in neonatal heart. Science.

TIAN, X., HU, T., ZHANG, H., HE, L., HUANG, X., LIU, Q., YU, W., HE, L., YANG, Z., ZHANG, Z., ZHONG, T. P., YANG, X., YANG, Z., YAN, Y., BALDINI, A., SUN, Y., LU, J., SCHWARTZ, R. J., EVANS, S. M., GROOT, A. C. G.-D., RED-HORSE, K. \& ZHOU, B. 2013. Subepicardial endothelial cells invade the embryonic ventricle wall to form coronary arteries. Nature Publishing Group.

TIAN, X., LI, Y., HE, L., ZHANG, H., HUANG, X., LIU, Q., PU, W., ZHANG, L., LI, Y., ZHAO, H., WANG, Z., ZHU, J., NIE, Y., HU, S., SEDMERA, D., ZHONG, T. P., YU, Y., ZHANG, L., YAN, Y., QIAO, Z., WANG, Q.-D., WU, S. M., PU, W. T., ANDERSON, R. H. \& ZHOU, B. 2017. Identification of a hybrid myocardial zone in the mammalian heart after birth. Nature Communications.

TIAN, X., PU, W. T. \& ZHOU, B. 2015. Cellular origin and developmental program of coronary angiogenesis. Circ Res.

TOMITA, Y., MATSUMURA, K., WAKAMATSU, Y., MATSUZAKI, Y., SHIBUYA, I., KAWAGUCHI, H., IEDA, M., KANAKUBO, S., SHIMAZAKI, T., OGAWA, S., OSUMI, N., OKANO, H. \& FUKUDA, K. 2005. Cardiac neural crest cells contribute to the dormant multipotent stem cell in the mammalian heart. J Cell Biol.

TZENG, Y.-S., LI, H., KANG, Y.-L., CHEN, W.-C., CHENG, W.-C. \& LAI, D.-M. 2011. Loss of Cxcl12/Sdf-1 in adult mice decreases the quiescent state of hematopoietic stem/progenitor cells and alters the pattern of hematopoietic regeneration after myelosuppression. Blood.

VINCENT, S. D. \& BUCKInGHAM, M. E. 2010. Chapter One - How to Make a Heart: The Origin and Regulation of Cardiac Progenitor Cells. Current Topics in Developmental Biology - Volume 90.

VISEL, A., RUBIN, E. M. \& PENNACCHIO, L. A. 2009. Genomic views of distant-acting enhancers. Nature.

VON GISE, A. \& PU, W. T. 2012. Endocardial and epicardial epithelial to mesenchymal transitions in heart development and disease. Circ Res.

VRANCKEN PEETERS, M. P., GITTENBERGER-DE GROOT, A. C., MENTINK, M. M., HUNGERFORD, J. E., LITTLE, C. D. \& POELMANN, R. E. 1997. The development of the coronary vessels and their differentiation into arteries and veins in the embryonic quail heart. Dev Dyn.

WATANABE, Y. \& BUCKINGHAM, M. 2010. The formation of the embryonic mouse heart: heart fields and myocardial cell lineages. Ann N Y Acad Sci. 
WEGNER, M. 1999. From head to toes: the multiple facets of Sox proteins. Nucleic Acids Res.

WIESE, C., ROLLETSCHEK, A., KANIA, G., BLYSZCZUK, P., TARASOV, K. V., TARASOVA, Y., WERSTO, R. P., BOHELER, K. R. \& WOBUS, A. M. 2004. Nestin expression--a property of multi-lineage progenitor cells? Cell Mol Life Sci.

WONG, N. D. 2014. Epidemiological studies of CHD and the evolution of preventive cardiology. Nat Rev Cardiol.

WU, B., ZHANG, Z., LUI, W., CHEN, X., WANG, Y., CHAMBERLAIN, A. A., MORENORODRIGUEZ, R. A., MARKWALD, R. R., O'ROURKE, B. P., SHARP, D. J., ZHENG, D., LENZ, J., BALDWIN, H. S., CHANG, C.-P. \& ZHOU, B. 2012. Endocardial cells form the coronary arteries by angiogenesis through myocardial-endocardial VEGF signaling. Cell.

WYThE, J. D., DANG, L. T. H., DEVINE, W. P., BOUdREAU, E., ARTAP, S. T., HE, D., SCHACHTERLE, W., STAINIER, D. Y. R., OETTGEN, P., BLACK, B. L., BRUNEAU, B. G. \& FISH, J. E. 2013. ETS factors regulate Vegf-dependent arterial specification. Dev Cell.

YAMAMIZU, K., MATSUNAGA, T., UOSAKI, H., FUKUSHIMA, H., KATAYAMA, S., HIRAOKAKANIE, M., MITANI, K. \& YAMASHITA, J. K. 2010. Convergence of Notch and betacatenin signaling induces arterial fate in vascular progenitors. J Cell Biol.

YANG, Y. \& OLIVER, G. 2014. Development of the mammalian lymphatic vasculature. J Clin Invest.

YAWORSKY, P. \& KAPPEN, C. 1999. Heterogeneity of Neural Progenitor Cells Revealed by Enhancers in the Nestin Gene. Developmental Biology

YOUNG, N., HAHN, C. N., POH, A., DONG, C., WILHELM, D., OLSSON, J., MUSCAT, G. E., PARSONS, P., GAMBLE, J. R. \& KOOPMAN, P. 2006. Effect of disrupted SOX18 transcription factor function on tumor growth, vascularization, and endothelial development. J. Natl. Cancer Inst., 98, 1060-1067.

YZAGUIRRE, A. D., PADMANABHAN, A., DE GROH, E. D., ENGLEKA, K. A., LI, J., SPECK, N. A. \& EPSTEIN, J. A. 2015. Loss of neurofibromin Ras-GAP activity enhances the formation of cardiac blood islands in murine embryos. Elife.

ZEINI, M., HANG, C. T., LEHRER-GRAIWER, J., DAO, T., ZHOU, B. \& CHANG, C.-P. 2009. Spatial and temporal regulation of coronary vessel formation by calcineurin-NFAT signaling. Development.

ZHANG, H., PU, W., LI, G., HUANG, X., HE, L., TIAN, X., LIU, Q., ZHANG, L., WU, S. M., SUCOV, H. M. \& ZHOU, B. 2016. Endocardium Minimally Contributes to Coronary Endothelium in the Embryonic Ventricular Free Walls. Circ Res.

ZHOU, B., MA, Q., RAJAGOPAL, S., WU, S. M., DOMIAN, I., RIVERA-FELICIANO, J., JIANG, D., VON GISE, A., IKEDA, S., CHIEN, K. R. \& PU, W. T. 2008. Epicardial progenitors contribute to the cardiomyocyte lineage in the developing heart. Nature.

ZHOU, Y., WILLIAMS, J., SMALLWOOD, P. M. \& NATHANS, J. 2015. Sox7, Sox17, and Sox18 Cooperatively Regulate Vascular Development in the Mouse Retina. PLoS ONE.

ZIMMERMAN, L., PARR, B., LENDAHL, U., CUNNINGHAM, M., MCKAY, R., GAVIN, B., MANN, J., VASSILEVA, G. \& MCMAHON, A. 1994. Independent regulatory elements in the nestin gene direct transgene expression to neural stem cells or muscle precursors. Neuron. 



\section{Imagen de portada:}

Proyección máxima de la cara ventral de un corazón whole-mount Nes-Gfp; Nes-CreERT2; R26-Tomato inducido con tamoxifeno a E15.5 y analizado a E17.5. el linaje Nestina en tomato marca las arterias coronarias y los capilares, pero no las venas. En cian se muestra el marcador Endomucina

\section{Imagen de contraportada:}

Se muestra una ampliación del mismo corazón de la portada en el que el endotelio de la arteria es positivo para los canales GFP y tomato (amarillo). Sin embargo, los pericitos y células murales asociadas al vaso son únicamente GFP+, indicando que la mayoría no se marca con el linaje Nestina. 

